\title{
WestVirginiaUniversity
}

THE RESEARCH REPOSITORY @ WVU

Graduate Theses, Dissertations, and Problem Reports

2012

\section{Optimization tool for transit bus fleet management}

\author{
Feng Zhen \\ West Virginia University
}

Follow this and additional works at: https://researchrepository.wvu.edu/etd

\section{Recommended Citation}

Zhen, Feng, "Optimization tool for transit bus fleet management" (2012). Graduate Theses, Dissertations, and Problem Reports. 600.

https://researchrepository.wvu.edu/etd/600

This Dissertation is protected by copyright and/or related rights. It has been brought to you by the The Research Repository @ WVU with permission from the rights-holder(s). You are free to use this Dissertation in any way that is permitted by the copyright and related rights legislation that applies to your use. For other uses you must obtain permission from the rights-holder(s) directly, unless additional rights are indicated by a Creative Commons license in the record and/ or on the work itself. This Dissertation has been accepted for inclusion in WVU Graduate Theses, Dissertations, and Problem Reports collection by an authorized administrator of The Research Repository @ WVU.

For more information, please contact researchrepository@mail.wvu.edu. 


\title{
OPTIMIZATION TOOL FOR TRANSIT BUS FLEET MANAGEMENT
}

\author{
by \\ Feng Zhen \\ Dissertation submitted to the \\ College of Engineering and Mineral Resources \\ at West Virginia University \\ in partial fulfillment of the requirements \\ for the degree of \\ Doctor of Philosophy \\ in \\ Mechanical Engineering
}

Approved by

Nigel N. Clark, Ph.D., Committee Chairperson

W. Scott Wayne, Ph.D.

Hailin Li, Ph.D.

Benjamin C. Shade, Ph.D.

Roy S. Nutter, Jr., Ph.D.

Department of Mechanical and Aerospace Engineering

Morgantown, West Virginia

2012

Keywords: Transit Bus Operation, Cost Evaluation, Greenhouse Gas Emissions, Operation

Optimization, Genetic Algorithm

Copyright 2012 Feng Zhen 


\section{ABSTRACT \\ OPTIMIZATION TOOL FOR TRANSIT BUS FLEET Management \\ By Feng Zhen}

Transit agencies face the challenge of being environmentally-friendly, while maintaining cost-effective operation. Many studies have focused on investigating new bus technologies to reduce emissions and cost. However, they ignored the potential environmental and economic gain by improving the fitness and harmony between individual buses and routes in fleets. This dissertation provided, for the first time, a tool for fleet operator to intelligently dispatch buses and select new technologies that are tailored to their needs and business.

One key element in this tool is a bus life cycle cost model that can simulate and predict every capital and operational cost category for different bus technologies. The cost model was funded by Transportation Research Board and developed in Transit Cooperative Research Program (TCRP) C-15 project, the purpose of which was to assess hybrid-electric bus performance in real-world operation. The research team (author as a key member) picked four bus transit agencies among a handful of test sites that were operating hybrid-electric buses and collected 28 month bus operation data at almost all data collection sites. The sophisticated life cycle cost model is the backbone of this tool to calculate cost.

The other key element is a green house gas (GHG) emissions model, which was based on the fuel consumption model in the TCRP C-15 project and GREET model generated at Argonn National Laboratory. The GHG model utilizes fuel consumption data to provide tail pipe GHG emissions and well-to-tank GHG emissions for specific fuels and bus propulsion technologies.

The last key element is the use of genetic algorithm (GA) as a search and optimization scheme in the fleet management tool. A ranking matrix was developed to rate and compare different dispatch strategies on multiple criteria, which can vary in units or scales. When a fleet has large number of buses (dozens to thousands) on multiple routes, the number of all possible 
bus dispatch strategies becomes tremendously huge and difficult to explore. The GA uses the evolution theory of "Only the strongest survive" to find the best strategy.

The tool shows that optimization objectives dictated dispatch strategies that are successful in specific applications. For example, in a 35-bus fleet examined in this dissertation, the proposed dispatch strategy could reduce fleet well-to-wheels (WTW) GHG emissions up to 364 metric tons of carbon dioxide equivalents, a $17.5 \%$ GHG emissions reduction from the initial dispatch strategy. The same dispatch strategy increased \$75K in annual operation cost, a $7 \%$ increase. However, a different dispatch strategy, found for maximizing cost reduction, could save $\$ 90 \mathrm{~K}$ instead, a $9 \%$ reduction in annual operation cost. For the case of reducing operation cost, the operation cost difference between the best and worst dispatch strategy was $\$ 220 \mathrm{~K}$ a year. 


\section{DEDICATION}

I dedicate this dissertation work to my family, especially to my sweet wife, Hua Jing. I cannot accomplish this without your endless support. This work is for my precious daughters, Ivy and Elly, the best products we have made. You bring eternal joy to mother and me. I especially appreciate you two kept sticking with your mother all the time. I also dedicate this dissertation to my parents, Zhizhong Zhen and Suzhen Yuan who brought me to science and art fields and required me to pursue academic excellence. I must also thank my parents-in-law, Jingwen Jing and Xiulan Ren for helping us with baby-sitting and taking care of us. 


\section{ACKNOWLEDGEMENTS}

I want to sincerely thank Professor Nigel Clark for his long-term guidance, support, and patience during my PhD program. He has taught me so much how to do well both in academia and life. My thanks also go to my committee members. I gratefully acknowledge your valuable inputs and helps.

The work is an expansion of bus life cycle cost model developed under TCRP Project C-15. The C-15 project was led by West Virginia University (WVU), with major subcontract support from the Transit Resource Center (TRC), and Battelle Memorial Institute (Battelle). TRC contributes significantly on the life cycle cost (LCC) model development. For this doctoral research, I both played a major role in a team executing the C-15 program, and then individually extended the C-15 philosophy to cover whole fleet evaluations and assignments.

The C-15 program benefited greatly from the assistance of the managers and staff at six transit agencies (New York City Transit, King County Metro, Washington Metropolitan Area Transit Authority, Long Beach Transit, Dallas Area Rapid Transit, and OC Transpo (Ottawa City, Canada)), and three hybrid drive OEMs (Allison Transmission, BAE SYSTEMS, and ISE Corporation). WMATA also provided the test buses and the test site for emissions testing that provides the emissions data for life cycle emissions modeling.

Significant data used in the C-15 program were gathered through a US Department of Energy funded program, conducted by the National Renewable Energy Laboratory (NREL, Golden, Colo.), with support from Battelle.

I also gratefully acknowledge the valuable input from the members of the TCRP C-15 Panel, and from TRB program managers Stephan Parker and Larry Goldstein and CAFEE staff who helped operate the Translab and analytic facilities. I highly appreciated that Transportation Research Board (TRB) through the National Academy of Sciences (NAS) grants permission to use the $\mathrm{C}-15$ project material in my dissertation. 


\section{TABLE OF CONTENTS}

ABSTRACT

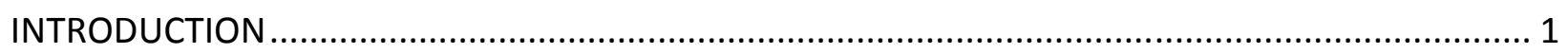

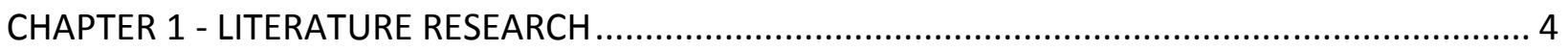

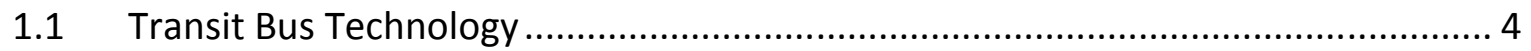

1.2 Transit Bus Emissions and Fuel Economy ................................................... 17

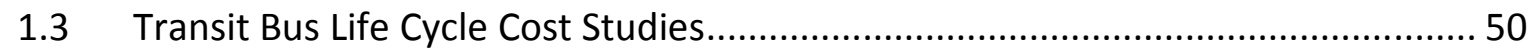

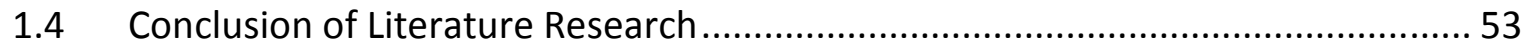

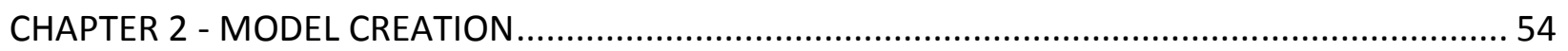

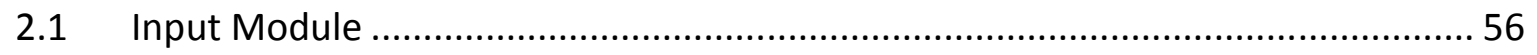

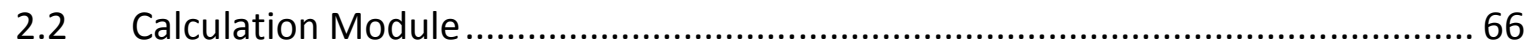

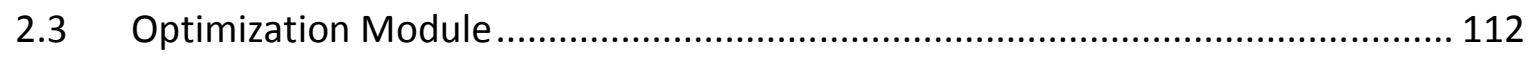

CHAPTER 3 - TOOL DEMONSTRATION AND USERS INSTUCTION........................................ 129

3.1 Validation Test of Using Fleet Management Tool on a Four-Bus Fleet ............... 129

3.2 Case Studies for a 35-Bus Fleet and User Instruction ................................... 134

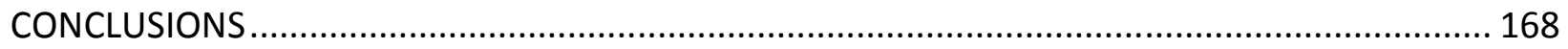

SUGGESTED FUTURE RESEARCH AND MODEL DEVELOPMENT ............................................ 172 


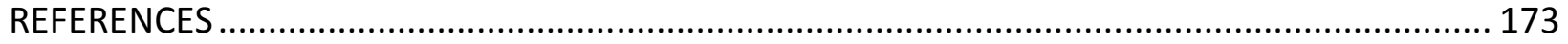

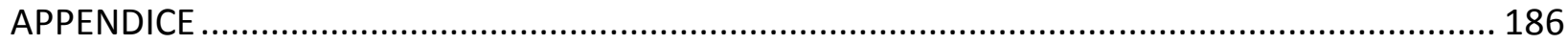




\section{LIST OF FIGURES}

Figure 1: The Manhattan Cycle as an Example of Low-Speed Operation Suited to Hybrid

Drive Applications. 10

Figure 2: The Urban Dynamometer Driving Schedule (UDDS) [44] ................................ 33

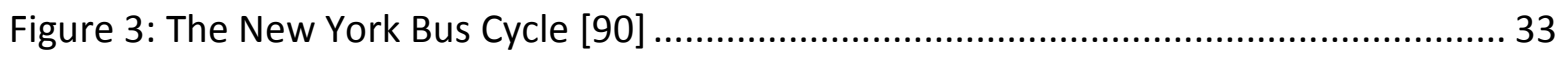

Figure 4: Continuous $\mathrm{CO}_{2}$ Emissions of a Typical Heavy-Duty Diesel Bus over the UDDS.... 34

Figure 5: Continuous NOx Emissions of a Typical Heavy-Duty Diesel Bus over the UDDS.... 35

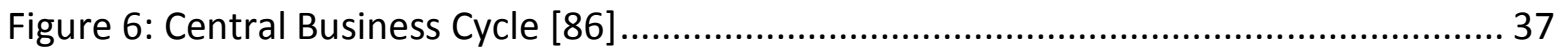

Figure 7: All studies' PM results over the CBD cycle .................................................... 38

Figure 8: All studies' NOx results over CBD cycle ........................................................... 38

Figure 9: All studies' Fuel Economy Results over CBD Cycle ........................................... 39

Figure 10: CO, HC, and PM Emissions Comparisons between MY 2002 - 2004 Hybrid Buses and MY 1999 Diesel Buses with and without DPF.

Figure 11: NOx Emissions and FE Comparisons between MY 2002 - 2004 Hybrid Buses and MY 1999 Diesel Buses with and without DPF 42

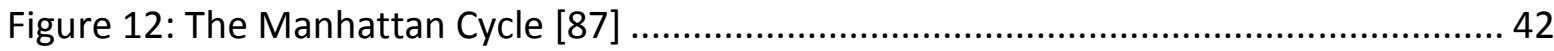

Figure 13: Orange County Transit Authority Cycle (OCTA) [61] ...................................... 43

Figure 14: FE Comparison between New Flyer 60-ft Diesel and Diesel HEB...................... 47

Figure 15: FE Comparison between Gillig 40-ft Diesel and Diesel HEB ............................. 48

Figure 16: FE Comparison between New Flyer 40-ft Diesel, CNG, and Gasoline HEB ......... 49

Figure 17: FE Comparison between Orion 40-ft Diesel and Diesel HEB ............................ 50

Figure 18: Fleet Model Overall Flow Chart ................................................................... 55

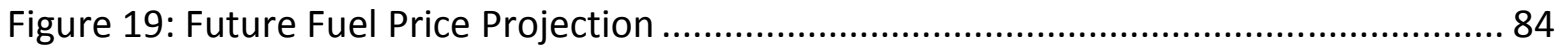

Figure 20: Diesel Bus Fuel Economy Data and Parabolic Trend Lines ............................... 92

Figure 21: Diesel Hybrid Bus Fuel Economy Data and Parabolic Trend Lines ..................... 93

Figure 22: CNG Bus Fuel Economy Data and Parabolic Trend Lines.................................. 95

Figure 23: Gasoline Hybrid Bus Fuel Economy Data and Parabolic Trend Lines. The chassis curve was derived from diesel hybrid data. 
Figure 24: Battery Replacement Percentage Chart during 12-Year Bus Life..................... 101

Figure 25: Comparison of Maintenance Costs' Speed Correct Factors............................ 108

Figure 26: Diesel Bus GHG Data and Parabolic Trend Lines ........................................... 110

Figure 27: Diesel Hybrid Bus GHG Data and Parabolic Trend Lines ................................ 110

Figure 28: CNG Bus GHG Data and Parabolic Trend Lines............................................ 111

Figure 29: Gasoline Hybrid Bus GHG Data and Parabolic Trend Lines ............................ 111

Figure 30: Genetic Algorithm Flow Chart for Fleet Management .................................. 114

Figure 31: Examples of Bus Dispatch Strategies Represented as Gene Compositions ....... 116

Figure 32: Illustration New Dispatch Bus-Route Assignment......................................... 118

Figure 33: Roulette Wheel Dispatch Selection Algorithm ........................................... 123

Figure 34: Crossover Process Illustration (Step 1 and 2 of the three steps) ...................... 124

Figure 35: Step 3 in Crossover Process .................................................................... 126

Figure 36: Steps of Searching New Bus Technologies in Mutation ................................ 128

Figure 37: The Four-Bus Fleet Complete Solution Space (24 Different Dispatch Strategies and Their GHG Emissions and Costs). Dispatch 5 and 19 were found to have lowest GHG emissions and operation cost. 131

Figure 38: The Four-Bus Fleet Fitness Evolution for Low Cost Case............................... 133

Figure 39: The Four-Bus Fleet Fitness Evolution for Low GHG Emissions Case ................ 133

Figure 40: Screenshot of "FleetInfo" tab in the Fleet Management Tool (version 4.6)...... 135

Figure 41: Basic Fleet Information of the 35-Bus Case Study (Screenshot of FMT Section I) 136

Figure 42: Existing and Replacement Bus Technology Information in the 35-bus Fleet

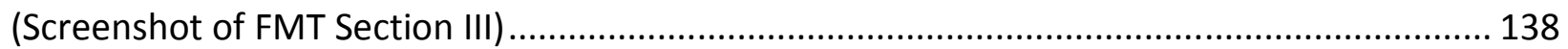

Figure 43: Route Information of the 35-bus Fleet (Screenshot of FMT Section IV)............ 139

Figure 44: Route Distance-Speed Profile of the 35-Bus Fleet Based on Nine Actual Routes Operated by Mountain Line Transit at Morgantown, West Virginia. Speed calculation was based on bus schedule from the transit agency and distance obtained from Google online map application. The bus schedule might not be completely accurate in time, so a small section of speed profile (70 mph) could be unrealistic. For example, Route Campus PM has nearly $70 \mathrm{mph}$ 
operating speed between the fifth and sixth stops, because the schedule shows it takes 1 minute to cover 1.2 mile distance.

Figure 45: Original Dispatch Strategy Information of the 35-bus Fleet (Screenshot of FMT Section V)

Figure 46: Bus ID and Bus Technology Distribution of Original Fleet Dispatch Strategy of the 35-Bus Fleet. Buses with the same speed data labels are operated in the same route. The top chart shows bus series names, and the bottom chart shows the bus propulsion technologies.

Figure 47: Original GA Settings Information of the 35-Bus Fleet. (Screenshot of FMT Section $\mathrm{VI})$

Figure 48: Example of an Important Index Targeting Reducing Operation Cost. (Screenshot of FMT Section II) 145

Figure 49: Start Buttons in "FleetInfo" Tab of Fleet Management Tool. The first button is for generating performance report of original dispatch strategy. The section button is for starting searching algorithm of new dispatch strategies. 146

Figure 50: Input Summary Table of Breaking down Each Route and Bus Combination. (Screenshot of a Partial FMT Section VII). The complete table is too large to display in one page.

Figure 51: Cost and GHG Emissions Summary Table of Breaking down Each Route and Bus Combination. (Screenshot of a Partial FMT Section VIII). The complete table is too large to display in one page.

Figure 52: An Example of Fleet Overall GHG Emissions and Cost Summary Table of Current (in blue box) and Proposed Dispatch Strategies (in red box). The table lists five proposed dispatch strategies during the optimization process. The five strategies are evenly distributed in the optimization process. (Screenshot of a Partial FMT Section IX) 149

Figure 53: An Example of Dispatch Strategy Chart. (Screenshot of a Partial FMT Section IX)

Figure 54: An Example of Fleet Fitness Evolution Progress Chart over GA Optimization Process. The left chart is for the best fitness progress. The right chart includes the best, 
average, the worst fitness. Detail definitions are described in Figure 34. (Screenshot of a Partial FMT Section IX) 150

Figure 55: Fitness Evolution Progress Chart over GA Optimization Process for Minimal Operation Cost Scenario. The process converged at the 282th generation.

Figure 56: Performance Summary Table and Optimized Fleet Dispatch Strategy for the 35-

bus Fleet. The dispatch strategy was for minimizing operation cost.

Figure 57: Bus Daily Travel Distance per Routes in the 35-Bus Fleet

Figure 58: Performance Summary Table and Optimized Fleet Dispatch Strategy for the 35bus Fleet. The dispatch strategy was for minimizing operation cost, when diesel price were changed from default $\$ 3.09 /$ gal to $\$ 4 /$ gal.

Figure 59: Performance Summary Table and Optimized Fleet Dispatch Strategy for the 35bus Fleet. (Screenshot of FMT Section XI) The dispatch strategy was for maximizing operation cost. It is a worst case scenario used to compare to the low operation cost scenario. 156

Figure 60: Performance Summary Table and Optimized Fleet Dispatch Strategy for the 35bus Fleet. The dispatch strategy was for minimizing well-to-wheels greenhouse gas emissions.

Figure 61: Performance Summary Table and Optimized Fleet Dispatch Strategy for the 35bus Fleet. The dispatch strategy was for minimizing well-to-tank greenhouse gas emissions. 159

Figure 62: Performance Summary Table and Optimized Fleet Dispatch Strategy for the 35bus Fleet. The dispatch strategy was for minimizing tank-to-wheels greenhouse gas emissions.

Figure 63: Performance Summary Table and Optimized Fleet Dispatch Strategy for the 35bus Fleet. The dispatch strategy was for multiple goals. Operation cost was set with weight "9", TTW GHG emissions were set with weight " 6 ", and WTT-GHG emissions gas emissions were set with weight " 3 ". 162

Figure 64: Performance Summary Table and Optimized Fleet Dispatch Strategy for the 35bus Fleet. The dispatch strategy was an optimization for multiple criteria in Section 3.2.7. The dispatch strategy (case 1 strategy in the section) was for the existing fleet. 166 
Figure 65: Performance Summary Table and Optimized Fleet Dispatch Strategy for the 35bus Fleet. The dispatch strategy was an optimization for multiple criteria in Section 3.2.7. The dispatch strategy (case 2 strategy in the section) was for the new fleet that included five new

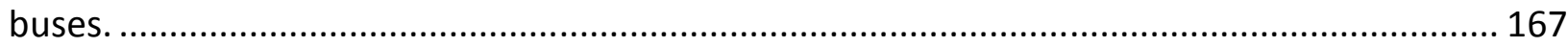




\section{LIST OF TABLES}

Table 1: Bus Power Source, Percent of Buses Powered by Engines or Motors using Named

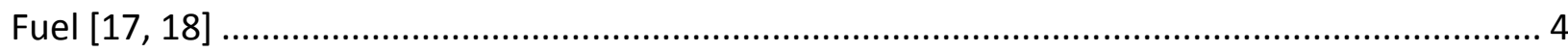

Table 2: Truck and Bus Production Numbers ............................................................. 5

Table 3: Test cycle or Schedule Descriptions............................................................... 31

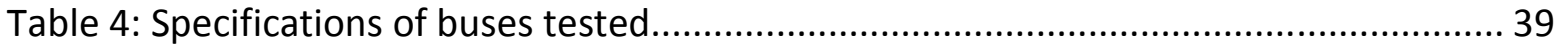

Table 5: Emissions and FE from the buses tested ........................................................ 40

Table 6: ADVISOR computer simulation buses performance comparison results [105]...... 45

Table 7: An Example of Basic Bus Fleet Information in Input Module ............................... 58

Table 8: An Example of Importance Index in Input Module.............................................. 59

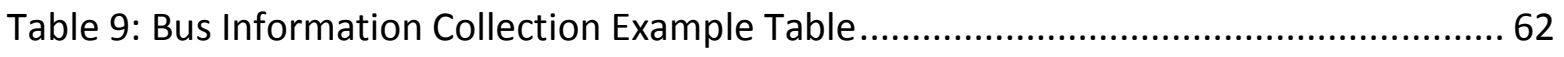

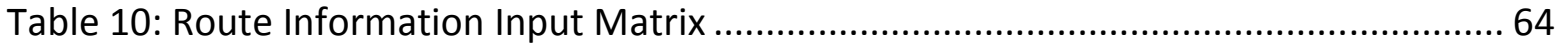

Table 11: An Example of Route Specifications Calculated by Input Module ....................... 65

Table 12: An Example of Current Fleet Dispatch Matrix in Input Module ......................... 65

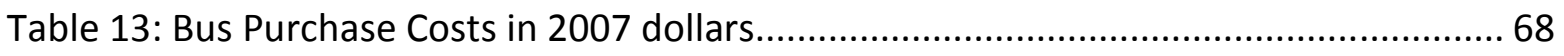

Table 14: Bus Purchase Costs in 2007 Dollars used in FMT ............................................ 69

Table 15: Diagnostic Equipment Prices for Every 50 Buses at One Workshop .................. 70

Table 16: Diagnostic Equipment Prices for Every 50 Buses at One Workshop in FMT ........ 71

Table 17: Buses Three Years Extended Warranty Costs ................................................. 75

Table 18: Three Year Extended Warranty Used in FMT ................................................ 75

Table 19: Bus Training Hours for Operator and Mechanics .......................................... 77

Table 20: Bus Training Hours for Operator and Mechanics in FMT ................................ 77

Table 21: Crude Oil Price Projections from Original Studies; Projections are not adjusted to 2007 dollars, and each projection has its own baseline year.............................................. 78

Table 22: Consumer Price Index Used to Adjust Crude Oil and CNG Price to 2007 Dollars.. 79 Table 23: Adjusted Crude Oil Price Projections and Final Oil Price Projection Data (2007 -

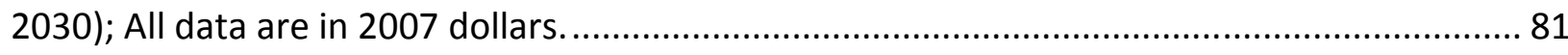


Table 24: Untaxed Diesel and Gasoline Price Factors to Crude Oil Price. These factors convert dollar per barrel values for crude oil to dollar per gallon values for refined product.... 82

Table 25: Untaxed Diesel and Gasoline Price Forecast from 2007 to 2030 in 2007 Dollars. 83

Table 26: CNG Original Price Projections from Original Studies ..................................... 86

Table 27: Adjusted CNG Price Projections and Final CNG Price Projection Data (2007 - 2030)

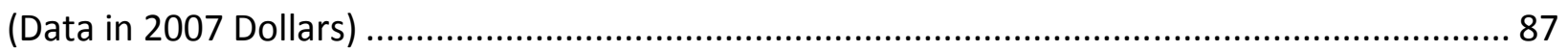

Table 28: Average Federal and State Fuel Tax............................................................. 88

Table 29: Fuel Price Projection Used in FMT ................................................................. 88

Table 30: KC Metro FE Conversion Factor for 40 and 60-Foot Buses.................................. 90

Table 31: Comparison of Field Fuel Economy and Predicted Fuel Economy for Diesel Buses

Table 32: Comparison of Field Fuel Economy and Predicted Fuel Economy for Diesel Hybrid Buses 94

Table 33: Comparison of Diesel Hybrid Buses FE Advantage to Diesel Buses for Field and Prediction 94

Table 34: Comparison of Field Fuel Economy and Predicted Fuel Economy for CNG Buses 96 Table 35: Comparison of CNG Buses FE Penalty to Diesel Buses for Field and Prediction ... 96 Table 36: Hotel Load Effects on Bus FE for Four Bus Technologies................................... 98 Table 37: Battery Replacement Schedule for an 80-Hybrid Bus Fleet (6-year Battery Life)101 Table 38: Internal Combustion Engine Rebuild/Replacement Costs .............................. 103 Table 39: Primary Power Unit Rebuild/Replacement Costs ........................................... 104

Table 40: Transmission Rebuild/Replacement Costs ................................................ 105

Table 41: Maintenance Costs for Three Bus Types at the Four Test Sites ........................ 106

Table 42: Maintenance Costs in Dollar per Mile. .......................................................... 106

Table 47: WTT GHG per Fuel Consumption ................................................................. 112

Table 48: An Example of Genetic Algorithm Parameters in Optimization Module ............ 115

Table 49: Characteristic of Requirements in Importance Index.................................... 120

Table 50: An Example of Ranking Matrix for Fitness Function...................................... 121

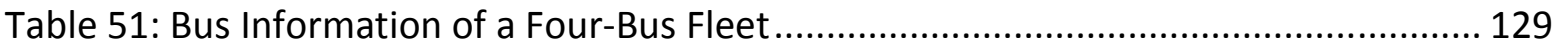


Table 52: Route Information of the Four-Bus Fleet in Validation Test

Table 53: Key Bus Information of the 35-bus Fleet Entered into the FMT.

Table 54: Replacement Bus Information

Table 55: Important Index Table for Three Cases in Existing Fleet Optimization

Table 56: Comparison of Three Cases Targeting WTW, WTT, and TTW GHG Emission

Reduction

Table 57: Importance Index Table for Bus Technology Selection Case

Table 58: Effects of Two Proposed Dispatch Strategies on the Performance of Cost, Emissions, etc. Both strategies had the same weighing on selection criteria. Dispatch strategy one was based on improving existing bus fleet. Dispatch strategy two was based on improving new future bus fleet that includes five new buses. 164 


\section{ACRONYMS}

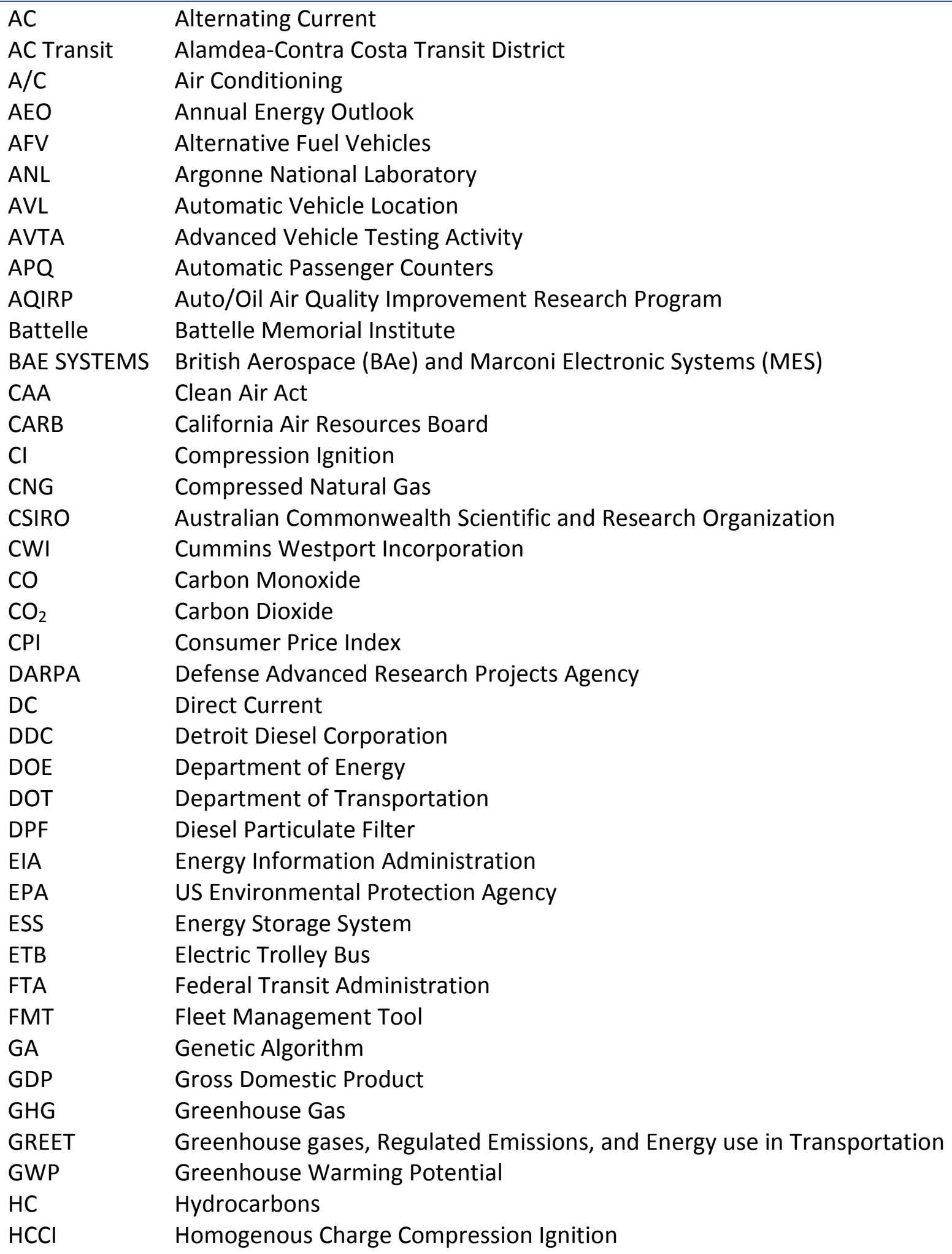




\begin{tabular}{|c|c|}
\hline HEV & Hybrid Electric Vehicle \\
\hline HVAC & Heating, Ventilating, and Air Conditioning \\
\hline ICE & Internal Combustion Engine \\
\hline ITS & Intelligent Transportation System \\
\hline KAT & Knoxville Area Transit \\
\hline KC Metro & King County Metro \\
\hline LBNL & Lawrence Berkeley National Laboratory \\
\hline LBT & Long Beach Transit \\
\hline LCC & Life Cycle Cost \\
\hline LCE & Life Cycle Emissions \\
\hline LCSM & Life Cycle Synthesis Model \\
\hline Li-lon & Lithium Ion \\
\hline LNG & Liquefied Natural Gas \\
\hline LP & Liquefied Petroleum \\
\hline LTC & Low Temperature Combustion \\
\hline $\mathrm{mmBTU}$ & Million British Thermal Units \\
\hline MBRC & Mile Between Road Calls \\
\hline MSERC & Mobile Source Emission Reduction Credits \\
\hline MY & Model Year \\
\hline NAAQS & National Ambient Air Quality Standards \\
\hline NAVC & Northeast Advanced Vehicle Consortium \\
\hline NEC & Net Energy Change \\
\hline $\mathrm{NiMH}$ & Nickel Metal Hydride \\
\hline NMHC & Non-Methane Hydrocarbon \\
\hline NOx & Nitrogen Oxides \\
\hline NREL & National Renewable Energy Laboratory \\
\hline NTC & Not-To-Exceed \\
\hline NYCT & New York City Transit \\
\hline OAQPS & Office of Air Quality Planning and Standards \\
\hline OCTA & Orange County Transit Authority Cycle \\
\hline OEM & Original Equipment Manufacturers \\
\hline PM & Particulate Matters \\
\hline PSAT & Powertrain System Analysis Toolkit \\
\hline PTI & Pennsylvania Transportation Institute \\
\hline$R \& R$ & Remove and Replace \\
\hline RESS & Rechargeable Energy Storage System \\
\hline RFG & Reformulated Gasoline \\
\hline RVP & Reid Vapor Pressure \\
\hline SCR & Selective Catalytic Reduction \\
\hline SI & Spark Ignition \\
\hline SOC & State-of-Charge \\
\hline TCRP & Transit Cooperative Research Program \\
\hline THEPS & Tool for Hybrid Electric Powertrain Synthesis \\
\hline Translab & Transportable Heavy-Duty Vehicle Emissions Testing Laboratory \\
\hline
\end{tabular}




$\begin{array}{ll}\text { TRC } & \text { Transit Resource Center } \\ \text { TTC } & \text { Toronto Transit Commissions } \\ \text { TTW } & \text { Tank-to- Wheels } \\ \text { TWC } & \text { Three-Way Catalyst } \\ \text { UDDS } & \text { Urban Dynamometer Driving Schedule } \\ \text { ULSD } & \text { Ultra Low Sulfur Diesel } \\ \text { VBA } & \text { Visual Basic for Application } \\ \text { WMATA } & \text { Washington Metropolitan Area Transit Authority } \\ \text { WTT } & \text { Well-to-Tank } \\ \text { WTW } & \text { Well-to-Wheels } \\ \text { WVU } & \text { West Virginia University }\end{array}$




\section{INTRODUCTION}

The Toronto Transit Commission (TTC) (Toronto, Canada) were disappointed that their new hybrid-electric buses did not meet their expectations for fuel economy [1]. The hybrid-electric technology was adopted to improve fuel economy and reduce emissions by recovering partial braking energy that was generally wasted as heat by friction brakes. Those new buses saved only $10 \%$ in terms of fuel consumption instead of the $20 \%$ to $30 \%$ values that were reported by New York City Transit (NYCT) operating the same bus technology [1].

Investigation found that low fuel saving was mainly because TTC ran those buses mostly on suburban routes and fuel economy evaluation was conducted in summer [1]. Suburban routes generally lacked a traffic pattern of stop-and-go operation. Often existing-in urban routes, the stop and go operation had relatively high frequency of braking events for energy regeneration. Summer time drew more air conditioning (AC) usage, a substantial energy impact on hybridelectric technology compared to conventional drivetrain technology. It was found that as much as $50 \%$ fuel economy penalty could occur in hybrid-electric technology $[2,3]$.

However, two questions were raised:

- Was it really a bad idea to operate hybrid-electric buses on suburban routes?

- Was it a bad business decision to purchase hybrid-electric buses, which generally cost $50 \%$ more than conventional diesel buses?

To answer these questions, there is a need for a tool to allow users to simulate and understand how bus operation can affect overall fleet performance. It can validate if it is ideal to operate certain bus technologies on certain routes to achieve the emissions and financial goals. The tool could also help to compare different types of bus technology in the new procurement. 
Some studies have been conducted to evaluate cost or emissions performance of bus technologies over different operation conditions [4-15]. Among them, the TCRP C-15 bus LCC model $^{1}$ was the most comprehensive cost model [2]. The model was built to assess hybridelectric transit bus technologies with direct comparison to both the conventional diesel and compressed natural gas (CNG) bus technologies during real-world bus operation.

The sophisticated tool could calculate the overall cost of purchasing and operating a fleet of buses (single technology) over one route during a specific time span. The C-15 model was used to evaluate the TTC case, and simulation results successfully matched fuel saving in the TTC case $^{1}$. However, the model had no built-in functions to evaluate the overall performance of a complex fleet, a composite of multiple technologies and routes. It made direct use of the C15 model to evaluate and optimize fleet dispatch strategy difficult and even harder when selecting new technologies.

This dissertation introduces a fleet management tool that can help. The tool is composed of cost and emissions models that were capable to evaluate different scenarios in forms of various bus and route combinations. An optimization schedule used objective-oriented approaches to find the best dispatch strategy that excelled in overall performance for current fleet. Similarly, the model was able to mix new buses into the existing fleet and identified the most suitable technologies for new purchases.

The emissions model in the tool evaluated only the emissions of $\mathrm{CO}_{2}$ and methane, two major greenhouse gases (GHG) and a focus of public concern in recent years due to the increasing concentration of the gases in the atmosphere implicated in climate change [2]. The cost model was based on the C-15 model to evaluate bus overall performance in capital and operation costs.

\footnotetext{
${ }^{1}$ Transit Bus Life Cycle Cost Model was developed in Transit Cooperative Research Program (TCRP) C-15
} program. Fuel economy was calculated for MY 2007 buses operating at suburban routes (average speed at 12.72 mph) and maximum AC load. 
Agencies or users were given the luxury to decide how to balance GHG emissions with cost. Once the priority or weights were defined, a genetic algorithm (GA) was used as the tool's search and optimization method. GA mimicked the process of genetic evolution through natural selection, the rule of "survival of the fittest" [16]. The GA was a unique tool to solve the fleet optimization problem, because a bus fleet could be treated as a series of buses in sequence like a chain-type chromosome. The GA's two genetic alterations, crossover and mutation, mimicked the processes of bus-route dispatch strategy rearrangement and new bus technology selection separately. The tool was designed to start a new approach to assess bus technologies for fleet management. 


\section{CHAPTER 1 - LITERATURE RESEARCH}

A broad literature survey has been conducted through many studies that the author has done for the TCRP C-15 project and a fleet analysis of the Chicago Transit Agency. This chapter briefly reviews available bus technologies in the current North American market. The technology review was prepared for the Chicago Transit Agency. Next, bus fuel economy and emissions studies are presented for conventional bus technologies and advanced technologies that involved the use of alternative fuels, aftertreatment, or efficient powertrains. The chapter ends with a few bus life cycle cost studies in the public domain.

\subsection{Transit Bus Technology}

Transit buses most typically are equipped with two axles and have a nominal length of $40 \mathrm{ft}$. and a nominal lifetime of 12 years. Over the last decade, $60 \mathrm{ft}$. articulated buses have become more common across North America, because they offer higher passenger capacity, and reduced driver costs for peak load. However, they prove cumbersome in downtown city operation and can increase operating costs in off-peak hours. Some transit fleets include $30 \mathrm{ft}$. or $35 \mathrm{ft}$. buses of similar design to $40 \mathrm{ft}$. buses, and rated with a 12-year life. These may be used on less populous routes. Buses smaller than $30 \mathrm{ft}$ in length are typically of different design and reduced average life. Three axle coaches, usually $45 \mathrm{ft}$. in length, are used typically only in commuter or freeway service. Conventional buses in North America have been traditionally equipped with automatic transmissions, which incorporate a torque converter. APTA data (Table 1) show that recent fleets of transit buses are dominated by diesel engines with these conventional drivetrains $[17,18]$.

Table 1: Bus Power Source, Percent of Buses Powered by Engines or Motors using Named Fuel [17, 18]

\begin{tabular}{ccccccccc}
\hline YEAR & $\begin{array}{c}\text { CNG \& } \\
\text { BLENDS }\end{array}$ & DIESEL & $\begin{array}{c}\text { ELECTRIC } \\
\text { \& OTHER } \\
\text { (HYBRID) }\end{array}$ & $\begin{array}{c}\text { GASO- } \\
\text { LINE }\end{array}$ & $\begin{array}{c}\text { LNG \& } \\
\text { BLENDS }\end{array}$ & PRO-PANE & OTHER $^{1}$ & TOTAL $^{2}$ \\
\hline 1996 & $2.1 \%$ & $95.4 \%$ & $0.1 \%$ & $0.5 \%$ & $0.7 \%$ & $0.1 \%$ & $1.1 \%$ & $100.0 \%$ \\
\hline 1997 & $3.1 \%$ & $94.7 \%$ & $0.0 \%$ & $0.5 \%$ & $0.7 \%$ & $0.1 \%$ & $1.0 \%$ & $100.0 \%$ \\
\hline 1998 & $4.3 \%$ & $93.5 \%$ & $0.1 \%$ & $0.5 \%$ & $0.7 \%$ & $0.0 \%$ & $1.0 \%$ & $100.0 \%$ \\
\hline
\end{tabular}




\begin{tabular}{|c|c|c|c|c|c|c|c|c|}
\hline 1999 & $4.8 \%$ & $92.5 \%$ & $0.1 \%$ & $0.4 \%$ & $1.4 \%$ & $0.0 \%$ & $0.8 \%$ & $100.0 \%$ \\
\hline 2000 & $5.7 \%$ & $92.1 \%$ & $0.1 \%$ & $0.4 \%$ & $1.4 \%$ & $0.0 \%$ & $0.2 \%$ & $100.0 \%$ \\
\hline 2001 & $7.5 \%$ & $90.1 \%$ & $0.1 \%$ & $0.4 \%$ & $1.5 \%$ & $0.1 \%$ & $0.2 \%$ & $100.0 \%$ \\
\hline 2002 & $9.5 \%$ & $88.0 \%$ & $0.2 \%$ & $0.4 \%$ & $1.5 \%$ & $0.2 \%$ & $0.2 \%$ & $100.0 \%$ \\
\hline 2003 & $10.8 \%$ & $86.6 \%$ & $0.3 \%$ & $0.4 \%$ & $1.6 \%$ & $0.2 \%$ & $0.2 \%$ & $100.0 \%$ \\
\hline 2004 & $10.7 \%$ & $86.3 \%$ & $0.3 \%$ & $0.4 \%$ & $1.7 \%$ & $0.2 \%$ & $0.3 \%$ & $100.0 \%$ \\
\hline 2005 & $12.1 \%$ & $83.6 \%$ & $1.1 \%$ & $0.5 \%$ & $1.8 \%$ & $0.5 \%$ & $0.4 \%$ & $100.0 \%$ \\
\hline 2006 & $13.3 \%$ & $81.4 \%$ & $1.7 \%$ & $0.6 \%$ & $1.9 \%$ & $0.5 \%$ & $0.7 \%$ & $100.0 \%$ \\
\hline 2007 & $13.7 \%$ & $79.8 \%$ & $2.3 \%$ & $0.6 \%$ & $1.9 \%$ & $0.6 \%$ & $1.1 \%$ & $100.0 \%$ \\
\hline 2009 & $18.3 \%^{2}$ & $68.9 \%$ & $5.1 \%^{3}$ & $0.7 \%$ & $N / A^{2}$ & $N / A^{2}$ & $7.0 \%$ & $100.0 \%$ \\
\hline $\begin{array}{l}1 . \\
2 . \\
3 .\end{array}$ & $\begin{array}{l}\text { It includes bio/ } \\
\text { The } 2010 \text { fact } \\
\text { The electricity } \\
\text { categories of e }\end{array}$ & $\begin{array}{l}\text { el, biodi } \\
\text { ombine } \\
\text { source } \\
\text { and oth }\end{array}$ & $\begin{array}{l}\text { Iydroger } \\
\text { LNG, a } \\
2 \% \text { of } t \\
\text { brid) [1 }\end{array}$ & $\begin{array}{l}\text { tanol, e } \\
\text { pane to } \\
\text { urces in }\end{array}$ & $\begin{array}{l}\text { nd var } \\
\text { egory } \\
0 \text { fact }\end{array}$ & $\begin{array}{l}\text { ends. } \\
\text { The nu }\end{array}$ & as add & the \\
\hline
\end{tabular}

\subsubsection{Conventional diesel transit buses}

The diesel engines in buses generally employ the same technology as truck engines, since truck sales exceed bus sales by over two orders of magnitude, as shown in Table 2. Present day bus diesel engines are substantially different from bus engines of the 90 's in that they must meet low NOx and particulate matter standards. These requirements have made the engines substantially more costly and complex, and have eroded some of the efficiency that they might otherwise enjoy. Specific maintenance for exhaust particulate filters is now required, and exhaust gas recirculation systems are the norm. In 2010 the standard for NOx reduced to 0.2 $\mathrm{g} / \mathrm{bhp}$-hr, and almost all bus engines (and heavy-duty truck engines) are equipped with Urea Selective Catalytic Reduction Systems (Urea SCR). This adds further complexity to the engine and requires that urea is carried on board.

Table 2: Truck and Bus Production Numbers

\begin{tabular}{rccc}
\hline & ${\text { Heavy } \text { Truck }^{1}}$ & Bus $^{2}$ & $\begin{array}{c}\text { Ratio (Truck to } \\
\text { Bus) }\end{array}$ \\
\hline $\mathbf{2 0 0 4}$ & 355,461 & 2,874 & 124 \\
$\mathbf{2 0 0 5}$ & 422,403 & 3102 & 136 \\
$\mathbf{2 0 0 6}$ & 461,818 & 3012 & 153 \\
& 278,924 & 2488 & 112 \\
1. Heavy truck production numbers are from IBISWorld Industry Report [19]. & $\mathbf{1 3 1}$ \\
\hline
\end{tabular}


Diesel engines are likely to continue to be used over the next two decades due to their excellent fuel consumption, but the future global imbalance of the gasoline/diesel split between refining capability and engine use may make gasoline almost as attractive as diesel. However, diesel technology is likely to evolve further, perhaps allowing the elimination of Urea SCR through use of more advanced combustion regimes and advanced reducing catalyst systems. Additionally, diesel engines are likely to remain lower Greenhouse Gas (GHG) emitters than gasoline engines [21, 22, and 23]. Both controls and hardware will continue to grow in complexity and sophistication. Combustion regimes termed "Low Temperature Combustion" (LTC) and "Homogenous Charge Compression Ignition" ( $\mathrm{HCCl}$ ) may become a reality, at least over part of the engine load range. Engine boost levels will rise, power density will rise, and bus engine displacement will fall. Engine efficiency is likely to rise slightly.

Most North American buses typically have automatic transmissions with a torque converter. Modern automatic transmissions have improved conventional bus powertrain efficiency by employing four or more speeds (gear ratios) with a lockup capability on the torque converter.

A modest rise in efficiency of conventional buses may be anticipated over the next two decades. For example, the SCR technologies can improve diesel's fuel economy as much as 5\% in the chassis and engine tests [24, 25]. Improvement of truck fuel efficiency has been targeted by several federal programs, including "21st Century Truck" from the US Department of Energy (DOE) and the Smartway program from Environmental Protection Agency (EPA) [26, 27]. The fuel economy improvements will be realized by improving truck aerodynamics, using lower rolling resistance tires, improving drivetrain efficiency, developing measures to reduce idling and auxiliary loads and exploring hybrid drivetrains for trucks with low average speeds. The aerodynamic studies will not translate into a benefit for buses, where average speeds imply that wind drag is small, and where gaps between a tractor \& trailer do not exist. Hybrid bus drivetrains receive attention separately below. It is likely that drivetrain improvements, reduction in tire losses, and auxiliary load reduction (through the electrification or redesign of systems) are the primary pathways for improving conventional transit bus performance. The 
radiator fan represents a major auxiliary load, which will be addressed in the future by using rooftop cooling or fan electrification. Tire losses and service braking represent the overwhelming majority of the overall engine energy use, so designing lighter buses is a priority. Since passengers typically represent only $10 \%$ of the bus weight in average revenue service, weight reductions have a significant impact. Along with reduction in engine load comes the ability to downsize the engine and drivetrain components, with further fuel economy benefit. It is possible that the trend of increasing bus engine power may be reversed for lighter buses, with future $40-\mathrm{ft}$ buses dropping back to around $250 \mathrm{hp}$ at the flywheel. These improvements are likely to lead to a 20 to $30 \%$ improvement in fuel economy over the next two decades. However, further fuel economy improvements may be gained by reducing air conditioning power demand, both through the use of more thermodynamically efficient systems, and through improved rejection of convective and radiative heat in summer. In winter, some buses employ diesel fueled heaters where insufficient engine heat is available. Improved insulation can help in these instances as well.

In summary, diesel-fueled transit buses with conventional drivetrains offer low capital cost, but high fuel cost. Their efficiency gain is likely to be 20 to $30 \%$ over the next two decades, but many of the competing technologies will also realize similar gains.

\subsubsection{Diesel-electric charge-sustaining hybrid transit buses}

Hybrid buses use more than one energy source for propulsion. They use either an internal combustion engine or fuel cell to convert fuel to energy, and also use chemical batteries or capacitors to store on-board energy. In some cases the batteries are charged prior to service to augment the fuel use. These are termed plug-in hybrids and are treated separately below. Fuelcell powered buses, whether hybrid or direct electric drive, are also treated separately below. In addition to employing fuel saving strategies favored for conventional buses, the hybrid system focuses on recovering energy loss during braking and deceleration and increasing average powertrain efficiency over a daily route.

An evaluation of conventional bus propulsion energy use in slow city operation shows that about half of the energy is used for acceleration, much of which is wasted as friction heat later 
by the application of the service brakes. By recapturing the braking energy, using "regeneration," it is possible to reduce the fuel demand with hybrid bus propulsion systems. Even if the regeneration, storage, and energy re-use efficiencies are modest, fuel use may still be cut by $25 \%$. Generally, the hybrid advantage diminishes as the transient nature of the operation diminishes. Higher average operating speeds imply lower transient operation.

Three major architectures are widely acknowledged for hybrid buses. With series architectures, all of the power flows electrically to a final drive motor. With parallel systems, an electric motor and a mechanical drive can supply power simultaneously. Additionally, for planetary systems, two electric machines provide for the control of a variable transmission ratio. Each system has advantages and disadvantages with respect to regeneration, efficiency and complexity. The relative advantages may vary with duty cycle.

Electrical machine efficiencies are high, and correspond to modest powertrain losses. The Achilles' heel of hybrid buses is the on-board energy storage system (ESS). In most cases, chemical batteries are used, and their charging and discharging inefficiencies are attributed in part to their internal electrical resistance. Within each chemistry type, efficiencies have improved over time, and new chemistries have been adopted which offer superior performance. Both Nickel Metal Hydride(NiMH) and Lithium Ion (Li-lon) technologies are now accepted for advanced hybrid applications. Another disadvantage of battery systems is low specific power (Watts $/ \mathrm{kg}$ ), and the loss of battery charging or discharging efficiency under high power (high current) scenarios. Low battery specific energy (Watt-hours $/ \mathrm{kg}$ ) relative to petroleum fuel also makes on-board energy storage heavy. Despite these drawbacks, the use of battery storage is still effective. Battery life remains an issue, and for some chemistries, particularly lead-acid, deep discharge shortens the life. Additional information on ESS is provided in a separate section below.

Some buses have employed ultracapacitor (or supercapacitor) ESS. These allow for high power density but have low energy density. Ultracapacitors have a long life, and are suited to hybrid bus designs that favor rapid regenerative braking energy capture, followed by launch assist. They may be used in combination with batteries, but, unlike batteries, have a variable 
operating voltage, which requires the use of solid state voltage-to-voltage conversion. If no voltage conversion is used, the effective energy storage of the ultracapacitors is reduced by over $50 \%$ and the bus voltage varies substantially.

Since hybrid buses are able to use both electrical and engine power for propulsion, and since launch from a standstill is the usual metric for performance, the designs in most cases allow for engine downsizing, leading to added cycle-averaged efficiency. The minimum engine power rating is then based on acceptable performance for sustained hillclimbs. The hybrid control strategy may also allow for engine operation in zones of highest efficiency in the operating envelope, rather than just recapture energy and provide acceleration assistance.

Several recent studies have recorded the benefit of present-day hybrid bus drivetrains on fuel economy [4, 28-32]. In very slow city operation, fuel efficiency gains of over $40 \%$ have been recorded, with benefits of 20 to $30 \%$ in typical city use [4, 28-32]. Present-day hybrid buses cost about $60 \%$ more than a conventional bus of similar size, and may require mid-life battery pack renewal. A basic life-cycle cost assessment shows that the benefit of hybrid buses is realized in actual service for high fuel prices or when the average speed is low. Low average speed, exemplified by the Manhattan Cycle (Figure 1) implies highly transient operation. 


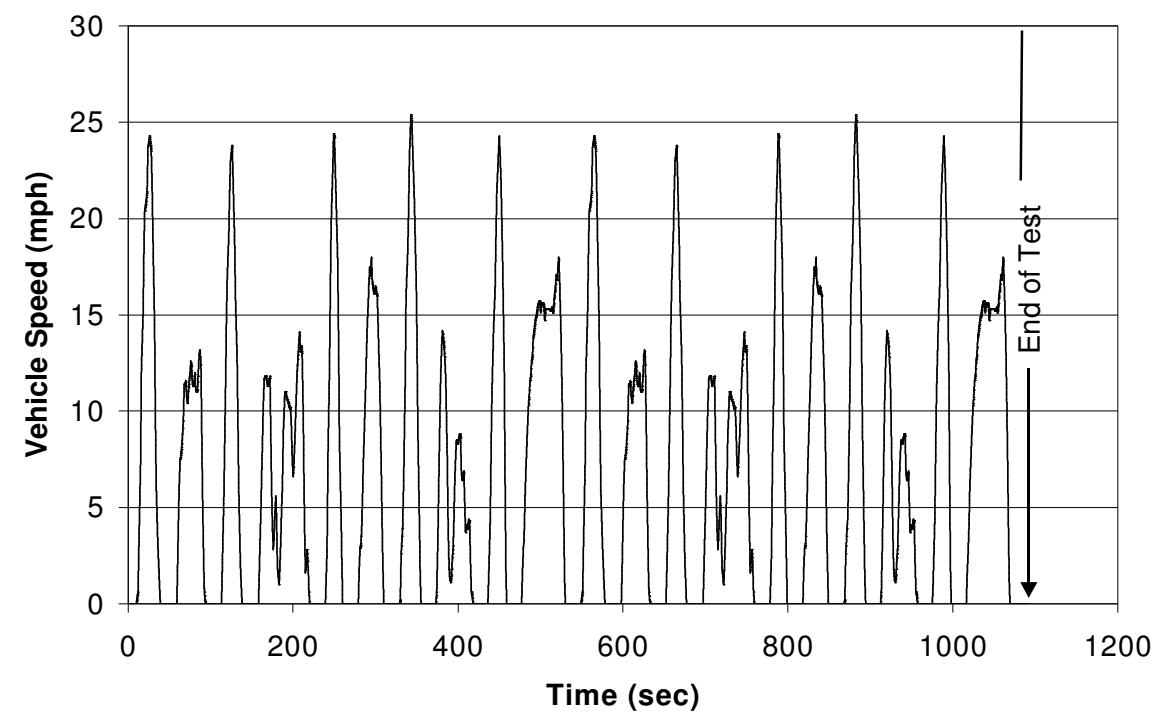

Figure 1: The Manhattan Cycle as an Example of Low-Speed Operation Suited to Hybrid Drive Applications.

Many hybrid bus technology advances will be similar to those for conventional buses, involving improved efficiency of accessories, lighter construction, and improved engine efficiency. But hybrid buses will also enjoy the benefits of evolving battery technology. It is difficult to say whether these advances will be incremental or revolutionary, but they should increase on-board energy storage and allow further engine downsizing, or, conversely, reduce bus weight. It is also likely that more light-duty automobile hybrid control strategies, such as engine-off operation, will be adopted, and that control strategies will become more adaptive. It is likely that $40-\mathrm{ft}$ diesel electric hybrid buses could achieve $8 \mathrm{mpg}$ fuel economy within a decade in typical city use. Flywheel ESS technologies have been proposed for hybrid electric bus applications, but are unlikely to replace chemical storage systems.

\subsubsection{Hydraulic hybrid transit buses}

Many of the advantages of hybrid electric heavy-duty vehicles can be realized by using a hydraulic motor-generator system, with energy stored in compressed gas accumulators. Usually the energy stored on board is low, but high power production is possible, so that a strategy using regenerative braking and launch assist is favored. This technology has seen limited use in refuse trucks and in package delivery applications [33], but has not penetrated the transit bus market. Although it may evolve in small bus applications, there is no indication that it will 
impact the full size bus market. Fuel economy gain from this technology would, however, be attractive, and might be similar to that of an ultracapacitor hybrid electric bus architecture.

\subsubsection{Gasoline transit buses}

Gasoline may be used as a propulsion fuel in either conventional or hybrid vehicles. Diesel engines have been favored historically for their efficiency, while throttled engines were shunned because pumping losses eroded fuel economy. The drive for low NOx emissions in California has encouraged the use of gasoline engines, with three way catalysts, in a hybrid drivetrain configuration. However, there is no reason that gasoline engines should not be used in a conventional drivetrain too. While diesel engines remain more efficient than gasoline engines today, diesel engine fuel efficiency and complexity have been dictated by the need to reduce NOx and PM emissions. However, gasoline engines have been enjoying progressively better fuel economy through improved combustion efficiency and by using tools such as cylinder deactivation. The balance of diesel and gasoline fuel production worldwide, and in the USA, has also caused a price imbalance between the two fuels, even on an energy content basis, making gasoline attractive. However, the distance-specific GHG production by gasoline is still higher. While it is unlikely that conventional spark-ignited gasoline engines will replace diesel powerplants, alternative combustion modes such as $\mathrm{HCCl}$ and LTC may make use of gasoline, and the present clear distinction between gasoline and diesel engines may become blurred within a decade.

\subsubsection{Biodiesel, ethanol and Fischer-Tropsch fuel transit buses}

Alternative fuels have been explored to augment petroleum supplies, improve energy security, and address emissions issues. Biodiesel in the USA has been produced primarily from soybean plants, although waste grease and animal fats have been used. Globally plants such as jatropha and canola (rapeseed) have been employed [31, 32]. The biodiesel is used as a methyl ester, which promotes stability and reduces polymerization, and is usually blended with petroleum diesel. Biodiesel customarily reduces PM, but leaves NOx equivalent or slightly elevated in comparison to pure diesel combustion. The oils may also be processed and refined differently to yield a fuel with a high cetane rating. Biodiesel is promoted to reduce GHG emissions on a well-to-wheels basis, because it is derived from a renewable resource, but it has 
come under attack globally for impacting food prices and causing the destruction of natural habitats [21, 22, and 23].

Fischer-Tropsch fuel is presently produced by gasifying coal or natural gas to produce hydrogen and carbon monoxide, which are then reacted over a catalyst to form a waxy product from which fuel can be distilled. The process can yield gasoline, but diesel-like fuel with a high cetane rating is more common. The process is found to be unfavorable for GHG reduction unless biomass replaces all or part of the feedstock, or unless carbon sequestration is employed.

Both biodiesel and Fischer-Tropsch fuel may be blended with petroleum diesel, and used in compression ignition applications. Their availability, cost, and environmental signature will vary over time, and the decision to adopt or reject these fuels will not have a substantial impact on the technology chosen for transit. Advances are being made in producing compression ignition fuels from algae in an intensive environment, and this work has the potential to provide an abundant product with a low GHG signature.

Ethanol is customarily used as a substitute for gasoline in spark ignited engines. Its high octane rating could offer high efficiency with a dedicated design, but it is usually used in a flex fuel design. The ethanol in the USA is produced primarily from corn, with imported ethanol from sugar beet or cane. Most attractive are proposals to produce the ethanol from cellulosic agricultural products. While it is possible that a niche bus, using ethanol and hybrid technology, might provide good fuel economy and GHG improvements, it is more likely that the ethanol will find transit use as a blend with gasoline where gasoline is the fuel of choice.

\subsubsection{Gaseous fuel transit buses}

Nationally natural gas, stored as compressed gas (CNG) or liquefied natural gas (LNG), has not seen widespread automotive use because a distribution infrastructure is lacking. However, for transit fleets, which are captive and centrally fueled, it has found widespread use. About $14 \%$ of the current US transit bus fleet is fueled by natural gas (see Table 1). Traditionally CNG offered lower PM and NOx emissions compared to diesel fuel in transit applications, but recent standards have closed that gap through use of exhaust filtration and exhaust gas recirculation. Lean-burn CNG engines, which were dominant in transit use, also produced unburned methane 
at the tailpipe, which contributed to GHG. Recently CNG engines have moved to stoichiometric burn, which implies lower exhaust gas hydrocarbons, because a three way catalyst can be used. These engines were able to meet 2010 emissions standards two years ahead of the goal. After 2010, it is likely that criteria pollutants will no longer be the driving force for the use of CNG, and continued use of the fuel will be predicated on cost advantages, or the need for fuel diversity to preserve liquid petroleum reserves, or the need to reduce GHG. CNG engines may be used in hybrid buses, and the hybrid controls can offer higher percent improvements with throttled engines than with unthrotted engines, as a result of their part-load efficiency characteristics. However, few CNG hybrid programs have been pursued to date due to the weight of both compressed gas tanks and battery components on board, and due to the perceived complexity of combining two alternate technologies.

When a new CNG fleet is considered, cost analysis should include the installation of a CNG fueling station, which incorporates gas compression, and the need to avoid ignition sources for CNG, since it is less dense than air and will rise to the ceiling in an enclosed maintenance facility.

\subsubsection{Fuel cell}

Fuel cells have been employed in prototype buses for over a decade. Usually they are used in conjunction with a series hybrid configuration to allow the fuel cell to be sized for average load, rather than peak load and to accommodate the slow power swings favored by fuel cells. They offer direct conversion of hydrogen to electrical power, with no primary moving parts. However, the fuel cell requires pumps and fans as part of the practical installation. Present day disadvantages are seen to be cost, the on-board storage of hydrogen, and the lack of a national hydrogen distribution infrastructure. The "tank to wheels" efficiency can be outstanding, and tank-to-wheels GHG are very attractive [21, 22, and 23], but the hydrogen source emissions must also be considered. The National Renewable Energy Laboratory (NREL) evaluated over 20months of fuel cell bus operation at SunLine Transit Agency and Alamdea-Contra Costa Transit District (AC Transit) in California. This summary is available in NREL evaluation reports [34, 35].

SunLine Transit operated one prototype fuel cell buses, and AC Transit operated three prototype fuel cell buses. All fuel cell buses used the ISE Corp. series hybrid drivetrain. The fuel 
cell bus costs about 2.4 million dollars. Both agencies were using on-site reformers to generate hydrogen from either CNG or methane, although CNG contains mainly methane. The cost of purchasing, installing and maintaining the reformers was not reported. SunLine estimated that it costs about $\$ 8$ to generate 1 kilogram hydrogen. At the average 12 mile per hour average speed, fuel cell hybrid-electric bus's fuel economy was about 7.5 miles per diesel equivalent gallon, which was nearly double the comparable diesel bus fuel economy. If diesel fuel costs $\$ 4 / g a l$, fuel cell bus cost per mile is similar to the diesel bus fuel cost per mile, but the volatility of fuel prices makes long term prediction difficult.

According to the NREL report, fuel cell buses show $30 \%$ higher maintenance cost than the diesel buses at AC Transit and 50\% higher than the CNG buses operated by SunLine Transit [35]. Average fuel cells bus maintenance cost was $0.51 \$ /$ mile from the two sites. Fuel cell buses at AC Transit showed a number of road calls close to the number for the to the diesel buses. However, fuel cell buses run about one third of average monthly mileage that comparable diesel or CNG buses run, because fuel cell buses met much longer downtime and have a lower availability rate. The mile between road calls (MBRC) was better for diesel buses at about 4600 MBRC, while fuel cell buses had about 1300 MBRC. However, one must consider the relative maturity of technologies and the benefit of production volume in reducing capital and maintenance costs. SunLine Transit fuel cell bus MBRC were lower than the CNG buses MBRC, but road calls on the hybrid system batteries influenced this outcome.

\subsubsection{Plug-in hybrid buses}

A plug-in hybrid-electric bus is a hybrid variant with a sufficiently large on-board ESS that a substantial fraction of a shift's operation can be conducted using the stored power. The bus starts operation with a high State of Charge (SOC), and ends with a low SOC. This type of hybrid-electric bus can store substantial energy and use external electric sources by plugging into the electric grid. It has to employ a larger battery pack than a charge-sustaining hybrid, and the operation is termed "charge-depleting." During the charge depleting operation, the plug-in hybrid-electric bus can deeply discharge the battery pack. Like a battery electric bus, described below, it produces zero tailpipe emissions and zero tailpipe fossil fuel consumption during this stage, although pollutants or GHG from the electric generation source must be considered. 
Unlike battery electric buses, this technology also employs an engine-generator system, often with a low power rating, to charge the batteries when they are depleted during operation. When the energy reserve is drained to certain level, the engine and generator are engaged and the hybrid system starts running in the conventional charge sustaining mode (unless demand exceeds supply of power). The engine is termed a range extender in these applications. A continuum of designs is possible between charge-sustaining hybrid buses, which are now common in service, and battery-electric buses, which presently have limited operational range. The ratio of ESS size to engine size can be chosen to suit a specific route or application. In some services, with quick-charge facilities available, it is possible to recharge the plug-in ESS during a pause in service, reducing the demand for the engine and generator operation.

Plug-in hybrid-electric bus performance is significantly affected by bus route and control strategy, since route and control strategy together define how much the pure-electric mode accounted for in the total operation. In addition, life-cycle cost assessment is strongly dependent on the ratio of costs of electricity and petroleum or alternative fuels for the range extender. Modeling for typical service shows that energy cost per mile for battery electric bus is about $\$ 0.22$ per mile compared to $\$ 1.06$ per mile for a conventional diesel bus and $\$ 0.89$ per mile for a diesel hybrid-electric bus, when diesel is $\$ 4.07$ per gallon and electricity is $\$ 0.10$ per kWhr. The plug-in hybrid bus can therefore vary its energy cost per mile between 0.22 and 0.89 $\$ /$ mile, depending on usage. Fuel costs strongly affect life cycle assessments.

Tailpipe emissions are generally lower, if electric-mode operation is managed well. The plug-in hybrid bus advantage is highest if charged by electricity generated by clean power, such as solar, wind, or even nuclear power. However, the attribution of power source is somewhat artificial in most applications, and the fungibility of power from diverse sources makes exact environmental assessment difficult.

It is expected that the plug-in hybrid-electric bus price would be slightly higher than the cost of conventional hybrid-electric bus because it would have a larger and more sophisticated battery pack. The transit agency may also incur capital costs by electrical supplies and providing charging stations. However, no studies have addressed this cost increment. 
At the time of writing, dozens of plug-in hybrid school buses using post-transmission parallel hybrid technology made by Enova are being demonstrated in several states in the US as a part of the Advanced Energy School Bus Program [36, 37]. The program showed through testing over a suburban route that the plug-in hybrid school bus saved $70 \%$ fuel and reduced tailpipe emissions of nitrogen oxides by $20 \%$, particulate matter by $30 \%$, and carbon dioxide by $40 \%$ compared to a conventional diesel school bus [36, 37]. It should be noted that a significant amount of energy on the school routes was derived from the pre-charged battery pack.

\subsubsection{Battery electric transit buses}

Battery-electric buses have only one power source, an ESS which must be recharged before a shift or at intervals along the route. It is assumed that any modern battery electric bus would employ regenerative braking. They are attractive in their simplicity and due to their good onboard efficiency, but the present day constraint is that insufficient energy can be stored onboard under constraint of weight using chemical cells (batteries). A section below specifically covers battery energy density. Consider Li-ion batteries, which are chosen to represent advanced storage technology. They are able to store about $100 \mathrm{Wh} / \mathrm{kg}$. For 10 hours of operation, at even $20 \mathrm{~kW}$ average power, 200 tons of batteries would be needed.

Unless there is disruptive change in battery technology, it is unlikely that power densities of commercially available products will increase by the factor of 20 needed to enable full shift operation without a recharge. However, battery-only buses may find an operational niche where there is time available for fast recharge along a route. At this time, however, technology for a fast charge is not established. It is likely that next generation buses will still require chemical energy conversion on-board, so that they would be termed plug-in hybrids or fuel cell hybrids rather than battery buses.

\subsubsection{Trolleys}

Trolley buses are attractive due to their inherent efficiency and their ability to operate solely from overhead lines. Traditional concerns included electrical safety issues, disconnection from overhead lines, and immobility in the event of electrical failure. These issues have been overcome in modern designs. However, the cost of the electrical infrastructure is high, the 
trolleys cannot be deployed on routes used by a self-powered fleet, and fragility of the infrastructure is a concern. Life cycle cost analysis must explore the offset between capital and operating costs. One reference [38] observes that "The trolley infrastructure costs about US $\$ 1.3$ million per mile for the overhead alone. On top of that is the cost of substations to distribute the 600v DC power. However, with high-efficiency electric motors, plus regeneration of some power back into the overhead grid during braking, trolleys shine in overall energy impacts. It costs approximately 20 cents per mile to power an electric trolley bus (ETB) compared with about 75 cents per mile for diesels averaged over TransLink's entire diesel fleet."

Both 40 foot and 60 foot articulated electric bus designs are already available in the marketplace $[39,40]$. Concerns over immobilized buses due to a short spatial or temporal power interruption can be allayed by storing some energy on-board the trolley bus. The manufacturer New Flyer represent that "A battery-powered emergency power unit provides power when the overhead line is not available, giving the trolley the ability to maneuver around obstructions without difficulty. [39]" Technology of this kind can be extended to include more on-board power, leading to a design that is part trolley, and part battery electric bus. Vehicles of this kind could charge while on a main route, and provide service off the overhead line for part of the route. If an improvement in battery energy density is projected over the next two decades, it is likely that buses of this kind could operate for up to an hour off the overhead lines, thereby substantially reducing the capital cost of overhead line installation.

\subsection{Transit Bus Emissions and Fuel Economy}

Fossil fueled vehicles have been known to produce harmful exhaust emissions. In urban areas, these emissions had higher impact where they could not be easily diluted. As a result, transit operators were obliged to purchase buses with engines that met either the Environmental Protection Agency (EPA) or, in California, the California Air Resources Board (CARB) transit bus engines emissions standards. In addition, state or local policies could prescribe the use of low emission bus technology that might involve the use of alternative fuels, aftertreatment, or hybrid powertrains. 
Vehicle emissions can play an important role in influencing the procurement or retrofit of transit buses, and emissions restrictions were the primary driver for current engine and propulsion system development. It was therefore necessary for transit managers to understand transit bus emissions and the influence that engine design, fuel type and propulsion technology had on those emissions. The two chassis-based low emissions technologies that have received most attention involve the use of natural gas fuel with conventional drivetrains or the use of conventional fuel with hybrid drivetrains. In 2007, emissions standards required that diesel engine particulate matter (PM) emissions be reduced by one order of magnitude. In 2010, the engine nitrogen oxides (NOx) emissions standard for buses would be ten times lower than the previous one. These rapid reductions in diesel engine emissions levels substantially affected how newly developed technologies were compared.

This section consists of three sub-sections:

- An emissions overview of major pollutants from fossil fuel transit buses

- An introduction of transit bus emissions test methodology

- A summary of the emissions and FE research results from the latest North American technologies of hybrid-electric buses and in comparison with diesel control buses.

Additional emissions results, including the historical technology of HEB and natural gas transit buses, are presented in Appendix F of TCRP Report 132 [2].

\subsubsection{Transit Bus Emissions Overview}

The Clean Air Act (CAA) required the EPA to set National Ambient Air Quality Standards (NAAQS) for pollutants which were considered harmful to public health and the environment [41]. Six criteria pollutants have been identified by the EPA Office of Air Quality Planning and Standards (OAQPS): carbon monoxide (CO), lead $(\mathrm{Pb})$, nitrogen dioxide $\left(\mathrm{NO}_{2}\right)$, ground-level ozone $\left(\mathrm{O}_{3}\right)$, particulate matter (PM) and sulfur dioxide $\left(\mathrm{SO}_{2}\right)$. The EPA regulated levels of $\mathrm{CO}$, hydrocarbon $(\mathrm{HC})$, oxides of nitrogen (NOx), and PM emissions from transit vehicle engines. The EPA did not regulate emissions of carbon dioxide $\left(\mathrm{CO}_{2}\right)$, even though it was a major greenhouse gas. In the following subsections, these five (CO, $\mathrm{HC}, \mathrm{NOx}, \mathrm{PM}$, and $\mathrm{CO}_{2}$ ) species are explored. 
Within the transit industry, it was assumed that all piston engines would burn one of the following fuels:

- Diesel (via compression ignition)

- Natural Gas (via spark ignition)

- Gasoline (via spark ignition)

Propane might be used in spark-ignited engines, but was less common in bus applications than diesel, natural gas or gasoline. A small number of buses used turbines in a hybrid design, and both propane and diesel have been used as turbine fuel.

\section{Carbon Monoxide}

Generally, CO was a local emissions issue with impact typically occurring in low lying areas like urban canyons [42]. CO is a colorless, odorless, flammable and poisonous gas. It can be harmful to human health, because it reduces blood's ability to carry oxygen. CO is formed when carbon in the fuel is not burned completely in internal combustion engines (ICE).

Excess $\mathrm{CO}$ emissions from gasoline engines were usually associated with cold startups and operation in open loop mode, in which the computerized engine management system provided a fixed richer air-to-fuel ratio before engine warming to operating temperature. At operating temperature, the oxidation catalyst was usually sufficient to complete at least partial combustion of excess $\mathrm{HC}$ and $\mathrm{CO}$ into $\mathrm{CO}_{2}$, and emissions rates of $\mathrm{CO}$ from modern gasoline engines with catalysts operating in closed loop mode were low. Stoichiometric propane or natural gas engines behaved much like gasoline engines with respect to $\mathrm{CO}$. Diesel engines produced $\mathrm{CO}$ in appreciable concentrations only when the fueling rate is high. This might occur at high engine loads or during transient acceleration. $\mathrm{CO}$ was generally reduced by oxidation catalysts or exhaust PM filters (when present) on diesel vehicles. Lean-burn natural gas engines might produce $\mathrm{CO}$ due to poor air/fuel ratio control during transient operation.

\subsubsection{Hydrocarbons}

$\mathrm{HC}$ are chemical compounds of carbon and hydrogen. Chemical reactions involving $\mathrm{HC}$ and NOx in the presence of sunlight form smog, which is a mixture of pollutants, principally ground- 
level ozone. Smog can harm health, damage the environment and cause poor visibility. Groundlevel ozone is a serious air pollutant in cities across the US. Ozone can cause several types of short-term health effects in the lungs [43].

$\mathrm{HC}$ could result from either from unburned fuel and incomplete fuel combustion, or, in a small percentage of cases, from lubricating oil. Although $\mathrm{HC}$ could arise from rich (high fuel/air ratio) operation, this occurred only with overfueling (un-normally extra fuel supplied). Usually, HC was produced through the fuel and air mixture that were too cold to burn or too lean in fuel to burn. Some $\mathrm{HC}$ might also be stored in the oil film on the cylinder wall, and escaped combustion in this way. Generally, modern compression ignition (Cl) engines had very low HC emissions, except during a cold start and at light load in cold weather conditions. Spark ignition (SI) engines (gasoline, propane or natural gas) operating at a stoichiometric air/fuel ratio produced low HC emissions if a three-way catalyst was used. SI engines would produce high HC during misfire or partial combustion. Since very lean operation promoted incomplete combustion, natural gas engines that used high air/fuel ratios for NOx reduction produced $\mathrm{HC}$ in significant quantity. However, the bulk of the HC from natural gas fueled engines was methane (a greenhouse gas), which was considered to have a lesser environmental impact than nonmethane hydrocarbons (NMHC). NMHC are precursors to ground-level ozone, and make key contributions to smog.

\subsubsection{Nitrogen Oxides}

$\mathrm{NOx}$ is the generic term for a mixture of reactive gases, consisting primarily of $\mathrm{NO}$ and $\mathrm{NO}_{2}$. NOx and NMHC (or total HC) are regulated by EPA as precursors for ozone formation. They created ground-level ozone in the presence of light, which could trigger serious respiratory problems. NOx can react to form nitrate particles, acid aerosols causing respiratory problems. NOx is also responsible, in part, for acid rain and for nutrient overload that deteriorates water quality $[53,54]$.

Most NOx are formed from the complex chemical reactions between nitrogen and oxygen during high combustion temperatures in the engine, although a small fraction of NOx might be derived from nitrogen in the fuel. NO was formed in all engines, but NO levels were higher in 
diesel engines, where there were high temperature zones with available oxygen, and in lean burn natural gas engines if the air/fuel ratio was insufficiently lean. Reduction of NOx was the most complicated problem in designing modern diesel or lean-burn natural gas engines. But for stoichiometric engines NOx could be substantially reduced using mature three-way catalyst technology. The first commercial stoichiometric CNG engine made by Cummins Westport Incorporation (CWI) was claimed to meet 2010 NOx standard of $0.2 \mathrm{~g} / \mathrm{bhp}-\mathrm{hr}$. For most diesel and natural gas engines in bus use, the $\mathrm{NO}_{2} / \mathrm{NO}$ ratio was small (about $5 \%$ ). But the $\mathrm{NO}_{2}$ fraction could approach or exceed $50 \%$ for buses equipped with passive exhaust PM filters, because there was an active effort to oxidize $\mathrm{NO}$ to $\mathrm{NO}_{2}$ in the filter to encourage low temperature regeneration. $\mathrm{NO}_{2}$ emissions were considered to be more damaging than NO.

\subsubsection{Particulate Matter}

Ambient PM is composed of small solid and liquid particles suspended in ambient air. Because more than 90 percent of the carbon particles (by mass) were less than 1 micron in size, they typically remain airborne and could easily be inhaled into the lungs [51]. PM from diesel exhaust has been named a toxic air contaminant in California.

Diesel engines emitted higher levels of PM than spark-ignited engines. PM emitted from ICE was a combination of carbon particles, on the surface of which organic compounds were absorbed. PM would also contain metals (from wear and lubricant) and condensed sulfate (sulfuric acid). Usually PM was grouped into two groups: PM 2.5 (fine) and PM 10 (coarse). The number means the particle diameter sizes of 2.5 and 10 microns each. The size was used to define air quality. Virtually all automotive PM felled into the fine category. PM was formed during incomplete combustion from engine overfueling, engine misfiring or partial combustion, lubricant combustion and fuel impurity. The organic fraction depended on the type of combusted fuel, combustion residence time, combustion temperature, engine lubricant, and whether an oxidation catalyst or particulate trap was installed. Dilution affected both the PM mass and number of particles entering the environment. It might be the adsorbed organic fraction that posed the largest toxic risk associated with the PM. Recent health effects concern 
has focused on the presence of nuclei-mode particles that were high in number count but low in mass in dilute exhaust.

\subsubsection{Carbon Dioxide}

$\mathrm{CO}_{2}$ has been regularly implicated in climate change. $\mathrm{CO}_{2}$ was the principle product of carbon formed from the combustion of hydrocarbon fuels. $\mathrm{CO}_{2}$ has been the focus of public concern in recent years due to the increasing concentration of this gas in the atmosphere as a result of the combustion of fossil fuels.

For transit buses, there were several ways to reduce $\mathrm{CO}_{2}$, namely (i) improving FE by raising engine efficiency, (ii) using lower carbon content and alternative fuels (for example, natural gas, bio-diesel, and bio-alcohol) and (iii) using advanced vehicle transmission technologies (such as hybrid-electric drive) and efficient auxiliaries (such as air conditioning).

\subsubsection{Transit Bus Emissions Test Methodology}

\subsubsection{Chassis and Engine Dynamometers}

Heavy-duty transit bus engines were certified for emissions compliance using dynamometers. The engine was exercised through a prescribed test schedule of torque and speed while regulated gaseous emissions were measured and PM was collected. The PM mass was defined by the sampling method, which involves use of a dilution tunnel and filter system. The procedures were presented in the Code of Federal Regulations, Title 40 [54]. This test schedule did not necessarily represent the way in which the engine would be employed in the bus application [55] and the resulting data did not allow for benefits arising from innovation in the bus design. As a result, engine emissions standards could be used only as a guideline in comparing whole vehicle emissions.

To examine both fuel consumption and emissions from transit buses in an accurate, relevant, and repeatable fashion, a whole vehicle must be tested. Only in this way could the benefits of drivetrain efficiency or hybrid architectures be quantified. Heavy-duty vehicle chassis dynamometers were used for this purpose, but there were few available nationally and most were at fixed sites. Heavy-duty chassis dynamometer facilities with research-grade 
emissions measurement capability were available in Los Angeles and Richmond, CA, Golden, CO, San Antonio, TX. , Research Triangle Park, NC, and New York, NY.

Two Transportable Heavy-Duty Vehicle Emissions Testing Laboratories (TransLabs) designed, constructed and operated by WVU - have provided transportable chassis dynamometer capability. The majority of heavy-duty vehicle emissions data in the USA have been acquired using these two TransLabs. Several technical papers have been published on the design of the laboratories and on emissions data collected from them [56-54]. The Translab consisted of a dynamometer test bed, instrumentation trailer and support trailer. The test bed had a set of rolls to support the vehicle wheels, but power was taken from the vehicle hubs. Flywheels and a power absorber system simulated the inertia and road load of the vehicle. The instrumentation trailer holds both the emissions measurement system and the data acquisition and control hardware necessary for the operation of the test bed. Exhaust from the vehicle was piped into a dilution tunnel at the instrumentation trailer. Levels of $\mathrm{CO}, \mathrm{HC}, \mathrm{NOx}$, and $\mathrm{CO}_{2}$ were measured continuously, and then integrated over the complete test. A gravimetric measurement of PM was obtained by using 70-mm fiberglass filters. The fuel consumption of the vehicle was estimated based on a carbon balance. Most fixed base laboratories employed similar exhaust sampling equipment. (Additional data on bus emissions have also been gathered by Environment Canada [55, 56, and 57] and there was an international program for the International Energy Agency being led by VTT Technical Research Centre of Finland.)

Recently, there has been growing interest in measuring emissions while a heavy-duty vehicle was driven on the road [59-63]. Because the technology to do so was still developing, measurement of PM on the road was remains in its infancy. Also, for technology comparisons, there was no assurance that on-road driving conditions would be repeatable between different runs. Protocols for comparing on-road data between technologies had yet to be developed. Onroad measurements were now required of engine manufacturers to demonstrate compliance with NOx standards while the engine operated in a Not-To-Exceed (NTE) zone. The NTE zone was defined using the engine torque curve, where emissions limits were specified for the regulated pollutions. 


\subsubsection{Emissions Units}

Emission units often depended on the measurement technology used. Engine certification data were given in work-specific units, such as $\mathrm{g} / \mathrm{hp}-\mathrm{hr}$. Chassis dynamometer data were most often expressed in units of $\mathrm{g} / \mathrm{mile}$, with the option of $\mathrm{g} / \mathrm{ahp}$-hr (based on power at the rear wheels). On-board measurement data might be in $\mathrm{g} / \mathrm{mile}$, or may be based on an inferred engine output. Most data could be processed to yield emissions in units of g/gallon (or diesel gallon equivalent) of fuel, or an average emission rate in $\mathrm{g} / \mathrm{hour}$.

Engine Certification Data. They were acquired using an engine dynamometer and were expressed in units of $\mathrm{g} / \mathrm{hp}$-hr. They were openly available and were accurate and repeatable on engine emissions. However, they did not accurately project inventory or distance-specific emissions for transit bus operation because they did not account for drivetrain efficiency and accessory loads, nor did they consider the bus holistically. The test schedule did not necessarily represent the bus operation in actual use. In particular, HEB engines might not operate in a fashion that was characteristic of engines in conventional vehicles.

Chassis Dynamometer Data. They were available in units of $\mathrm{g} / \mathrm{mile}$ and $\mathrm{g} / \mathrm{gallon}$. They reflected transit bus emissions accurately, provided that the speed-time test schedule was sufficiently representative of bus operation. Repeatable measurements were more difficult to make than with an engine dynamometer because accessory loads could vary with time environmental factors could vary, and driver behavior might differ from run to run. WVU had extensive chassis data available in a comprehensive database.

On-board Measurement Data. They were gathered using a mobile emissions measurement system. They reflected transit bus emissions realistically by conducting the test on the road over a real route. However, it was more difficult to achieve high levels of accuracy using miniaturized analysis equipment, and few data were available in the public domain. Furthermore, routes were not generally repeatable. 


\subsubsection{Vehicle Simulation Software}

There were several commercial and free software packages available for transit managers and developers to evaluate the potential effects of implementing new hybrid-electric technologies.

AirCred. Its online version was designed by the Argonne National Laboratory (ANL) using Visual.net. This software provided output information based on the input data. It was used to calculate ozone emission reduction credits for clean cities vehicles. Based on the EPA's MOBILE model, AirCred also took into account the emissions test certification data for new OEM alternative fuel vehicles (AFV) and their gasoline/diesel counterparts.

The model started by selecting a location to assign the MOBILE5b-computed emission factors appropriate to either the midsummer ozone season or the midwinter $\mathrm{CO}$ conditions in each major city. The net $\mathrm{g} /$ mile credit could be taken for the AFV by determining the "clean gap" in NMHC, CO, and NOx between the certification values from the AFV and their gasoline/diesel counterparts.

VISION. The model has also been developed by the ANL with the sponsorship of the Office of Energy Efficiency and Renewable Energy, the US Department of Energy (DOE). This model could be used, "to provide estimates of the potential energy use, oil use and carbon emission impacts through 2050 of advanced light- and heavy-duty vehicle technologies and alternative fuels" [58]. Current version of the VISION model is "VISION 2007 AEO Base Case Expanded". The models can be accessed at the following link

ADVISOR 2004-Virtual Vehicle Analysis. It was designed by National Renewable Energy Laboratory (NREL) by using MATLAB/Simulink software and has been commercialized as ADVISOR 2004 by AVL Powertrain Engineering, Inc. It was used for, "rapid analysis of the performance and FE of conventional and advanced, light and heavy-duty vehicle models as well as hybrid-electric and fuel cell vehicle models." It was continuously updated with actual component test data. Detailed information on the model could be found at the following link. 
PSAT/PSAT-PRO. The Powertrain System Analysis Toolkit (PSAT) has been developed by Argonne National Laboratory by using MATLAB/Simulink software. PSAT-PRO was the updated version of PSAT. It was considered, "an accurate flexible simulation and prototyping tool used for hardware-in-the-loop (HIL) that can simulate more than 100 drivetrain configurations" [59]. This software could also be used for 'Real-Time Simulation' and 'Rapid Prototyping.' The software has evolved into Autonomie, a new generation of simulation tool [60].

AUTONOMIE. Argonne National Laboratory developed this vehicle control system based on MATLAB/Simulink software. It aimed to use mathematical models and environment to speed up the development, optimization and optimization of vehicle control system [60]. It had more than 400 pre-defined drivetrain configurations embedded in the system in 2010 [60]. It was a more powerful tool in vehicle simulation and prototyping than PSAT series was [60].

\subsubsection{Hybrid-Electric Chassis Testing Protocol}

Different types of hybrid drive systems were commercially available, but there was little history of procedures for measuring hybrid-electric vehicle (HEV) exhaust emissions and FE. The Society of Automotive Engineers (SAE) promulgated a light-duty HEV chassis testing protocol SAE J1711 and the Northeast Advanced Vehicle Consortium (NAVC) collaborated on development of a heavy-duty HEV chassis protocol SAE J2711, which was based on SAE J1711 [61].

Heavy-Duty Hybrid-Electric Vehicles, SAE Standard J2711. The "Recommended Practice for Measuring FE and Emissions of Hybrid-Electric and Conventional Heavy-Duty Vehicles," was established to provide an accurate, uniform and reproducible procedure for the testing of heavy-duty HEV and conventional vehicles on dynamometers for measuring emissions and calculating FE. This standard procedure was aimed at making direct comparisons between hybrid-electric and conventional vehicles. In detail, it described the emissions testing procedure, including state of charge correction, recommended drive cycles, test preparations, pre- and post- data collection, test instrumentation, data recording, test validation, and the final test product. It recommended three cycles: the Manhattan Cycle (low-speed transit bus operation), the Orange County Transit Cycle (intermediate-speed bus operation), and the UDDS (high- 
speed bus operation). The UDDS could also be used for the evaluation of high-speed operation for buses and tractor-trailers. This procedure did not specify which criteria pollutants to evaluate. That decision has been left to satisfy the objectives of the emissions testing program. It should be noted that most heavy-duty vehicles addressed in this document would be powered by engines that are certified separately for emissions.

\subsubsection{State-of-Charge Correction}

State-of-Charge (SOC) correction was essential when comparing HEV emissions to conventional vehicle emissions, because HEV gain power from two energy sources. One was a consumable fuel like a conventional vehicle, and the other was rechargeable energy storage system (RESS). SOC represented the state of energy in RESS.

During the HEV's driving cycle, the RESS was charged by the power unit during driving and through the capture of braking energy during deceleration. A significant amount of energy was stored in the RESS. In order to precisely compare the emissions from HEV and conventional vehicles, SAE J2711 outlined a correction protocol. The data from the HEV test must be corrected so that the net energy change (NEC) in the RESS was zero. This correction ensured that the energy consumed by the vehicle necessary to complete the test cycle was demanded from the consumed fuel.

\subsubsection{Factors Affecting Transit Bus Emissions}

\subsubsection{Fuel Effects}

Diesel. Diesel fuel is a complex mixture of hydrocarbon molecules. Commercial diesel fuels contained aliphatic, olefinic, cycloparafinic, and aromatic hydrocarbons, and additives to improve their fueling properties [62].

Diesel engine emissions contain a wide range of chemical compounds, which vary as a result of the crude oil source and nature of refining. Fuel is normally defined in terms of its properties, which include measures of its volatility, cetane number (ability to auto ignite), sulfur content, aromatic content, lubricity and cold flow properties. Traditionally, diesel fuel has been required to meet specifications such as ASTM D975. Initiated by California, some regions and 
states required a "clean" diesel fuel that has more stringent standards, such as aromatic content limited to $10 \%$. In addition, North America has started producing ultra-low sulfur diesel (ULSD meets $15 \mathrm{ppm}$ maximum sulfur content). Using fuel of less than $15 \mathrm{ppm}$ is either to reduce emissions of sulfur oxides ( $\mathrm{SOx}$ ) or to enable the use of sulfur-sensitive aftertreatment.

Diesel properties can affect emissions. Generally, diesel fuel with a high paraffin content has a high cetane number, and offers low NOx and PM emissions levels. Whereas aromatic content contributes to lower cetane number, and thus higher PM and NOx. Several studies exist to describe the effects of fuel on emissions. These effects could vary depending on the fuel injection system design [64-68]. Although virtually all diesel fuels have petroleum base, synthetic diesel can be produced by the Fischer-Tropsch process, while offering reduced emissions levels [69-71]. Petroleum diesel and biodiesel can also be blended; this usually reduces PM, while increasing NOx emissions slightly. Several studies exist to describe biodiesel emissions effects [72-77].

Gasoline. Gasoline is a complex mixture of volatile hydrocarbons ranging from seven to eleven carbons in weight, with additives to improve properties such as octane rating (knock resistance) and often with oxygenates (such as MTBE or ethanol) added. Although methanol and ethanol have been used as alternative spark-ignited engine fuels, they have not penetrated the gasoline market substantially (except in low-alcohol blends). The most important pollutants from gasoline include CO, NOx, and HC. The current closed-loop engine control with a threeway catalyst system used in transportation was effective in reducing $\mathrm{CO}, \mathrm{HC}$, and NOx. The sulfur level in gasoline was regulated, because sulfur content in gasoline could affect the conversion efficiency of exhaust catalysts, thereby increasing emissions. The Auto/Oil Air Quality Improvement Research Program (AQIRP) completed a study of the combined effects of fuel parameters on emissions from modern vehicles [78]. The fuel effects on mass emissions from this study were listed below:

- Effects of aromatics content were not found.

- Oxygenate containing fuels reduces $\mathrm{CO}$ emissions, but had smaller and less consistent effects on $\mathrm{HC}$ and NOx. 
- Reduction of gasoline Reid vapor pressure (RVP) to 9 psi could reduce exhaust HC and CO emissions, and reduction of gasoline RVP can reduce evaporative emissions.

- Reduction of the sulfur content could reduce $\mathrm{CO}, \mathrm{HC}$, and NOx by increasing the efficiency of catalysts.

Several studies [78-80] described how gasoline aromatics content, the addition of oxygenated compounds, olefin content, $90 \%$ distillation temperature, RVP, and sulfur content could affect the composition of emissions, reactivity of emissions, and toxic air pollution.

Propane. Propane is a colorless, odorless, flammable gas, found in natural gas and petroleum. Propane is just one of the many fossil fuels that are included in the liquefied petroleum (LP) gas family. Because propane is the type of LP-gas most commonly used in the US, "propane" and "LP-gas" are often used synonymously. Propane is always stored as a liquid in pressurized tanks.

Compared to gasoline and diesel, propane has a higher octane rating. The EPA has estimated potential emission reduction offered by propane relative to conventional gasoline. Propane had potentially lower toxic, $\mathrm{CO}_{2}, \mathrm{CO}$, and $\mathrm{NMHC}$ emissions. As with gasoline, rich engine calibration yielded high NMHC levels and CO, but lower NOx. In the lean calibration condition, higher nitrogen dioxide emissions were formed, but lower NMHC and carbon monoxide.

CNG/LNG. Natural gas is a mixture of hydrocarbon compounds mostly of methane and small quantities of heavier hydrocarbons and various non-hydrocarbons existing in the gaseous phase or in solution with crude oil. Natural gas is commonly used as fuel for heating. Compressed natural gas (CNG) is stored in high pressure cylinders at 3,000 to 3,600 pounds per square inch (psi). Liquefied natural gas, LNG, is formed by cooling natural gas to a temperature of $-116^{\circ} \mathrm{F}$. During the liquefaction process, oxygen, carbon dioxide, sulfur compounds, and water are removed. The fuel is purified and methane content is increased from nearly 90 percent in the original natural gas to almost 100 percent. LNG must be stored in cryogenic tanks, usually at low pressure. 
For heavy-duty and medium-duty applications, natural gas engines often operate in a lean burn mode. Emissions could be significantly lower in CO and PM, relative to a commercial diesel engine, if the air/fuel ratio were managed to have the proper amount of fuel for given air flow rate under any operating condition. For light-duty applications, where stoichiometric engines were common, natural gas engine exhaust emissions were significantly lower than their gasoline counterparts for NMHC and CO. However, natural gas engines often had higher methane emissions, because natural gas has high content of methane and since lean burn operation was often associated with incomplete combustion.

\subsubsection{Test Weight Effects on Emissions}

Vehicle weight plays a significant role in emissions production [81-83]. However, for heavyduty vehicles, emissions regulations were imposed only on the engines by following the federal testing procedure prescribed in the Code of Federal Regulations, Title 40, Part 86, Subpart N [44]. Vehicle weight does not affect the emissions test and so the work-specific emissions rate is unaffected. Generally, vehicle FE is determined by road load, which itself is affected by tire and aerodynamics losses during steady state operation. Fuel is also consumed in climbing grades, accelerating, and fulfilling auxiliary load requirements. For a heavy-duty transit bus, aerodynamic losses are relatively small and can be ignored during urban stop and go driving and low speed cruise. Tire losses played a major role in road load, and tire losses were proportional to the weight of bus. Hill-climbing and acceleration demands were also proportional to weight. If two buses were equipped with the same engines, and the engines were certified to the same standard (g/bhp-hr), the heavier bus would consume more fuel. However, the relative fuel consumption will depend both on the driving cycle and the auxiliary loads.

Transit bus emissions in $\mathrm{g} / \mathrm{mile}$ would be influenced partly by the ratio of brake energy over distance (bhp-hr/mile) during operation, although emissions did vary over the engine map and as a result of transient engine behavior. When a whole bus was tested on a chassis dynamometer, it was customary to perform the test using a test weight of the empty bus, plus weight of driver, plus half of the weight of the seated passengers [61]. Research [81] by WVU 
has examined weight corrections for Class 7 and 8 diesel vehicles (trucks over 26,000 lb gross vehicle weight) on vehicle emissions. It was found that the NOx emissions had a nearly linear correlation with vehicle weight. $\mathrm{HC}$ emissions were not sensitive to the vehicle weight. $\mathrm{CO}$ and PM emissions were significantly affected by weight during transient operation, but they were not sensitive to steady-state operation. Graboski et al. [85] concluded that a heavier vehicle would produce more exhaust gas on a $\mathrm{g} / \mathrm{km}$ basis (distance-specific emissions) because of higher fuel consumption. A vehicle that used more fuel following a cycle would produce higher emissions in units of $\mathrm{g} / \mathrm{km} \mathrm{[85]}$.

\subsubsection{Drive Cycles or Schedules and Effects on Emissions}

Repeatable measurement of emissions from heavy-duty vehicles necessitates the use of a chassis dynamometer with a driving cycle representing the vehicle's driving pattern in real use. A wide variety of driving cycles has been developed to simulate the duty cycles of heavy-duty trucks and buses during realistic operation. A flaw in most of these cycles was that they neglect effects of road grade, which are substantial for heavy-duty vehicles in most locations. Some of the most common drive cycles are presented in the following paragraphs. In reviewing bus emissions and FE data, it was important to identify both the test weight and the test cycle used, because data would not translate reasonably between cycles. Table 3 gives a summary of common in-use drive cycles or schedules.

Table 3: Test cycle or Schedule Descriptions

\begin{tabular}{|c|c|c|c|c|c|c|c|}
\hline \multicolumn{2}{|l|}{ Cycles or Schedules } & \multirow{2}{*}{$\begin{array}{c}\text { Distance } \\
\text { (mile) }\end{array}$} & \multirow{2}{*}{$\begin{array}{l}\text { Total } \\
\text { Time } \\
\text { (sec) }\end{array}$} & \multirow{2}{*}{$\begin{array}{l}\text { Ave } \\
\text { Speed } \\
\text { (mph) }\end{array}$} & \multirow{2}{*}{$\begin{array}{l}\text { Max } \\
\text { Speed } \\
\text { (mph) }\end{array}$} & \multirow{2}{*}{$\begin{array}{c}\text { Stops } \\
\text { per Mile }\end{array}$} & \multirow{2}{*}{$\begin{array}{l}\% \text { of } \\
\text { idle }\end{array}$} \\
\hline Cycle Full Name & Abbreviation & & & & & & \\
\hline Central Business District Cycle & CBD [86] & 2.00 & 560 & 12.5 & 20.0 & 7 & 7.23 \\
\hline Urban Dynamometer Driving Schedule & UDDS [44] & 5.50 & 1060 & 18.8 & 58.0 & 1.6 & 31.5 \\
\hline Manhattan Cycle & Manhattan [87] & 2.10 & 1089 & 6.80 & 25.4 & 9.5 & 33.0 \\
\hline New York Bus Cycle & NY-Bus [88] & 0.60 & 600 & 3.70 & 30.8 & 18.3 & 62.3 \\
\hline Orange County Transit Authority Cycle & OCTA [61] & 6.71 & 2000 & 12.3 & 40.0 & 4.9 & 20.6 \\
\hline Washington Metro-Area Transit Authority Cycle & WMATA [89] & 4.30 & 1839 & 8.40 & 45.4 & 5.6 & 38.7 \\
\hline The City Suburban Heavy Vehicle Cycle & CSHVC [90] & 6.70 & 1700 & 14.2 & 43.8 & 1.9 & 23.5 \\
\hline European Transient Cycle & ETC [91] & 18.2 & 1800 & 36.6 & - & 0.4 & - \\
\hline Braunschweig City Cycle & Braunschweig [92] & 6.86 & 1740 & 14.3 & 36.4 & 4.22 & 20.8 \\
\hline Dutch Urban Driving Cycle & DUBDC [93] & 3.25 & 900 & 13.0 & 39.0 & 4.6 & - \\
\hline De Lijn Cycle & De Lijn [93] & 3.75 & - & - & 37.5 & 6.7 & - \\
\hline Otaniemi Cycle & Otaniemi [94] & 2.11 & 400 & 19.0 & - & 1.9 & - \\
\hline Line 23 Cycle & Line 23 [94] & 10.7 & 3720 & 10.3 & 33.0 & 5.7 & - \\
\hline Mexico City Driving Schedule & MCS [95] & 8.60 & 3000 & 11.2 & 43.0 & 4.5 & - \\
\hline
\end{tabular}


Transit buses were tested on recommended drive cycles in order to generate in-use emissions data. Each drive cycle used in the emissions program was unique in the sense that each one had its own vehicle speed-time characteristics. Differences in vehicle speed generated differences in average and maximum acceleration and deceleration. Each drive cycle also had unique idle segments with unique duration. Differences in vehicle speed and idle duration caused difference in power demand, which consequently affected emissions and FE. Therefore, drive cycles were considered one of the parameters that most heavily affect the emissions from heavy-duty diesel vehicles [81, 96, and 97].

Two widely used driving cycles - the UDDS (Figure 2) for heavy-duty vehicles and the NYBus Cycle (Figure 3) - were selected to show the effects of drive cycles on emissions. The UDDS covered approximately 5.5 miles in 1060 seconds, while the NY-Bus cycle covered 0.6 miles in 600 seconds. Average and maximum vehicle speeds of the UDDS were $18.8 \mathrm{mph}$ and $58 \mathrm{mph}$ while the average and maximum speed of the NY-Bus cycles were $3.7 \mathrm{mph}$ and $30.8 \mathrm{mph}$. Idle duration on the NY-Bus cycle (approximately 62\%) was almost double the idle duration of the UDDS cycle (approximately 32\%). The two cycles' substantial variation in idle duration and average vehicle speed caused differences on both the distance-specific and the time-specific emissions from the same vehicle when it was tested on these two cycles. The distance-specific emissions, time-specific emissions, and vehicle FE were sensitive to average cycle speed, acceleration, and idle duration [81, 94, and 98]. 


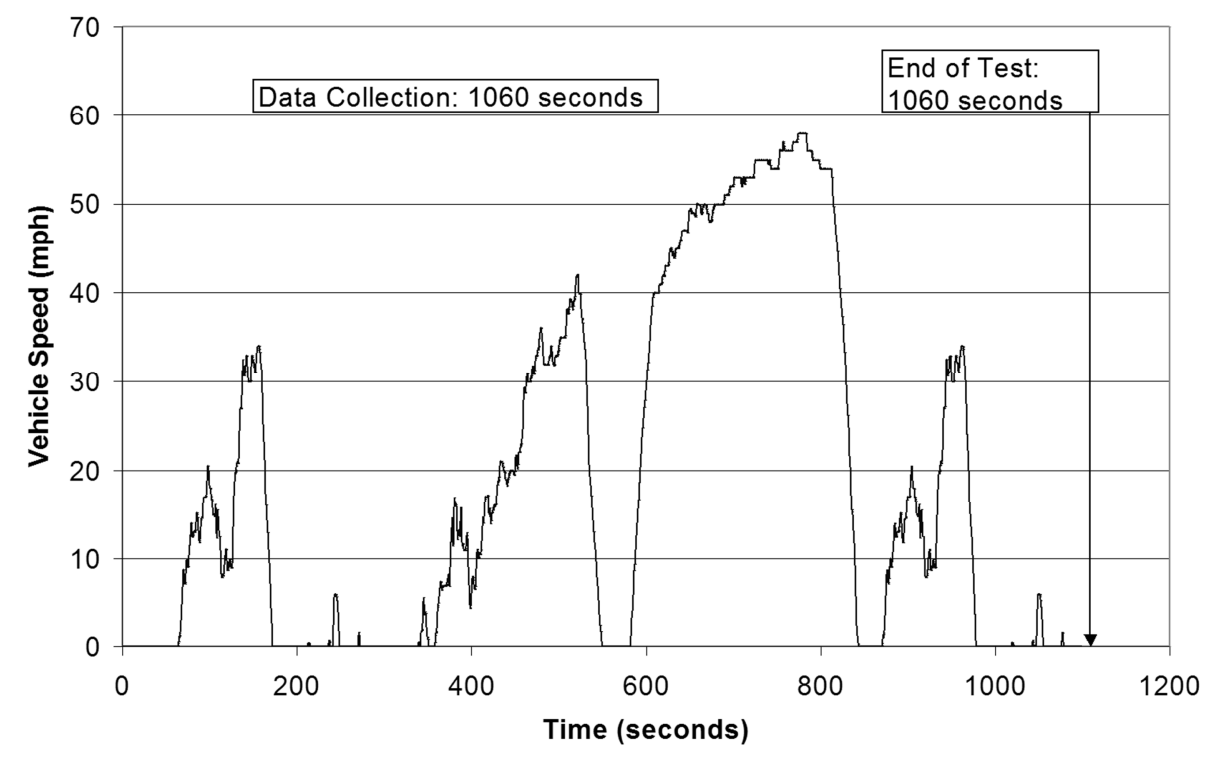

Figure 2: The Urban Dynamometer Driving Schedule (UDDS) [44]

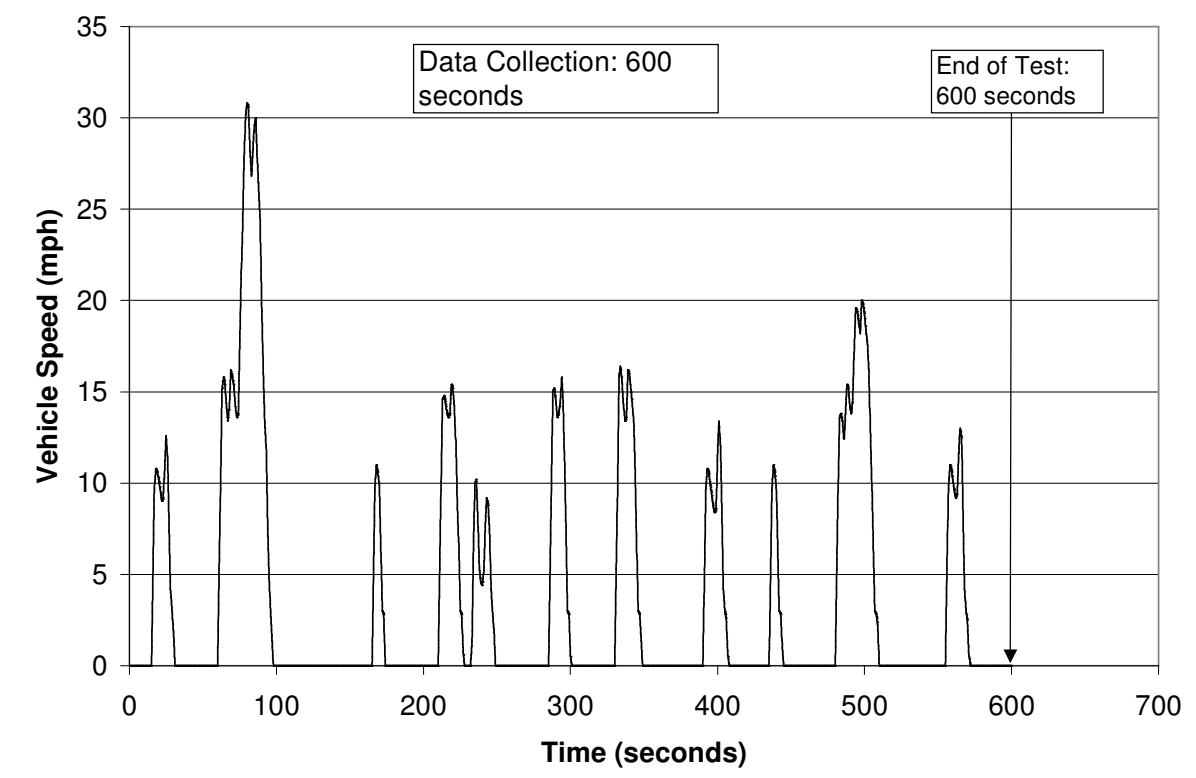

Figure 3: The New York Bus Cycle [90]

Figure 4 and Figure 5 present a test result of the continuous emissions of $\mathrm{CO}_{2}$ and $\mathrm{NOx}$ following the UDDS. They show how fuel consumption (as indicated by $\mathrm{CO}_{2}$ ) and NOx vary over the cycle. Clark et al. [81] examined the effect of test cycle choice on an 8.5 liter (275 rated hp, the Detroit Diesel Corporation (DDC) Series 50 engine) diesel bus from the Flint Mass Transit Authority. The bus emitted about $70 \mathrm{~g} /$ mile of NOx emissions when tested on the NY-Bus cycle. 
The same bus emitted about $27 \mathrm{~g} /$ mile of NOx when tested on the UDDS. PM emissions were also high in distance-specific units when the bus was tested on the NY-Bus cycle $(1.32 \mathrm{~g} / \mathrm{mile})$ in comparison to the UDDS (0.37 g/mile). Clark et al. [81] showed that PM emissions could vary by a factor 15 and NOx emissions could vary by a factor of 3 when measured using different chassis dynamometer test schedules. Graboski et al. [85], in the Northern Front Range Air Quality Study, found that the test cycle used affected the distance-specific emissions from trucks. This has been confirmed by subsequent truck studies [88, 89]. Therefore, test cycle is a critical factor, when interpreting the distance-specific emissions from heavy-duty vehicles.

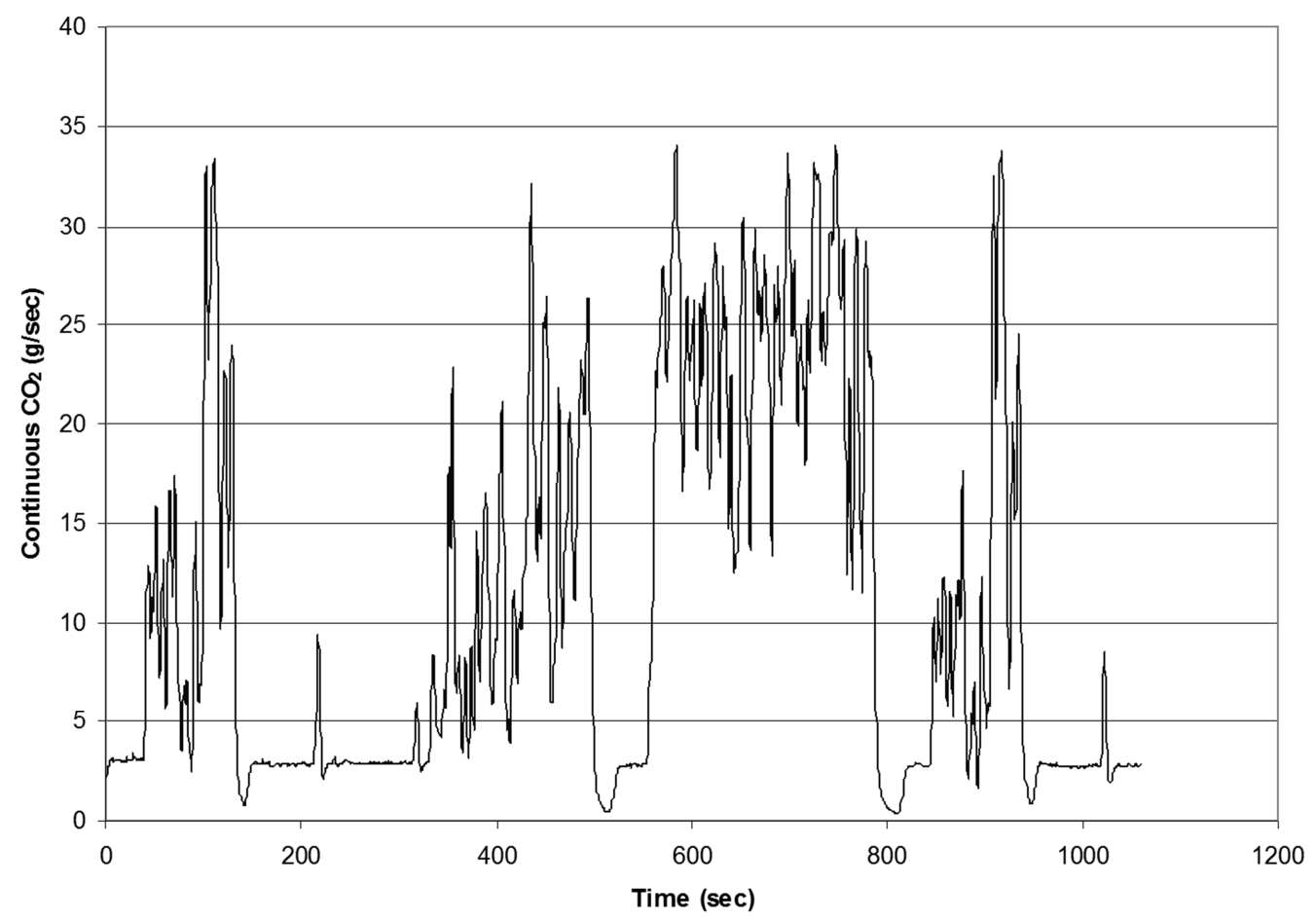

Figure 4: Continuous $\mathrm{CO}_{2}$ Emissions of a Typical Heavy-Duty Diesel Bus over the UDDS 


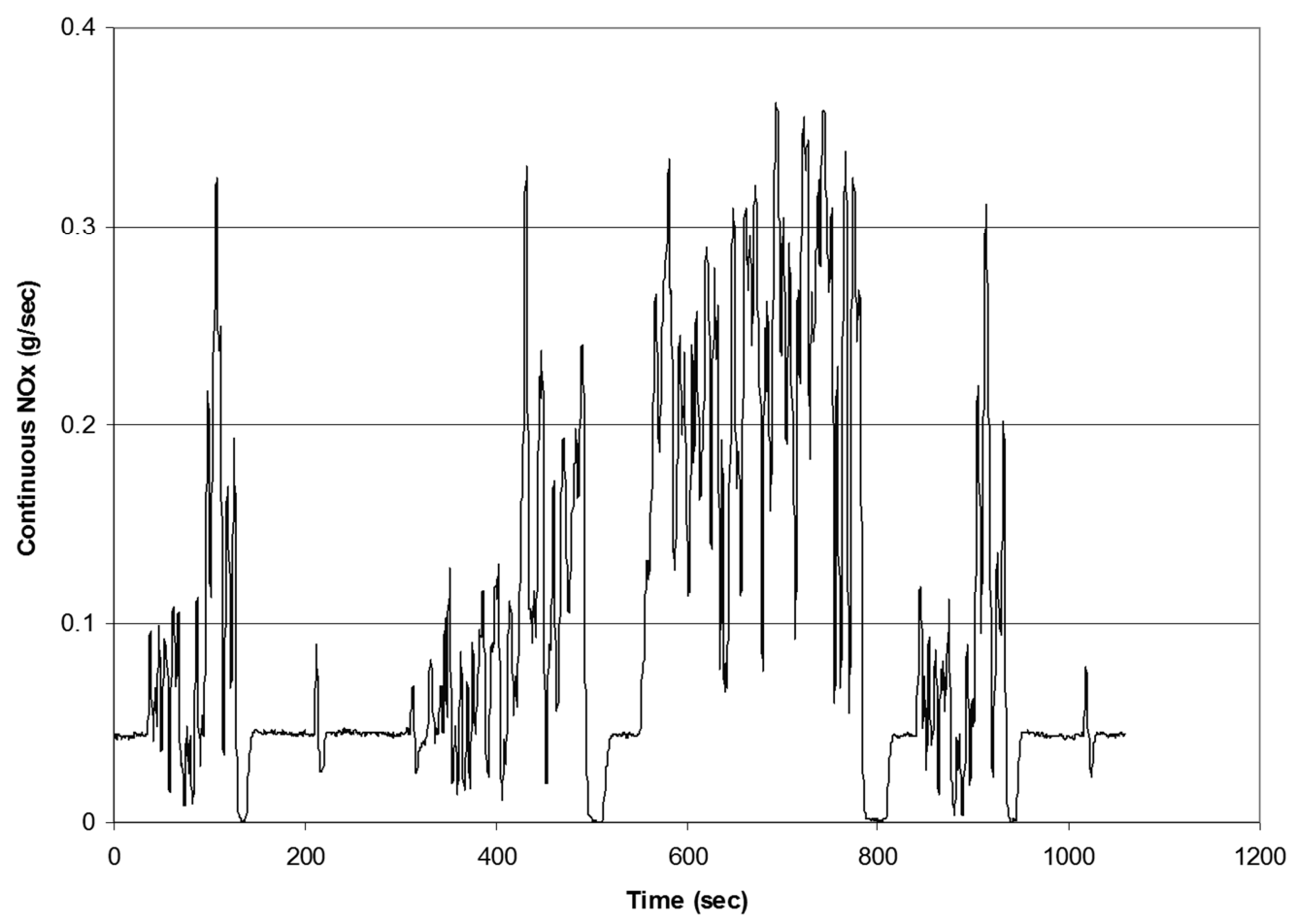

Figure 5: Continuous NOx Emissions of a Typical Heavy-Duty Diesel Bus over the UDDS

\subsubsection{Transit Bus Emissions and Fuel Economy Data}

This section discusses chassis dynamometer emissions and FE data taken from eight transit bus research studies conducted by WVU and Environment Canada. Part of the data were adapted from Transit Bus Emissions Survey, prepared by WVU, and presented to the US Department of Transportation (DOT) [99]. Furthermore, the FE performance of HEB was presented by comparing similar buses with different conventional engines in real tests and published results from computer simulations. Appendix F of TCRP Report 132 provides complete emissions results and discussion of these studies, which were grouped into two case studies on hybrid drive system and natural gas fueled transit buses [2].

The transit bus technologies reviewed in this section covered bus model years 1997 to 2004 and a total of fifty-eight full size HEB, CNG, LNG, and conventional diesel transit buses. Although there are many mid-age buses (model year 1994 to 1996) still in service, the research results from older technologies were not included in this report since their value to the deployment of future transit buses was of low importance to the C-15 program. Many 
references exist in the literature to describe the success of diesel (exhaust) particulate filters (DPF) in reducing PM (and other organics) from diesel-fueled trucks and school buses [100, 101, and 102]. Those data were not reproduced in this report, because the transit bus data were sufficient to demonstrate effectiveness of the DPF technology.

The emissions of PM and NOx, and FE, on the CBD cycle (Figure 6) from eight studies were presented in Figure 7, Figure 8, and Figure 9. Diesel bus PM emissions have decreased over 90\% during the last seven years, achieving the same PM emissions levels as both HEB and CNG buses. However, diesel particulate filter (DPF) aftertreatment played the most important role in reducing PM from diesel buses and diesel HEB. Both produced lower PM emissions than the single model year (MY) 1998 Gasoline HEB tested. The average NOx emissions from diesel buses were about $35 \%$ to $45 \%$ higher than the averages from CNG, LNG, and diesel HEB, which all produced nearly equivalent NOx emissions. The gasoline HEB exhibited NOx emissions that were lower by an order of magnitude, because the gasoline engine was stoichiometric and used a three-way catalyst. The FE of HEB increased nearly $50 \%$ over the last seven years. CNG and LNG buses did not change significantly. The FE of the single gasoline HEB was slightly better than CNG buses and close to LNG buses. However, diesel engines have suffered on FE in recent years due to emissions reduction technology. 


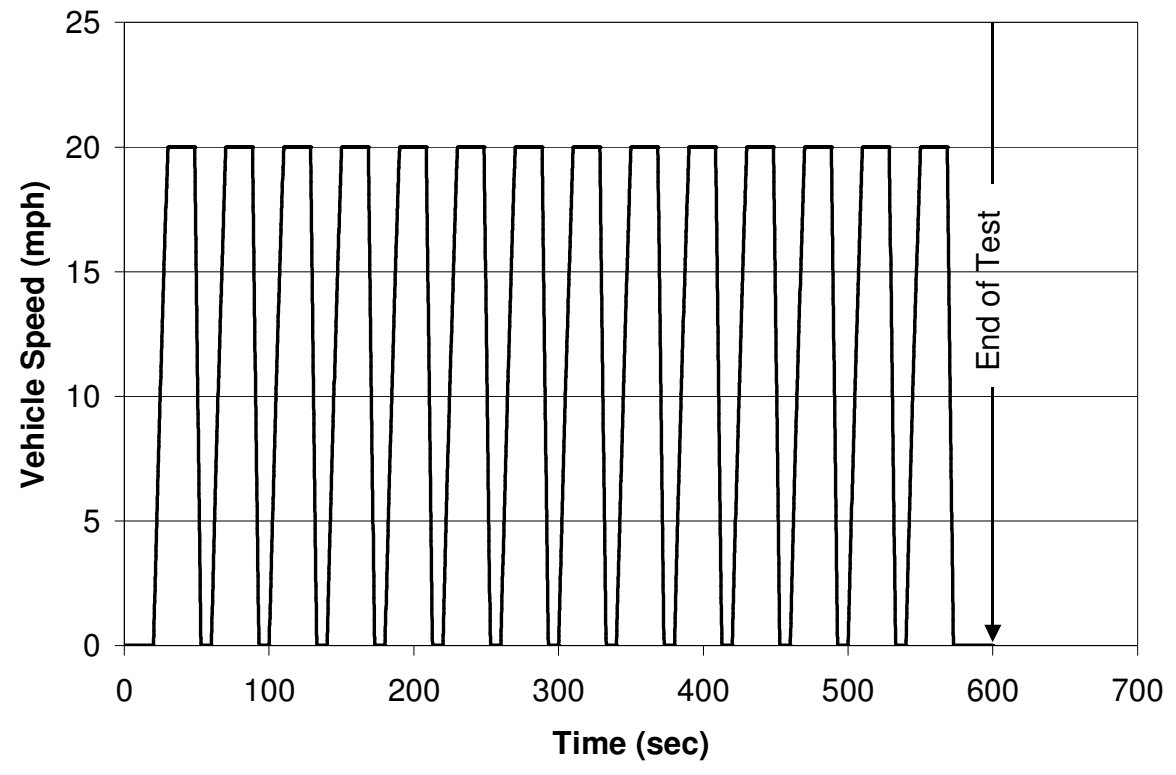

Figure 6: Central Business Cycle [86]

Yanowitz et al. [103] reviewed in-use emissions from more than 250 heavy-duty diesel vehicles. The study found that emissions of PM, CO, and total hydrocarbons (THC) decreased significantly over the past two decades. Emissions of NOx have not changed very much over that time. While evaluating bus emissions at the Ottawa chassis dynamometer test laboratory, Graham [104] observed a downward trend in NOx and PM emissions over the last two decades. 
Non-HEB

HEB

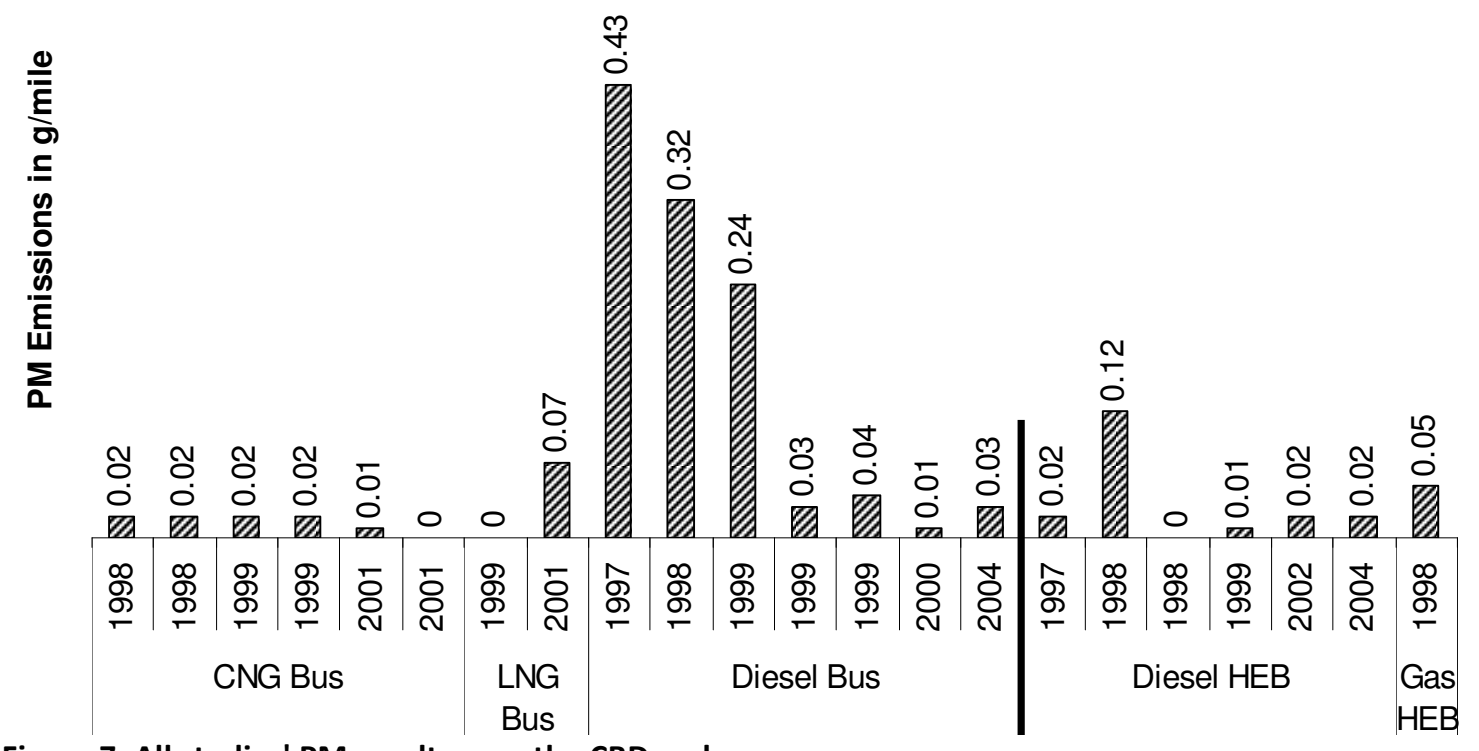

Figure 7: All studies' PM results over the CBD cycle

* 0 indicates that the result is round off or below detectable limit.

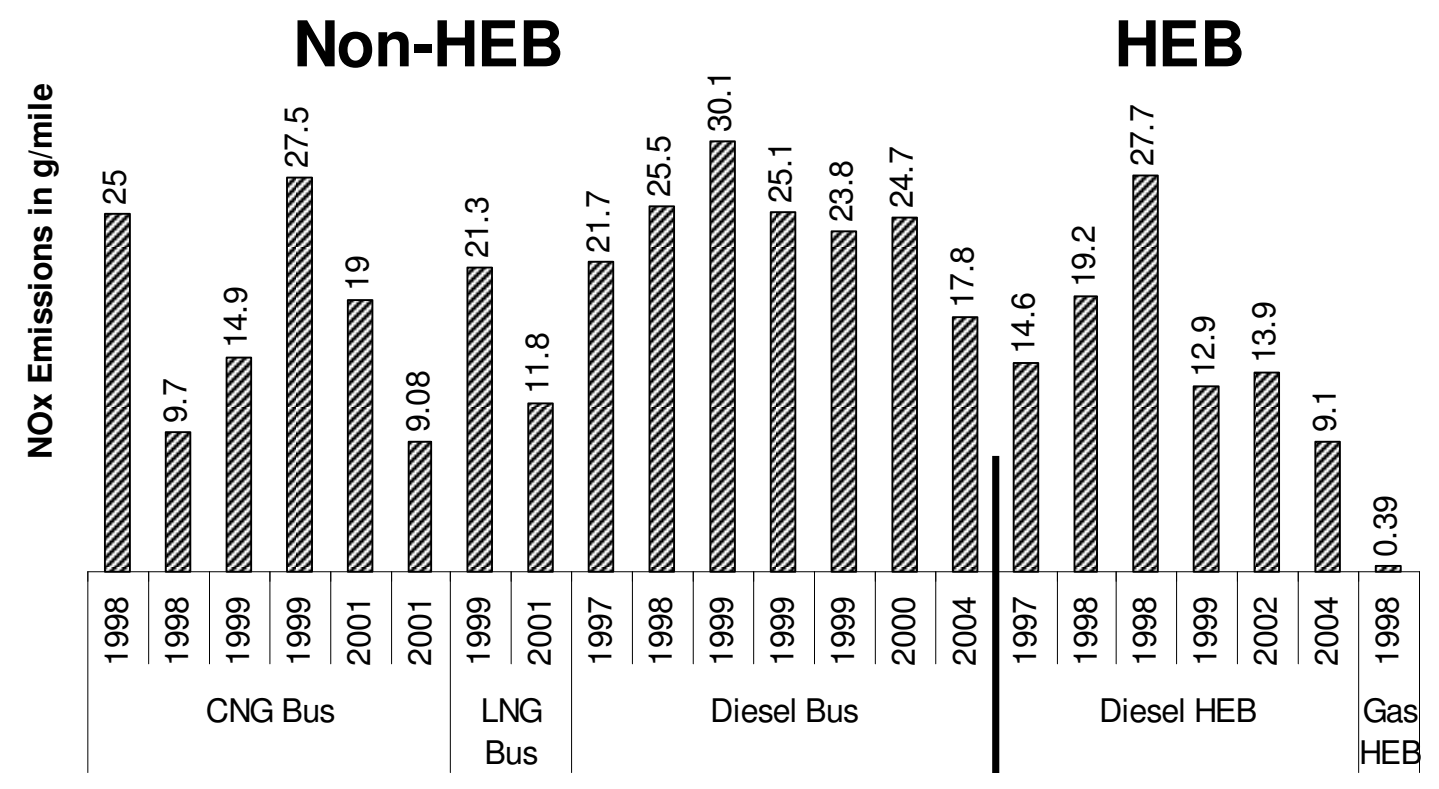

Figure 8: All studies' NOx results over CBD cycle 


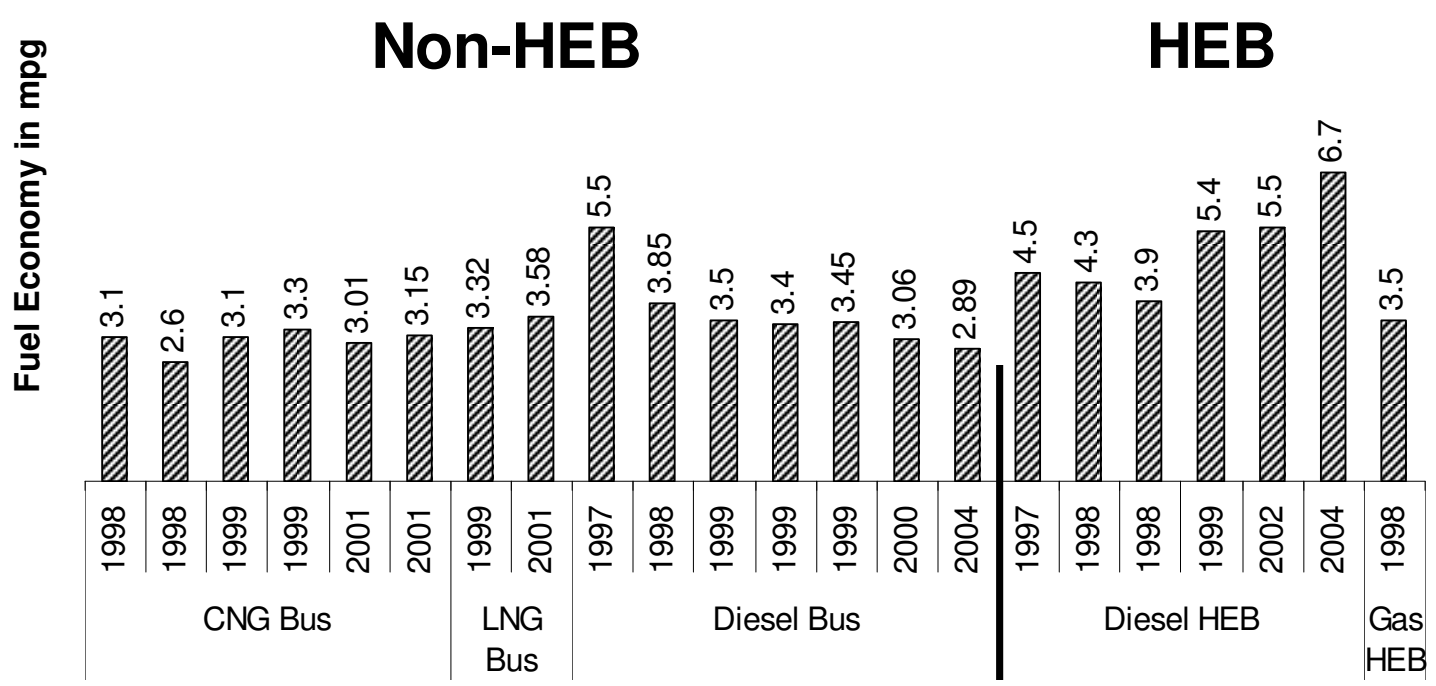

Figure 9: All studies' Fuel Economy Results over CBD Cycle

\subsubsection{Model Year 2002 and 2004 HEB Emissions and FE Study}

This section presents chassis dynamometer emissions data of three HEB research studies [55, 56, and 57] conducted by Environment Canada. Specifications of buses tested are listed in Table 4. Table 5, Figure 10, and Figure 11 present emissions and FE for four test cycles. The Manhattan Cycle (Figure 12) represents slow speed bus operation in city service with an average speed of $6.9 \mathrm{mph}$. The OCTA Cycle (Figure 13) represents intermediate speed bus operation with an average speed of $12.3 \mathrm{mph}$. The UDDS (Figure 2) includes high-speed bus operation with an average speed of $18.9 \mathrm{mph}$.

Table 4: Specifications of buses tested

\begin{tabular}{|c|c|c|c|c|c|c|c|}
\hline Bus Type & $\begin{array}{l}\text { Case Study } \\
\text { Manufacturer }\end{array}$ & MY & $\begin{array}{l}\text { GVWR } \\
\text { (lb) }\end{array}$ & Engine/Drive System & Fuel & $\begin{array}{c}\text { Exhaust } \\
\text { After- } \\
\text { treatment }\end{array}$ & $\begin{array}{l}\text { Num } \\
\text { of } \\
\text { Buses }\end{array}$ \\
\hline \multirow{3}{*}{$\begin{array}{l}\text { Diesel } \\
\text { Hybrid }\end{array}$} & Gillig & 2002 & 39,600 & $\begin{array}{c}\text { Cummins ISB275 } 275 \mathrm{hp} \mathrm{diesel} \\
\text { engine, Allison parallel hybrid } \\
\text { drive system }\end{array}$ & BP-15 & $\begin{array}{l}\text { Engelhard } \\
\text { DPX DPF }\end{array}$ & 1 \\
\hline & Orion VII & 2002 & 42,540 & $\begin{array}{c}\text { Cummins ISB275 } 275 \mathrm{hp} \text { diesel } \\
\text { engine, BAE SYSTEMS series } \\
\text { hybrid drive system }\end{array}$ & ULSD & $\begin{array}{l}\text { Engelhard } \\
\text { DPX DPF }\end{array}$ & 1 \\
\hline & Orion VII & 2004 & 42,540 & $\begin{array}{c}\text { Cummins ISB02 260hp diesel } \\
\text { engine (EGR), BAE SYSTEMS } \\
\text { series hybrid drive system }\end{array}$ & ULSD & $\begin{array}{l}\text { Johnson } \\
\text { Matthey } \\
\text { CRT }^{\text {TM }} \text { DPF }\end{array}$ & 1 \\
\hline $\begin{array}{l}\text { Convention } \\
\text { al Diesel }\end{array}$ & Orion V & 1999 & 40,600 & $\begin{array}{c}\text { DDC Series } 50275 \mathrm{hp} \mathrm{diesel} \\
\text { engine, automatic transmission }\end{array}$ & ULSD & $\begin{array}{l}\text { Johnson } \\
\text { Matthey } \\
\text { CRT }^{\text {TM }} \text { DPF }\end{array}$ & 2 \\
\hline
\end{tabular}

BP-15 = British Petroleum fuel (sulfur content is 13ppm.); EGR = Exhaust Gas Recirculation; NOx emissions were reduced for lower peak combustion temperature (heat absorbed by the exhaust gas recirculated into the intake manifold). 
Table 5: Emissions and FE from the buses tested

\begin{tabular}{|c|c|c|c|c|c|c|c|c|c|}
\hline \multirow{2}{*}{ Bus Type } & \multirow{2}{*}{$\begin{array}{l}\text { Case } \\
\text { Study }\end{array}$} & \multirow{2}{*}{ Manufacturer } & \multirow{2}{*}{ Test Cycle } & \multicolumn{5}{|c|}{ Emissions Rate (g/mile) } & \multirow{2}{*}{$\begin{array}{c}\text { Fuel } \\
\text { Econom } \\
\mathbf{y} \\
\text { (mpg) } \\
\end{array}$} \\
\hline & & & & $\mathrm{CO}$ & $\mathrm{HC}$ & NOx & PM & $\mathrm{CO} 2$ & \\
\hline \multirow{9}{*}{$\begin{array}{l}\text { Diesel } \\
\text { Hybrid }\end{array}$} & \multirow{4}{*}{$\begin{array}{c}\text { EC- } \\
\text { Allison }\end{array}$} & \multirow{4}{*}{ Gillig + DPF } & CBD & 1.40 & 0.03 & 13.9 & 0.019 & 1838 & 5.5 \\
\hline & & & OCTA & 2.30 & 0.03 & 13.1 & 0.028 & 1716 & 5.9 \\
\hline & & & $\begin{array}{c}\text { Manhatta } \\
\mathrm{n} \\
\end{array}$ & 8.00 & 0.11 & 20.6 & 0.029 & 2401 & 4.2 \\
\hline & & & UDDS & 1.90 & 0.04 & 9.10 & 0.033 & 1354 & 7.4 \\
\hline & NYCT & Orion VII + DPF & CBD & 0.08 & 0.11 & 12.9 & 0.012 & 1848 & 5.4 \\
\hline & \multirow{4}{*}{$\begin{array}{l}\text { EC- } \\
\text { BAE }\end{array}$} & \multirow{4}{*}{ Orion VII + DPF } & CBD & 0.15 & 0.02 & 9.10 & 0.022 & 1443 & 6.7 \\
\hline & & & OCTA & 0.17 & 0.03 & 9.50 & 0.020 & 1640 & 5.9 \\
\hline & & & $\begin{array}{c}\text { Manhatta } \\
\mathrm{n} \\
\end{array}$ & 0.23 & 0.05 & 14.3 & 0.036 & 2000 & 4.8 \\
\hline & & & UDDS & 0.10 & 0.03 & 7.98 & 0.018 & 1589 & 6.1 \\
\hline \multirow{2}{*}{$\begin{array}{c}\text { Conventiona } \\
\text { I Diesel }\end{array}$} & \multirow{2}{*}{ NYCT } & Orion V & CBD & 1.40 & 0.05 & 25.4 & 0.170 & 2916 & 3.5 \\
\hline & & Orion V + DPF & CBD & 0.13 & 0.02 & 25.1 & 0.030 & 2958 & 3.4 \\
\hline
\end{tabular}




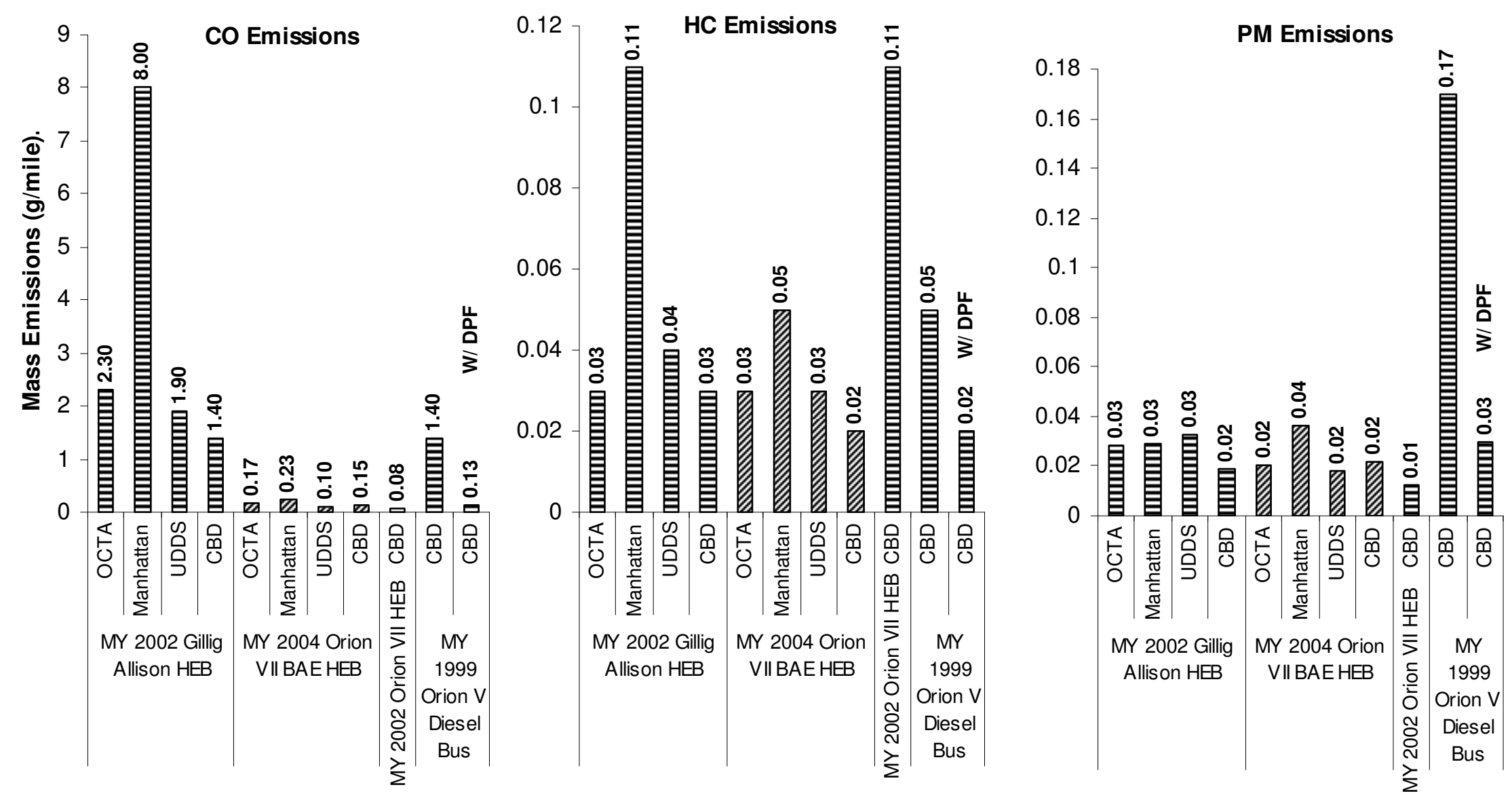

Figure 10: CO, HC, and PM Emissions Comparisons between MY 2002 - 2004 Hybrid Buses and MY 1999 Diesel Buses with and without DPF 

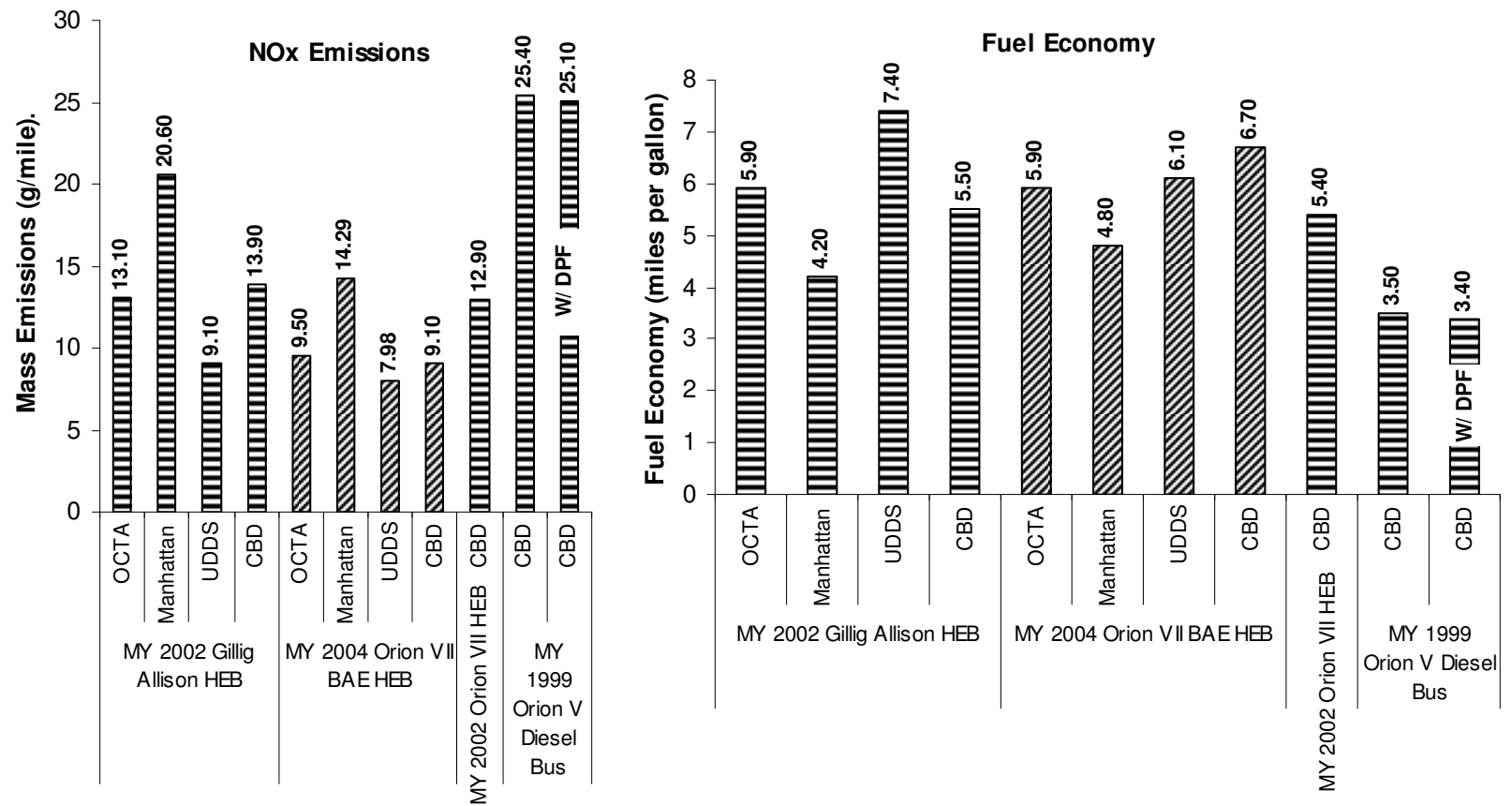

Figure 11: NOx Emissions and FE Comparisons between MY 2002 - 2004 Hybrid Buses and MY 1999 Diesel Buses with and without DPF

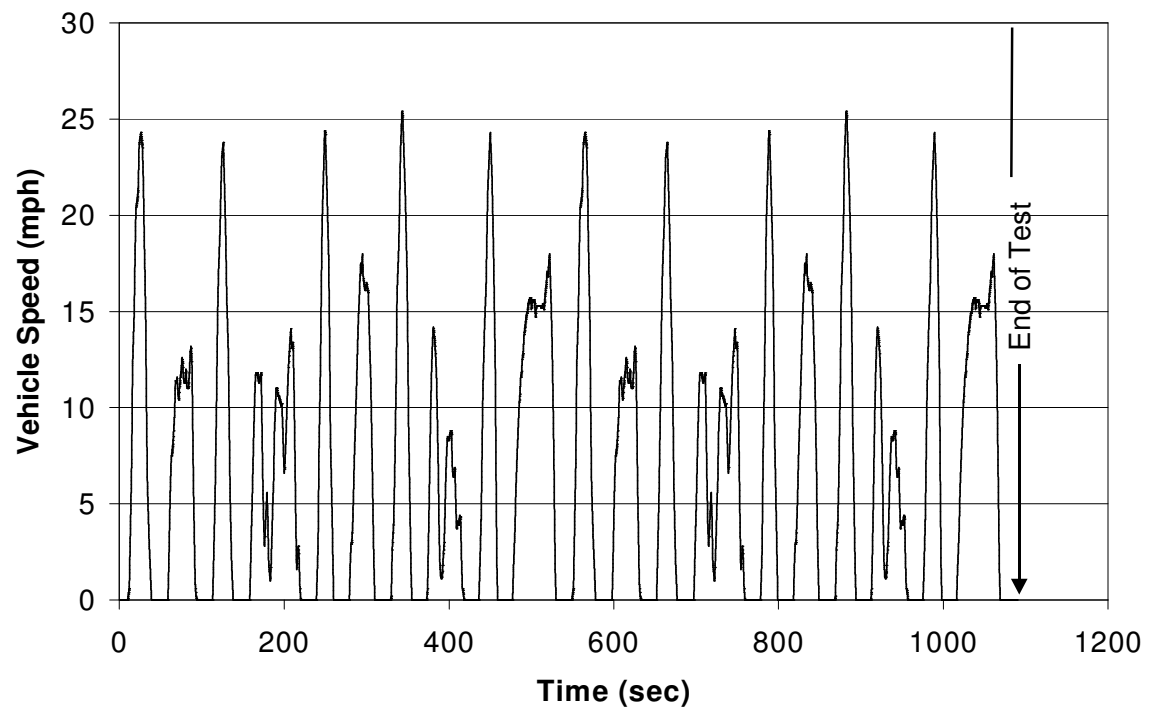

Figure 12: The Manhattan Cycle [87] 


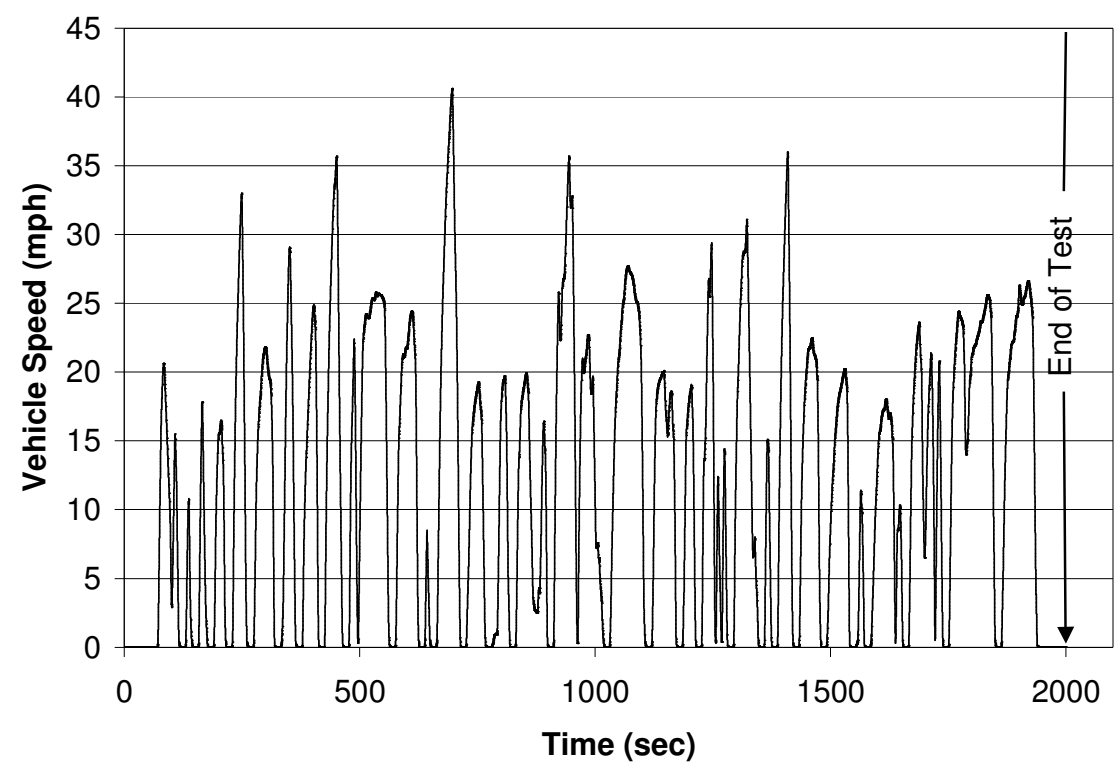

Figure 13: Orange County Transit Authority Cycle (OCTA) [61]

$\mathrm{HC}$ and PM emissions were comparable for the two HEB architectures examined. CO emissions were lower for the series architecture bus, but this may also be attributed to aftertreatment. The data showed that HEB PM emissions were lower than those from diesel buses on the CBD Cycle. Figure 11 shows that both HEB architectures showed substantially better FE than for a conventional legacy diesel bus on the CBD Cycle. Overall, the FE was comparable between the two HEB architectures, although the series bus showed a disadvantage on the UDDS but an advantage on the Manhattan and CBD cycles. The series HEB showed a modest advantage on NOx emissions but represented a later model year design.

NOx emissions from the HEB were lower than the conventional diesel buses by nearly $50 \%$ on the CBD Cycle. The MY 2004 series HEB showed nearly a 30\% reduction of NOx emissions and over a $20 \%$ better FE than MY 2002 series HEB on the CBD cycle. The new HEB was equipped with a $260 \mathrm{hp}$ EGR diesel engine, representing new engine emissions reduction technology. MY 2002 series HEB was equipped with a 275hp diesel engine.

The distance-specific emissions and the vehicle FE were sensitive to average cycle speed, acceleration, and idle duration. Lower speed cycles tended to have more stops per mile, which created more acceleration events. $\mathrm{CO}, \mathrm{HC}$, and NOx emissions rates increased and $\mathrm{FE}$ decreased 
when the average speed was lower. PM emissions of the Gillig HEB were not sensitive to the different cycles. The Orion VII HEB emitted the highest distance-specific PM when tested on the Manhattan Cycle, but there was no difference in PM emissions for this bus between the OCTA Cycle and UDDS. Emissions from heavy-duty vehicles needed to be correctly interpreted with respect to drive cycle before they could be projected for real-world use.

Additional emissions information about historical HEB, and current CNG and LNG bus technology, is attached in Appendix F of TCRP Report 132 [2].

\subsubsection{Hybrid-Electric Bus Fuel Economy}

HEB could offer potentially lower emissions and better FE, for four reasons:

- The HEB could be equipped with a smaller engine than a conventional bus, because additional power was available in most circumstances from the electric drive and ESS. A smaller engine consumed less fuel during idling and part load operation.

- With careful management, it might be possible to operate the engine in the most efficient zones of its operating envelope than was possible with a conventional drive. This was particularly important in the case of throttled engines. Spark ignited engines, whether stoichiometric or lean burn, were throttled.

- The HEB was capable of recapturing some of the braking energy that would otherwise be wasted as friction heat, when decelerating or traveling downhill. This was the most significant contribution in most HEV.

- It might be possible to operate the engine in a less transient fashion by using the ESS as a buffer for highly transient driver power demands. Transient engine operation could increase both diesel and spark-ignited engine emissions, and could detract from gasoline engine FE by demanding acceleration enrichment.

HEB were expected to demonstrate their greatest advantage in fuel economy when they were operated in stop-and-go, low-speed urban passenger service. Under high speed steady cruise conditions, an engine with a suitably geared mechanical drive was still attractive, due to the efficiency of a mechanical drive and the absence of hybrid system ESS and motors weight. 
Dawood and Emadi [105] used the ADVISOR simulation program [106, 107] to compare performance and FE of conventional diesel, hybrid, and fuel cell heavy-duty transit buses. A typical conventional transit bus (Orion VI low-floor equipped with the DDC Series 50, 8.5L, 275 $\mathrm{hp}$ diesel engine) was chosen as the baseline bus for comparison. The base configuration was scaled to find the performance characteristics of many combinations of fuel converter, power storage, and electric motor. Those buses were simulated on the UDDS cycle, which are presented in Appendix A and Appendix G of TCRP Report 132 [2].

Table 6 shows that heavy-duty transit buses, utilizing hybrid-electric drive trains with either an engine generator or a fuel cell to generate electricity on board, could have significantly higher FE than conventional diesel powered buses, especially in the parallel configuration [Section 1.1.2] for the UDDS.

Table 6: ADVISOR computer simulation buses performance comparison results [105]

\begin{tabular}{|c|c|c|c|c|}
\hline Bus Performance & $\begin{array}{c}\text { Conventional } \\
\text { Diesel }\end{array}$ & Series HEB & Fuel Cell* & Parallel HEB \\
\hline Fuel Converter (kW) & 350 & 100 & 200 & 150 \\
\hline Total Propulsion Power (kW) & 350 & 300 & 250 & 350 \\
\hline Fuel Economy (mpg) & 5.1 & 7.4 & 7.5 & 9.3 \\
\hline 0-60 mph (s) & 25.7 & 18.2 & 19.1 & 18 \\
\hline Grade-Ability (\%) & 6 & 2.5 & 2.3 & 2.5 \\
\hline Max Speed (mph) & 86 & 86.3 & 86.2 & 85.8 \\
\hline
\end{tabular}

* Fuel economy value in gasoline equivalent units for comparison purposes

HEV FE depended on vehicular configuration, control strategies [108], and duty cycles [Section 1.2.3.3]. The control strategy was of paramount importance. It was responsible for determining how much energy was transferred to and from the ESS, and how load-following the engine was. It also determined the target energy level, or SOC [Section 1.2.2.5], for the storage system. A high SOC provided assistance in propelling the vehicle, while a lower SOC allowed headroom for regenerative energy storage. Also, the control system may establish upper and lower SOC limits to preserve the batteries and avoid over-or under-voltage events or excessively high currents that would reduce certain battery's life such as lead acid batteries. 
Ciccarelli et al. [108] used ADVISOR to study the effects of hybrid system configuration and control strategies in improving the FE and emissions for operation of metropolitan transportation systems. The study found FE in mpg could improve up to $80 \%$ in areas with heavily congested traffic and a significant number of traffic light stops. Careful selection of control strategies and component size for HEB could provide further FE and emission reduction. During vehicle operation, different fuel consumption rates (and hence drive power) were required during idle, acceleration, cruise, and deceleration modes. Drive cycles or schedules varied with respect to average speed, maximum speed, idling time or number of stops, acceleration and deceleration rate. Bass and Alfermann [109] have tested a bus equipped with an Allison $E^{\mathrm{p}}$ SYSTEM $^{\mathrm{TM}}$ hybrid system on a chassis dynamometer using SAE Recommended Practice $\mathbf{2 7 1 1}$ on three drive cycles: the low speed Manhattan Cycle, the medium speed CBD cycle, and the relatively high-speed UDDS. The results showed that idle time contributed to a loss of energy, and was a significant parameter for predicting FE. Stopping frequency, which caused more regeneration activity, was found to be proportional to the FE benefit for the HEB. Also, average speed was inversely proportional to FE benefit, since high speed requires a greater proportion of engine operation. Data of this kind suggest that the choice between hybrid and conventional drive, and the choice of HEB architecture, should be predicated on the application.

The HEB has shown its FE and emissions benefits in real transit service. In a presentation by Lowell [110], ten pilot Orion VI HEB in New York City Transit (NYCT) were compared to standard diesel buses using the same duty cycle (6.4 average $\mathrm{mph}$ ). The FE (mpg) of the HEB was $10 \%$ higher overall and as much as $22 \%$ higher in winter. The Orion VI HEB used BAE's series hybrid drive system with sealed lead-acid battery pack [110]. Barnitt [111] evaluated ten Orion VII HEB, the second generation, and found the Orion VII HEB had 5.9\% lower mpg FE than the Orion VI HEB did. The introduction of EGR technology in the new HEB was considered lowering engine efficiency [111]. In a transit bus emissions project funded by the Defense Advanced Research Projects Agency (DARPA) [42] (see also Appendix F of TCRP Report 132 [2]), dynamometer data confirmed significant heavy-duty diesel HEB FE benefits. The diesel HEB had twice the FE (on an 
energy equivalent basis) relative to a CNG bus when operated on severe, slow duty cycles such as the NY-Bus Cycle.

Further data were available on new HEB FE performance from the Pennsylvania Transportation Institute (PTI), which conducted FE testing on a test track, simulating the CBD, Arterial, and Commuter cycles. The test followed a course based on the Transit Coach Operating Duty Cycle (ADB Cycle) at seated load weight using a procedure based on the FE Measurement Test (Engineering Type) For Trucks and Buses (SAE 1376 July 82). The three test cycles were: CBD cycle of 2 miles with 7 stops per mile and a top speed of $20 \mathrm{mph}$, an arterial phase of 2 miles with 2 stops per mile and a top speed of $40 \mathrm{mph}$, and a commuter phase of 4 miles with 1 stop and a maximum speed of $40 \mathrm{mph}$. During each designated stop, the bus remains stationary for seven seconds (time for opening and closing the passenger doors).

Figure 14 shows data from a 60-ft New Flyer bus with a Cummins ISL 330 diesel engine and an Allison B500 automatic transmission, compared to data from a New Flyer 60-ft diesel HEB with the same engine and an Allison $\mathrm{E}^{\mathrm{v}} 50$ hybrid drive. The FE benefits, on average, for the HEB were $45 \%$ for the CBD, $39 \%$ for the Arterial phase, and $24 \%$ for the Commuter phase.

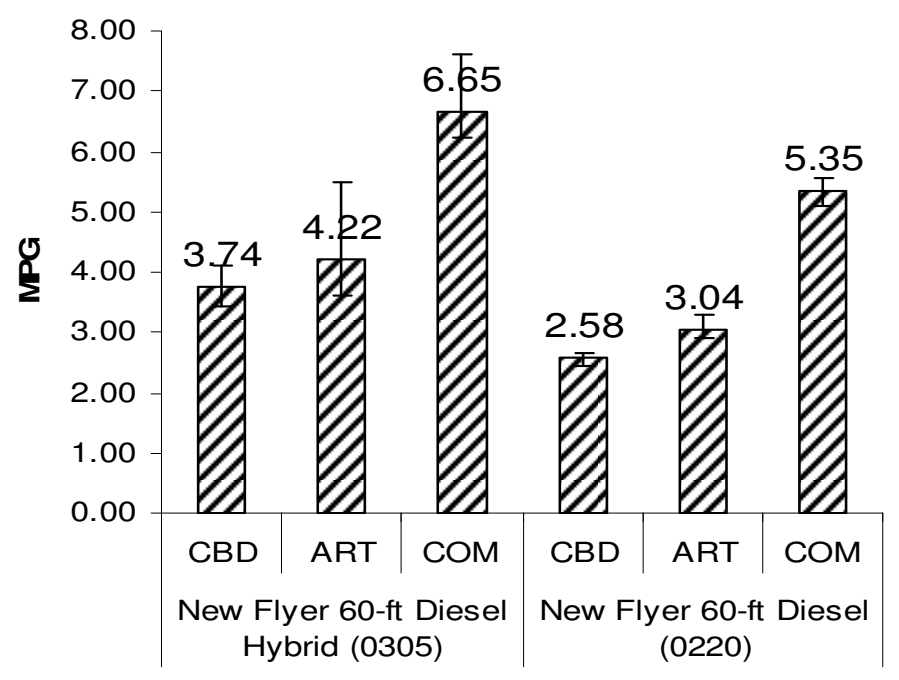

Figure 14: FE Comparison between New Flyer 60-ft Diesel and Diesel HEB

* Error bars represent range of values. 
Figure 15 shows data from Gillig 40-ft buses. One bus had a Cummins ISB $260 \mathrm{hp}$ diesel engine with an Allison $\mathrm{E}^{\mathrm{V}} 40$ drive, while the conventional bus had a Cummins ISM $280 \mathrm{hp}$ engine with a Voith automatic transmission. For the CBD, the HEB FE advantage was 50\%, but that advantage decreased to only $10 \%$ during the two higher speed phases.

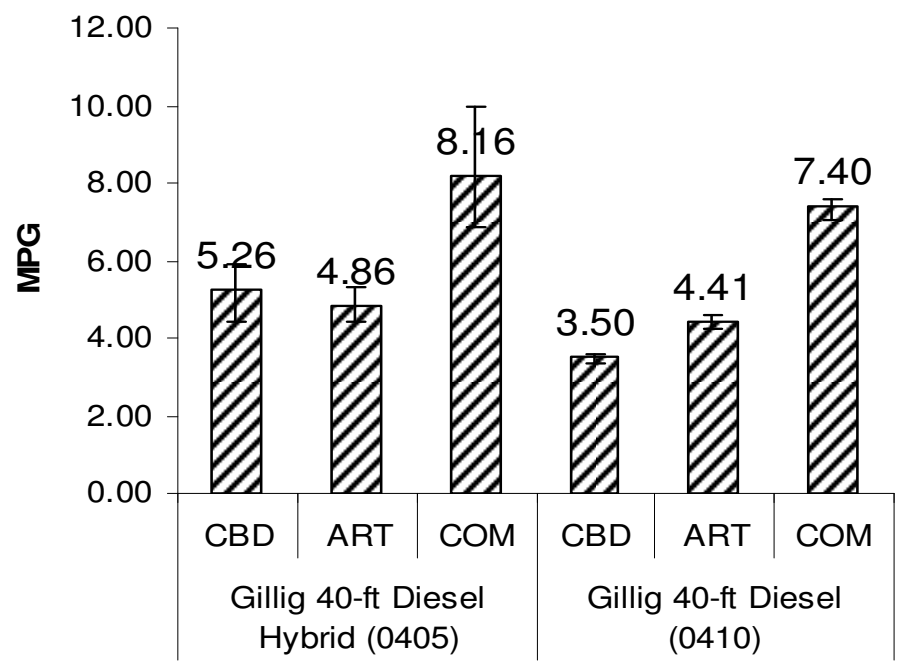

Figure 15: FE Comparison between Gillig 40-ft Diesel and Diesel HEB

* Error bars represent range of values.

Figure 16 shows data from a New Flyer ISE gasoline hybrid 40-ft bus with a Ford V-10 6.8 liter engine, a New Flyer 40-ft bus with a Cummins ISL $280 \mathrm{hp}$ diesel engine, and a New Flyer 40$\mathrm{ft}$ bus with a Detroit Diesel Series 50G (CNG) engine. The gasoline hybrid showed highest FE on the CBD, $20 \%$ better than the NG bus, and $29 \%$ better than the diesel bus. On the Arterial and Commuter phases, the CNG bus had the highest FE, followed by the diesel bus, and finally, the gasoline hybrid. 


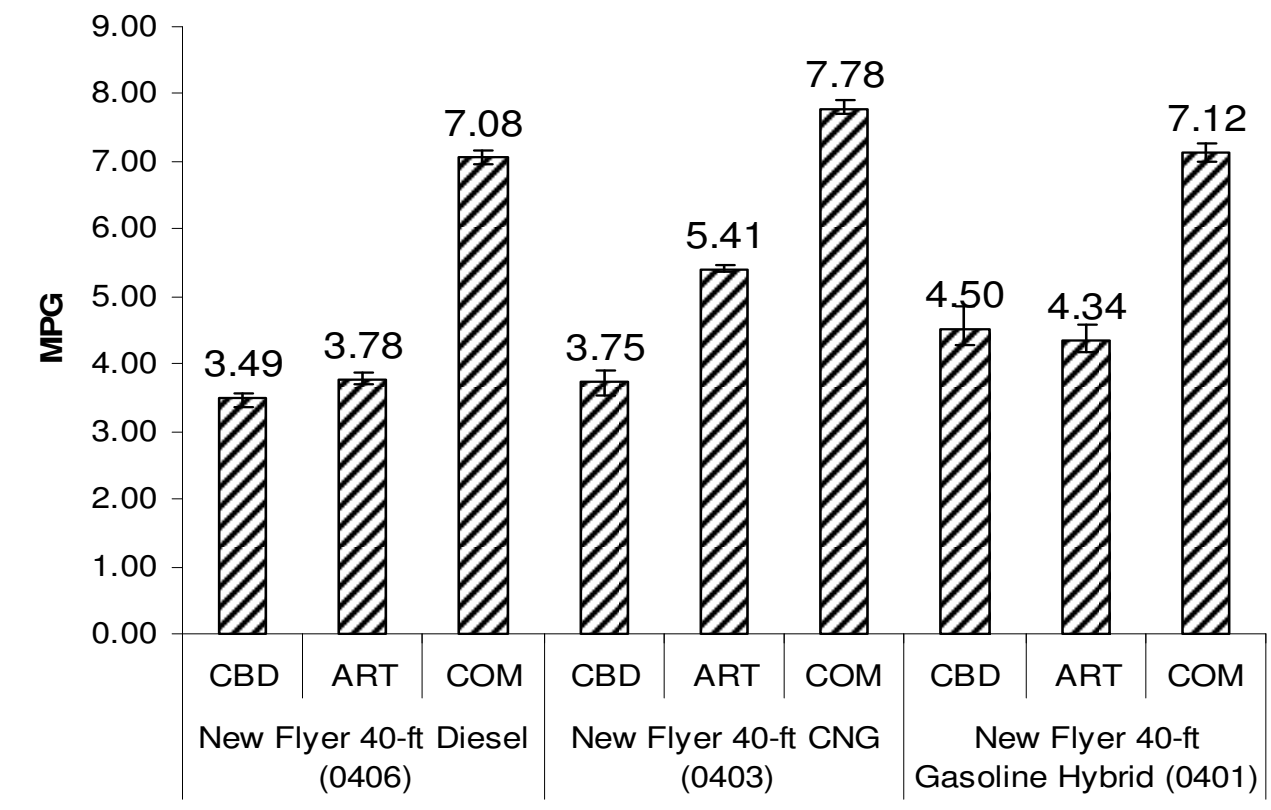

Figure 16: FE Comparison between New Flyer 40-ft Diesel, CNG, and Gasoline HEB

* Error bars represent range of values.

Figure 17 shows data from 40-ft Orion buses. The older Orion VI bus had the BAE (Lockheed-Martin) series hybrid drive with a Cummins ISB 260hp diesel engine. The Orion VII was a conventional diesel bus with a Detroit Diesel Series 50 engine. The newer diesel bus was found to have better FE on all three phases. 


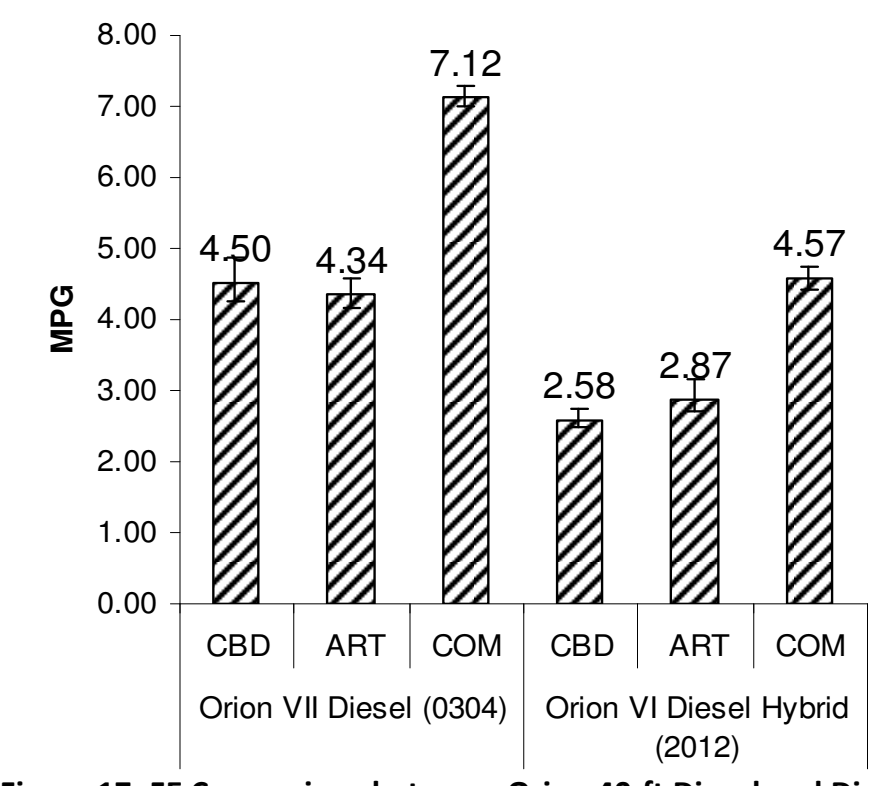

Figure 17: FE Comparison between Orion 40-ft Diesel and Diesel HEB

* Error bars represent range of values.

\subsection{Transit Bus Life Cycle Cost Studies}

The Northeast Advanced Vehicle Consortium (NAVC), sponsored by the Federal Transit Administration (FTA), has reviewed three electric drive technologies used in transit bus applications: battery-electric, hybrid-electric, and fuel cell electric drive [4]. Battery-electric and fuel cell technologies both use only electric motors to drive the vehicle. Battery-electric buses use on-board ESS to store and provide all energy during the on-road operation, and fuel cell buses generate electricity by combining fuel (such as hydrogen) and oxidant (such as oxygen from air) using electro-chemical processes. NAVC found that hybrid-electric technology is more attractive than the other two technologies for near term transit applications both technically and financially. They found that $10 \%$ to $15 \%$ better fuel economy was found from HEB in service. The capital cost of HEB was about $60 \%$ to $80 \%$ higher than a similar diesel bus. Based on limited real-world data, the investment in HEB can not be offset even by the fuel saved.

Henke has studied four major issues related to HEB procurement: economy, environment, policy, and technology [5]. In his economic analysis for the USA, after $80 \%$ of bus procurement costs are borne by the Federal Transit Administration, there is an incremental cost of about $\$ 40,000$ per bus for transit agencies to buy a HEB instead of a conventional diesel bus. Not 
considering the maintenance cost, future potential HEB price decreases, and tax credit, Henke found that HEB fuel saving alone can pay back the incremental costs in about nine years [5].

The National Renewable Energy Laboratory (NREL) has evaluated HEB operated by three US transit agencies: New York City Transit (NYCT), King County (KC) Metro Transit in Seattle, and Knoxville Area Transit (KAT), and has published reports on these evaluations [6-9]. This NREL study is a part of the US Department of Energy's (DOE) Advanced Vehicle Testing Activity (AVTA). Some of these data, for 40 and 60 foot buses, were included in the C-15 program analysis and used in this study [2].

WVU performed a transit bus 12-year LCC analysis for Federal Transit Administration (FTA), and projected transit bus emissions and fuel economy for 2007 model year buses [10]. It covered four bus types: diesel buses using ultra low sulfur diesel (ULSD), diesel buses using B20 biodiesel (20\% biodiesel and $80 \%$ ULSD), compressed natural gases (CNG) buses, and hybrid diesel-electric buses. The LCC study showed that diesel buses were still the most cost effective technology, and diesel buses fueled by B20 biodiesel were only slightly higher in overall cost due to the added expense of the fuel. In the case where only $20 \%$ of the bus procurement cost was considered, as a result of subsidies, the four bus types had a sufficiently similar LCC. The estimation showed that hybrid buses offered lower tailpipe PM, NMHC, and GHG than the diesel and CNG buses at a national average speed of $12.72 \mathrm{mph}$. The hybrid bus performed best on well to wheels GHG emissions at the same speed. By benefiting from low well-to-tank GHG emissions (which include plant uptake of $\mathrm{CO}_{2}$ ), B20 diesel buses were the second best bus technology for well to wheels GHG emissions.

MJ Bradley created a fuel cell LCC mode for DOT to do a comparison between FC buses with diesel, CNG, and diesel hybrid buses [11]. For the base case that comparing then existing FC bus operation with others, FC bus LCC was three times higher. However, capital cost (bus price) occupied more than $50 \%$ in FC buses' total LCC. If $20 \%$ of capital cost was covered by local agency, FC bus LCC per mile was $60-90 \%$ higher than others' cost. A best case analysis was that FC bus meets DOE/FTA cost objectives. In the cost scenario, total FC bus LCC reduced by $40 \%$. However, the capital cost was still close to $50 \%$ of total FC bus LCC. The same $80-20$ 
incentive rule made LCC per mile became $12 \%$ higher for FC buses compared to other technologies.

Hellgren completed his Ph.D. research by creating a model to simulate and compare LCC of different vehicles types: cars, city buses and intercity buses in Europe [12]. The model was used to optimize powertrain components by considering capital cost, fuel cost and component wear cost. Genetic algorithm created powertrain candidates and did LCC comparisons to rank the candidates. Each candidate was a combination of a primary power unit, energy storage system, transmission, energy storage system, electric machine and energy management algorithm. For current city bus application, a parallel hybrid-electric bus [Section 1.1.2] with a diesel internal combustion engine (ICE) and a supercapacitor as buffer was the best choice from economic view. In future city bus application, his model selected fuel cell bus working with supercapacitor.

GREET (Greenhouse gases, Regulated Emissions, and Energy use in Transportation) is a life cycle emissions and energy model [13]. Its fuel-cycle model (GREET 1.7) does the well-towheels energy and emissions analysis on vehicle/fuel system. The model calculates the emissions and energy outputs from three stages: feedstock, fuel, and vehicle operation. It includes more than 100 fuel production pathways and more than 70 vehicle/fuel systems. Fuel pathways include the ways from non-renewable sources (petroleum, natural gas, coal, residual oil, and nuclear) and renewable sources (soybeans, corn, sugarcane, cellulosic biomass, and others) to transportation energy containers (diesel, gasoline, CNG, LNG, hydrogen, electric, ethanol, etc). Default energy conversion rate and emissions production rate are assumed for each fuel pathway.

The Australian Commonwealth Scientific and Research Organization (CSIRO) created a Life Cycle Emissions (LCE) model of Heavy Vehicles to evaluate pre-combustion emissions and tailpipe emissions for vehicles in Australia [14]. Pre-combustion emissions were based on typical industrial scenarios for the production and transportation of fuels. Tailpipe emissions were estimated from EPA's emissions report on Central Business District (CBD) cycles. The 
study use emissions to rank different fuels by their GHG emissions and Pollutions corrected with health risk factors

Hackeny et al. created a LCC and LCE model of Light-duty passenger car [15]. The model evaluated 17 fuel-vehicle combinations' 12 -years costs and emissions and created a trade-off curve of the two factors. Full fuel cycle cost and emissions were emphasized in the model. It suggested reformulated gasoline (RFG) had the best emissions, energy (fuel-chain), and cost trade-off at the time of study.

\subsection{Conclusion of Literature Research}

The literature shows that a variety of bus technologies have been developed to reduce cost and emissions by improve fuel economy or use alternative fuels. Those technologies performance responding its operation conditions varied significantly, so the researchers of the literature try to find right technologies for certain operation. For example, the published TCRP C-15 model that the author of this dissertation worked on was developed as an accurate fleet model for life cycle cost. However, the model and others were limited to evaluate a specific bus technology over a specific route. They focused on comparing technologies head-to-head over a single objective (cost, fuel economy, or emissions). The previous researches could not give a transit agency a direct tool to study and improve the performance of a complex transit bus fleet.

This dissertation created a transit bus fleet model to simulate a whole fleet that could have a variety of bus technologies over multiple routes. The tool could optimize the fleet operation that had an optimal trade-offs between multiple objectives. 


\section{CHAPTER 2 - MODEL CREATION}

This chapter describes the creation of the fleet management tool (FMT) and its data sources. The model was built for fleet operation of any size. However, it was more useful for complex fleet operations, which generally manage various bus types on a variety of routes. A fleet with very few bus technologies or with a very small fleet could be more easily evaluated and optimized with direct calculation.

The model was programmed by Visual Basic for Application (VBA), which was built in Microsoft Excel ${ }^{\circledR}$ program. Many fleet setup and cost factors used the same or similar to what the TCRP C-15 LCC tools used [2]. The model has a straightforward process as shown in Figure 18.

The Input Module was for the users to first set up the fleet with the bus and route information. Section 1 describes the required information such as bus-route dispatch strategy and management goals or default values that were available for the users to use.

The Calculation Module was created to calculate various costs and GHG emissions for any fleet operations. For example, once the original fleet was defined in the Input Module, the Calculation Module can present the fleet performance in costs and GHG emissions. Section 2.2 describes how the cost and emissions functions were created.

The Optimization Module was used to search and locate optimal operation based on the management goals defined in the Input Module. Genetic algorithm (GA) was used as the optimization technique. GA is an analogy with natural biological process - Natural Selection, where GA was used to create and select biological individuals based on the law of "survival of the fittest." Section 2.3 describes the application of GA to bus operation optimization.

The Output Module was used to present fleet costs and emissions and optimization results in different tables and charts. The next chapter demonstrates the output tables and charts from the tool. 


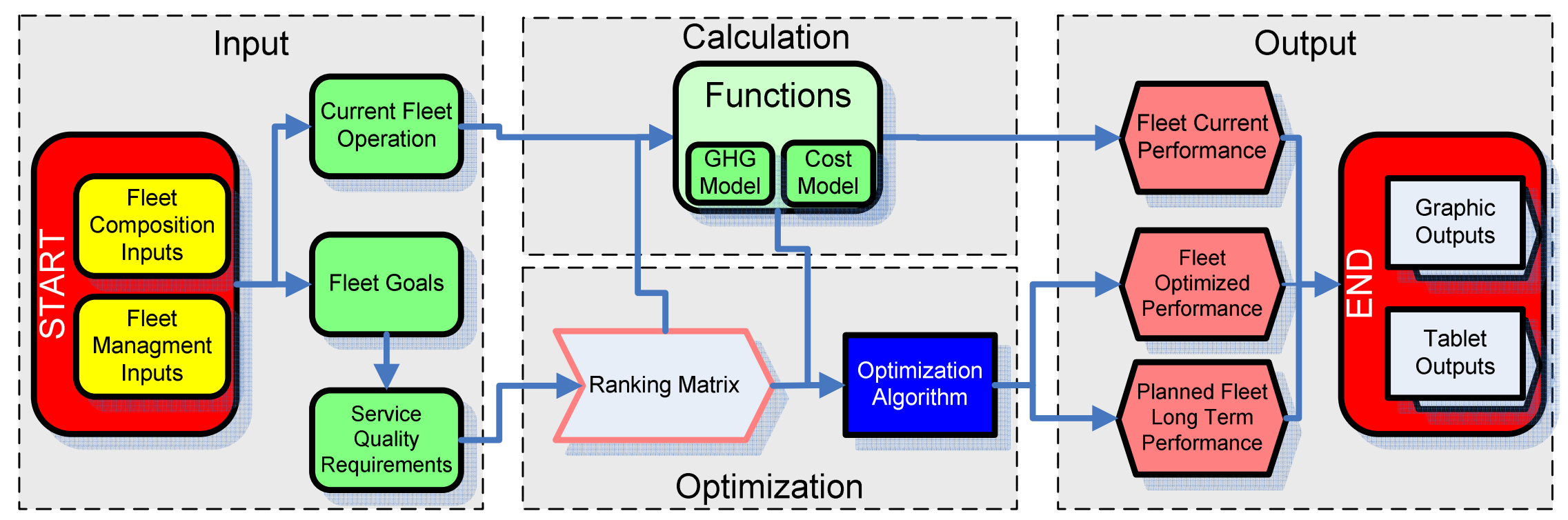

Figure 18: Fleet Model Overall Flow Chart 


\subsection{Input Module}

The Input Module sheet gathered data from supporting pages (Tabs in Excel spreadsheets in the FMT program). Data were from user inputs and/or default values. Five data sections were required in order to completely describe a fleet operation.

1. Basic Fleet Information

2. Management Importance Index (Fleet management goals)

3. Bus Information

4. Route Information

5. Route-Bus Dispatch Strategy Information

\subsubsection{Basic Fleet Information}

This section began by entering necessary information including number of routes, number of buses, base year (all costs were represented in the base year dollars), current year (the year at which user wanted to investigate performance), and number of bus types (technology, model year, or length). Other information such as expected bus life in years, inflation index, operator salary rate, technical salary rate, heat load, and A/C load has default values.

Definitions for basic fleet information

- Number of Routes - It describes how many routes the fleet needs to have for regular bus services. A route is a known traffic path with a schedule.

- Number of Buses - It is the total number of buses that are used for service, i.e. dispatched regularly to the routes mentioned above. When the user considers the back-up buses or emergency buses that are used occasionally, a pseudo route shall be defined in the system with zero annual millage and zero average speed.

- Operator Rate - It is hourly rate of operator. It might include all overhead to cover the administration cost. The model does not include operator wage in the cost model. The rate is mainly for training operators to use new types of buses or attend regular safety training, for natural gas buses, for example. 
- Technician Rate - It is hourly rate of technician cost. The hour rate is applied when technicians take time for training for new equipment or tools and servicing new bus types. The technicians' wages were imbedded in the maintenance cost.

- Inflation Index - It reflects a rate of changing in fleet related cost over time. The model uses a fix rate of 3\%. Annual inflation rate was developed in TCRP C-15 model. The next generation model might bear this function.

- Base Year - It is the year that all cost value are converted to that year dollar value for comparison purpose.

- Current Year - It is current year that analysis is done. It might be different from Base Year.

- Expected Bus Life - It is the number of years that a transit bus has to serve. It could be a mandatory requirement from government agency or company's internal requirement.

- $\quad$ A/C Load - Air Conditioning Loading: an impact of air conditioning (AC) on fuel economy and GHG emissions. It is a numeric value from 0 to 10 . Zero $(0)$ indicates there is no AC load (frigid climate, buses not equipped with $\mathrm{AC}$ ), 10 indicates that the $A C$ is always on and heavily loaded due to humidity and temperature effects (tropical climate). Five (5) indicates that the bus is operated in a temperate zone. Scale 5 is the default setting for the model. It represents moderate AC usage applicable for most US agencies (using AC nearly half time of a year). Bus fuel consumption and GHG emissions will be lower than the default value for lower scale $(<5)$ and vice versa.

- Heat Load - This setting takes into account the fuel economy and GHG emissions penalty resulting from the use of auxiliary heating units. It is a numeric value from 5 to 10 . Default value five (5) indicates the bus is not equipped with an auxiliary heater (or it is not used). Scale 10 indicates that the auxiliary heater is always used (frigid climate). Similar to AC load, fuel economy suffers for higher auxiliary heater use.

An example of inputs is listed in Table 7. 


\section{Table 7: An Example of Basic Bus Fleet Information in Input Module}

\begin{tabular}{|c|c|c|}
\hline \multicolumn{3}{|c|}{ Section I: Basic Fleet Information } \\
\hline Number of Routes & 8 & Routes \\
\hline Number of Buses & 50 & Buses \\
\hline Inflation Index & $3 \%$ & None \\
\hline Operator Rate & 50 & $\$ / h r$ \\
\hline Maintenance Technician Rate & 50 & $\$ / \mathrm{hr}$ \\
\hline Base Year & 2007 & None \\
\hline Current Year & 2010 & None \\
\hline Projection Life & 12 & Years \\
\hline Bus Useful Life & 12 & Years \\
\hline Number of Bus Types & 5 & Types \\
\hline Heat Load & 5 & None \\
\hline A/C Load & 5 & None \\
\hline
\end{tabular}

\subsubsection{Importance Index}

Importance index is an order of management priorities on cost factors and GHG emissions. They are the goals influencing fleet optimization process. A goal can be subjective, but it should be either computable or expressible in quantity. The goals don't have to be completely independent from each other. For example, tailpipe GHG emissions reduction could well overlap with social image improvement and clean energy promotion. However, the users need to carefully examine their objectives. There will be double counting, when applying importance level (weights) to the correlated goals.

The prioritized goal list has a rank range from 0 to 10 as shown in Table 8. Digit 10 indicates the most concerned or important level and digit 0 indicated no concerns to users at all. The model only allowed one requirement could be assigned as level 10. In turn, two requirements could be assigned as level 9, and three requirements could be level 8 and so on . Nine goals were included in the initial FMT. The definitions are given below. 
Table 8: An Example of Importance Index in Input Module

\section{Set of Effects}

Reduce Well-to-Wheels GHG Emissions

Reduce Vehicle-Related Capital Cost

Reduce Other Capital Cost

Reduce Operation Cost

Reduce Infrastructure Cost

Reduce Staff Training Cost

Reduce Well-to-Tank GHG

Reduce Tank-to-Wheels GHG (Tailpipe) Emissions Improve Social Image

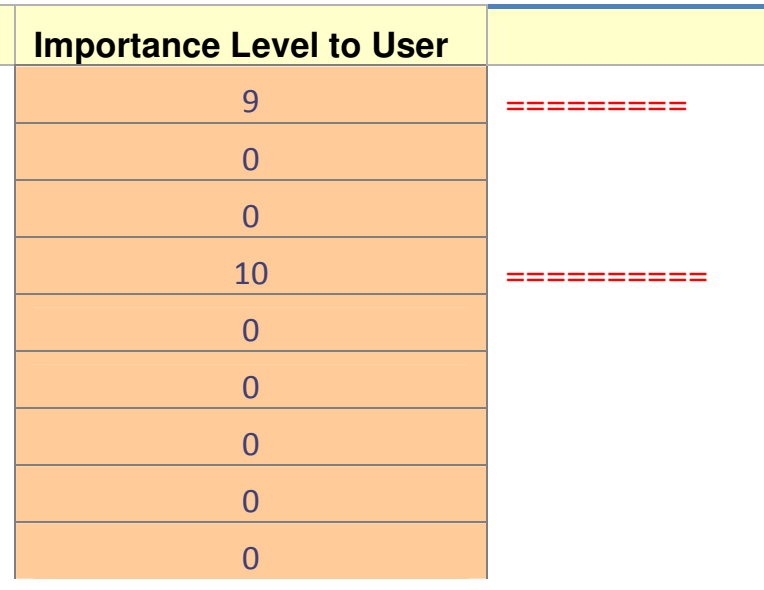

Definitions for Importance Index

- Reduce Well-to-Wheels GHG Emissions - The Well-to-Wheels GHG emissions is combined GHG emissions of Well-to-Tank (WTT) and Tank-to-Wheels (TTW) GHG emissions. It is the amount of total life cycle GHG emissions that emitted during fuel production, transportation, and consumption in vehicles. The detail WTT and TTW GHG emissions definitions are described below. The requirement is to reduce total GHG emissions.

- Reduce Vehicle-Related Capital Cost - The measure is total cost of bus purchase, warranty cost, energy storage system. Reduction in cost is desired.

- Reduce Other Capital Cost - It includes cost of infrastructure and equipment cost that comes with new technologies or additional bus purchases. Infrastructure cost is associated with expense of building new fuel or charging stations. Equipment includes special tools for special services that are required for new bus technologies.

- Reduce Operation Cost - The measure of the cost is the total cost of fuel, rehab and rebuild of engine and transmission, staff training cost, and scheduled maintenance cost.

- Reduce Infrastructure Cost - Although it is included in Other Capital Cost, the decision of building new infrastructure is generally a big commitment. A separate measure is added only if additional weight is desired in this objective. 
- Reduce Staff Training Cost - Similar to Infrastructure Cost, the cost gives the management a second weight if there are concerns on pulling people out from service to participate in training.

- Reduce Tailpipe GHG Emissions - The tailpipe GHG emissions is also called Tank-toWheels (TTW) GHG emissions. It is the amount of greenhouse gas emissions that were emitted into the local environment due to fuel consumption in buses. The requirement is to reduce tailpipe GHG emissions.

- Improve Social Image - The measure is related to drivetrain technology type. It is really a public view and option. Conventional diesel technology has the lowest rate at level 1. The alternative fuel technologies (CNG and B20 Biodiesel) are set at level 5. The advance drivetrain technologies (battery electric, fuel cell, and hybridelectric) are set at level 9.

\subsubsection{Bus Information}

This section defines the type of buses to be evaluated in the fleet. All factors that could affect cost and emissions shall be addressed in this section. All buses with identical technology and age are grouped together as the same bus type.

Some definitions in bus information:

- Bus Series - It is used to identify buses that have similar configuration and same age. They are usually from the same purchase order.

- Bus Technologies - The tool has listed seven bus technologies that differ in fuel type or drivetrain technologies.

- Conventional Diesel

- Conventional CNG

- B20 Biodiesel

- Battery Electric

- Fuel Cell - Hydrogen

- Diesel Hybrid-Electric

- Gasoline Hybrid-Electric 
- Model Year - Three time ranges were included in the tool, Pre-2007, 2007-2010, and Post 2010. This model assumed engine model year were same as bus model year for simplicity. Engine model year was preferred in this model. Those time ranges have the same engine emissions standards. Usually technologies are changed or improved according to emissions standards changing.

- Total Amount - It is the total number of buses in the bus series.

- Bus Length - Three typical bus lengths, 30-ft, 40-ft, and 60-ft, were used in the model. They were generally considered as small, standard, and articulated sizes. $35-\mathrm{ft}$ buses were not included separately. 35 -ft transit buses usually use the same engines that 40 $\mathrm{ft}$ buses do. The $35-\mathrm{ft}$ bus was considered as a standard size bus, although its size rides in the middle of 30-ft and 40-ft. However, the model should be tuned to reflect fuel economy and emissions discrepancy for these two types.

- Extended Warranty - Typical purchase comes with two year warranty. Extended warranty is generally an additional order item. The additional cost of warranty was based on number of years covered in the extended warranty contract.

- Bus Age - It is the number of years that the bus series have been used in service.

- New Infrastructure - It is the number of buses that the new infrastructure (fueling, maintenance and storage facilities) is capable to service. It can be larger than the number of buses being planned for purchase.

- Special Equipment - It is the special tools or devices that are needed to run and/or service specific bus series. Same to the infrastructure cost, you enter the number of buses that the new equipment is capable to serve.

- Engine Remove and Replacement (R\&R) Schedule - For each propulsion type the model assumed an original engine will last for a certain years before requiring its first engine rebuild. Subsequent rebuilds will occur at different intervals for different engine technologies. A selection of the "6,4.4..." schedule, for example, means the first rebuild takes place at the $6^{\text {th }}$ year with subsequent rebuilds occurring every four years thereafter until the bus reaches its useful life.

- Transmission R\&R Schedule - It is similar to engine R\&R schedule. 
- Number of Driver Trainees - It is the number of drivers who need new training when buses first arrive. Operating CNG and hydrogen Fuel Cell buses also require annual safety training.

- Number of Technician Trainee - It is similar to the input above.

- ESS Replacement Schedule - This schedule applies to only hybrids-electric and battery bus technologies. The input requires the battery life expectation for the technology.

Table 9 shows an example of all parameters or characters required in the model.

Table 9: Bus Information Collection Example Table

\begin{tabular}{|c|c|c|c|c|c|c|c|c|}
\hline \multicolumn{9}{|c|}{ Section III: Bus Information } \\
\hline $\begin{array}{l}\text { Bus } \\
\text { Series }\end{array}$ & $\begin{array}{c}\text { Bus } \\
\text { Technologies }\end{array}$ & Model Year & $\begin{array}{l}\text { Total } \\
\text { Amt }\end{array}$ & $\begin{array}{c}\text { Bus } \\
\text { Length }\end{array}$ & Bus Age & $\begin{array}{c}\text { Ext } \\
\text { Warranty }\end{array}$ & $\begin{array}{l}\text { New Infr } \\
\text { Bus Cap }\end{array}$ & $\begin{array}{l}\text { Eqpt Bus } \\
\text { Cap }\end{array}$ \\
\hline BusE & $\begin{array}{l}\text { Fuel Cell - } \\
\text { Hydrogen }\end{array}$ & $2007-2010$ & 1 & $40-\mathrm{ft}$ & 2 & 3 & 10 & 1 \\
\hline BusD & $\begin{array}{l}\text { Diesel Hybrid- } \\
\text { Electric }\end{array}$ & Post 2010 & 4 & $60-\mathrm{ft}$ & 1 & 3 & 0 & 5 \\
\hline BusC & $\begin{array}{l}\text { Diesel Hybrid- } \\
\text { Electric }\end{array}$ & Pre-2007 & 10 & $60-\mathrm{ft}$ & 7 & 0 & 0 & 0 \\
\hline BusB & $\begin{array}{l}\text { Conventional } \\
\text { Diesel }\end{array}$ & Pre-2007 & 10 & $30-\mathrm{ft}$ & 5 & 0 & 0 & 0 \\
\hline BusA & $\begin{array}{l}\text { Conventional } \\
\text { Diesel }\end{array}$ & Pre-2007 & 25 & $40-\mathrm{ft}$ & 10 & 0 & 0 & 0 \\
\hline \multicolumn{9}{|c|}{ Continue the above table } \\
\hline $\begin{array}{c}\text { Bus } \\
\text { Series }\end{array}$ & $\begin{array}{c}\text { Engine RR } \\
\text { Sched }\end{array}$ & $\begin{array}{l}\text { Transmissio } \\
\text { n RR Sched }\end{array}$ & $\begin{array}{r}\# \text { of } \\
\text { Tr }\end{array}$ & & $\begin{array}{l}\text { \# of Mech } \\
\text { Trainee }\end{array}$ & \multicolumn{3}{|c|}{ ESS Replacement Schedule } \\
\hline BusE & $\begin{array}{l}7,6,6,6,6,6 \ldots \ldots \\
\ldots \ldots\end{array}$ & $\begin{array}{l}7,6,6,6,6,6 \ldots \\
\ldots \ldots \ldots\end{array}$ & & 3 & 10 & \multicolumn{3}{|l|}{6 Year Life } \\
\hline BusD & $\begin{array}{l}7,6,6,6,6,6 \ldots \ldots \\
\ldots \ldots\end{array}$ & $\begin{array}{l}7,6,6,6,6,6 \ldots \\
\ldots \ldots \ldots\end{array}$ & & 10 & 20 & \multicolumn{3}{|l|}{6 Year Life } \\
\hline BusC & $\begin{array}{l}7,6,6,6,6,6 \ldots \ldots \\
\ldots \ldots\end{array}$ & $\begin{array}{l}7,6,6,6,6,6 \ldots \\
\ldots \ldots \ldots\end{array}$ & & 0 & 0 & \multicolumn{3}{|l|}{4 Year Life } \\
\hline BusB & $\begin{array}{l}6,4,4,4,4,4 \ldots \ldots \\
\ldots \ldots\end{array}$ & $\begin{array}{l}6,4,4,4,4,4 \ldots \\
\ldots \ldots \ldots\end{array}$ & & 0 & 0 & \multicolumn{3}{|c|}{ No Replacement } \\
\hline BusA & $\begin{array}{l}6,4,4,4,4,4 \ldots \ldots \\
\ldots \ldots\end{array}$ & $\begin{array}{l}6,4,4,4,4,4 \ldots \\
\ldots \ldots \ldots\end{array}$ & & 0 & 0 & \multicolumn{3}{|c|}{ No Replacement } \\
\hline
\end{tabular}

\subsubsection{Route Information}

There were two ways to enter route information into the FMT. The speed pattern is the key variable to describe a route. The first way was to insert all middle distances between every bus stops and relevant stop schedules (arrival and departure time) information as shown in top section of Table 10 . The second way was to use total route distance and time durance to define 
a route as shown in the bottom section of Table 10. The variable, Trips per day (Trips/Day) is required to fully define a route.

Definitions in route information

- Distance - It is the total distance of the route. The model automatically calculates the value based on stop distances and schedules.

- Trip Time - It is the schedule time span during which one bus finishes its service on the route.

- Trips/Day - It is how many bus trips that route has for a day.

- Average Speed - It is the average speed calculated by dividing the route distance by its trip time.

- Daily Distance - It is how many service miles that buses contributed in the route during a day. The model calculated it automatically.

- Annual Distance - It is how many service miles that buses make during a year. 


\section{mation Input Matrix}

\begin{tabular}{|c|c|c|c|c|c|c|c|c|}
\hline & Bus Stop & End & Stop 1-1 & Stop 1-2 & $\ldots \ldots$ & Stop 1-13 & Stop 1-14 & Stop 1-15 \\
\hline 15.2 miles |||||||||||||||| & Distance & mile & 1.8 & 3.0 & $\ldots \ldots$ & 15.0 & 15.2 & \\
\hline 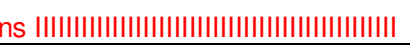 & Depart Time & minute & 2.0 & 7.0 & $\ldots \ldots$ & 45.0 & 47.0 & \\
\hline \multirow[t]{3}{*}{$.5 \mathrm{mph} \mid \mathrm{IIII||||||||||||||||||||||||||||||||||||||||||}$} & Ave Speed & $\underline{\mathrm{mph}}$ & 54.0 & 14.4 & $\ldots \ldots$ & 13.9 & 4.6 & \\
\hline & Trips/Day & $\underline{\text { Trip }}$ & 15 & & & & & \\
\hline & Bus Stop & End & Stop 1-1 & Stop 1-2 & & & & \\
\hline 8.5 miles IIIIIII & Distance & $\underline{\text { mile }}$ & 8.5 & & & & & \\
\hline 0 mins $|1|||||||||||||||||||||||||||||||||||||||||||||||||$ & Depart Time & minute & 40.0 & & & & & \\
\hline \multirow[t]{2}{*}{$12.8 \mathrm{mph} \mid \mathrm{|I|||||||||||||||||||||||||}$} & Ave Speed & $\underline{\mathrm{mph}}$ & 12.8 & & & & & \\
\hline & Trips/Day & Trip & 15 & & & & & \\
\hline
\end{tabular}


After the first step, model automatically calculates route specifications and presents the results as shown in Table 11. It is worth mentioning that fuel economy and GHG emissions calculations were based on mini trips defined by stops. In other words, two routes could have identical overall route specification (total distance, overall average speed, etc) but different fuel economy and GHG emissions. More details on fuel economy and GHG emissions calculations are presented in Section 2.2.1.

Table 11: An Example of Route Specifications Calculated by Input Module

\begin{tabular}{|c|c|c|c|c|c|c|c|c|}
\hline Route ID & Distance & Trip Time & Trips/Day & Ave Spd & Daily Dist. & Annul Dist. & AC Load & Heat Load \\
\hline Unit & Miles & Minute & Trips & $\mathrm{MPH}$ & Miles & Miles & & \\
\hline Route 1 & 15.2 & 47.0 & 15.0 & 19.5 & 228.0 & 83220.0 & 5.0 & 5.0 \\
\hline Route 2 & 9.0 & 55.0 & 42.0 & 9.9 & 378.0 & 137970.0 & 5.0 & 5.0 \\
\hline Route 3 & 7.2 & 42.0 & 16.0 & 10.3 & 115.2 & 42048.0 & 5.0 & 5.0 \\
\hline Route 4 & 19.0 & 47.0 & 15.0 & 24.3 & 285.0 & 104025.0 & 5.0 & 5.0 \\
\hline Route 5 & 19.8 & 47.0 & 15.0 & 25.3 & 297.0 & 108405.0 & 5.0 & 5.0 \\
\hline Route 6 & 8.6 & 55.2 & 10.0 & 9.4 & 86.0 & 31390.0 & 5.0 & 5.0 \\
\hline Route 7 & 12.9 & 18.0 & 20.0 & 43.0 & 258.0 & 94170.0 & 5.0 & 5.0 \\
\hline Route 8 & 8.5 & 40.0 & 15.0 & 12.8 & 127.5 & 46537.5 & 5.0 & 5.0 \\
\hline
\end{tabular}

\subsubsection{Current Fleet Dispatch Strategy Information}

Table 12 shows the format of dispatch information, which identifies bus types and corresponding amounts for each route. The number of buses per route contributes to the annual travel distance of those buses on the route. The distance is a critical factor in bus overall performance, because it will reflect actual fuel and maintenance costs. For example, high fuel economy and short distance can not translate into significant total fuel saving.

Table 12: An Example of Current Fleet Dispatch Matrix in Input Module

\begin{tabular}{cccccc}
\hline & BusE & BusD & BusC & BusB & BusA \\
\hline Bus Length & $40-\mathrm{ft}$ & $60-\mathrm{ft}$ & $60-\mathrm{ft}$ & $30-\mathrm{ft}$ & $40-\mathrm{ft}$ \\
\hline Bus Amt & 1 & 4 & 10 & 10 & 25 \\
Route 1 & 0 & 0 & 0 & 4 & 2 \\
Route 2 & 0 & 0 & 5 & 0 & 2 \\
Route 3 & 0 & 2 & 3 & 0 & 3 \\
Route 4 & 0 & 2 & 0 & 0 & 2 \\
\hline
\end{tabular}




\begin{tabular}{llllll}
\hline Route 5 & 0 & 0 & 0 & 0 & 7 \\
\hline Route 6 & 0 & 0 & 0 & 6 & 2 \\
Route 7 & 0 & 0 & 2 & 0 & 4 \\
\hline Route 8 & 1 & 0 & 0 & 0 & 3 \\
\hline
\end{tabular}

\subsection{Calculation Module}

The calculation module was designed to calculate cost and GHG emissions according to bus and route combination. It does not perform any optimization. Following sections describe the functions used in cost and emissions models.

\subsubsection{Cost Model}

Cost model in this dissertation was founded on TCRP C-15 LCC model [2]. Original C-15 LCC model identified hard costs associated with procuring and operating hybrid-electric buses, conventional diesel buses, and CNG buses. New cost model added Hydrogen fuel cells, biodiesel, and battery electric bus technologies. New model included 30-ft long buses along with 40 and $60-\mathrm{ft}$ bus lengths.

Data used in the TCRP C-15 cost model were obtained through various sources, including a 18 months data collection at four test sites, survey questionnaires sent to hybrid original equipment manufacturers (OEMs), and calls made to bus OEMs, other vendors and suppliers, transit agencies, and trade associations. Data in the literature were also reviewed. While much of the information contained in the TCRP C-15 model was based on data obtained from actual operational experience, projections had to be made for new added technologies where in-use experience was not sufficient.

C-15 cost model provided default cost values and with upper and lower limits for all cost items. The C-15 model also permits user to input individual assumptions and known data for a specific transit operation. There was no intention to develop another highly accurate cost model in this study. In this study, no upper and lower limits were included and simple projection for new technologies were made based on the baseline diesel buses from the C-15 model. Each cost element had a table of cost projection used in this study and followed a description of the cost elements used in the development of the C-15 cost model as references. 
Next eight cost sections first presented cost data and functions developed in the C-15 model then followed with relevant data and functions adopted and developed in the FMT.

\section{Vehicle Cost}

Each transit agency had different bus procurement requirements when it came to options, extended warranties, OEM-provided training, bus delivery, spare parts and other services and equipment that influence bus pricing. In particular, equipment that greatly affected the initial bus price consisted of Intelligent Transportation System (ITS) features such as automatic vehicle location (AVL), next stop annunciators, security cameras, automatic passenger counters (APC), radio and data communications, and various other onboard electronic systems. This was a confounding factor in interpreting bus acquisition cost data. For the LCC model, the costs used to reflect each type of bus were based on a vehicle minimally equipped with basic onboard equipment such as air conditioning, multiplexing basic electric destination signs, and standard warranty consisting of one year coverage for the entire vehicle and two years of powertrain coverage. The cost of extended powertrain warranty was accounted for separately in the LCC model.

From investigation, it was difficult to determine any significant insurance cost differences based on whether the bus was being operated as a diesel, CNG or hybrid unit. As a result, the LCC model assumed no cost differences for insurance. However, since insurance cost differences could exist for certain agencies based on their insurance requirements or carrier, users could add those values to the purchase price as appropriate in the LCC model.

Each of the major bus OEMs was contacted to obtain bus pricing information using the conditions described above. Basic bus pricing was used in the model as low, medium and high ranges, and a typical pricing differential was maintained between each bus type for comparison purposes. For example, using diesel bus as a baseline, an incremental cost increase of $\$ 30,000$ for CNG buses was retained throughout the low, medium and high price ranges. Because of the various technologies associated with HEB, incremental cost increases of $\$ 190,000, \$ 200,000$ and $\$ 210,000$ were used for the low, medium and high range values respectively when compared to a standard diesel bus. 
The price of all three bus types was based on 2007 models fitted with equipment needed to meet new EPA emissions requirements for engines of that year. Although some 2007 model year buses may have been delivered with 2006 model year engines, all engines built from 2007 onward have been required to meet a $0.01 \mathrm{~g} / \mathrm{bhp}-\mathrm{hr}$ PM standard, which obliges the manufacturer to employ exhaust filtration. For purchases in 2010 , a range of $\$ 4,000$ to $\$ 8,000$ was added to each diesel bus to meet more stringent 2010 EPA regulations for NOx. CNG bus prices for 2010 did not include a price increase (except for standard inflation) because 2007 CNG engines (operating with stoichiometric combustion) can already meet 2010 EPA requirements. For hybrid bus purchases in 2012, the LCC model included a price reduction of 7 to 30 percent range (with 15 percent being the default) based on projections made by hybrid OEMs that hybrid technology costs would go down in time as the technology matured and initial investments in advanced technology were recovered. Low, default, and high purchase prices in the model are shown in Table 13.

Table 13: Bus Purchase Costs in 2007 dollars

\begin{tabular}{|c|c|c|c|c|c|c|}
\hline & \multicolumn{2}{|c|}{ Diesel } & \multicolumn{2}{c|}{ CNG } & \multicolumn{2}{c|}{ Hybrid } \\
\hline & 2007 & 2012 & 2007 & 2012 & 2007 & 2012 \\
\hline 40-ft Low & $\$ 300,000$ & $\$ 304,000$ & $\$ 330,000$ & $\$ 330,000$ & $\$ 490,000$ & $\$ 416,500$ \\
\hline 40-ft Medium & $\$ 310,000$ & $\$ 316,000$ & $\$ 340,000$ & $\$ 340,000$ & $\$ 510,000$ & $\$ 433,500$ \\
\hline 40-ft High & $\$ 320,000$ & $\$ 328,000$ & $\$ 350,000$ & $\$ 350,000$ & $\$ 530,000$ & $\$ 450,500$ \\
\hline 60-ft Low & $\$ 390,000$ & $\$ 395,200$ & $\$ 429,000$ & $\$ 429,000$ & $\$ 637,000$ & $\$ 541,450$ \\
\hline 60-ft Medium & $\$ 403,000$ & $\$ 410,800$ & $\$ 442,000$ & $\$ 442,000$ & $\$ 663,000$ & $\$ 563,550$ \\
\hline 60-ft High & $\$ 416,000$ & $\$ 426,400$ & $\$ 455,000$ & $\$ 455,000$ & $\$ 689,000$ & $\$ 585,650$ \\
\hline
\end{tabular}

As with any input, users could run the LCC model with the default pricing value (mid), select other pre-assigned values for each bus type, or input other purchase costs for each bus depending on the cost of specific bus options selected. In addition, the ability to change bus purchase cost would allow the model structure to be useful even if future prices differed from the model projections.

Vehicle prices used in FMT are presented in Table 14. No cost adjustment was made to biodiesel buses. Battery-electric bus price was defined as the mean of conventional diesel and diesel hybrid. Fuel cell buses price was an average cost of fuel cell buses recorded in APTA 
database [20]. Since fuel cell buses were mainly prototype buses and sold in a very limited number, their purchase price might not present the actual commercial price when reaching a certain scale of production and sales. There were no upper and lower limits used in the FMT.

Table 14: Bus Purchase Costs in 2007 Dollars used in FMT

\begin{tabular}{|c|c|c|c|c|c|c|c|}
\hline & \multirow[b]{2}{*}{ Model Year } & \multicolumn{6}{|c|}{ Bus Length } \\
\hline & & \multicolumn{2}{|r|}{$30-\mathrm{ft}$} & \multicolumn{2}{|r|}{$40-\mathrm{ft}$} & \multicolumn{2}{|r|}{$60-\mathrm{ft}$} \\
\hline \multirow{3}{*}{ Conventional Diesel } & Pre-2007 & $\$$ & 255,000 & $\$$ & 300,000 & $\$$ & 390,000 \\
\hline & $2007-2010$ & $\$$ & 263,500 & $\$$ & 310,000 & $\$$ & 403,000 \\
\hline & Post 2010 & $\$$ & 268,600 & $\$$ & 316,000 & $\$$ & 410,800 \\
\hline \multirow{3}{*}{ Conventional CNG } & Pre-2007 & $\$$ & 289,000 & $\$$ & 340,000 & $\$$ & 442,000 \\
\hline & $2007-2010$ & $\$$ & 289,000 & $\$$ & 340,000 & $\$$ & 442,000 \\
\hline & Post 2010 & $\$$ & 289,000 & $\$$ & 340,000 & $\$$ & 442,000 \\
\hline \multirow{3}{*}{ Diesel Hybrid-Electric } & Pre-2007 & $\$$ & 450,500 & $\$$ & 530,000 & $\$$ & 689,000 \\
\hline & $2007-2010$ & $\$$ & 433,500 & $\$$ & 510,000 & $\$$ & 663,000 \\
\hline & Post 2010 & $\$$ & 368,475 & $\$$ & 433,500 & $\$$ & 563,550 \\
\hline \multirow{3}{*}{ B20 Biodiesel } & Pre-2007 & $\$$ & 255,000 & $\$$ & 300,000 & $\$$ & 390,000 \\
\hline & $2007-2010$ & $\$$ & 263,500 & $\$$ & 310,000 & $\$$ & 403,000 \\
\hline & Post 2010 & $\$$ & 268,600 & $\$$ & 316,000 & $\$$ & 410,800 \\
\hline \multirow{3}{*}{ Battery Electric } & Pre-2007 & $\$$ & 352,750 & $\$$ & 415,000 & $\$$ & 539,500 \\
\hline & 2007-2010 & $\$$ & 348,500 & $\$$ & 410,000 & $\$$ & 533,000 \\
\hline & Post 2010 & $\$$ & 318,538 & $\$$ & 374,750 & $\$$ & 487,175 \\
\hline \multirow{3}{*}{ Fuel Cell - Hydrogen } & Pre-2007 & $\$$ & $2,120,000$ & $\$$ & $2,494,118$ & $\$$ & $3,242,353$ \\
\hline & $2007-2010$ & $\$$ & $2,040,000$ & $\$$ & $2,400,000$ & $\$$ & $3,120,000$ \\
\hline & Post 2010 & $\$$ & $1,734,000$ & & $2,040,000$ & $\$$ & $2,652,000$ \\
\hline \multirow{3}{*}{$\begin{array}{l}\text { Gasoline Hybrid- } \\
\text { Electric }\end{array}$} & Pre-2007 & $\$$ & 450,500 & $\$$ & 530,000 & $\$$ & 689,000 \\
\hline & $2007-2010$ & $\$$ & 433,500 & $\$$ & 510,000 & $\$$ & 663,000 \\
\hline & Post 2010 & $\$$ & 368,475 & $\$$ & 433,500 & $\$$ & 563,550 \\
\hline
\end{tabular}

\section{Other Capital Costs and Facility Costs}

Diagnostic Equipment Cost. Costs for diagnostic equipment included only those special tools and diagnostic equipment items unique to the propulsion system of hybrid buses. It was assumed that transit agencies had already made investments in diagnostic equipment needed 
for standard ICEs used in all three bus types and for conventional automatic transmissions used in diesel and CNG buses. In this way the model was constructed to differentiate between technologies, because comparative accuracy was of the highest concern. Costing information for tools and diagnostic equipment unique to hybrid propulsion systems was obtained directly from the hybrid OEMs and verified by agencies that have purchased this equipment. As engine technology (such as SCR and OBD technologies) evolved, all of the bus types would require a similar level of investment in engine diagnostic tools. However, such new costs were not reviewed and included in this dissertation.

Given that the ICEs used in hybrids were typically diesel or gasoline, the costs of diagnostic equipment was averaged together for both engine types. An exception was the advanced level of diagnostic equipment applicable to hybrids fitted with gasoline engines that may be unique to an agency's fleet. In this case, cost inputs assumed that agencies purchasing gasoline hybrids would opt for more basic diagnostic equipment (i.e., equipment priced more in line with diesel and CNG engines) for the gasoline-powered Auxiliary Power Unit (APU). Obtaining the full level of diagnostics for gasoline engines could be as high as $\$ 20,000$. However, it was assumed that agencies with gasoline hybrids would use the services of a local dealer in those isolated cases when more advanced diagnostics were needed. Default diagnostic equipment prices are presented in Table 15.

Table 15: Diagnostic Equipment Prices for Every 50 Buses at One Workshop

\begin{tabular}{|c|c|c|c|}
\hline & Diesel & CNG & Hybrid \\
\hline Low & $\$ 0$ & $\$ 0$ & $\$ 3,000$ \\
\hline Medium & $\$ 0$ & $\$ 0$ & $\$ 5,000$ \\
\hline High & $\$ 0$ & $\$ 0$ & $\$ 7,000$ \\
\hline
\end{tabular}

Costs for hybrid diagnostic equipment were calculated for groups of up to 50 hybrid buses at each workshop location based on information provided by the hybrid OEMs. Once multiples of 50 buses were exceeded, the model would automatically add in the cost of another set of diagnostic equipment. As noted above, the LCC model was constructed by assuming no diagnostic equipment costs for diesel and CNG buses. If diagnostic equipment were desired for multiple locations, users would have to enter individual costs as needed. Using the concept, the 
following mid-range diagnostic equipment costs were assigned for the representative HEB fleet sizes:

- 1 to 50 HEB fleet with one workshop: $\$ 5,000$

- 1 to 50 HEB fleet with two workshops: $\$ 5,000 \times 2=\$ 10,000$

- 51 to 100 HEB fleet in one workshop: $\$ 5,000 \times 2=\$ 10,000$

- 61 HEB fleet with 10 in one workshop and 51 in the other: $\$ 5,000+\$ 5,000 \times 2=\$ 15,000$

FMT model used the costs for diagnostic equipment as presented below. The cost of battery and gasoline hybrid buses were similar to that of diesel hybrid-electric buses. Fuel Cell buses were assumed to cost twice on diagnostic equipment.

Table 16: Diagnostic Equipment Prices for Every 50 Buses at One Workshop in FMT

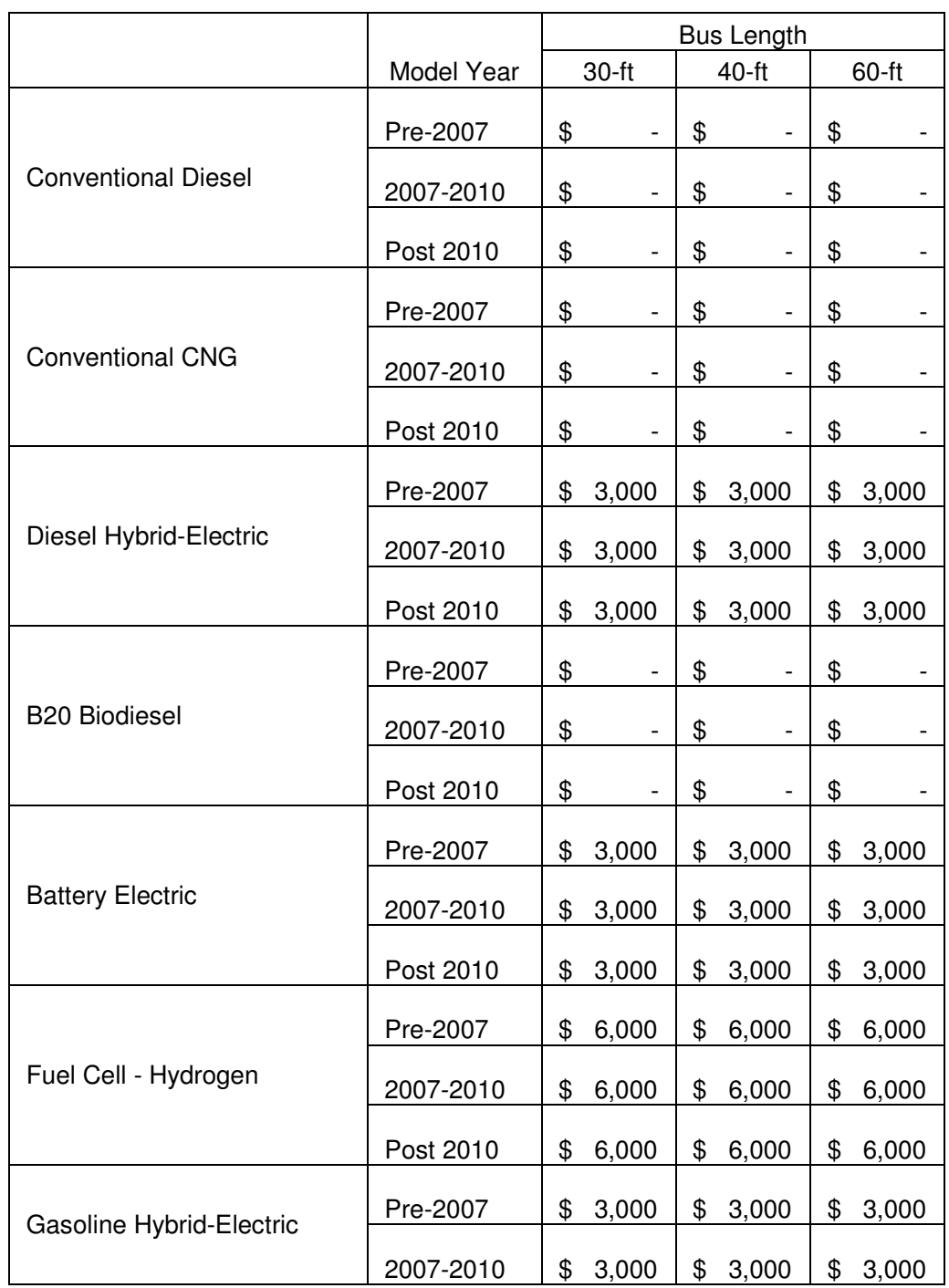




\begin{tabular}{|l|l|l|l|l|} 
& Post 2010 & $\$ 3,000$ & $\$ 3,000$ & $\$ 3,000$ \\
\hline Sources: TRCP C-15 LCC Model
\end{tabular}

Infrastructure and Maintenance Costs. Originally, cost inputs for infrastructure upgrades were to include facility modifications required for both CNG and hybrid buses, with diesel buses not requiring any upgrades. However, as the research for this project progressed it became apparent that lead acid battery storage systems and the battery recharging/reconditioning that went with it were no longer used in the latest technology. As a result, infrastructure upgrades for hybrids were no longer an issue and CNG remained as the only bus type requiring infrastructure upgrades.

Understanding that costs for CNG infrastructure (fueling stations and maintenance and storage facilities) could vary greatly depending on several factors such as climate, condition of existing facilities, required full rate and code requirements, assigning costs for CNG infrastructure was challenging. WVU researchers previously gathered data on CNG facility cost as part of an FTA study, and found the following information [10].

CNG infrastructure costs included two costs: for depot modification and for the refueling station. The available data have wide ranges on both costs: depot modification costs were found to be $\$ 500,000$ to $\$ 15,000,000$ and refueling station costs were found to be $\$ 320,000$ to $\$ 7,400,000$. The report had $\$ 875,000$ for depot modification and $\$ 2,000,000$ for refueling station on a basis of 100-bus purchase. The electricity for compression (\$0.14/DGE) was calculated and considered the only additional cost for CNG station noting the lack of available data. Hence, CNG infrastructure cost for the 100 -bus purchase was $\$ 2,875,000$ and the additional maintenance cost was about $\$ 198,000$ per year (assuming that CNG buses run 37,000 miles per year at 2.62 miles/DGE). The infrastructure maintenance cost was about $6.8 \%$ of the infrastructure cost. The results were fairly close to those from the method developed for the LCC model as described below.

Discussions regarding CNG infrastructure were also held with various agencies operating CNG buses, as well as representatives from CNG organizations including the Natural Gas Vehicle 
Institute, NGVAmerica, Trillium, and Clean Energy. After reviewing CNG infrastructure costs from these sources, a formula was developed that began by assigning an infrastructure cost of one million dollars and then added $\$ 15,000$ for each $C N G$ bus purchased. The formula calculated the default CNG infrastructure cost. The low and high costs were $20 \%$ reduction and increment to the default cost. Included in the these costs were the costs associated with constructing a fueling facility and modifications needed for maintenance and storage facilities such as methane detection, ventilation, electrical modifications, and other needed modifications. Infrastructure maintenance costs were identified separately in the model and were described below. In case of any expected infrastructure expenses for diesel and HEB, the user would have the ability to include the cost.

Using this formula, the following mid-range infrastructure costs were assigned for the representative CNG fleet sizes:

- 25 CNG Bus Fleet: $\$ 1$ Million $+\$ 375,000=\$ 1,375,000$

- 50 CNG Bus Fleet: $\$ 1$ Million $+\$ 750,000=\$ 1,750,000$

- 100 CNG Bus Fleet: $\$ 1$ Million $+\$ 1,500,000=\$ 2,500,000$

- 200 CNG Bus Fleet: $\$ 1$ Million $+\$ 3,000,000=\$ 4,000,000$

Additional costs related to the CNG facility were the extra electricity expense to operate the CNG fueling compressors, the cost to rebuild them, and other special operational needs for the CNG fueling facility. Costs varied with each location and the approach used to power compressors, but in the end six percent of the overall CNG infrastructure cost was used to reflect annual CNG facility maintenance and operating costs. The cost was the differential expense. In other words, the model did not consider the facility maintenance cost for diesel and gasoline bus operation, and assumed no cost associated with them. It should be noted that some CNG providers had arrangements whereby infrastructure and/or annual maintenance and operating costs were included in unit price of the delivered CNG. Subsidies and incentives were also offered to offset CNG infrastructure cost. All of these factors must be considered when accepting default value or assigning CNG infrastructure costs by the user. 
In FMT, CNG infrastructure costs were inherited from the $\mathrm{C}-15$ formula. Hydrogen infrastructure used $\$ 19,833$ per bus instead of $\$ 15,000$ per bus in the formula. Electric bus charge station used $\$ 6,400$ per bus.

\section{Extended Powertrain Warranty Cost}

As noted in the Vehicle Costs section above, the price of all three bus types included the standard warranty of only one year for the entire vehicle and two years for the drivetrain. Understanding that extended drivetrain warranties were popular, the LCC model itemized these warranties as separate cost items.

Extended powertrain warranty costs were based how many years warranty coverage was desired. The cost of the first two years of powertrain warranty coverage was assumed to be included in the original bus purchase price. Cost information was obtained from hybrid OEMs, bus OEMs and from transit agencies. The default (mid-range) cost for extended propulsion warranty coverage provided in the LCC model accounted for the average cost from those providing data.

Extended powertrain warranty costs for hybrid buses encompassed coverage for the entire hybrid propulsion system including the APU and ICE. Based on information provided by the hybrid OEMs, a 20 percent reduction in extended powertrain warranty costs was assumed for purchases made in 2012 because of anticipated improvements in reliability. Extended powertrain warranty for diesel and CNG buses covered the ICE and more conventional automatic transmission.

Calculating the actual cost of extended warranty was somewhat difficult for several reasons. Bus OEMs typically purchased warranties from powertrain vendors, and the OEMs might or might not mark up those costs to the agency, or may even decide to discount extended warranty costs because of other aspects of the procurement. In addition, because of the competitive nature of bus procurements, some OEMs were reluctant to share detailed warranty cost information. Regardless of sensitivities involved with warranty, all information obtained from OEMs and agencies were analyzed and the ranges were believed to be representative. 
Using a diesel bus as the baseline, extended drivetrain warranty costs for CNG were estimated at ten percent higher than diesel, while extended powertrain warranty coverage costs for hybrid buses were much higher (158 to 460 percent) than diesel. As mentioned above, extended powertrain warranty costs for hybrid purchases made in 2012 , however, fell because of anticipated improvements in reliability (106 to 348 percent higher than diesel in 2007 dollars). The model considered three years extended warranty as default setting. Table 17 presents the costs for three years warranty of three bus technologies.

Table 17: Buses Three Years Extended Warranty Costs

\begin{tabular}{|c|c|c|c|c|}
\hline & Diesel & CNG & \multicolumn{2}{|c|}{ Hybrid } \\
\hline Year & $2007 / 2010$ & $2007 / 2010$ & 2007 & 2010 \\
\hline Low & $\$ 6,000$ & $\$ 6,600$ & $\$ 15,500$ & $\$ 12,400$ \\
\hline Medium & $\$ 6,750$ & $\$ 7,425$ & $\$ 25,000$ & $\$ 20,000$ \\
\hline High & $\$ 7,500$ & $\$ 8,250$ & $\$ 42,000$ & $\$ 33,600$ \\
\hline
\end{tabular}

In FMT, biodiesel buses used the price for diesel buses. Battery electric buses were assumed to have the same cost as diesel hybrid-electric buses. Fuel Cell buses were estimated to be double the cost for hybrid-electric buses. The costs are listed in Table 18.

Table 18: Three Year Extended Warranty Used in FMT

\begin{tabular}{|c|c|c|c|c|c|c|c|}
\hline & \multirow[b]{2}{*}{ Model Year } & \multicolumn{6}{|c|}{ Bus Length } \\
\hline & & & $0-\mathrm{ft}$ & & $-\mathrm{ft}$ & & $0-\mathrm{ft}$ \\
\hline \multirow{3}{*}{ Conventional Diesel } & Pre-2007 & $\$$ & 6,750 & $\$$ & 6,750 & $\$$ & 6,750 \\
\hline & $2007-2010$ & $\$$ & 6,750 & $\$$ & 6,750 & $\$$ & 6,750 \\
\hline & Post 2010 & $\$$ & 6,750 & $\$$ & 6,750 & $\$$ & 6,750 \\
\hline \multirow{3}{*}{ Conventional CNG } & Pre-2007 & $\$$ & 7,425 & $\$$ & 7,425 & $\$$ & 7,425 \\
\hline & $2007-2010$ & $\$$ & 7,425 & $\$$ & 7,425 & $\$$ & 7,425 \\
\hline & Post 2010 & $\$$ & 7,425 & $\$$ & 7,425 & $\$$ & 7,425 \\
\hline \multirow{3}{*}{ Diesel Hybrid-Electric } & Pre-2007 & $\$$ & 30,000 & $\$$ & 30,000 & $\$$ & 30,000 \\
\hline & $2007-2010$ & $\$$ & 25,000 & $\$$ & 25,000 & $\$$ & 25,000 \\
\hline & Post 2010 & $\$$ & 20,000 & $\$$ & 20,000 & $\$$ & 20,000 \\
\hline \multirow{3}{*}{ B20 Biodiesel } & Pre-2007 & $\$$ & 6,750 & $\$$ & 6,750 & $\$$ & 6,750 \\
\hline & $2007-2010$ & $\$$ & 6,750 & $\$$ & 6,750 & $\$$ & 6,750 \\
\hline & Post 2010 & $\$$ & 6,750 & $\$$ & 6,750 & $\$$ & 6,750 \\
\hline Battery Electric & Pre-2007 & & & & & & \\
\hline
\end{tabular}




\begin{tabular}{|c|c|c|c|c|c|c|c|}
\hline & & $\$$ & 30,000 & $\$$ & 30,000 & $\$$ & 30,000 \\
\hline & $2007-2010$ & $\$$ & 25,000 & $\$$ & 25,000 & $\$$ & 25,000 \\
\hline & Post 2010 & $\$$ & 20,000 & $\$$ & 20,000 & $\$$ & 20,000 \\
\hline \multirow{3}{*}{ Fuel Cell - Hydrogen } & Pre-2007 & $\$$ & 60,000 & $\$$ & 60,000 & $\$$ & 60,000 \\
\hline & $2007-2010$ & $\$$ & 50,000 & $\$$ & 50,000 & $\$$ & 50,000 \\
\hline & Post 2010 & $\$$ & 40,000 & $\$$ & 40,000 & $\$$ & 40,000 \\
\hline \multirow{3}{*}{ Gasoline Hybrid-Electric } & Pre-2007 & $\$$ & 30,000 & $\$$ & 30,000 & $\$$ & 30,000 \\
\hline & $2007-2010$ & $\$$ & 25,000 & $\$$ & 25,000 & $\$$ & 25,000 \\
\hline & Post 2010 & $\$$ & 20,000 & $\$$ & 20,000 & $\$$ & 20,000 \\
\hline
\end{tabular}

\section{Training Cost}

Training costs for both operators and mechanics were based on training needed beyond what would be required for a traditional diesel bus (i.e., assumed no additional training costs for diesel buses). All costs were based on number of trainees and their labor rates (default rates were $\$ 50$ per hour for both operators and mechanics.) and included safety training. All costs are one-time expenses required only when buses first arrive (i.e., refresher training costs are not included) except that a CNG bus purchase required 0.5 hours per operator per year for annual safety training. It is possible that high voltage electric safety training might emerge for hybrid vehicles, but this was left to the user to quantify.

Costs for training labor were obtained from bus OEMs and from transit agencies that have undertaken training for CNG and hybrid buses. Since CNG and hybrid buses were designed to be relatively seamless to the driver, operator training for both groups was minimal ( 0.5 to 4 hours per operator) and consisted primarily of safety training. Maintenance training, also calculated as the number of incremental hours over standard diesel training, ranged from eight to 12 additional hours per mechanic for CNG, and 16-20 additional hours per mechanic for hybrid buses. Agencies should enter the number of operators and mechanics that required training and their labor rates, and the LCC model would make the appropriate calculations for each bus type. The default number for operators was the number of new buses, and the default number 
for mechanics was $20 \%$ of the purchase number. The training hours required are presented in Table 19.

Table 19: Bus Training Hours for Operator and Mechanics

\begin{tabular}{|l|l|c|c|}
\hline & Diesel & CNG & Hybrid \\
\hline Operators Low & 0 hour & 0.5 hour +0.5 hour/year & 1 hour \\
\hline Operators Medium & 0 hour & 1 hour +0.5 hour $/$ year & 2 hour \\
\hline Operators High & 0 hour & 1.5 hour +0.5 hour $/$ year & 4 hour \\
\hline Mechanics Low & 0 hour & 8 hour & 16 hour \\
\hline Mechanics Medium & 0 hour & 10 hour & 18 hour \\
\hline Mechanics High & 0 hour & 12 hour & 20 hour \\
\hline
\end{tabular}

In FMT, training hours for electric and Fuel Cell buses were assumed to a combination of hours for CNG and hybrid buses. Biodiesel buses used the training hours required for CNG buses. The number of hours is shown in Table 20.

Table 20: Bus Training Hours for Operator and Mechanics in FMT

\begin{tabular}{|c|c|c|c|c|}
\hline & $\begin{array}{c}\text { Operator } \\
\text { Hours }\end{array}$ & & $\begin{array}{c}\text { Mechanical } \\
\text { Hours }\end{array}$ & \\
\hline & One Time & $\begin{array}{l}\text { Per } \\
\text { Year }\end{array}$ & One Time & $\begin{array}{l}\text { Per } \\
\text { Year }\end{array}$ \\
\hline Conventional Diesel & 0 & 0 & 0 & 0 \\
\hline Conventional CNG & 1 & 0.5 & 10 & 0 \\
\hline Diesel Hybrid-Electric & 1 & 0 & 18 & 0 \\
\hline B20 Biodiesel & 1 & 0.5 & 10 & 0 \\
\hline Battery Electric & 2 & 0.5 & 28 & 0 \\
\hline Fuel Cell - Hydrogen & 2 & 0.5 & 28 & 0 \\
\hline Gasoline Hybrid-Electric & 1 & 0 & 18 & 0 \\
\hline
\end{tabular}

\section{Vehicle Fuel Cost}

Fuel cost was one of largest portions of the operation cost for a transit agency and therefore called for detailed study in formulating the model. As shown in the following equation, a bus life-cycle fuel cost involved fuel price, bus fuel economy, bus life travel mileage, and fuel credits and taxes.

Bus Life Cycle Fuel Cost $=$ Life Travel Mileage $/$ FE $\times$ (Fuel Price + Taxes - Credits) 
The bus life cycle fuel cost was in dollar units. The unit of bus life travel mileage was the mile. FE was expressed in miles-per-gallon. Fuel price, tax, and credits had the same dollar-pergallon unit. The next sections address how the future fuel price and FE were estimated. A brief description of fuel tax and credits is also included.

Fuel Price Forecast (2007 2030). Bus life fuel cost required long term fuel price estimation extending 12 years or more. The model utilized the forecasts made by a number of fuel and energy studies. The following two sections show how to approach the low, high and default price values for diesel, gasoline and CNG fuels.

\section{Diesel and Gasoline Prices}

There were few direct diesel and gasoline price predictions. The two fuel prices were tied to crude oil price closely. Imbalance in the gasoline/diesel demand ratio may affect fuel prices in the long term. Twelve different crude oil price studies were conducted by different organizations. The original prices (dollar-per-barrel) are presented in the Table 21.

Table 21: Crude Oil Price Projections from Original Studies; Projections are not adjusted to 2007 dollars, and each projection has its own baseline year.

\begin{tabular}{|c|c|c|c|c|c|c|c|c|c|c|c|c|}
\hline & 1 & 2 & 3 & 4 & 5 & 6 & 7 & 8 & 9 & 10 & 11 & 12 \\
\hline Year & $\begin{array}{c}\text { EIA } \\
2007\end{array}$ & GII & IEA & EEA & DB & SEER & EVA & EU & Texas & GEM & OPEC & DELPHI \\
\hline \$ year & 2005 & 2005 & 2005 & 2005 & 2005 & 2005 & 2005 & 1995 & 2005 & 2000 & 2005 & 1997 \\
\hline 1997 & & & & & & & & & & & & $\$ 19.77$ \\
\hline 1998 & & & & & & & & & & & & $\$ 19.57$ \\
\hline 1999 & & & & & & & & & & & & $\$ 19.49$ \\
\hline 2000 & & & & & & & & & & $\$ 28.00$ & & $\$ 19.53$ \\
\hline 2001 & & & & & & & & & & & & $\$ 19.82$ \\
\hline 2002 & & & & & & & & & & & & $\$ 20.10$ \\
\hline 2003 & & & & & & & & & & & & $\$ 20.29$ \\
\hline 2004 & $\$ 42.87$ & & & & & & & & & & & $\$ 20.50$ \\
\hline 2005 & $\$ 56.76$ & & & & & & & & & & $\$ 50.00$ & $\$ 20.72$ \\
\hline 2006 & $\$ 69.11$ & & & & & & & $\$ 20.00$ & $\$ 51.88$ & & $\$ 45.00$ & $\$ 20.86$ \\
\hline 2007 & $\$ 66.71$ & & & & & & & $\$ 20.00$ & $\$ 47.25$ & & $\$ 37.00$ & $\$ 21.05$ \\
\hline 2008 & $\$ 64.09$ & & & & & & & $\$ 21.00$ & $\$ 44.13$ & & $\$ 31.00$ & $\$ 21.24$ \\
\hline 2009 & $\$ 60.91$ & & & & & & & $\$ 22.40$ & $\$ 43.69$ & & $\$ 27.00$ & $\$ 21.45$ \\
\hline 2010 & $\$ 57.47$ & $\$ 57.11$ & $\$ 51.50$ & $\$ 56.94$ & $\$ 39.66$ & $\$ 44.21$ & $\$ 42.28$ & $\$ 24.00$ & $\$ 43.25$ & $\$ 50.00$ & $\$ 25.00$ & $\$ 21.67$ \\
\hline 2011 & $\$ 54.33$ & & & & & & & $\$ 24.40$ & $\$ 43.90$ & & $\$ 25.00$ & $\$ 21.94$ \\
\hline 2012 & $\$ 51.71$ & & & & & & & $\$ 24.80$ & $\$ 44.32$ & & $\$ 25.00$ & $\$ 22.21$ \\
\hline 2013 & $\$ 49.99$ & & & & & & & $\$ 25.20$ & $\$ 44.27$ & & $\$ 25.00$ & $\$ 22.49$ \\
\hline 2014 & $\$ 49.64$ & & & & & & & $\$ 25.60$ & $\$ 44.08$ & & $\$ 25.00$ & $\$ 22.79$ \\
\hline 2015 & $\$ 49.87$ & $\$ 46.54$ & $\$ 47.80$ & $\$ 49.80$ & $\$ 40.11$ & $\$ 45.27$ & $\$ 42.35$ & $\$ 26.00$ & $\$ 43.88$ & & $\$ 25.00$ & $\$ 23.10$ \\
\hline 2016 & $\$ 49.75$ & & & & & & & $\$ 26.50$ & $\$ 44.15$ & & $\$ 25.00$ & $\$ 23.41$ \\
\hline 2017 & $\$ 50.80$ & & & & & & & $\$ 27.00$ & $\$ 44.66$ & & $\$ 25.00$ & $\$ 23.74$ \\
\hline 2018 & $\$ 51.28$ & & & & & & & $\$ 27.70$ & $\$ 45.18$ & & $\$ 25.00$ & $\$ 24.07$ \\
\hline 2019 & $\$ 51.95$ & & & & & & & $\$ 28.20$ & $\$ 45.72$ & & $\$ 25.00$ & \\
\hline 2020 & $\$ 52.04$ & $\$ 45.06$ & $\$ 50.20$ & $\$ 47.42$ & $\$ 39.73$ & $\$ 45.87$ & $\$ 45.76$ & $\$ 29.00$ & $\$ 46.28$ & $\$ 47.00$ & $\$ 25.00$ & \\
\hline
\end{tabular}




\begin{tabular}{|c|c|c|c|c|c|c|c|c|c|c|c|c|}
\hline 2021 & $\$ 52.73$ & & & & & & & $\$ 29.18$ & $\$ 48.50$ & & $\$ 25.00$ & \\
\hline 2022 & $\$ 53.43$ & & & & & & & $\$ 29.66$ & $\$ 50.13$ & & $\$ 25.00$ & \\
\hline 2023 & $\$ 54.90$ & & & & & & & $\$ 30.14$ & $\$ 52.19$ & & $\$ 25.00$ & \\
\hline 2024 & $\$ 55.64$ & & & & & & & $\$ 30.62$ & $\$ 53.50$ & & $\$ 25.00$ & \\
\hline 2025 & $\$ 56.37$ & $\$ 43.21$ & $\$ 52.60$ & $\$ 45.16$ & $\$ 39.95$ & $\$ 46.23$ & $\$ 49.45$ & $\$ 31.10$ & $\$ 55.56$ & & $\$ 25.00$ & \\
\hline 2026 & $\$ 57.11$ & & & & & & & $\$ 31.86$ & $\$ 57.09$ & & $\$ 25.00$ & \\
\hline 2027 & $\$ 57.63$ & & & & & & & $\$ 32.62$ & $\$ 58.67$ & & $\$ 25.00$ & \\
\hline 2028 & $\$ 58.12$ & & & & & & & $\$ 33.38$ & $\$ 60.14$ & & $\$ 25.00$ & \\
\hline 2029 & $\$ 58.61$ & & & & & & & $\$ 34.14$ & $\$ 61.55$ & & $\$ 25.00$ & \\
\hline 2030 & $\$ 59.12$ & $\$ 40.25$ & $\$ 55.00$ & & $\$ 40.16$ & $\$ 46.60$ & & $\$ 35.00$ & $\$ 63.30$ & $\$ 60.00$ & $\$ 25.00$ & \\
\hline \multicolumn{13}{|c|}{$\begin{array}{l}\text { 1-7. EIA = Energy Information Administration; GII = Global Insight, Inc.; IEA = International energy Agency; EEA = Energy and Environmental } \\
\text { Analysis, Inc.; DB = Deutsche Bank AG; SEER = Strategic Energy and Economic Research, Inc.; EVA = Energy Ventures Analysis, Inc. [113] } \\
\text { 8. EU = European Union (European Commission) [114] } \\
\text { 9. TEXAS = Texas Comptroller's Revenue Estimating Division [115] } \\
\text { 10. GEM = German Economy Ministry [116] } \\
\text { 11. OPEC = Organization of the Petroleum Exporting Countries [117] } \\
\text { 12. Delphi = 1997 Delphi IX Oil Price Survey [118] }\end{array}$} \\
\hline
\end{tabular}

The following adjustments were made to obtain the gasoline and diesel price data.

- For discrete data (such as studies 2 to 7 and 10), linear interpolation was used to create the intermediate year value between the available values.

- All prices were adjusted into 2007 dollars by using the domestic consumer price index (CPI) provided by the Department of Labor at the time of the research (Table 22).

- All pre-2006 prices were not considered from the report.

- Year 2006 oil price (known value) was used as the baseline price. All projection prices in 2006 were aligned to the baseline price by shifting their price curves up or down. It remained the prediction trends from all studies. The baseline 2006 oil price was the price recorded in the 2007 Annual Energy Outlook (AEO), prepared by Energy Information Administration (EIA) of Department of Energy.

Table 22: Consumer Price Index Used to Adjust Crude Oil and CNG Price to 2007 Dollars

\begin{tabular}{|c|c|}
\hline $\begin{array}{c}\text { CPI calculated by Inflation Calculator on } \\
\text { http://www.bls.gov/cpi/ }\end{array}$ \\
\hline & Inflation Rate \\
\hline & 1.36 \\
\hline 1995 to 07 & 1.29 \\
\hline 1997 to 07 & 1.20 \\
\hline 2000 to 07 & 1.15 \\
\hline 2002 to 07 & 1.06 \\
\hline 2005 to 07 & \\
\hline
\end{tabular}


Those adjustments yielded 12 projections having the same start-year (2006) and start-price (73.25 \$/barrel). Table 23 shows the adjusted crude oil prices. The default value used weighted average of 12 projections. The most recent and comprehensive 2007 AEO had a weight of 50\% in the averaging and the rest eleven predictions shared the rest $50 \%$ evenly. The low value at the certain year was the minimum price found in the projection data at the year. Similarly, the high value was the maximum possible price. Table 23 shows the three values in 2007 dollar from 2007 to 2030 . Clearly it is not possible to project the substantial swings in fuel price seen in 2008, and confidence in the model rests on the prediction accuracy averaged over the whole bus life. 
cude Oil Price Projections and Final Oil Price Projection Data (2007 - 2030); All data are in 2007 dollars.

\begin{tabular}{|c|c|c|c|c|c|c|c|c|c|c|c|c|}
\hline & & & & & & & & & & & & \\
\hline 3 & 4 & 5 & 6 & 7 & 8 & 9 & 10 & 11 & 12 & & Weighted & \\
\hline EA & EEA & DB & SEER & EVA & EU & Texas & GEM & OPEC & DELPHI & Min & Ave & Max \\
\hline 007 & 2007 & 2007 & 2007 & 2007 & 2007 & 2007 & 2007 & 2007 & 2007 & 2007 & 2007 & 2007 \\
\hline .25 & $\$ 73.25$ & $\$ 73.25$ & $\$ 73.25$ & $\$ 73.25$ & $\$ 73.25$ & $\$ 73.25$ & $\$ 73.25$ & $\$ 73.25$ & $\$ 73.25$ & $\$ 73.25$ & $\$ 73.25$ & $\$ 73.25$ \\
\hline .59 & $\$ 70.03$ & $\$ 65.45$ & $\$ 66.66$ & $\$ 66.14$ & $\$ 73.25$ & $\$ 65.51$ & $\$ 75.89$ & $\$ 62.55$ & $\$ 73.50$ & $\$ 62.55$ & $\$ 69.79$ & $\$ 75.89$ \\
\hline .92 & $\$ 66.80$ & $\$ 57.65$ & $\$ 60.06$ & $\$ 59.03$ & $\$ 74.61$ & $\$ 62.39$ & $\$ 78.53$ & $\$ 56.55$ & $\$ 73.74$ & $\$ 56.55$ & $\$ 66.71$ & $\$ 78.53$ \\
\hline .26 & $\$ 63.58$ & $\$ 49.84$ & $\$ 53.46$ & $\$ 51.93$ & $\$ 76.52$ & $\$ 61.95$ & $\$ 81.17$ & $\$ 52.55$ & $\$ 74.01$ & $\$ 49.84$ & $\$ 63.55$ & $\$ 81.17$ \\
\hline .59 & $\$ 60.36$ & $\$ 42.04$ & $\$ 46.86$ & $\$ 44.82$ & $\$ 78.69$ & $\$ 61.51$ & $\$ 83.81$ & $\$ 50.55$ & $\$ 74.30$ & $\$ 42.04$ & $\$ 60.37$ & $\$ 83.81$ \\
\hline 3.81 & $\$ 58.84$ & $\$ 42.14$ & $\$ 47.09$ & $\$ 44.83$ & $\$ 79.24$ & $\$ 62.16$ & $\$ 83.45$ & $\$ 50.55$ & $\$ 74.65$ & $\$ 42.14$ & $\$ 58.57$ & $\$ 83.45$ \\
\hline 3.02 & $\$ 57.33$ & $\$ 42.23$ & $\$ 47.31$ & $\$ 44.85$ & $\$ 79.78$ & $\$ 62.58$ & $\$ 83.09$ & $\$ 50.55$ & $\$ 74.99$ & $\$ 42.23$ & $\$ 57.04$ & $\$ 83.09$ \\
\hline 2.24 & $\$ 55.82$ & $\$ 42.33$ & $\$ 47.54$ & $\$ 44.86$ & $\$ 80.32$ & $\$ 62.53$ & $\$ 82.73$ & $\$ 50.55$ & $\$ 75.36$ & $\$ 42.33$ & $\$ 55.95$ & $\$ 82.73$ \\
\hline 1.45 & $\$ 54.30$ & $\$ 42.42$ & $\$ 47.76$ & $\$ 44.88$ & $\$ 80.87$ & $\$ 62.34$ & $\$ 82.37$ & $\$ 50.55$ & $\$ 75.74$ & $\$ 42.42$ & $\$ 55.59$ & $\$ 82.37$ \\
\hline 0.67 & $\$ 52.79$ & $\$ 42.52$ & $\$ 47.99$ & $\$ 44.89$ & $\$ 81.41$ & $\$ 62.14$ & $\$ 82.01$ & $\$ 50.55$ & $\$ 76.14$ & $\$ 42.52$ & $\$ 55.54$ & $\$ 82.01$ \\
\hline 1.18 & $\$ 52.28$ & $\$ 42.44$ & $\$ 48.11$ & $\$ 45.61$ & $\$ 82.09$ & $\$ 62.41$ & $\$ 81.65$ & $\$ 50.55$ & $\$ 76.54$ & $\$ 42.44$ & $\$ 55.54$ & $\$ 82.09$ \\
\hline 1.69 & $\$ 51.78$ & $\$ 42.36$ & $\$ 48.24$ & $\$ 46.34$ & $\$ 82.77$ & $\$ 62.92$ & $\$ 81.29$ & $\$ 50.55$ & $\$ 76.97$ & $\$ 42.36$ & $\$ 56.18$ & $\$ 82.77$ \\
\hline 2.19 & $\$ 51.27$ & $\$ 42.27$ & $\$ 48.37$ & $\$ 47.06$ & $\$ 83.72$ & $\$ 63.44$ & $\$ 80.93$ & $\$ 50.55$ & $\$ 77.39$ & $\$ 42.27$ & $\$ 56.52$ & $\$ 83.72$ \\
\hline 2.70 & $\$ 50.77$ & $\$ 42.19$ & $\$ 48.50$ & $\$ 47.78$ & $\$ 84.40$ & $\$ 63.98$ & $\$ 80.57$ & $\$ 50.55$ & & $\$ 42.19$ & $\$ 56.01$ & $\$ 84.40$ \\
\hline 3.21 & $\$ 50.27$ & $\$ 42.11$ & $\$ 48.62$ & $\$ 48.51$ & $\$ 85.49$ & $\$ 64.54$ & $\$ 80.21$ & $\$ 50.55$ & & $\$ 42.11$ & $\$ 56.15$ & $\$ 85.49$ \\
\hline 3.72 & $\$ 49.79$ & $\$ 42.16$ & $\$ 48.70$ & $\$ 49.29$ & $\$ 85.74$ & $\$ 66.76$ & $\$ 81.77$ & $\$ 50.55$ & & $\$ 42.16$ & $\$ 56.74$ & $\$ 85.74$ \\
\hline 4.23 & $\$ 49.31$ & $\$ 42.21$ & $\$ 48.77$ & $\$ 50.07$ & $\$ 86.39$ & $\$ 68.39$ & $\$ 83.33$ & $\$ 50.55$ & & $\$ 42.21$ & $\$ 57.33$ & $\$ 86.39$ \\
\hline .74 & $\$ 48.83$ & $\$ 42.25$ & $\$ 48.85$ & $\$ 50.85$ & $\$ 87.04$ & $\$ 70.45$ & $\$ 84.89$ & $\$ 50.55$ & & $\$ 42.25$ & $\$ 58.35$ & $\$ 87.04$ \\
\hline 25 & $\$ 48.35$ & $\$ 42.30$ & $\$ 48.93$ & $\$ 51.63$ & $\$ 87.70$ & $\$ 71.76$ & $\$ 86.45$ & $\$ 50.55$ & & $\$ 42.30$ & $\$ 58.94$ & $\$ 87.70$ \\
\hline 76 & $\$ 47.87$ & $\$ 42.35$ & $\$ 49.00$ & $\$ 52.42$ & $\$ 88.35$ & $\$ 73.82$ & $\$ 88.01$ & $\$ 50.55$ & & $\$ 42.35$ & $\$ 59.57$ & $\$ 88.35$ \\
\hline 6.26 & & $\$ 42.39$ & $\$ 49.08$ & & $\$ 89.38$ & $\$ 75.35$ & $\$ 89.57$ & $\$ 50.55$ & & $\$ 42.39$ & $\$ 61.38$ & $\$ 89.57$ \\
\hline 6.77 & & $\$ 42.44$ & $\$ 49.16$ & & $\$ 90.42$ & $\$ 76.93$ & $\$ 91.13$ & $\$ 50.55$ & & $\$ 42.44$ & $\$ 61.91$ & $\$ 91.13$ \\
\hline 7.28 & & $\$ 42.48$ & $\$ 49.24$ & & $\$ 91.45$ & $\$ 78.40$ & $\$ 92.69$ & $\$ 50.55$ & & $\$ 42.48$ & $\$ 62.43$ & $\$ 92.69$ \\
\hline 7.79 & & $\$ 42.53$ & $\$ 49.32$ & & $\$ 92.48$ & $\$ 79.81$ & $\$ 94.25$ & $\$ 50.55$ & & $\$ 42.53$ & $\$ 62.94$ & $\$ 94.25$ \\
\hline 8.30 & & $\$ 42.57$ & $\$ 49.40$ & & $\$ 93.65$ & $\$ 81.56$ & $\$ 95.81$ & $\$ 50.55$ & & $\$ 42.57$ & $\$ 63.49$ & $\$ 95.81$ \\
\hline
\end{tabular}


Diesel and gasoline prices were obtained by applying a diesel-to-oil price factor and a gasoline-to-oil price factor to the crude oil price (low, default, and high). The two factors were again adopted from the 2007 AEO, which projected transportation diesel and gasoline price as well as the price of crude oil. As Table 24 shows, the two yearly factors were the ratio of yearby-year diesel and gasoline price (\$/gallon) to crude oil price $(\$ /$ barrel). The factors were about $4 \%$ and decreased in the future (i.e. the fuel production cost was projected to reduce.). Using these factors, final diesel and gasoline prices (low, default, and high) were calculated from the oil price (low, default, and high) and are shown in the Table 25 and Figure 19.

Table 24: Untaxed Diesel and Gasoline Price Factors to Crude Oil Price. These factors convert dollar per barrel values for crude oil to dollar per gallon values for refined product.

\begin{tabular}{|l|c|c|}
\hline & Diesel-Oil Price Factor & Gasoline-Oil Price Factor \\
\hline $\mathbf{2 0 0 7}$ & $4.05 \%$ & $3.86 \%$ \\
\hline $\mathbf{2 0 0 8}$ & $3.90 \%$ & $3.77 \%$ \\
\hline $\mathbf{2 0 0 9}$ & $3.90 \%$ & $3.73 \%$ \\
\hline $\mathbf{2 0 1 0}$ & $4.01 \%$ & $3.78 \%$ \\
\hline $\mathbf{2 0 1 1}$ & $4.04 \%$ & $3.85 \%$ \\
\hline $\mathbf{2 0 1 2}$ & $4.08 \%$ & $3.96 \%$ \\
\hline $\mathbf{2 0 1 3}$ & $4.17 \%$ & $4.02 \%$ \\
\hline $\mathbf{2 0 1 4}$ & $4.09 \%$ & $3.93 \%$ \\
\hline $\mathbf{2 0 1 5}$ & $4.08 \%$ & $3.91 \%$ \\
\hline $\mathbf{2 0 1 6}$ & $4.17 \%$ & $3.93 \%$ \\
\hline $\mathbf{2 0 1 7}$ & $4.07 \%$ & $3.88 \%$ \\
\hline $\mathbf{2 0 1 8}$ & $4.05 \%$ & $3.86 \%$ \\
\hline $\mathbf{2 0 1 9}$ & $4.08 \%$ & $3.89 \%$ \\
\hline $\mathbf{2 0 2 0}$ & $4.06 \%$ & $3.88 \%$ \\
\hline $\mathbf{2 0 2 1}$ & $4.02 \%$ & $3.86 \%$ \\
\hline $\mathbf{2 0 2 2}$ & $4.05 \%$ & $3.87 \%$ \\
\hline $\mathbf{2 0 2 3}$ & $3.86 \%$ & $3.74 \%$ \\
\hline $\mathbf{2 0 2 4}$ & $3.85 \%$ & $3.73 \%$ \\
\hline $\mathbf{2 0 2 5}$ & $3.87 \%$ & $3.73 \%$ \\
\hline $\mathbf{2 0 2 6}$ & $3.80 \%$ & $3.64 \%$ \\
\hline $\mathbf{2 0 2 7}$ & $3.81 \%$ & $3.64 \%$ \\
\hline $\mathbf{2 0 2 8}$ & $3.85 \%$ & $3.66 \%$ \\
\hline $\mathbf{2 0 2 9}$ & $3.80 \%$ & $3.63 \%$ \\
\hline $\mathbf{2 0 3 0}$ & $3.82 \%$ & $3.64 \%$ \\
\hline & & \\
\hline
\end{tabular}


Table 25: Untaxed Diesel and Gasoline Price Forecast from 2007 to 2030 in 2007 Dollars

\begin{tabular}{|l|c|c|c|c|c|c|}
\hline \multicolumn{3}{|c|}{ Diesel Price } & \multicolumn{3}{c|}{ Gasoline Price } \\
\hline & Low & Default & High & Low & Default & High \\
\hline $\mathbf{2 0 0 7}$ & $\$ 2.54$ & $\$ 2.83$ & $\$ 3.08$ & $\$ 2.41$ & $\$ 2.69$ & $\$ 2.93$ \\
\hline $\mathbf{2 0 0 8}$ & $\$ 2.20$ & $\$ 2.60$ & $\$ 3.06$ & $\$ 2.13$ & $\$ 2.51$ & $\$ 2.96$ \\
\hline $\mathbf{2 0 0 9}$ & $\$ 1.94$ & $\$ 2.48$ & $\$ 3.16$ & $\$ 1.86$ & $\$ 2.37$ & $\$ 3.03$ \\
\hline $\mathbf{2 0 1 0}$ & $\$ 1.69$ & $\$ 2.42$ & $\$ 3.36$ & $\$ 1.59$ & $\$ 2.28$ & $\$ 3.17$ \\
\hline $\mathbf{2 0 1 1}$ & $\$ 1.70$ & $\$ 2.36$ & $\$ 3.37$ & $\$ 1.62$ & $\$ 2.26$ & $\$ 3.21$ \\
\hline $\mathbf{2 0 1 2}$ & $\$ 1.72$ & $\$ 2.33$ & $\$ 3.39$ & $\$ 1.67$ & $\$ 2.26$ & $\$ 3.29$ \\
\hline $\mathbf{2 0 1 3}$ & $\$ 1.77$ & $\$ 2.33$ & $\$ 3.45$ & $\$ 1.70$ & $\$ 2.25$ & $\$ 3.33$ \\
\hline $\mathbf{2 0 1 4}$ & $\$ 1.74$ & $\$ 2.27$ & $\$ 3.37$ & $\$ 1.67$ & $\$ 2.19$ & $\$ 3.24$ \\
\hline $\mathbf{2 0 1 5}$ & $\$ 1.74$ & $\$ 2.27$ & $\$ 3.35$ & $\$ 1.66$ & $\$ 2.17$ & $\$ 3.21$ \\
\hline $\mathbf{2 0 1 6}$ & $\$ 1.77$ & $\$ 2.31$ & $\$ 3.42$ & $\$ 1.67$ & $\$ 2.18$ & $\$ 3.23$ \\
\hline $\mathbf{2 0 1 7}$ & $\$ 1.72$ & $\$ 2.28$ & $\$ 3.37$ & $\$ 1.64$ & $\$ 2.18$ & $\$ 3.21$ \\
\hline $\mathbf{2 0 1 8}$ & $\$ 1.71$ & $\$ 2.29$ & $\$ 3.39$ & $\$ 1.63$ & $\$ 2.18$ & $\$ 3.23$ \\
\hline $\mathbf{2 0 1 9}$ & $\$ 1.72$ & $\$ 2.29$ & $\$ 3.45$ & $\$ 1.64$ & $\$ 2.18$ & $\$ 3.29$ \\
\hline $\mathbf{2 0 2 0}$ & $\$ 1.71$ & $\$ 2.28$ & $\$ 3.47$ & $\$ 1.63$ & $\$ 2.18$ & $\$ 3.32$ \\
\hline $\mathbf{2 0 2 1}$ & $\$ 1.70$ & $\$ 2.28$ & $\$ 3.45$ & $\$ 1.63$ & $\$ 2.19$ & $\$ 3.31$ \\
\hline $\mathbf{2 0 2 2}$ & $\$ 1.71$ & $\$ 2.32$ & $\$ 3.49$ & $\$ 1.63$ & $\$ 2.22$ & $\$ 3.35$ \\
\hline $\mathbf{2 0 2 3}$ & $\$ 1.63$ & $\$ 2.25$ & $\$ 3.36$ & $\$ 1.58$ & $\$ 2.18$ & $\$ 3.26$ \\
\hline $\mathbf{2 0 2 4}$ & $\$ 1.63$ & $\$ 2.27$ & $\$ 3.38$ & $\$ 1.58$ & $\$ 2.20$ & $\$ 3.27$ \\
\hline $\mathbf{2 0 2 5}$ & $\$ 1.64$ & $\$ 2.30$ & $\$ 3.42$ & $\$ 1.58$ & $\$ 2.22$ & $\$ 3.29$ \\
\hline $\mathbf{2 0 2 6}$ & $\$ 1.61$ & $\$ 2.33$ & $\$ 3.40$ & $\$ 1.54$ & $\$ 2.24$ & $\$ 3.26$ \\
\hline $\mathbf{2 0 2 7}$ & $\$ 1.62$ & $\$ 2.36$ & $\$ 3.47$ & $\$ 1.54$ & $\$ 2.25$ & $\$ 3.32$ \\
\hline $\mathbf{2 0 2 8}$ & $\$ 1.64$ & $\$ 2.40$ & $\$ 3.57$ & $\$ 1.55$ & $\$ 2.28$ & $\$ 3.39$ \\
\hline $\mathbf{2 0 2 9}$ & $\$ 1.62$ & $\$ 2.39$ & $\$ 3.58$ & $\$ 1.54$ & $\$ 2.28$ & $\$ 3.42$ \\
\hline $\mathbf{2 0 3 0}$ & $\$ 1.63$ & $\$ 2.42$ & $\$ 3.66$ & $\$ 1.55$ & $\$ 2.31$ & $\$ 3.49$ \\
\hline
\end{tabular}




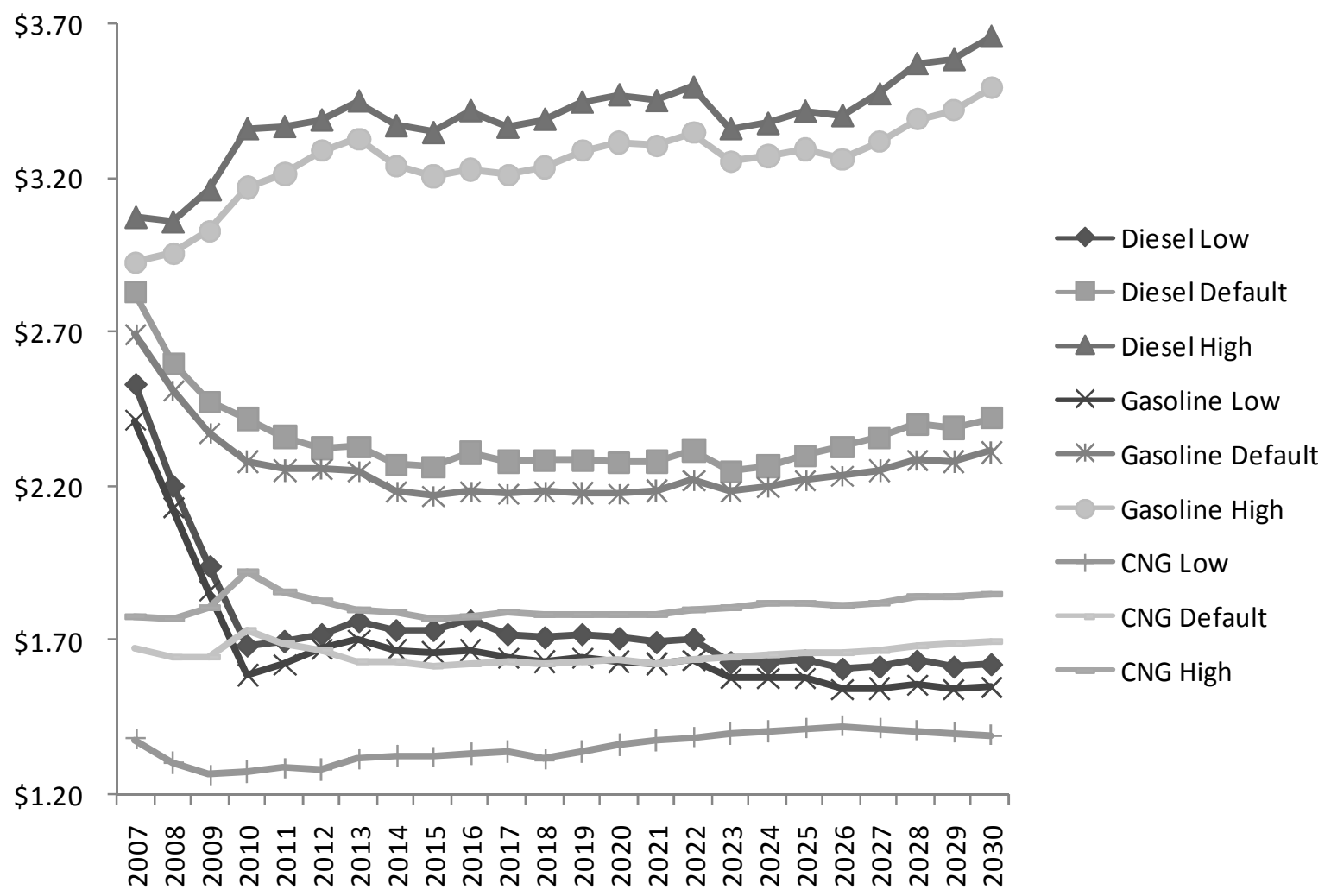

Figure 19: Future Fuel Price Projection

\section{Compressed Natural Gas Price}

Table 26 presents original CNG prices in 13 studies that predicted the future price of different types of CNG, covering natural gas transportation price, commercial end user price, lower 48 wellhead price, and Henry hub price. These data were standardized to natural gas price for transportation use and appropriate year by following adjustments. The exploitation of unconventional natural gas sources might have an disruptive impact to natural gas for their potential lower prices. However, the impact were not researched and included in this study.

- For discrete values, linear interpolation created the intermediate values.

- Lawrence Berkeley National Laboratory (LBNL) and New York Mercantile Exchange, Inc. (NYMEX) presented their CNG prices in terms of a nominal price. According to their description, the nominal prices were converted back to year 2000 dollars by using the 
EIA gross domestic product (GDP) chain type price index. The methodology was applied to BPA data as well.

- All prices were adjusted into 2007 dollars using the domestic consumer price index (CPI) (Table 22) provided by the Department of Labor at the time of research.

- All price units were converted to dollar per Diesel Equivalent Gallon (\$/DEG). The conversion was based on energy equivalent content. A typical No.2 diesel fuel has 129,800 BTU per gallon. One thousand cubic feet CNG has 1,028,000 BTU of energy. Hence one mcf (one thousand cubic feet) of CNG is equal to 7.92 DEG, and one MMBTU (million British thermal unit) equals 7.70 DEG.

- The 2006 average natural gas price (the price for transportation purpose) reported in the 2007 AEO report was selected as the baseline price. The other 12 prices were adjusted up or down to the same start price.

Table 27 shows the adjusted CNG prices from different studies. Similar to the crude oil price, natural gas default price used the weighted average (50\% to IEA price and $50 \%$ to the rest). The yearly minimum and maximum prices were for the low and high CNG price at the certain year. Figure 19 presents the CNG projection prices from year 2007 to year 2030. 
Table 26: CNG Original Price Projections from Original Studies

\begin{tabular}{|c|c|c|c|c|c|c|c|c|c|c|c|c|c|}
\hline & 1 & 2 & 3 & 4 & 5 & 6 & 7 & 8 & 9 & 10 & 11 & 12 & 13 \\
\hline Year & EIA 2007 & GII & EVA & EEA & DB & SEER & Altos & EEA & Texas & NYMEX & BPA & LBNL & LBNL \\
\hline & Transportation & $\begin{array}{l}\text { Commercial } \\
\text { End-User } \\
\text { Prices }\end{array}$ & $\begin{array}{c}\text { Lower } 48 \\
\text { wellhead } \\
\text { price }\end{array}$ & $\begin{array}{l}\text { Commercial } \\
\text { End-User } \\
\text { Prices }\end{array}$ & $\begin{array}{c}\text { Lower } \\
48 \\
\text { wellhea } \\
\text { d price }\end{array}$ & $\begin{array}{l}\text { Commercial } \\
\text { End-User } \\
\text { Prices }\end{array}$ & $\begin{array}{c}\text { Lower } 48 \\
\text { wellhead } \\
\text { price }\end{array}$ & $\begin{array}{l}\text { Henry } \\
\text { Hub Price }\end{array}$ & NA & $\begin{array}{l}\text { Henry Hub } \\
\text { Price }\end{array}$ & $\begin{array}{l}\text { Henry } \\
\text { Hub Price }\end{array}$ & $\begin{array}{l}\text { Henry } \\
\text { Hub Price }\end{array}$ & $\begin{array}{l}\text { Henry } \\
\text { Hub Price }\end{array}$ \\
\hline \$ year & 2005 & 2005 & 2005 & 2005 & 2005 & 2005 & 2005 & 2002 & 2005 & Nominal & Nominal & Nominal & Nominal \\
\hline & $\$ / \mathrm{mcf}$ & $\$ / m c f$ & $\$ / m c f$ & $\$ / m c f$ & $\$ / m c f$ & $\$ / m c f$ & $\$ / m c f$ & \$/MMbtu & $\$ / m c f$ & \$/MMbtu & \$/MMbtu & \$/MMbtu & \$/MMbtu \\
\hline 2002 & & & & & & & & $\$ 3.36$ & & & & & \\
\hline 2003 & & & & & & & & $\$ 5.29$ & & & & & \\
\hline 2004 & $\$ 12.28$ & & & & & & & $\$ 4.51$ & & & & & \\
\hline 2005 & $\$ 15.20$ & $\$ 11.54$ & $\$ 7.51$ & $\$ 11.54$ & $\$ 7.51$ & $\$ 11.54$ & $\$ 7.51$ & $\$ 5.57$ & & & & & \\
\hline 2006 & $\$ 12.34$ & & & & & & & $\$ 3.90$ & $\$ 7.92$ & & $\$ 6.66$ & & \\
\hline 2007 & $\$ 12.65$ & & & & & & & $\$ 4.18$ & $\$ 5.91$ & $\$ 8.40$ & $\$ 7.06$ & $\$ 8.40$ & $\$ 8.40$ \\
\hline 2008 & $\$ 12.50$ & & & & & & & $\$ 3.45$ & $\$ 5.33$ & $\$ 8.48$ & $\$ 6.76$ & $\$ 8.48$ & $\$ 8.48$ \\
\hline 2009 & $\$ 12.69$ & & & & & & & $\$ 4.93$ & $\$ 5.06$ & $\$ 8.10$ & $\$ 5.65$ & $\$ 8.10$ & $\$ 8.10$ \\
\hline 2010 & $\$ 14.38$ & & & & & & & $\$ 4.22$ & $\$ 5.14$ & $\$ 7.65$ & $\$ 5.24$ & $\$ 7.65$ & $\$ 7.65$ \\
\hline 2011 & $\$ 13.91$ & & & & & & & $\$ 5.10$ & $\$ 5.21$ & $\$ 7.20$ & $\$ 5.20$ & $\$ 7.20$ & $\$ 7.20$ \\
\hline 2012 & $\$ 13.69$ & & & & & & & $\$ 4.88$ & $\$ 5.19$ & & $\$ 5.51$ & $\$ 6.90$ & $\$ 7.10$ \\
\hline 2013 & $\$ 13.44$ & & & & & & & $\$ 3.30$ & $\$ 5.43$ & & $\$ 5.77$ & $\$ 6.65$ & $\$ 7.00$ \\
\hline 2014 & $\$ 13.33$ & & & & & & & $\$ 4.87$ & $\$ 5.49$ & & $\$ 6.09$ & $\$ 6.55$ & $\$ 7.22$ \\
\hline 2015 & $\$ 13.25$ & $\$ 10.05$ & $\$ 5.55$ & $\$ 9.98$ & $\$ 6.07$ & $\$ 8.83$ & $\$ 5.60$ & $\$ 4.43$ & $\$ 5.50$ & & $\$ 6.56$ & $\$ 6.61$ & $\$ 7.28$ \\
\hline 2016 & $\$ 13.28$ & & & & & & & $\$ 4.24$ & $\$ 5.56$ & & $\$ 6.72$ & $\$ 6.82$ & $\$ 7.49$ \\
\hline 2017 & $\$ 13.42$ & & & & & & & $\$ 4.20$ & $\$ 5.64$ & & & $\$ 7.25$ & $\$ 7.92$ \\
\hline 2018 & $\$ 13.34$ & & & & & & & $\$ 4.33$ & $\$ 5.42$ & & & $\$ 7.25$ & $\$ 7.92$ \\
\hline 2019 & $\$ 13.33$ & & & & & & & $\$ 4.40$ & $\$ 5.62$ & & & $\$ 7.30$ & $\$ 7.97$ \\
\hline 2020 & $\$ 13.36$ & & & & & & & $\$ 4.64$ & $\$ 5.76$ & & & $\$ 7.52$ & $\$ 8.19$ \\
\hline 2021 & $\$ 13.34$ & & & & & & & & $\$ 5.94$ & & & $\$ 7.61$ & $\$ 8.28$ \\
\hline 2022 & $\$ 13.47$ & & & & & & & & $\$ 6.12$ & & & $\$ 8.00$ & $\$ 8.67$ \\
\hline 2023 & $\$ 13.50$ & & & & & & & & $\$ 6.31$ & & & $\$ 8.40$ & $\$ 9.07$ \\
\hline 2024 & $\$ 13.59$ & & & & & & & & $\$ 6.51$ & & & $\$ 8.70$ & $\$ 9.37$ \\
\hline 2025 & $\$ 13.62$ & $\$ 10.02$ & $\$ 6.06$ & $\$ 10.08$ & $\$ 5.71$ & $\$ 9.51$ & $\$ 6.96$ & & $\$ 6.71$ & & & $\$ 8.80$ & $\$ 9.47$ \\
\hline 2026 & $\$ 13.57$ & & & & & & & & $\$ 6.91$ & & & $\$ 9.15$ & $\$ 9.82$ \\
\hline 2027 & $\$ 13.64$ & & & & & & & & $\$ 7.13$ & & & $\$ 9.50$ & $\$ 10.17$ \\
\hline 2028 & $\$ 13.76$ & & & & & & & & $\$ 7.35$ & & & $\$ 9.95$ & $\$ 10.62$ \\
\hline 2029 & $\$ 13.80$ & & & & & & & & $\$ 7.58$ & & & $\$ 10.25$ & $\$ 10.92$ \\
\hline 2030 & $\$ 13.86$ & $\$ 9.81$ & & & $\$ 5.45$ & $\$ 9.96$ & $\$ 7.55$ & & $\$ 7.81$ & & & $\$ 10.50$ & $\$ 11.17$ \\
\hline
\end{tabular}

1-7. EIA = Energy Information Administration; GII = Global Insight, Inc.; EVA = Energy Ventures Analysis, Inc.; EEA = Energy and Environmental Analysis, Inc.; DB = Deutsche Bank AG; SEER = Strategic Energy and Economic Research, Inc.; Altos = Altos Management Partners Inc. [112]; 8. EEA = Energy and Environmental Analysis [118]; 9. Texas = Texas Comptroller's Revenue Estimating Division [114]; 10. NYMEX = New York Mercantile Exchange Inc. [119]; 11. BPA = Bonneville Power Administration [120]; 12-13. LBNL = Lawrence Berkeley National Laboratory [119] 
Table 27: Adjusted CNG Price Projections and Final CNG Price Projection Data (2007 - 2030) (Data in 2007 Dollars)

\begin{tabular}{|c|c|c|c|c|c|c|c|c|c|c|c|c|c|c|c|c|}
\hline Year & $\begin{array}{c}\text { EIA } \\
2007\end{array}$ & GII & EVA & EEA & DB & SEER & Altos & EEA & Texas & NYMEX & BPA & LBNL & LBNL & Min & $\begin{array}{c}\text { Weight } \\
\text { Average }\end{array}$ & Max \\
\hline 2007 & $\$ 1.69$ & $\$ 1.63$ & $\$ 1.63$ & $\$ 1.63$ & $\$ 1.63$ & $\$ 1.62$ & $\$ 1.63$ & $\$ 1.69$ & $\$ 1.38$ & $\$ 1.78$ & $\$ 1.68$ & $\$ 1.78$ & $\$ 1.78$ & $\$ 1.38$ & $\$ 1.67$ & $\$ 1.78$ \\
\hline 2008 & $\$ 1.67$ & $\$ 1.61$ & $\$ 1.60$ & $\$ 1.61$ & $\$ 1.61$ & $\$ 1.58$ & $\$ 1.60$ & $\$ 1.58$ & $\$ 1.31$ & $\$ 1.77$ & $\$ 1.63$ & $\$ 1.77$ & $\$ 1.77$ & $\$ 1.31$ & $\$ 1.65$ & $\$ 1.77$ \\
\hline 2009 & $\$ 1.70$ & $\$ 1.59$ & $\$ 1.57$ & $\$ 1.59$ & $\$ 1.59$ & $\$ 1.54$ & $\$ 1.58$ & $\$ 1.81$ & $\$ 1.27$ & $\$ 1.70$ & $\$ 1.47$ & $\$ 1.70$ & $\$ 1.70$ & $\$ 1.27$ & $\$ 1.65$ & $\$ 1.81$ \\
\hline 2010 & $\$ 1.93$ & $\$ 1.57$ & $\$ 1.55$ & $\$ 1.57$ & $\$ 1.57$ & $\$ 1.51$ & $\$ 1.55$ & $\$ 1.70$ & $\$ 1.28$ & $\$ 1.63$ & $\$ 1.41$ & $\$ 1.63$ & $\$ 1.63$ & $\$ 1.28$ & $\$ 1.74$ & $\$ 1.93$ \\
\hline 2011 & $\$ 1.86$ & $\$ 1.55$ & $\$ 1.52$ & $\$ 1.55$ & $\$ 1.56$ & $\$ 1.47$ & $\$ 1.52$ & $\$ 1.83$ & $\$ 1.29$ & $\$ 1.56$ & $\$ 1.39$ & $\$ 1.56$ & $\$ 1.56$ & $\$ 1.29$ & $\$ 1.70$ & $\$ 1.86$ \\
\hline 2012 & $\$ 1.83$ & $\$ 1.53$ & $\$ 1.49$ & $\$ 1.53$ & $\$ 1.54$ & $\$ 1.43$ & $\$ 1.50$ & $\$ 1.80$ & $\$ 1.29$ & & $\$ 1.42$ & $\$ 1.51$ & $\$ 1.53$ & $\$ 1.29$ & $\$ 1.67$ & $\$ 1.83$ \\
\hline 2013 & $\$ 1.80$ & $\$ 1.51$ & \$1.47 & $\$ 1.51$ & $\$ 1.52$ & $\$ 1.40$ & $\$ 1.47$ & $\$ 1.56$ & $\$ 1.32$ & & \$1.44 & $\$ 1.46$ & $\$ 1.50$ & $\$ 1.32$ & $\$ 1.63$ & $\$ 1.80$ \\
\hline 2014 & $\$ 1.78$ & $\$ 1.49$ & $\$ 1.44$ & $\$ 1.48$ & $\$ 1.50$ & $\$ 1.36$ & $\$ 1.45$ & $\$ 1.80$ & $\$ 1.33$ & & $\$ 1.47$ & $\$ 1.44$ & $\$ 1.52$ & $\$ 1.33$ & $\$ 1.63$ & $\$ 1.80$ \\
\hline 2015 & $\$ 1.77$ & $\$ 1.47$ & $\$ 1.42$ & $\$ 1.46$ & $\$ 1.48$ & $\$ 1.33$ & $\$ 1.42$ & $\$ 1.73$ & $\$ 1.33$ & & $\$ 1.51$ & $\$ 1.43$ & $\$ 1.51$ & $\$ 1.33$ & $\$ 1.62$ & $\$ 1.77$ \\
\hline 2016 & $\$ 1.78$ & $\$ 1.47$ & $\$ 1.42$ & $\$ 1.47$ & $\$ 1.47$ & $\$ 1.33$ & $\$ 1.44$ & $\$ 1.70$ & $\$ 1.34$ & & $\$ 1.51$ & $\$ 1.44$ & $\$ 1.52$ & $\$ 1.33$ & $\$ 1.62$ & $\$ 1.78$ \\
\hline 2017 & $\$ 1.80$ & $\$ 1.47$ & $\$ 1.43$ & $\$ 1.47$ & $\$ 1.47$ & $\$ 1.34$ & $\$ 1.46$ & $\$ 1.70$ & $\$ 1.35$ & & & $\$ 1.48$ & $\$ 1.55$ & $\$ 1.34$ & $\$ 1.63$ & $\$ 1.80$ \\
\hline 2018 & $\$ 1.79$ & $\$ 1.47$ & $\$ 1.44$ & $\$ 1.47$ & $\$ 1.46$ & $\$ 1.35$ & $\$ 1.48$ & $\$ 1.72$ & $\$ 1.32$ & & & $\$ 1.46$ & $\$ 1.54$ & $\$ 1.32$ & $\$ 1.63$ & $\$ 1.79$ \\
\hline 2019 & $\$ 1.78$ & $\$ 1.47$ & $\$ 1.44$ & $\$ 1.47$ & $\$ 1.46$ & $\$ 1.36$ & $\$ 1.49$ & $\$ 1.73$ & $\$ 1.34$ & & & $\$ 1.45$ & $\$ 1.52$ & $\$ 1.34$ & $\$ 1.63$ & $\$ 1.78$ \\
\hline 2020 & $\$ 1.79$ & $\$ 1.47$ & $\$ 1.45$ & $\$ 1.47$ & $\$ 1.45$ & $\$ 1.37$ & $\$ 1.51$ & $\$ 1.76$ & $\$ 1.36$ & & & $\$ 1.46$ & $\$ 1.53$ & $\$ 1.36$ & $\$ 1.64$ & $\$ 1.79$ \\
\hline 2021 & $\$ 1.79$ & $\$ 1.47$ & $\$ 1.46$ & $\$ 1.47$ & $\$ 1.45$ & $\$ 1.38$ & $\$ 1.53$ & & $\$ 1.39$ & & & $\$ 1.46$ & $\$ 1.53$ & $\$ 1.38$ & $\$ 1.62$ & $\$ 1.79$ \\
\hline 2022 & $\$ 1.80$ & $\$ 1.47$ & $\$ 1.46$ & $\$ 1.47$ & $\$ 1.44$ & $\$ 1.39$ & $\$ 1.55$ & & $\$ 1.41$ & & & $\$ 1.48$ & $\$ 1.55$ & $\$ 1.39$ & $\$ 1.64$ & $\$ 1.80$ \\
\hline 2023 & $\$ 1.81$ & $\$ 1.47$ & $\$ 1.47$ & $\$ 1.47$ & $\$ 1.44$ & $\$ 1.40$ & $\$ 1.57$ & & $\$ 1.44$ & & & $\$ 1.51$ & $\$ 1.57$ & $\$ 1.40$ & $\$ 1.64$ & $\$ 1.81$ \\
\hline 2024 & $\$ 1.82$ & $\$ 1.47$ & $\$ 1.48$ & $\$ 1.48$ & $\$ 1.43$ & $\$ 1.41$ & $\$ 1.59$ & & $\$ 1.46$ & & & $\$ 1.52$ & $\$ 1.58$ & $\$ 1.41$ & $\$ 1.65$ & $\$ 1.82$ \\
\hline 2025 & $\$ 1.82$ & $\$ 1.47$ & $\$ 1.48$ & $\$ 1.48$ & $\$ 1.43$ & $\$ 1.42$ & $\$ 1.60$ & & $\$ 1.49$ & & & $\$ 1.51$ & $\$ 1.57$ & $\$ 1.42$ & $\$ 1.66$ & $\$ 1.82$ \\
\hline 2026 & $\$ 1.82$ & $\$ 1.46$ & & & $\$ 1.42$ & $\$ 1.43$ & $\$ 1.62$ & & $\$ 1.52$ & & & $\$ 1.53$ & $\$ 1.59$ & $\$ 1.42$ & $\$ 1.66$ & $\$ 1.82$ \\
\hline 2027 & $\$ 1.83$ & $\$ 1.46$ & & & $\$ 1.42$ & $\$ 1.44$ & $\$ 1.64$ & & $\$ 1.55$ & & & $\$ 1.54$ & $\$ 1.60$ & $\$ 1.42$ & \$1.67 & $\$ 1.83$ \\
\hline 2028 & $\$ 1.84$ & $\$ 1.45$ & & & $\$ 1.41$ & $\$ 1.45$ & $\$ 1.65$ & & $\$ 1.58$ & & & $\$ 1.57$ & $\$ 1.63$ & $\$ 1.41$ & $\$ 1.69$ & $\$ 1.84$ \\
\hline 2029 & $\$ 1.85$ & $\$ 1.45$ & & & $\$ 1.40$ & $\$ 1.46$ & $\$ 1.67$ & & $\$ 1.61$ & & & $\$ 1.58$ & $\$ 1.63$ & $\$ 1.40$ & $\$ 1.69$ & $\$ 1.85$ \\
\hline 2030 & $\$ 1.85$ & $\$ 1.44$ & & & $\$ 1.40$ & $\$ 1.48$ & $\$ 1.68$ & & $\$ 1.64$ & & & $\$ 1.58$ & $\$ 1.64$ & $\$ 1.40$ & $\$ 1.70$ & $\$ 1.85$ \\
\hline
\end{tabular}


Fuel Tax, Subsidies and Incentives. The model provided tools for the user to compensate for fuel tax and incentives. Since situations could vary widely for different agencies, the default values were presented as an average value for federal and states taxes (Table 28). The default local tax was set to zero in the model. The average value was chosen to allow a national LCC assessment by a user, if no specific value were entered. The author did apprehend that some transit operations may benefit from reduced taxes, but this will require user entry.

Table 28: Average Federal and State Fuel Tax

\begin{tabular}{|c|c|c|c|}
\hline & Federal Tax & State Tax & Unit \\
\hline Diesel & 0.244 & 0.240 & $\$ /$ DGE \\
\hline Gasoline & 0.184 & 0.175 & $\$ / G G E$ \\
\hline CNG & 0.183 & 0.126 & $\$ / G G E$ \\
\hline
\end{tabular}

Incentives were another issue for fuel pricing. Currently, CNG has fuel tax credit from Federal Highway Bill. This was equivalent to $\$ 50$ cents/GGE at time of writing and is planned to last until December 31, 2011. Thus, the time span of the credit was included in the model in addition to the amount of credit. The fuel incentive in LCC was left as zero as default.

In FMT, hydrogen and electricity costs were assumed to remain the current value in next 20 years. The cost of diesel, gasoline, and CNG fuels were adopted from C-15 model. Biodiesel cost $2.2 \%$ higher than regular diesel did.

Table 29: Fuel Price Projection Used in FMT

\begin{tabular}{|c|c|c|c|c|c|c|}
\hline & Diesel & Gasoline & Biodiesel & CNG & Electricity & H2 \\
\hline & $\$ / g a l$ & $\$ / g a l$ & $\$ / g a l$ & $\$ / D G E$ & $\$ / k W h r$ & $\$ / \mathrm{kg}$ \\
\hline 2007 & 2.83 & 2.69 & 2.89 & 1.67 & 0.10 & 8.00 \\
\hline 2008 & 2.60 & 2.51 & 2.66 & 1.65 & 0.10 & 8.00 \\
\hline 2009 & 2.48 & 2.37 & 2.53 & 1.65 & 0.10 & 8.00 \\
\hline 2010 & 2.42 & 2.28 & 2.47 & 1.74 & 0.10 & 8.00 \\
\hline 2011 & 2.36 & 2.26 & 2.42 & 1.70 & 0.10 & 8.00 \\
\hline 2012 & 2.33 & 2.26 & 2.38 & 1.67 & 0.10 & 8.00 \\
\hline 2013 & 2.33 & 2.25 & 2.38 & 1.63 & 0.10 & 8.00 \\
\hline 2014 & 2.27 & 2.19 & 2.32 & 1.63 & 0.10 & 8.00 \\
\hline 2015 & 2.27 & 2.17 & 2.32 & 1.62 & 0.10 & 8.00 \\
\hline 2016 & 2.31 & 2.18 & 2.36 & 1.62 & 0.10 & 8.00 \\
\hline 2017 & 2.28 & 2.18 & 2.33 & 1.63 & 0.10 & 8.00 \\
\hline 2018 & 2.29 & 2.18 & 2.34 & 1.63 & 0.10 & 8.00 \\
\hline 2019 & 2.29 & 2.18 & 2.34 & 1.63 & 0.10 & 8.00 \\
\hline 2020 & 2.28 & 2.18 & 2.33 & 1.64 & 0.10 & 8.00 \\
\hline 2021 & 2.28 & 2.19 & 2.33 & 1.62 & 0.10 & 8.00 \\
\hline
\end{tabular}




\begin{tabular}{|l|l|l|l|l|l|l|}
\cline { 3 - 3 } 2022 & 2.32 & 2.22 & 2.37 & 1.64 & 0.10 & 8.00 \\
\hline 2023 & 2.25 & 2.18 & 2.30 & 1.64 & 0.10 & 8.00 \\
\hline 2024 & 2.27 & 2.20 & 2.32 & 1.65 & 0.10 & 8.00 \\
\hline 2025 & 2.30 & 2.22 & 2.36 & 1.66 & 0.10 & 8.00 \\
\hline 2026 & 2.33 & 2.24 & 2.38 & 1.66 & 0.10 & 8.00 \\
\hline 2027 & 2.36 & 2.25 & 2.41 & 1.67 & 0.10 & 8.00 \\
\hline 2028 & 2.40 & 2.28 & 2.46 & 1.69 & 0.10 & 8.00 \\
\hline 2029 & 2.39 & 2.28 & 2.45 & 1.69 & 0.10 & 8.00 \\
\hline 2030 & 2.42 & 2.31 & 2.48 & 1.70 & 0.10 & 8.00 \\
\hline
\end{tabular}

\section{Fuel Economy Model}

The author led the development of the FE model with the project C-15 research team. Chassis FE data were gathered from U.S. Department of Energy [121] and U.S. Department of Transportation funded chassis dynamometer testing of buses on various cycles over a wide range of average cycle speeds. It was evident that in-use FE data showed a lower FE (lower mile per gallon (mpg)) than the chassis data. This higher fuel consumption can be attributed in part to additional bus idling that is not reflected in the average speed of the bus route. In other words, for the chassis data, the average bus speed was for the cycle (mimicking a route) alone, but for the field data the average bus speed included both revenue and non-revenue service, and the fuel consumed reflected fuel use during idling or low speed operation at the depot, as well as the fuel used on the route and during deadheading without passengers. Other causes contributing to the difference between fuel consumption in the field and on the chassis dynamometer included the possible use of air conditioning, heating (if the bus was equipped with auxiliary burners), cold starting, and fan loads that did not correspond to the chassis dynamometer fan loads. Also, chassis dynamometer data do not take into account the adverse effects of terrain that was not zero gradient. Of course, bus technology would also cause the fuel consumed to vary. For example, chassis data collected from the Cummins ISM powered New Flyer buses at WMATA may not be representative of all the diesel buses in the field study. New bus technologies such SCR and waste heat recovery can improve FE without sacrificing emissions.

The in-use FE data from four test sites (see site information and technologies in section 1.3) were for 40 -foot long buses except for the KC Metro buses. If the KC Metro data were to be of use in estimating 40-foot bus fuel economy, they would need to be adjusted for the difference 
in bus size. The bus size correction adopted the conclusion from Clark et al. [122] that the weight difference between 60-foot KC Metro bus and 40-foot bus could be used for the adjustment. The fuel consumption (gallon per mile units) percent difference was close to the half of weight percent difference, calculated by assuming that both bus sizes were under half passenger load. Half load meant that the bus weight includes the vehicle curb weight plus one driver and half of the seated capacity. Average human weight was assumed to be $150 \mathrm{lb}$. Table 30 shows the calculation formula and results (60-foot to 40 -foot FE conversion factors) for KC Metro buses (60-foot diesel and diesel hybrid buses). In FMT, 30-foot bus was corrected to 10\% better than 40 -foot buses in fuel economy.

Table 30: KC Metro FE Conversion Factor for 40 and 60-Foot Buses

\begin{tabular}{|c|c|c|c|c|}
\hline & 40-foot Diesel & 60-foot Diesel & 40-foot Hybrid & 60-foot Hybrid \\
\hline Curb Weight & $28,500 \mathrm{lb}$ & $41,500 \mathrm{lb}$ & $29,900 \mathrm{lb}$ & $43,700 \mathrm{lb}$ \\
\hline $\begin{array}{l}\text { Number of } \\
\text { Seats }\end{array}$ & 40 & 64 & 39 & 62 \\
\hline Half Load $^{\text {a }}$ & $31,650 \mathrm{lb}$ & $46,450 \mathrm{lb}$ & $33,050 \mathrm{lb}$ & $48,500 \mathrm{lb}$ \\
\hline $\mathrm{FC}_{60} / \mathrm{FC}_{40}{ }^{\mathrm{b}}$ & \multicolumn{2}{|c|}{$1+0.5 \times(46,450-31,650) / 31,650=1.23$} & \multicolumn{2}{|c|}{$1+0.5 \times(48,500-33,050) / 33,050=1.23$} \\
\hline $\mathrm{FE}_{60} / \mathrm{FE}_{40}{ }^{\mathrm{c}}$ & \multicolumn{2}{|c|}{$1 / 1.23=0.81$} & \multicolumn{2}{|c|}{$1 / 1.23=0.81$} \\
\hline
\end{tabular}

a. Half Load $=$ Curb Weight + (Half Number of Seats +1 Driver) $\times 150$

b. $\quad F C=$ Fuel Consumption (Gallons per Mile)

c. $\quad \mathrm{FE}=$ Fuel Economy (Miles per Gallon)

The limited number of test sites could not provide a complete range of FE data covering all operation speeds. However, recent WVU WMATA bus emissions and FE studies yielded chassis dynamometer data from 16 different test cycles for diesel, CNG, and diesel hybrid buses. The average operation speed of the cycles ranged from $3.69 \mathrm{mph}$ to $43.64 \mathrm{mph}$. The researchers determined that the LCC FE model, with a speed relationship generated from the chassis dynamometer data, would be adjusted to reflect the in-field bus operation.

The model was not corrected for the non-revenue fuel consumption. It is essential when considering average speed to know whether this speed is only for the route itself, or whether it includes idling, deadheading or low speed depot activity as well. It was the opinion of the C-15 research team that the average speed for all activity was close to the route speed, or that 
additional activity would generally lower the average speed slightly relative to the route speed. Idling detracts from speed, whereas deadheading would be expected to increase speed.

Weather effects (atmosphere temperature and humidity) for FE were deduced from field data and were studied and included in the FE model as a correction factor. These effects are addressed in a sub-section below. Although the terrain effect could affect FE dramatically in very steep terrain, there is insufficient data available to be used to generate a reliable factor in the FE model. Kern et al. [123] concluded that terrain effects were small until grades were steep enough to require use of brakes. It would be also a difficult task for a transit agency to find local geographic characteristics. Therefore, the terrain effects were omitted in the FE model, and are presented through the range of FE in the model. The cooling fan work load between chassis dynamometer test and on-road might affect FE in a percent level. But the effect was not considered for the challenge to separate the impact of weather and vehicle speed from both chassis dynamometer and on-road FE data.

Diesel Bus Fuel Economy. The four diesel bus sites did not yield a sufficiently high range of average speed for all LCC applications. WMATA yielded different data for two routes, so a total of five pairs of speed and fuel economy data were available. These values are shown in Table 31, in which the KC Metro data have been adjusted to 40 -foot bus equivalence.

Table 31: Comparison of Field Fuel Economy and Predicted Fuel Economy for Diesel Buses

\begin{tabular}{|c|c|c|c|c|}
\hline & $\begin{array}{c}\text { Ave Speed } \\
(\mathbf{m p h})\end{array}$ & Field FE (mpg) & $\begin{array}{c}\text { Prediction FE } \\
\text { (mpg) }\end{array}$ & Difference (\%) \\
\hline NYCT & 6.35 & 2.33 & 2.20 & $-5.5 \%$ \\
\hline KC Metro (40 ft equivalent) & 12.25 & 3.15 & 3.11 & $-1.2 \%$ \\
\hline LBT & 13.80 & 3.45 & 3.31 & $-4.0 \%$ \\
\hline WMATA-Montgomery & 17.10 & 3.53 & 3.69 & $4.5 \%$ \\
\hline WMATA-Landover & 17.50 & 3.46 & 3.73 & $7.8 \%$ \\
\hline & & & $\begin{array}{c}\text { Average } \\
\text { Difference \% }\end{array}$ & $0.3 \%$ \\
\hline
\end{tabular}

Data on chassis dynamometer fuel economy for diesel buses (Cummins ISM engine) at WMATA were plotted against average cycle speed for 16 cycles. These data were fitted with a parabolic line to provide a trend against average operating speed. This line and the diesel 
chassis dynamometer data are shown in Figure 20. The line was not forced through the origin, even though zero speed should imply zero mpg.

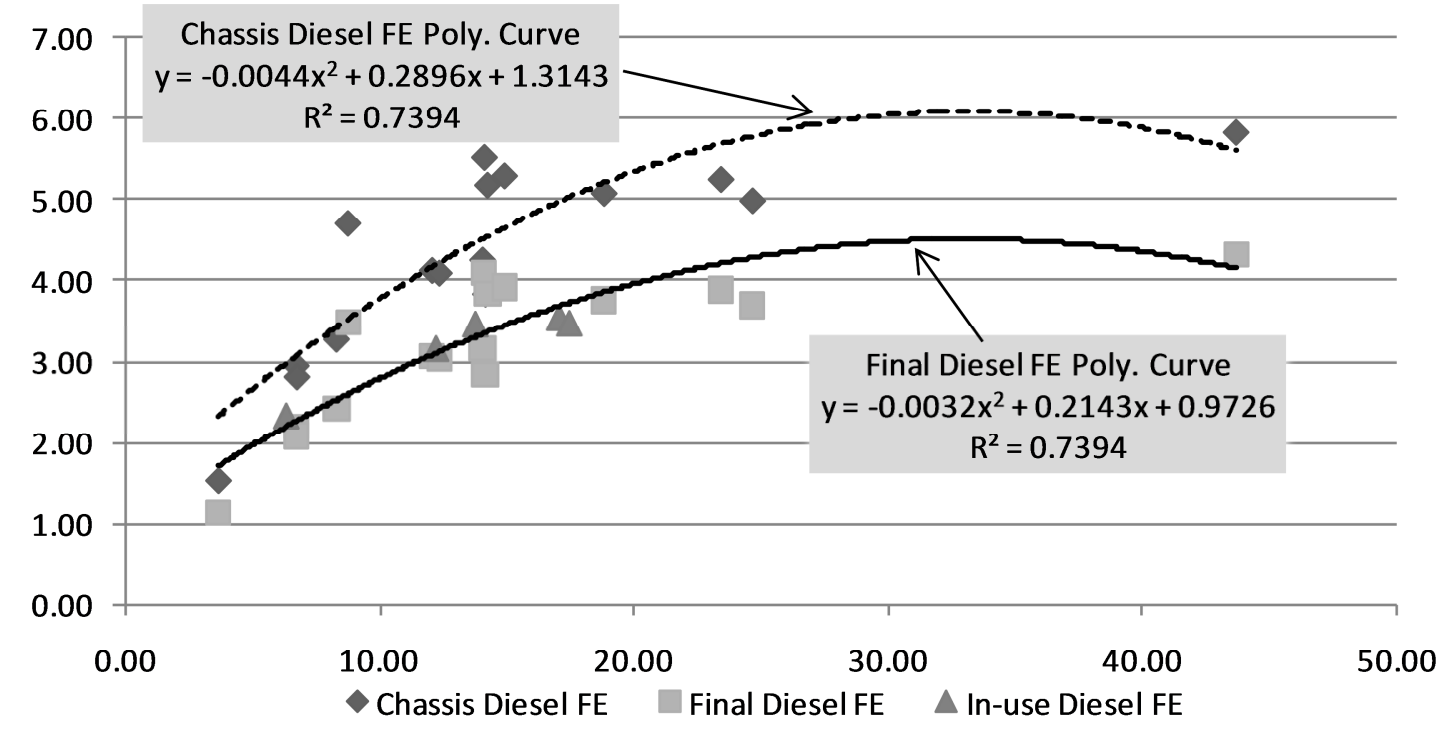

Figure 20: Diesel Bus Fuel Economy Data and Parabolic Trend Lines

The authors assumed that there was a certain percentage FE reduction due to air conditioner $(\mathrm{A} / \mathrm{C})$ or heating load as well as possible FE loss from terrain. A FE reduction ratio was used. Figure 20 shows that the dotted line represents the diesel bus in-use FE performance by reducing FE by $26 \%$ from the chassis data (solid line). A parabolic curve and equation shown in Figure 20 were used in the LCC model to predict diesel bus fuel economy from the average speed.

The predicted in-field FE (calculated the parabolic equation and operation speed) were compared to the real in-field FE, as shown in Table 31. The differences of five sites ranged from $-5.5 \%$ to $7.8 \%$ with an average difference of $0.3 \%$. The parabolic diesel FE equation is Diesel FE = $-0.003 \times$ Speed $^{2}+0.214 \times$ Speed +0.972 . 
Diesel Hybrid Bus Fuel Economy. The same methodology was used for the diesel hybrid FE model. Three sites had diesel hybrid bus in-field FE data. KC Metro field FE data (60-foot diesel hybrid buses) were adjusted to relative 40 -foot diesel buses FE by a factor of 1.23 (found in Table 30). The WMATA site provided data for two distinct routes. A total four pairs of speed-FE data were therefore available. Hybrid bus chassis dynamometer data were collected from WMATA diesel hybrid buses. For hybrid bus case, a reduction percentage $24.5 \%$ was found and applied to the chassis dynamometer data, as shown in Figure 21. In the figure, the dotted line represents a parabolic curve, created from the adjusted data. The relative equation is the FE model for a hybrid bus, which has $F E=-0.003 \times$ Speed $^{2}+0.202 \times$ Speed +1.798 . The ratio of differences between the chassis dynamometer data and field data was similar for conventional diesel and diesel hybrid buses (26\% and $24.5 \%)$, which lends confidence to the process used for the LCC FE model.

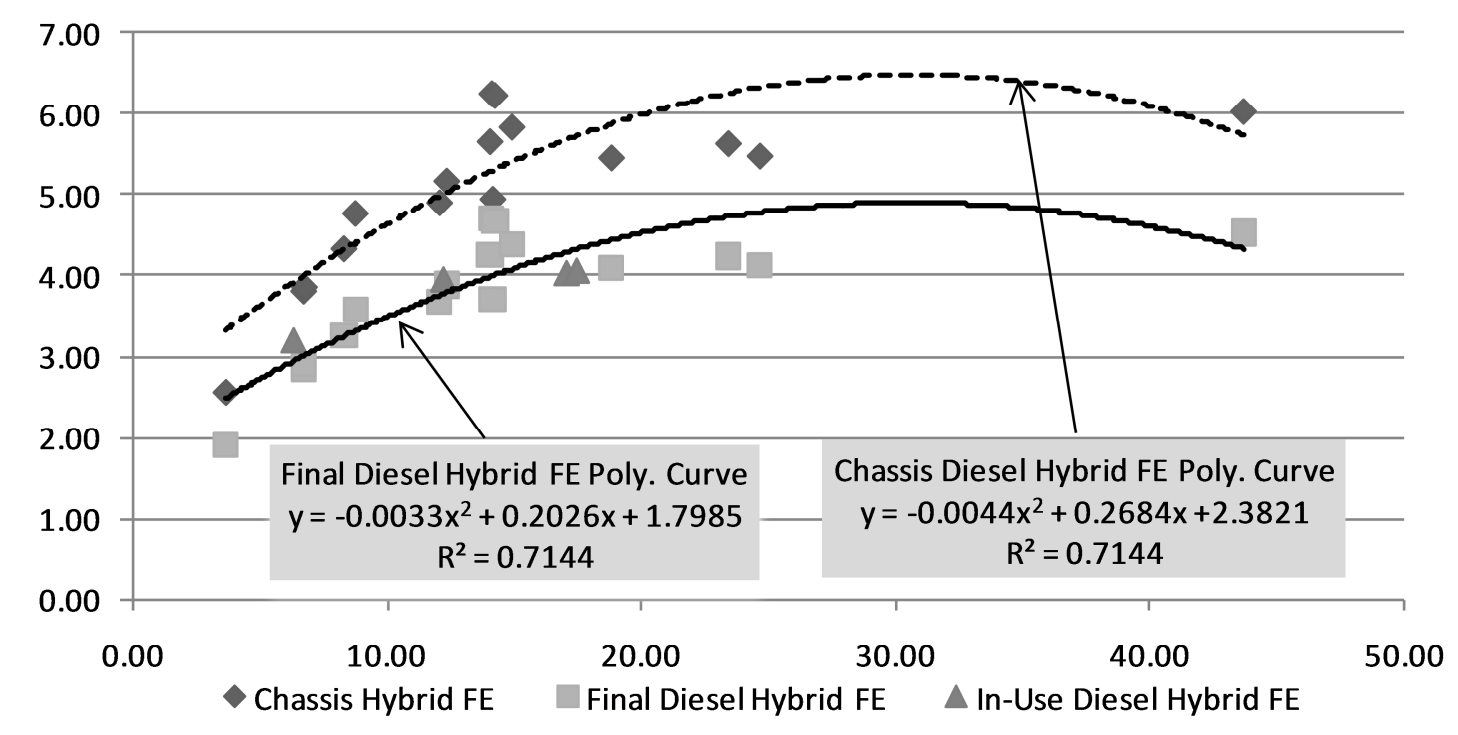

Figure 21: Diesel Hybrid Bus Fuel Economy Data and Parabolic Trend Lines

The predicted FE values for diesel hybrid buses are compared to the real FE values for the sites in Table 32, and it shows that the differences range from $-7.5 \%$ to $6.4 \%$ and the average 
difference is $0.2 \%$. In addition, the hybrid drive advantage for FE is compared for real and predicted cases in Table 33. The model represented the hybrid technology actual performance reasonably, but NYCT FE ratio differs most from the prediction. The predicted $34 \%$ FE ratio was lower than the $48 \%$ found in practice in NYCT bus operation. It could reflect the effect of bus technology on FE, and reflect the problems associated with predicting FE at very low operating speeds.

Table 32: Comparison of Field Fuel Economy and Predicted Fuel Economy for Diesel Hybrid Buses

\begin{tabular}{|c|c|c|c|c|}
\hline & Ave Speed (mph) & Field FE (mpg) & $\begin{array}{c}\text { Prediction FE } \\
\text { (mpg) }\end{array}$ & Difference (\%) \\
\hline NYCT & 6.35 & 3.19 & 2.95 & $-7.5 \%$ \\
\hline KC Metro & 12.25 & 3.96 & 3.78 & $-4.5 \%$ \\
\hline WMATA-Montgomery & 17.10 & 4.04 & 4.29 & $6.3 \%$ \\
\hline WMATA-Landover & 17.50 & 4.07 & 4.33 & $6.4 \%$ \\
\hline & & & $\begin{array}{c}\text { Average } \\
\text { Difference \% }\end{array}$ \\
\hline
\end{tabular}

Table 33: Comparison of Diesel Hybrid Buses FE Advantage to Diesel Buses for Field and Prediction

\begin{tabular}{|c|c|c|}
\hline & Field FE: Hybrid to Diesel & Prediction FE: Hybrid to Diesel \\
\hline NYCT & $48 \%$ & $34 \%$ \\
\hline KC Metro & $27 \%$ & $22 \%$ \\
\hline WMATA-Montgomery & $14 \%$ & $16 \%$ \\
\hline WMATA-Landover & $16 \%$ & $16 \%$ \\
\hline
\end{tabular}

CNG Bus Fuel Economy. All field and chassis CNG bus FE data were for lean burn engines. It was a difficult task to construct the CNG bus FE model, because of limited knowledge of the emerging stoichiometric CNG engine technology and inadequate field data. Since there were no published data on fuel economy benefit from stoichiometric technology, the model did not include any adjustment for it. The primary manufacturer of the stoichiometric technology has represented a small fuel economy improvement over lean burn technology, but for throttled engines, the fuel economy ratio between the lean burn and stoichiometric technology is likely to vary with engine load, and hence with average bus operating speed. As shown in Figure 22, the CNG final FE curve was adjusted using a pair of in-use FE operating points. The parabolic equation is $F E=-0.002 \times$ Speed $^{2}+0.194 \times$ Speed +0.552 . 


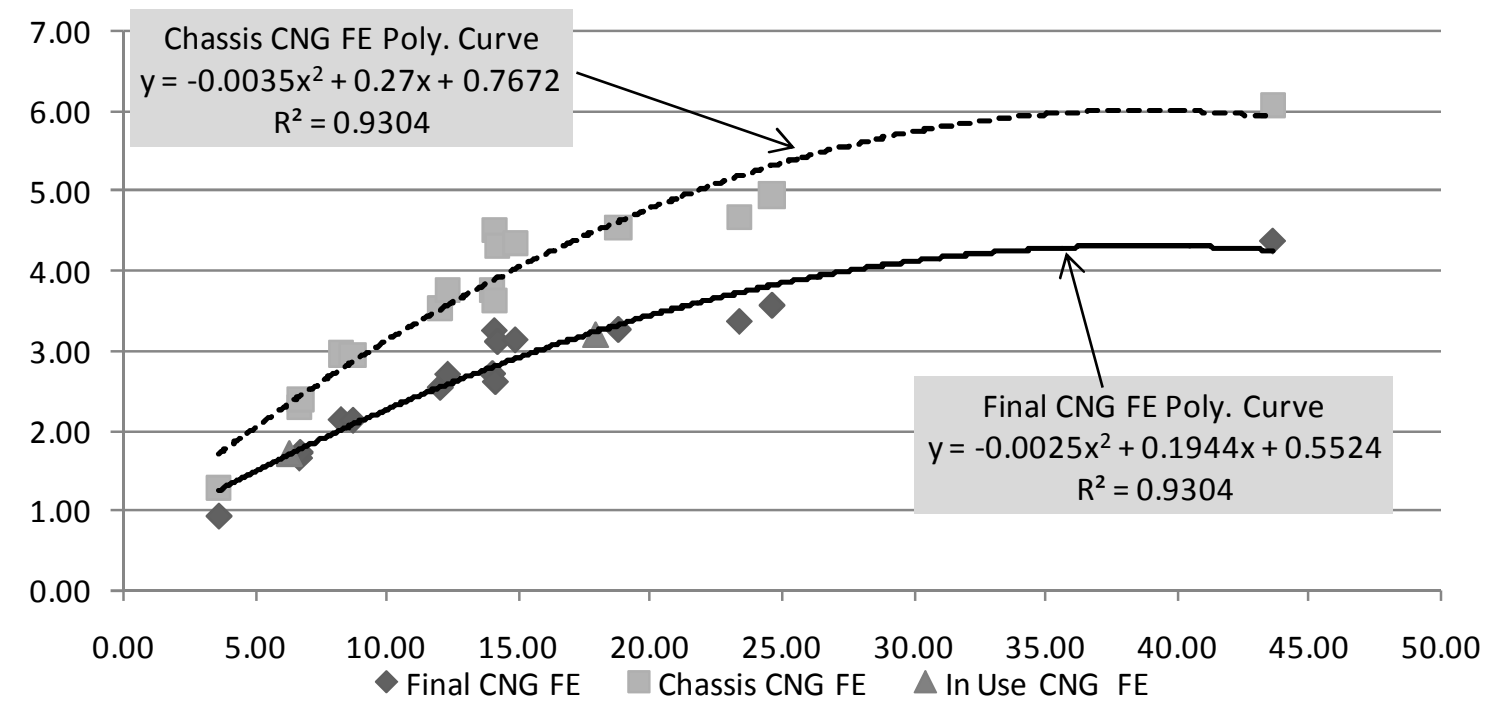

Figure 22: CNG Bus Fuel Economy Data and Parabolic Trend Lines

The prediction equation matched the in-use data well, as shown in Table 34. For the two sites, the prediction differences were $-0.8 \%$ and $1.2 \%$. The model was further tested by using the 2006 NREL WMATA CNG bus study [123]. At the average speed of $11.6 \mathrm{mph}$, the prediction FE was $4 \%$ higher than the in-field FE. The CNG bus FE model was compared with the diesel FE model. Table 35 presents the comparison results. At slow speed CNG buses had $23 \%$ poorer FE than diesel buses compared to $27 \%$ found in the real operation. However, the field data were collected from old diesel and CNG technology buses. For the latest technology and at high speed, the field data suggest that CNG performed better than the model would predict; $14 \%$ reduction was predicted against $8 \%$ reduction in real operation. However, the model represents a close match with the previous WMATA NREL study; field data had a 17\% reduction corresponding to the $18 \%$ projection by the model. In the future, throttling losses, coupled with exhaust gas recirculation strategy, and influenced by bus gearing and operating speed, will continue to make CNG fuel economy more difficult to predict than diesel fuel economy. 
Table 34: Comparison of Field Fuel Economy and Predicted Fuel Economy for CNG Buses

\begin{tabular}{|c|c|c|c|c|}
\hline & $\begin{array}{c}\text { Ave Speed } \\
(\mathbf{m p h})\end{array}$ & $\begin{array}{c}\text { Field FE } \\
(\mathbf{m p g})\end{array}$ & $\begin{array}{c}\text { Prediction FE } \\
(\mathbf{m p g})\end{array}$ & $\begin{array}{c}\text { Difference } \\
(\%)\end{array}$ \\
\hline NYCT & 6.35 & 1.7 & 1.69 & $-0.8 \%$ \\
\hline WMATA-Four Mile Run & 17.90 & 3.19 & 3.23 & $1.2 \%$ \\
\hline \multicolumn{2}{|c|}{} & & Average & $0.2 \%$ \\
\hline \multicolumn{2}{|c|}{ Difference $\%$} & 2.47 & $4 \%$ \\
\hline \multicolumn{2}{|c|}{ The 2006 NREL study data were not used in the FE model. } \\
\hline
\end{tabular}

Table 35: Comparison of CNG Buses FE Penalty to Diesel Buses for Field and Prediction

\begin{tabular}{|c|c|c|}
\hline & Field FE: CNG to Diesel & Prediction FE: CNG to Diesel \\
\hline NYCT & $-27 \%$ & $-23 \%$ \\
\hline WMATA-Four Mile Run ${ }^{\text {a }}$ & $-8 \%$ & $-14 \%$ \\
\hline WMATA-2006 NREL Study & $-17 \%$ & $-18 \%$ \\
\hline
\end{tabular}

Gasoline Hybrid Bus Fuel Economy. There was only one test site in the C-15 program that operated gasoline hybrid buses, and there were no complete chassis dynamometer FE data available for gasoline hybrid buses. It was assumed that gasoline hybrid buses would have similar behavior as diesel hybrid buses, although it is acknowledged that the gasoline engine might suffer lower FE at light loads due to throttling losses. The diesel hybrid final FE data (after adjustment) were adopted as baseline data to simulate gasoline field data. There was only one in-use gasoline HEB FE point (3.71 mpg at $13.80 \mathrm{mph}$ ) available. If the diesel HEB curve was perfect align to $3.71 \mathrm{mpg}$ at $13.80 \mathrm{mph}$, the FE was $12 \%$ better than the diesel FE at the speed. LBT Gasoline HEB FE was found 7\% better than diesel buses FE at LBT. The percentage was named as gasoline FE advantage. Hence, the diesel HEB FE curve was reduced slightly more to $3.65 \mathrm{mpg}$, so that gasoline FE advantage in the model became $10 \%$, closer to the field advantages (7\%). The difference between estimated FE (3.65 mpg) and field FE (3.71 mpg) was $2 \%$. As shown in the Figure 23 , the gasoline hybrid buses FE were created from a reduction of $8 \%$ from the diesel hybrid bus FE. 


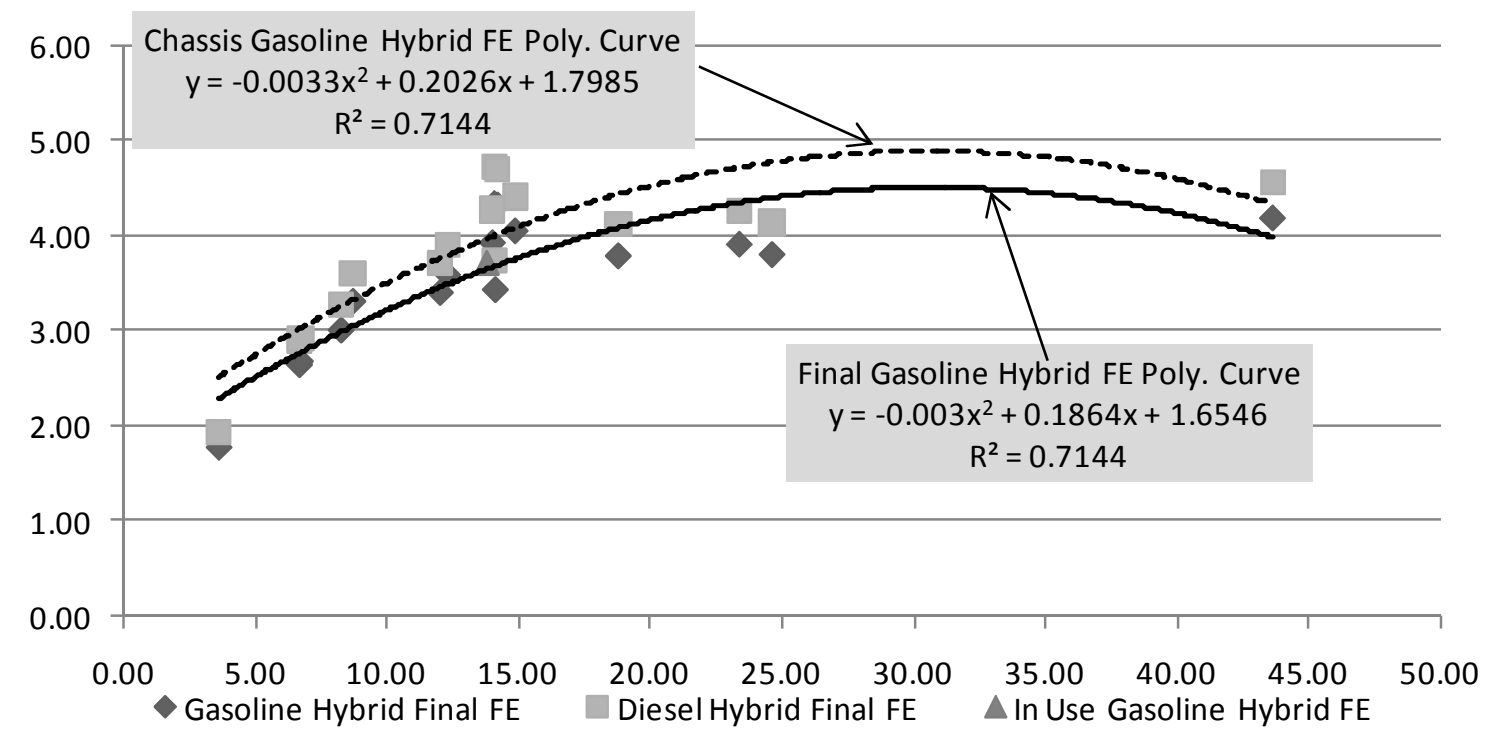

Figure 23: Gasoline Hybrid Bus Fuel Economy Data and Parabolic Trend Lines. The chassis curve was derived from diesel hybrid data.

Hotel Load Effects on Fuel Economy. Hotel load effects (A/C and auxiliary burner) were revealed by the bus FE performance at the test sites during the four seasons. Average monthly temperature was used as an indicator of how much the hotel load (particularly for air conditioning) was a factor. Although humidity was another important factor, humidity varies too widely within a season and it was too complex for this model to predict FE using temperature and humidity together. The researchers adopted the following simple approach. The three coldest months and three hottest months were identified according to the historical city temperature record. The average FE values for cold and hot months were calculated separately, and compared to the yearly average FE. For most of the cases, transit buses were equipped with air conditioning systems. Generally, coolest months had highest FE (lowest fuel use), and hottest months yielded lowest FE. However, KC Metro buses presented opposing results. This was because those buses spent extra fuel for burner heat for the cold season, and mild summer temperatures did not make substantial use of $A / C$.

After the calculation, each site offered a low (for 3 months), default (for 12 months), and high (for 3 months) FE for four technologies. Low FE represented the maximum hotel load (A/C 
or auxiliary burner) for the bus technology. Default represented the bus usage for a temperate zone without extreme weather conditions, with mild A/C usage. High FE represented the bus usage in a cold climate, where $A / C$ was not used or even not present on the bus. The heating auxiliary burner was considered to be uncommon equipment for the US bus fleet. Table 36 presents the four technology performance according the climate at the four test sites. At the time of composing this LCC component, WMATA depots were not able to provide a complete one year diesel FE data set. The two hottest month FE data sets were not available. However, the one remaining hot month data set was used for the low FE (high A/C use).

Table 36: Hotel Load Effects on Bus FE for Four Bus Technologies

\begin{tabular}{|c|c|c|c|c|c|}
\hline Diesel Bus & $\begin{array}{c}\text { Average } \\
\text { (mpg) }\end{array}$ & $\begin{array}{c}\text { High FE } \\
\text { (mpg) }\end{array}$ & $\begin{array}{c}\text { Low FE } \\
\text { (mpg) }\end{array}$ & $\begin{array}{l}\text { High to } \\
\text { Average }\end{array}$ & $\begin{array}{l}\text { Low to } \\
\text { Average }\end{array}$ \\
\hline NYCT-MCH & 2.39 & 2.54 & 2.27 & $6 \%$ & $-5 \%$ \\
\hline NYCT-WF & 2.28 & 2.35 & 2.17 & $3 \%$ & $-5 \%$ \\
\hline KC Metro-RB & 2.95 & 3.02 & 2.79 & $2 \%$ & $-5 \%$ \\
\hline LBT & 3.45 & 3.63 & 3.29 & $5 \%$ & $-5 \%$ \\
\hline WMATA-Montgomery & 3.53 & 3.66 & 3.14 & $4 \%$ & $-11 \%$ \\
\hline \multirow[t]{2}{*}{ WMATA-Landover } & 3.46 & 3.56 & 3.17 & $3 \%$ & $-8 \%$ \\
\hline & & & Average & $4 \%$ & $-7 \%$ \\
\hline Diesel Hybrid Bus & $\begin{array}{c}\text { Average } \\
\text { (mpg) }\end{array}$ & $\begin{array}{c}\text { High FE } \\
\text { (mpg) }\end{array}$ & $\begin{array}{c}\text { Low FE } \\
\text { (mpg) }\end{array}$ & $\begin{array}{l}\text { High to } \\
\text { Average }\end{array}$ & $\begin{array}{c}\text { Low to } \\
\text { Average }\end{array}$ \\
\hline NYCT-MCH & 3.19 & 3.59 & 2.77 & $13 \%$ & $-13 \%$ \\
\hline KC Metro-Ac Base & 3.65 & 3.73 & 3.58 & $2 \%$ & $-2 \%$ \\
\hline WMATA-Montgomery & 4.04 & 4.21 & 3.78 & $4 \%$ & $-6 \%$ \\
\hline \multirow[t]{2}{*}{ WMATA-Landover } & 4.07 & 4.29 & 3.69 & $5 \%$ & $-9 \%$ \\
\hline & & & Average & $6 \%$ & $-8 \%$ \\
\hline CNG Bus & $\begin{array}{c}\text { Average } \\
\text { (mpg) }\end{array}$ & $\begin{array}{c}\text { High FE } \\
\text { (mpg) }\end{array}$ & $\begin{array}{c}\text { Low FE } \\
\text { (mpg) }\end{array}$ & $\begin{array}{l}\text { High to } \\
\text { Average }\end{array}$ & $\begin{array}{l}\text { Low to } \\
\text { Average }\end{array}$ \\
\hline NYCT-MCH & 1.7 & 1.76 & 1.64 & $4 \%$ & $-4 \%$ \\
\hline WMATA-Old (Cummins) & 2.36 & 2.5 & 2.23 & $6 \%$ & $-6 \%$ \\
\hline WMATA-Old (JD) & 2.43 & 2.67 & 2.23 & $10 \%$ & $-8 \%$ \\
\hline \multirow[t]{2}{*}{ WMATA-4 Miles Run } & 3.19 & 3.34 & 2.96 & $5 \%$ & $-7 \%$ \\
\hline & & & Average & $6 \%$ & $-6 \%$ \\
\hline Gasoline Hybrid Bus & $\begin{array}{c}\text { Average } \\
\text { (mpg) }\end{array}$ & $\begin{array}{c}\text { High FE } \\
\text { (mpg) }\end{array}$ & $\begin{array}{c}\text { Low FE } \\
\text { (mpg) }\end{array}$ & $\begin{array}{l}\text { High to } \\
\text { Average }\end{array}$ & $\begin{array}{l}\text { Low to } \\
\text { Average }\end{array}$ \\
\hline \multirow[t]{2}{*}{ LBT } & 3.67 & 3.89 & 3.35 & $6 \%$ & $-9 \%$ \\
\hline & & & Average & $6 \%$ & $-9 \%$ \\
\hline
\end{tabular}

Unless the LCC model user is considering extreme climate conditions, or is using the model as a tool to predict FE performance for a specific hot or cold season, the default FE in the model 
reflects average yearly FE for most transit agencies. The four sites had no severe case, such as heavy use of both $\mathrm{A} / \mathrm{C}$ and winter auxiliary burner. The final LCC model employed a scale for adjustment of FE by the user if a typical A/C or heater use were anticipated.

In FMT, diesel, CNG, and hybrid buses used FE equations developed in the C-15 project. B20 biodiesel has less energy density (Kilo Joule/Volume) than the diesel does. B20 biodiesel bus fuel economy was estimated as $98.5 \%$ of the similar conventional diesel bus FE when actual biodiesel gallons were used [10]. 40-ft electric buses had a measured $1.536 \mathrm{kWhr} / \mathrm{mile}$ fuel economy operating on a route of $16.1 \mathrm{mph}$ average speed [124]. Battery charger efficiency was assumed to be $80 \%$. That made the charger-to-wheels FE to be $1.92 \mathrm{kWhr} / \mathrm{mile}$, which was about 19.8 miles per diesel equivalent gallon. Battery electric buses fuel economy curve was corrected from FE of the diesel hybrid electric buses by timing 4.72. Similarly, Fuel Cell bus FE equation was corrected by an increment of $46 \%$ on diesel hybrid bus FE curve. It based on fuel cell bus evaluation done at AC Transit. The Fuel Cell buses at AC Transit had a fuel economy of 6.97 miles per diesel equivalent gallon at operation average speed of $14.3 \mathrm{mph}$ [34]. It was about 73\% improvement between Fuel Cell buses and baseline diesel buses. C-15 model calculated the fuel economies of diesel and diesel hybrid electric buses were $3.38 \mathrm{mpg}$ and 4.02 mpg. $73 \%$ increase was scaled down to $46 \%$ when comparing Fuel Cell buses to diesel hybrid buses.

\section{Major Component Replacement Energy Storage System Rehabilitation.}

The cost of replacing the energy storage pack (for electric, and hybrid buses only) included the labor to remove and replace $(R \& R)$ the major components at a rate of $\$ 50$ per hour, along with miscellaneous supplies needed during the $R \& R$ process. Costs associated with replacing energy storage equipment were unique to hybrid buses and were obtained directly from the hybrid OEMs. Given the diverse mix of energy storage systems currently available for hybrid buses, costs varied widely from lithium ion and nickel metal hydride batteries, to ultracapacitors. Lead acid batteries, although currently used in some hybrid applications, were not considered in the model as a cost input because of the change to other energy storage devices 
being made for 2007 and newer hybrids, thereby making lead acid batteries obsolete for current and future hybrid bus procurements. A difficult issue was raised by the likelihood that technology advances over the life of future buses are likely to be so great that advanced technology may be substituted at time of rebuild for the original technology. However, there was no reasonable way to project cost impacts of such events.

The average cost for the energy storage equipment was determined to be $\$ 27,500$, and the model based the high, low and default cost on the expected life of battery pack. The mid cost value (default) assumed that each pack would last six years. The high cost value assumed a four-year battery life (more frequent replacements required during bus useful life), and the low cost value assumed eight-year battery life.

In addition, the model did not simply assume that all battery packs would have to be replaced exactly at their estimated life. Instead, the model assumed that a given battery pack (original or replaced pack) would have a 50\% chance of failing at their expected life, a $25 \%$ chance of failing one year early, and a $25 \%$ chance of failing one year later. Even if replacements were to be planned, a spread in the time of retrofits might support this " $25-50-25$ " assumption. The effect of compounding the assumption is shown in Figure 24. 


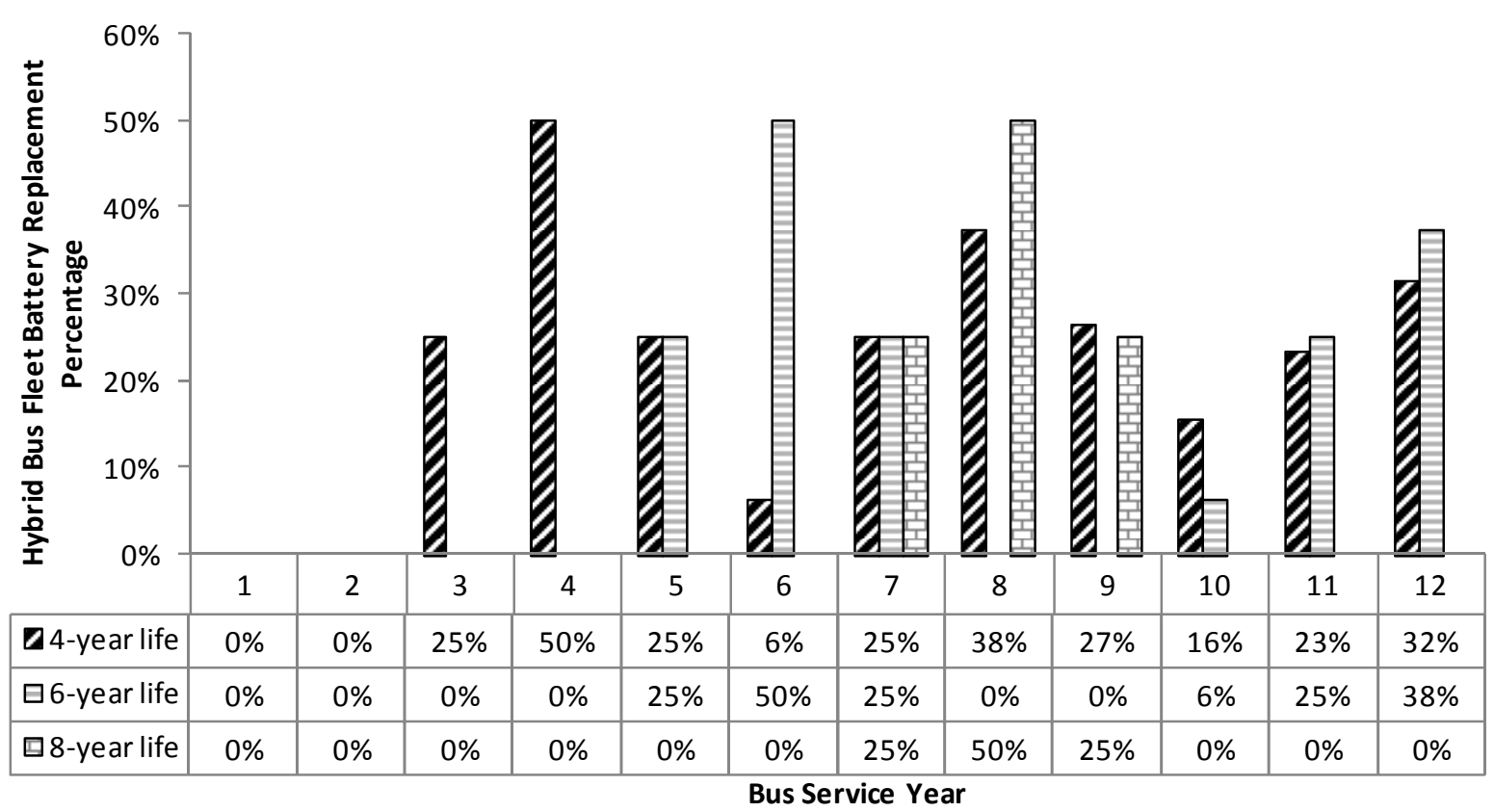

Figure 24: Battery Replacement Percentage Chart during 12-Year Bus Life

For example, if a fleet were to have 80 new hybrid buses, and expected that their battery pack life was six years, Table 37 shows that 20 buses ( $25 \%$ of 80 ) would have their battery packs first replaced on the fifth year, 40 packs ( $50 \%$ of 80 ) will be replaced on the sixth year, and the remaining 20 packs ( $25 \%$ of 80 ) would need the replacements on the seventh year. These replaced packs would follow the $25-50-25$ rule. In the tenth year, 5 buses (25\% of 20 ) would need their second replacement. In the eleventh year, 20 bus battery packs would be replaced. Ten of these would be from $50 \%$ of the fifth year replacements and ten would be from $25 \%$ of the sixth year replacements. Similarly, in the twelfth year, 30 bus battery pack replacements would occur. The possibility of retrofits toward the end of bus useful life also provokes questions on early or late retirement of buses, but since policy would vary on bus retirement from site to site, no specific provisions were made in the LCC for adjustment of retirement age. The bus life employed in the model was used regardless of the retrofit or replacement schedule.

Table 37: Battery Replacement Schedule for an 80-Hybrid Bus Fleet (6-year Battery Life)

\begin{tabular}{|c|c|c|c|c|c|c|c|c|}
\hline & $\mathbf{5}^{\text {th }}$ year & $\mathbf{6}^{\text {th }}$ year & $\mathbf{7}^{\text {th }}$ year & $\mathbf{8}^{\text {th }}$ year & $\mathbf{9}^{\text {th }}$ year & $\mathbf{1 0}^{\text {th }}$ year & $\mathbf{1 1}^{\text {th }}$ year & $\mathbf{1 2}^{\text {th }}$ year \\
\hline $1^{\text {st }}$ Replacements & 20 & 40 & 20 & & & & & \\
\hline $\begin{array}{c}2^{\text {nd }} \\
\text { Replacements }\end{array}$ & & & & & & 5 & $10+10$ & $5+20+5$ \\
\hline
\end{tabular}


The cost of a spare energy pack was also set at $\$ 27,500$ if agencies choose to keep one in inventory at all times. One spare energy pack per 20 hybrid buses was set as the default (mid cost input), one spare pack per 30 buses represented the low cost input, while one spare energy pack for every 10 hybrid buses represented the high cost input.

In FMT, battery packs of electric buses and Fuel Cell buses were expected to last for four years on average.

\section{Engine and Transmission Rehabilitation}

Costs associated with rebuilding the ICE for all bus types, costs associated with rebuilding automatic transmissions for diesel and CNG buses, and the costs associated with rebuilding the unique hybrid propulsion system were itemized separately. To achieve a level of consistency for all rebuilds, cost information was obtained from OEM authorized rebuild vendors to ensure that overhead costs were fairly captured for all equipment.

In the case of hybrid propulsion system rebuilds, costs were obtained directly from the hybrid OEMs and were based on removing the original hybrid drive system and replacing it with a factory remanufactured unit, at least until use of this equipment becomes more widespread and agencies gain the knowledge and tools needed to perform the rebuilding themselves. Likewise, costs associated with rebuilding the ICE for all bus types and the automatic transmissions for diesel and CNG buses were based on replacing the original units with rebuilt units from an OEM authorized rebuilding facility. Because hybrid bus OEMs were expected to downsize ICEs used on these vehicles in the future, ICE rebuild costs for hybrid buses were projected to be lower than ICE rebuild costs for conventional diesel buses (see Table 38 below).

Engine and transmission rebuild followed a rebuild schedule, which defined, for each propulsion system, when the original engine or transmission would require its first rebuild and when its subsequent rebuilds would occur. For example, a selection of $(6,4,4,4 \ldots)$ represented that the first rebuild took place in year six and with subsequent rebuilds occurring every four years thereafter until the bus reached its useful life. The replacement used the same 25-50-25 rule as used for the battery pack replacement schedule. $25 \%$ of new or replacement 
components would fail (or be scheduled for replacement) on year prior to the expected life year, $50 \%$ of them would fail on the expected life year, and $25 \%$ of them would fail one year after the expected life year. The default replacement schedule for hybrid bus engines and transmissions was $(7,6,6,6 \ldots$.$) , and for CNG and diesel buses was (6,4,4,4 \ldots$.$) . The model also$ provided $(7,7,7,7 \ldots)$ and $(7,5,5,5 \ldots$.$) as possible different second replacement schedule for$ hybrid engines and transmissions. Similarly, the $(6,6,6,6 \ldots)$ and $(6,3,3,3 \ldots)$ schedules were offered as options for diesel and CNG buses.

Engine Rehabilitation Cost. As long as the replacement schedule was defined, the engine rehabilitation costs were decided by the parts and labor cost. One time replacement costs for diesel and CNG engines were based on the assumption that the engine would be rebuilt as a factory remanufactured unit (i.e., no in-chassis rebuilds) and included labor cost to remove and replace the engine. The costs were based on rebuilds conducted by an outside vendor to capture all overhead costs associated with the rebuilds or replacements. In the case of hybrid buses, where a variety of diesel engines can be used and rebuild/replacement data was sparse, costs were based on replacement engines (i.e., engines were replaced and not rebuilt). Replacement is commonplace for engines that do not have cylinder liners and engines of this kind are commonplace in hybrid applications. In addition, the model assumed a longer interval between engine replacements. The costs for the three bus technologies were shown in Table 38.

Table 38: Internal Combustion Engine Rebuild/Replacement Costs

\begin{tabular}{|c|c|c|c|}
\hline & Diesel & CNG & Hybrid \\
\hline Low & $\$ 15,000$ & $\$ 15,000$ & $\$ 10,000$ \\
\hline Medium & $\$ 20,000$ & $\$ 20,000$ & $\$ 15,000$ \\
\hline High & $\$ 25,000$ & $\$ 25,000$ & $\$ 20,000$ \\
\hline
\end{tabular}

In some cases the bus purchaser might know of substantial future costs associated with a bus purchase. For example, a purchaser of 2008 diesel buses might have an internal obligation to meet 2010 EPA emissions standards around the time of the first engine rebuild. Because of this, the model provided the option of adding in a miscellaneous one-time cost for future years in a separate model section. The engine rebuild cost did not include the additional costs associated with the possible engine technology update. 
In the FMT model, Biodiesel engine R\&R costs were assumed to have no change from conventional diesel costs. The cost was zero for battery electric buses, because battery pack replacement has been considered separately. Fuel Cell unit costs were estimated from bus purchase price increment between Fuel Cell buses and diesel hybrid buses.

Table 39: Primary Power Unit Rebuild/Replacement Costs

\begin{tabular}{|c|c|c|c|c|c|c|c|}
\hline \multirow{5}{*}{ Conventional Diesel } & \multirow{3}{*}{$\begin{array}{l}\text { Model Year } \\
\text { Pre-2007 }\end{array}$} & \multicolumn{6}{|c|}{ Bus Length } \\
\hline & & \multicolumn{2}{|c|}{$30-\mathrm{ft}$} & \multicolumn{2}{|c|}{$40-\mathrm{ft}$} & \multicolumn{2}{|c|}{$60-\mathrm{ft}$} \\
\hline & & $\$$ & 20,000 & $\$$ & 20,000 & $\$$ & 20,000 \\
\hline & 2007-2010 & $\$$ & 20,000 & $\$$ & 20,000 & $\$$ & 20,000 \\
\hline & Post 2010 & $\$$ & 20,000 & $\$$ & 20,000 & $\$$ & 20,000 \\
\hline \multirow{3}{*}{ Conventional CNG } & Pre-2007 & $\$$ & 20,000 & $\$$ & 20,000 & $\$$ & 20,000 \\
\hline & $2007-2010$ & $\$$ & 20,000 & $\$$ & 20,000 & $\$$ & 20,000 \\
\hline & Post 2010 & $\$$ & 20,000 & $\$$ & 20,000 & $\$$ & 20,000 \\
\hline \multirow{3}{*}{ Diesel Hybrid-Electric } & Pre-2007 & $\$$ & 15,000 & $\$$ & 15,000 & $\$$ & 15,000 \\
\hline & $2007-2010$ & $\$$ & 15,000 & $\$$ & 15,000 & $\$$ & 15,000 \\
\hline & Post 2010 & $\$$ & 15,000 & $\$$ & 15,000 & $\$$ & 15,000 \\
\hline \multirow{3}{*}{ B20 Biodiesel } & Pre-2007 & $\$$ & 20,000 & $\$$ & 20,000 & $\$$ & 20,000 \\
\hline & $2007-2010$ & $\$$ & 20,000 & $\$$ & 20,000 & $\$$ & 20,000 \\
\hline & Post 2010 & $\$$ & 20,000 & $\$$ & 20,000 & $\$$ & 20,000 \\
\hline \multirow{3}{*}{ Battery Electric } & Pre-2007 & $\$$ & - & $\$$ & - & $\$$ & - \\
\hline & 2007-2010 & $\$$ & - & $\$$ & - & $\$$ & - \\
\hline & Post 2010 & $\$$ & - & $\$$ & - & $\$$ & - \\
\hline \multirow{3}{*}{ Fuel Cell - Hydrogen } & Pre-2007 & $\$$ & 70,588 & $\$$ & 70,588 & $\$$ & 70,588 \\
\hline & 2007-2010 & $\$$ & 70,588 & $\$$ & 70,588 & $\$$ & 70,588 \\
\hline & Post 2010 & $\$$ & 70,588 & $\$$ & 70,588 & $\$$ & 70,588 \\
\hline \multirow{3}{*}{ Gasoline Hybrid-Electric } & Pre-2007 & $\$$ & 15,000 & $\$$ & 15,000 & $\$$ & 15,000 \\
\hline & 2007-2010 & $\$$ & 15,000 & $\$$ & 15,000 & $\$$ & 15,000 \\
\hline & Post 2010 & $\$$ & 15,000 & $\$$ & 15,000 & $\$$ & 15,000 \\
\hline
\end{tabular}

Transmission Rehabilitation Cost. Again, vendor rebuild costs were used to capture related overhead costs. In the case of the hybrid drive system it was expected that factory rebuilds 
done on an exchange basis would be the only available option, at least until use of this equipment became more widespread and agencies gained the knowledge and tools needed to perform the rebuilding themselves. In the case of diesel and CNG buses, agencies who rebuild their own automatic transmissions could insert their actual parts and labor cost (with or without accounting for overhead). Likewise, as more information became available on the rebuilding of hybrid drive systems, agencies could override the default setting by entering another, more appropriate, value. The costs for three bus technologies are shown in Table 40.

Table 40: Transmission Rebuild/Replacement Costs

\begin{tabular}{|c|c|c|c|}
\hline & Diesel & CNG & Hybrid \\
\hline Low & $\$ 10,500$ & $\$ 10,500$ & $\$ 31,300$ \\
\hline Medium & $\$ 11,750$ & $\$ 11,750$ & $\$ 35,850$ \\
\hline High & $\$ 13,000$ & $\$ 13,000$ & $\$ 40,400$ \\
\hline
\end{tabular}

Transmission rebuild cost assumptions for diesel and CNG buses are identical for low, mid and high values. For diesel and CNG buses the model assumed that:

- Transmissions would be rebuilt with factory remanufactured unit and included labor cost to R\&R the transmission.

- Rebuilds would be conducted by an outside vendor to capture all overhead costs associated with the rebuilds.

For hybrid buses, transmissions rebuild cost assumptions were based on removal of original hybrid propulsion system and replacement with a factory remanufactured unit.

In FMT, Biodiesel buses costs were similar to diesel buses in transmissions rebuild. Electric, Fuel Cell buses were set to have the similar costs to hybrid-electric buses.

\section{Scheduled and Unscheduled Vehicle Maintenance Cost}

Maintenance costs (Table 41) for all three bus types were taken from the four test sites and were categorized under scheduled and non-scheduled maintenance. In one case, however, projections had to be made where no actual field experience existed. That case consisted of unscheduled maintenance cost for 2007 diesel buses; it was estimated that these costs would be five percent greater than for pre-2007 diesel buses. Scheduled and non-scheduled 
maintenance costs were then combined to represent total maintenance costs for each of the three bus types.

Table 41: Maintenance Costs for Three Bus Types at the Four Test Sites

\begin{tabular}{|c|c|c|c|c|c|c|c|c|c|c|c|c|c|c|}
\hline & \multicolumn{3}{|c|}{ WMATA (NREL) } & \multicolumn{2}{|c|}{ KC Metro } & \multicolumn{2}{|c|}{ NYCT } & \multicolumn{2}{|c|}{ NYCT Year 2} & \multicolumn{2}{|c|}{ LBT } & \multicolumn{3}{|c|}{ WMATA $^{1}$} \\
\hline & $\begin{array}{l}\text { CNG- } \\
\text { CWI }\end{array}$ & $\begin{array}{l}\text { CNG- } \\
\text { Deere }\end{array}$ & Diesel & $\mathrm{D}-\mathrm{H}$ & Diesel & $\begin{array}{c}\text { D-H } \\
(125)\end{array}$ & CNG & $\begin{array}{c}\text { D-H } \\
(125)\end{array}$ & $\begin{array}{c}\text { D-H } \\
(200)\end{array}$ & G-H & Diesel & CNG & $\mathrm{D}-\mathrm{H}$ & Diesel \\
\hline Scheduled & 0.26 & 0.3 & 0.27 & 0.14 & 0.15 & 0.28 & 0.29 & 0.32 & 0.22 & 0.08 & 0.08 & 0.1 & 0.07 & 0.06 \\
\hline Unscheduled & 0.26 & 0.27 & 0.32 & 0.3 & 0.31 & 0.95 & 1.01 & 1.1 & 0.53 & 0.14 & 0.4 & 0.18 & 0.06 & 0.08 \\
\hline Total & 0.52 & 0.57 & 0.59 & 0.44 & 0.46 & 1.23 & 1.3 & 1.42 & 0.75 & 0.22 & 0.48 & 0.28 & 0.13 & 0.14 \\
\hline Propulsion & 0.14 & 0.13 & 0.12 & 0.13 & 0.12 & 0.36 & 0.35 & 0.34 & 0.16 & 0.07 & 0.2 & - & - & - \\
\hline Brake & 0.03 & 0.07 & 0.07 & 0.01 & 0 & 0.04 & 0.18 & 0.16 & 0.07 & 0 & 0.03 & - & - & - \\
\hline Bus Age & 4 & 3 & 2 & 2 & 2 & $2-3$ & $2-3$ & 4 & $2-3$ & $1-2$ & $3-4$ & $1-2$ & 1 & 1 \\
\hline Bus MY & 2001 & 2001 & 2000 & 2004 & 2004 & 2002 & 2002 & 2002 & 2004 & $\begin{array}{l}2004- \\
2005\end{array}$ & 2002 & $\begin{array}{l}2005- \\
2006\end{array}$ & 2006 & 2006 \\
\hline
\end{tabular}

1. The cost data were not used in the model at the time of writing this report, because the data collection was not accomplished yet. It will be updated when complete data were collected and analyzed.

Propulsion and brake related maintenance costs were isolated as subsets of the total maintenance costs. Propulsion maintenance costs excluded those costs associated with rebuilding the ICE for all three bus types, transmission rebuilding costs for diesel and CNG buses, and unique hybrid equipment rebuild costs. Those costs were itemized separately elsewhere in the model. As shown in Table 41, the maintenance costs varied dramatically at different test sites, because each had unique management and operation situations, and test buses at each agency were of different model years. Simply mixing test data from four sites was not appropriate at this point. The maintenance costs were more relative to the baseline fleet for each individual site. For the reason, pre-2007 diesel buses were selected as the baseline bus, and their maintenance data were assumed to be the average of four test sites. The other four bus type maintenance costs were referenced to the baseline and are presented in Table 42.

Table 42: Maintenance Costs in Dollar per Mile.

\begin{tabular}{|c|c|c|c|c|c|c|c|c|c|c|c|c|c|c|c|}
\hline & \multicolumn{3}{|c|}{ Pre-2007 Diesel } & \multicolumn{4}{c|}{ Diesel } & \multicolumn{3}{c|}{ Hybrid-Diesel } & \multicolumn{3}{c|}{ Hybrid-Gasoline } & \multicolumn{3}{c|}{ CNG } \\
\hline & Low & Mid & High & Low & Mid & High & Low & Mid & High & Low & Mid & High & Low & Mid & High \\
\hline Scheduled & 0.08 & 0.17 & 0.27 & 0.15 & 0.21 & 0.27 & 0.08 & 0.18 & 0.28 & 0.08 & 0.18 & 0.28 & 0.14 & 0.28 & 0.3 \\
\hline Unscheduled & 0.3 & 0.36 & 0.43 & 0.32 & 0.38 & 0.45 & 0.13 & 0.41 & 0.95 & 0.13 & 0.41 & 0.95 & 0.27 & 0.4 & 1.01 \\
\hline Total & 0.38 & 0.53 & 0.7 & 0.47 & 0.59 & 0.72 & 0.21 & 0.59 & 1.23 & 0.21 & 0.59 & 1.23 & 0.41 & 0.68 & 1.31 \\
\hline $\begin{array}{c}\text { Propulsion } \\
\text { Portion }\end{array}$ & 0.12 & 0.15 & 0.18 & 0.13 & 0.16 & 0.19 & 0.13 & 0.19 & 0.37 & 0.13 & 0.19 & 0.37 & 0.14 & 0.18 & 0.35 \\
\hline $\begin{array}{c}\text { Brake } \\
\text { Portion }\end{array}$ & 0.04 & 0.07 & 0.16 & 0.04 & 0.07 & 0.16 & 0.02 & 0.05 & 0.12 & 0.02 & 0.05 & 0.12 & 0.04 & 0.07 & 0.16 \\
\hline
\end{tabular}


Warranty is one of the key factors that affected bus maintenance costs. It must be noted, however, that given the newness of hybrid buses, OEMs made repairs and adjustment to buses at these sites that were covered under warranty and were not reflected in the maintenance costs. This also happened to other new bus technologies, where OEMs had an interest in monitoring equipment performance closely and in some cases the nature of repairs was not known in detail. OEMs might undertake repairs themselves as a way of obtaining firsthand feedback to further improve their product. In addition, new products typically encounter teething problems during the early stages of in-service field use that diminish over time as the product becomes refined. There were no available data over a long enough time span to capture the offset of costs by warranty. It was estimated from some reviews of historical bus maintenance data that maintenance cost would be reduced to the half of costs during the warranty period (standard two years warranty and possible extended warranty).

There was a concern that average speed might play a role in maintenance costs. The high distance-based NYCT maintenance costs were probably due to the slow operation (each mile to represent more hours and more fuel consumption). Arguments exist that engine life may be dictated by key-on hours or even by cumulative fuel consumed. A correction factor for "per mile" maintenance costs was introduced to account for higher per mile costs in low-speed operation. Based on a review of the data, it was determined that cost was twice as high at 6 mph as compared to $15 \mathrm{mph}$. NYCT data supported this thought. This suggests a correction of the kind.

\section{Correction Cost $=$ Original Cost $\times(a+b /$ average speed $)$}

In the absence of sufficient data, the researchers elected to use values $a=0.5$ and $b=7.5$ (shown as Weakened Function in Figure 25). These were in preference to values of $a=0.333$ and $b=10$ (shown as Original Function in Figure 25), which were also considered. The two functions are compared in Figure 25. 


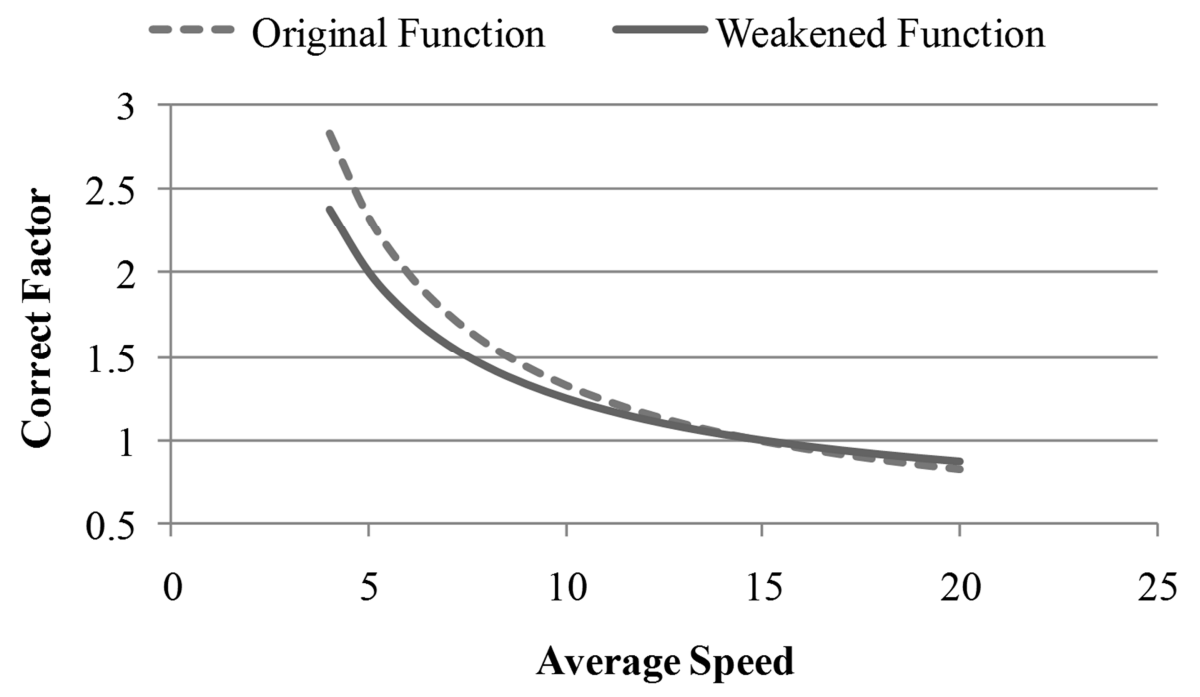

Figure 25: Comparison of Maintenance Costs' Speed Correct Factors

The following example shows how vehicle maintenance cost is corrected for warranty and operation speed factors. The example is for diesel hybrid bus operation for 12 years and at 12 $\mathrm{mph}$ average speed, and three years of extended warranty is purchased.

- Original hybrid bus total maintenance cost $=\$ 0.59 / \mathrm{mile}$

- First two years standard and three years extended warranty maintenance cost = $\$ 0.30 /$ mile

- $\quad$ Remaining seven years maintenance cost $=\$ 0.59 / \mathrm{mile}$

- $\quad$ Speed corrector factor $=0.5+(7.5 / 12)=1.125$

- Corrected hybrid bus total maintenance cost $=1.125 \times(5 / 12 \times 0.30+7 / 12 \times 0.59)=$ $\$ 0.53 / \mathrm{mile}$

The value of $\$ 0.53 /$ mile represents an average over the life of the bus, in baseline year dollars.

In FMT, Diesel, CNG, and Hybrid buses used the per mile maintenance cost from C-15 models. The maintenance cost of biodiesel buses was similar to what of diesel buses. For 
electric buses, maintenance costs were considered total propulsion-related maintenance costs minus engine-related maintenance costs. It was found that percentage of non-engine related maintenance costs of total cost was $89 \%$ [8]. So battery electric buses maintenance costs were obtained from hybrid-electric buses with a reduction of $11 \%$. Similarly, Fuel Cell buses maintenance costs increased by $29.5 \%$ from the costs for diesel buses that were found in AC Transit study [34]. Speed correction factors were applied for all technologies.

\subsubsection{GHG Emissions Model}

The model estimates two types of GHG emissions: well-to-tank (WTT) and tank-to-wheels (TTW) GHG emissions. WTT GHG emissions were the GHG generation that happened during fuel production and transportation process. TTW GHG happened during fuel consumption in buses. They were part of the tailpipe emissions that were emitted into the local environment.

\subsubsection{TTW (Tailpipe) Greenhouse Gas Emissions}

In FMT, the tailpipe GHG were considered to be only $\mathrm{CO}_{2}$ and methane. The EIA have concluded that methane is 23 times more effective as a greenhouse gas than $\mathrm{CO}_{2}$ [27]. TTW GHG model was developed in a similar way that fuel economy model was built in this study, because GHG has strong correlation with fuel consumption. $\mathrm{CO}_{2}$ and THC data were taken from the U.S. Department of Energy [121] and the U.S. Department of Transportation funded chassis dynamometer testing of buses on various cycles over a wide range of average cycle speeds. $\mathrm{CO}_{2}$ and THC models were generated from the chassis dynamometer data and were adjusted by in-field fuel consumption data to reflect the in-field bus operation. Weather and bus size effects used the same correction factors that were determined in fuel economy models but they were adjusted to reverse the trend towards GHG emissions.

Diesel and hybrid buses were assumed to emit no significant methane relative to $\mathrm{CO}_{2}$ output, and the methane quantity used in the CNG bus computation was derived from a methane/NMHC split of 0.95 that was found in FTA LCC study [10]. By averaging McCormick's latest B20 emissions study [24] and the WVU study, B20 biodiesel buses were found to emit 2\% higher $\mathrm{CO}_{2}$ at tailpipe than the diesel buses. Thus $2 \%$ value is related to the fuel energy content and relative carbon to oxygen ratio. Electric and Fuel Cell buses were considered having zero 
TTW GHG emissions. Figure 26 to Figure 29 show that the greenhouse gas data as $\mathrm{CO}_{2}$ equivalence for different type of $40-\mathrm{ft}$ bus technologies.

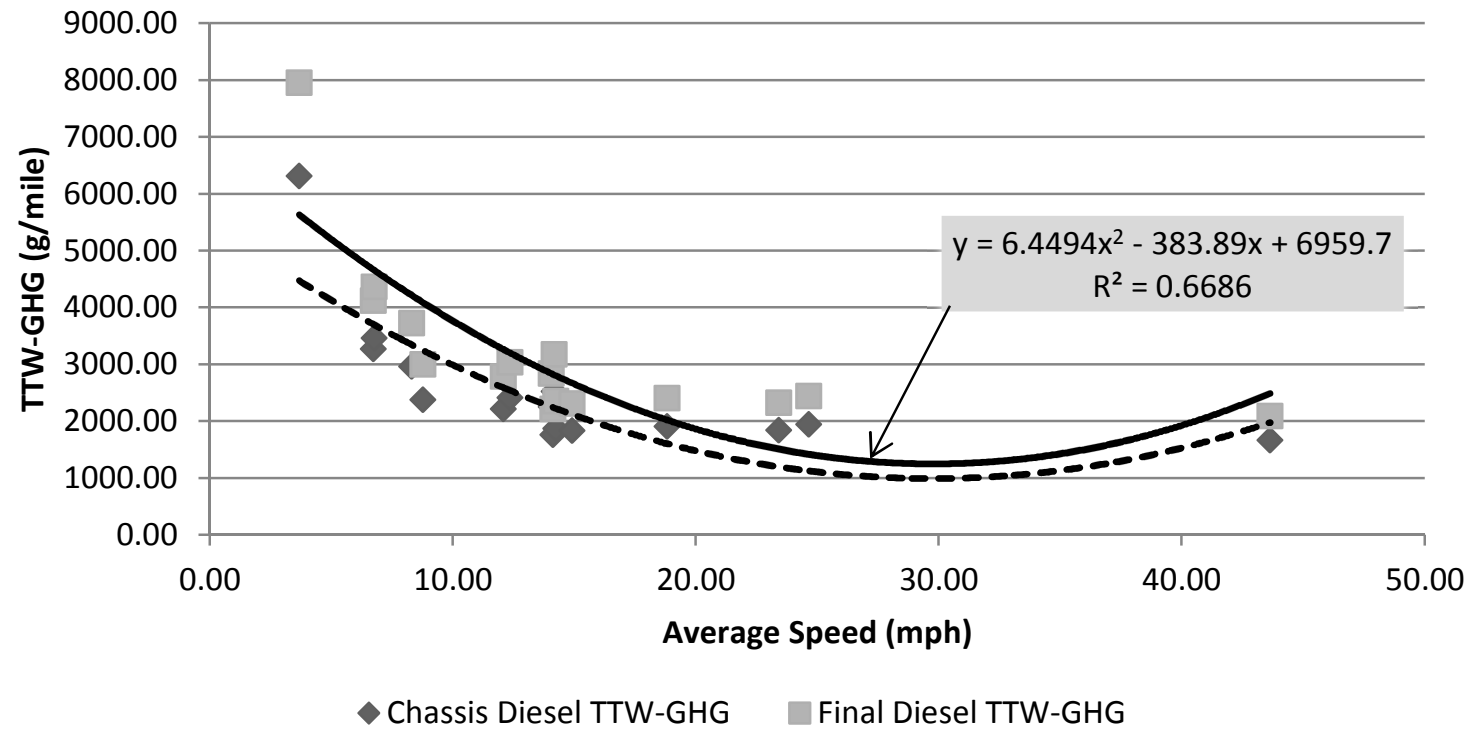

Figure 26: Diesel Bus GHG Data and Parabolic Trend Lines

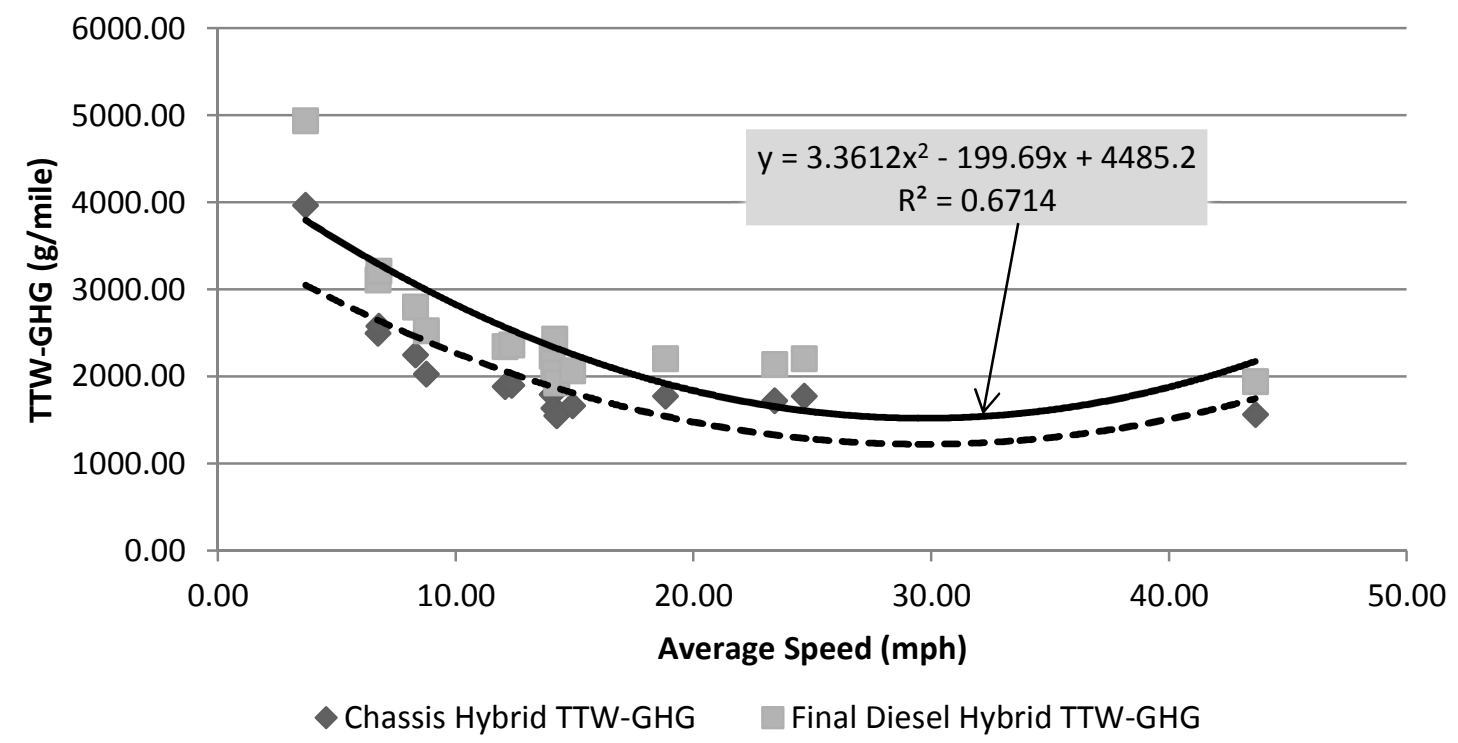

Figure 27: Diesel Hybrid Bus GHG Data and Parabolic Trend Lines 


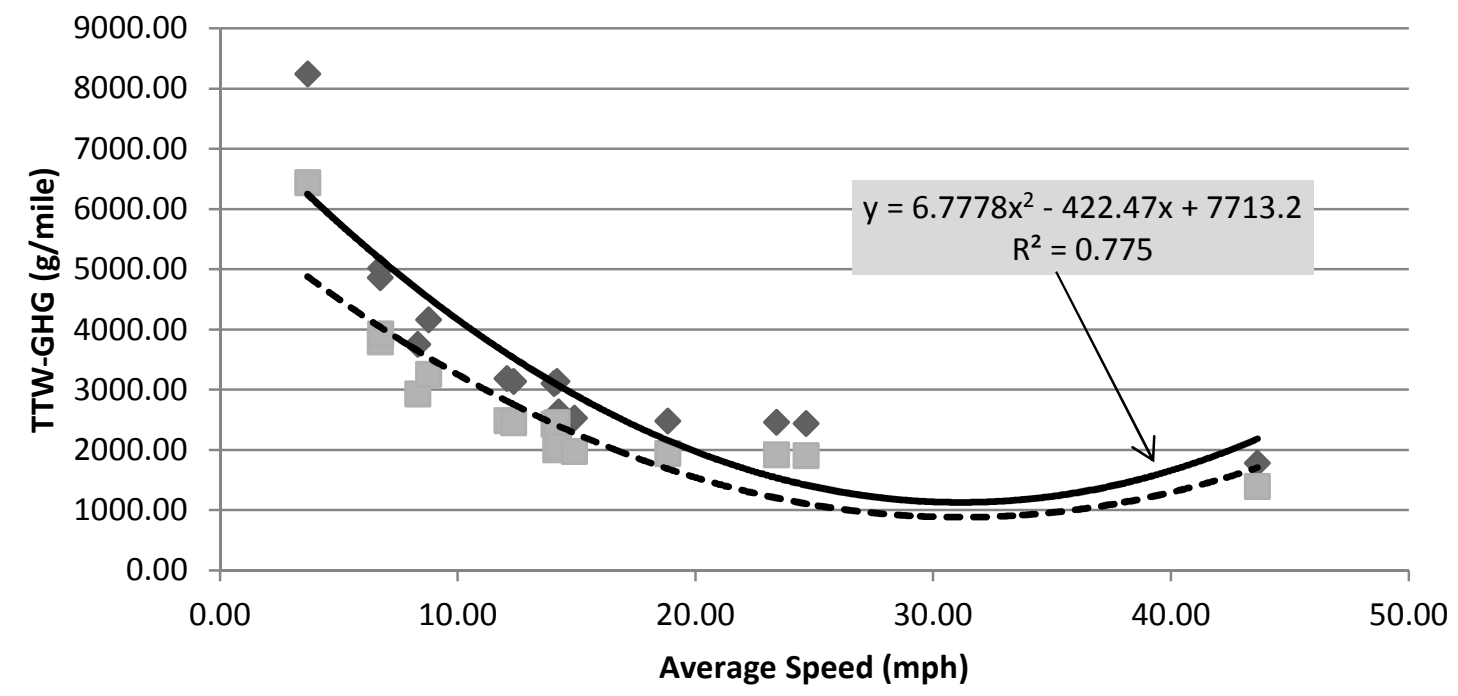

$\downarrow$ Final CNG TTW-GHG $\quad$ Chassis CNG TTW-GHG

Figure 28: CNG Bus GHG Data and Parabolic Trend Lines

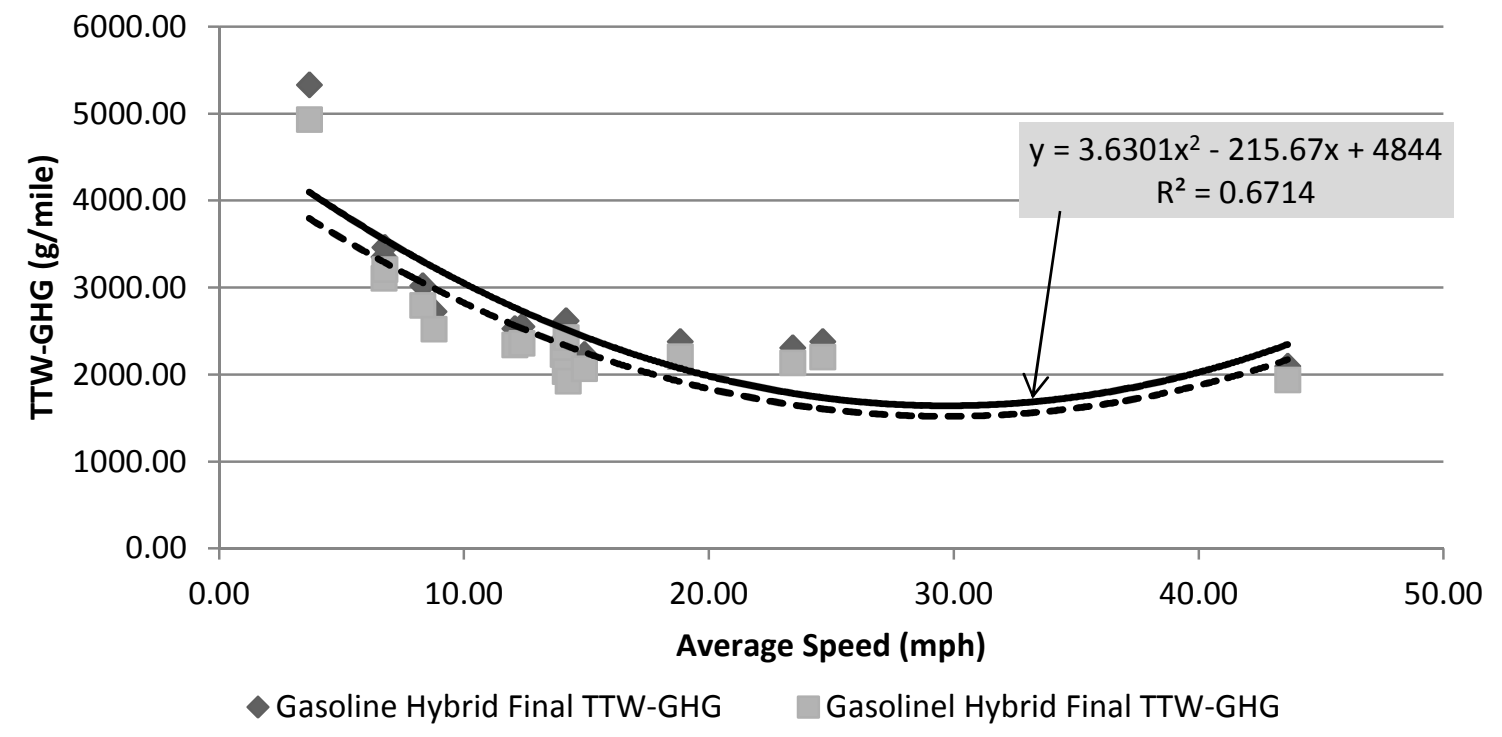

Figure 29: Gasoline Hybrid Bus GHG Data and Parabolic Trend Lines

\subsubsection{Well-to-Tank Greenhouse Gas Emissions}

WTT GHG emission prediction from 2007 to 2019 was from the GREET (Greenhouse Gases, Regulated Emissions, and Energy Use in Transportation) model developed by Argonne National Laboratory. The model was available at Argonne's website [28]. The WTT GHG emissions 
estimation used the GREET default setting on fuel production simulation methodologies and pathways. The only adjustment was that the ULSD market share (as opposed to Low Sulfur Diesel) was changed to $100 \%$ during the period (GREET uses $40 \%$ in $2007,60 \%$ in 2008 , and $80 \%$ in 2010). The GREET GHG emissions data were available in grams per MMBTU. The data were converted into grams per gallon by using the fuel properties supplied by the GREET model. In the model, the ULSD heating value is 129,488 BTU/gallon, and B100 biodiesel has 119,550 BTU/gallon. Therefore, the B20 biodiesel heating value is 127,500 BTU/gallon (a sum of $20 \%$ biodiesel and $80 \%$ ULSD heating value). The unit was converted from grams per gallon to grams per mile by using the fuel economy, estimated in the fuel economy section. Table 43 shows the WTT GHG emissions estimation per fuel consumption. Once annual fuel consumption was calculated by total mileage and fuel economy, total mass of WTT GHG emissions were easily calculated using the table.

Table 43: WTT GHG per Fuel Consumption

\begin{tabular}{|c|c|c|c|c|c|c|}
\hline Fuel Type & Diesel & CNG & $\mathrm{B} 20$ & Electricity & $\mathrm{H}_{2}$ & Gasoline \\
\hline WTT GHG (g $\left.\mathrm{g}_{\mathrm{co} 2} / \mathrm{mmBTU}\right)$ & 18249 & 17903 & 8983 & 228269 & 119325 & 20964.53 \\
\hline Fuel Heat Value (BTU/gal) & 129488 & $129800^{1}$ & 127500 & $129800^{1}$ & $129488^{1}$ & 110520 \\
\hline WTT GHG (g $\left.\mathrm{cos}_{\mathrm{c}} / \mathrm{gal}\right)$ & 2363 & 2324 & 1145 & 29629 & 15488 & 2317 \\
\hline
\end{tabular}

\subsection{Optimization Module}

Previous two sections present Input Module and Calculation Module. Input Module feeds fleet information to the FMT. The bus and route information and dispatch strategy would provide sufficient information for the Calculation Module to give the user a whole fleet's cost and GHG emissions evaluation. The users need an optimal solution on certain goals such as lowering overall cost and emissions. They define the goals by setting rankings (weights) to different goals in the Important Index of Input Module (Section 2.1.2).

The functions of the Optimization Module were to search a new dispatch strategy or suitable new technologies to best meet the goals. In optimization theory, the exhaustive searching method examines all possible solution and always provides the overall best solution. 
For bus fleet optimization, the exhaustive searching method would be the examination of every possible bus dispatch combination.

It was feasible to do the global search for a small fleet with few bus types and routes. Solution space could easily grow much large for larger fleets that might operate a number of buses on various routes especially the buses vary in technology, size or age. The Equation below estimates how large the solution domain could be for a fleet that had $\mathrm{n}$ buses with $\mathrm{m}$ types of different buses. The number of possible permutations is

$$
\prod_{i}^{m-1} \frac{\left(n-\sum_{j}^{m-1} x_{j-1}\right) !}{\left(n-\sum_{j}^{m-1} x_{j}\right) ! \times x_{j} !}=\frac{n !}{\prod_{i}^{m} x_{j} !}
$$

Where, $x_{j}$ represents the number of buses of bus type $i$.

The case in demonstration Section has a fleet operating 50 buses with five bus types.

For $n=50, m=5, x_{1}=1, x_{2}=4, x_{3}=10, x_{4}=10, x_{5}=25$.

$$
\frac{n !}{\prod_{i}^{m} x_{j} !}=\frac{50 !}{1 ! \times 4 ! \times 10 ! \times 10 ! \times 25 !}=6.2 e 24
$$

The solution space would become much larger if the model was used to search new bus technologies to replace old buses. The situation would increase the number of new types into the system. Genetic algorithm (GA) was chosen as an effective way of fast approaching a reasonable solution in a large and complex solution space. The technique is based on an analogy of natural biological process. It was inspired by the evolution of species and selection of individuals based on the law of "survival of the fittest". Next section introduces how the algorithm was implemented in the model.

\subsubsection{Genetic Algorithm Approach}

Basics of GA include population, individual, environment, selection, and reproduction. Population is generally a group of individuals, which is equivalent to bus dispatch planes in fleet optimization problem. The dispatch strategies (individuals) try to survive in a given environment. Environment is the total bus performance in cost and emissions against the management goals. 
The fitter an individual to the environment, the higher chance the individual survives the environment. The survival dispatch strategies (individuals) go to reproduction and create new dispatch population, a new generation. Mutation and crossover (described later in this section) happens during the reproduction phrase. The new generation repeats the process till a good dispatch strategy is found.

Figure 30 shows a flow chart for implementing GA in the fleet optimization and selection model. The first generation was created by randomly selecting a group of dispatch strategies from the whole solution domain. Each dispatch strategy performance was evaluated in fitness function defined by using a ranking matrix discussed later.

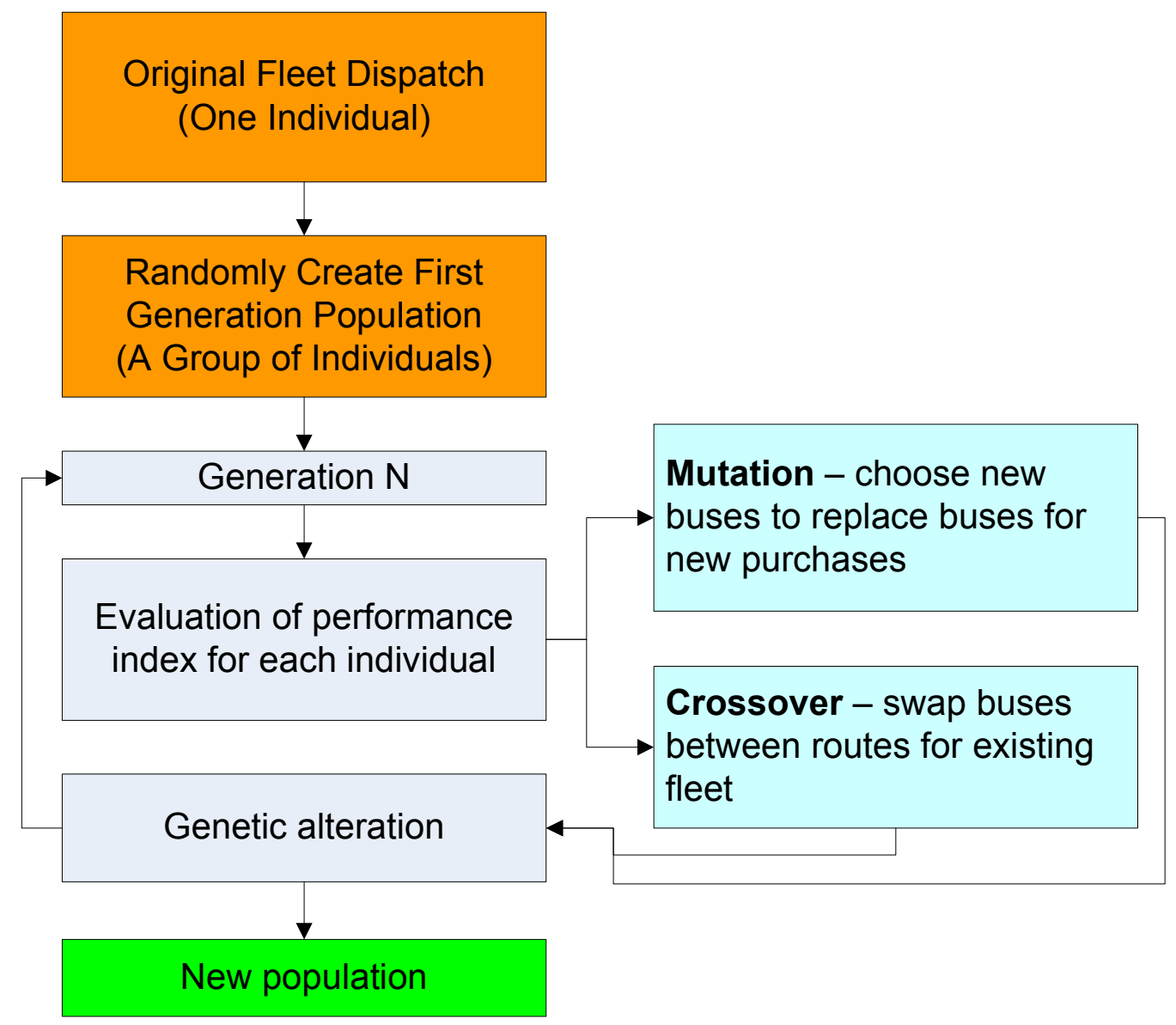

Figure 30: Genetic Algorithm Flow Chart for Fleet Management 
The dispatch strategies with high-level performance have better chance to survive to the next generation, and also had more chance to be selected as parent dispatch strategies to create new dispatch strategies through genetic alteration including crossover and mutation.

Crossover is a biological process that parents' chromosomes break and recombine to generate new chromosomes. In this fleet case, it was about exchanging bus locations and bus types from two individual dispatch strategies. Mutation was a process that allowed a bit or piece of gene changed its status or state. Mutation in this model was to change an aged bus type with a new one. Mutation is a great way in assessing new bus technologies.

The FMT model used the number of generations to control when to stop repeating GA process. The best dispatch strategy was selected from the final generation. Table 44 shows an example of all parameters used to control the GA process. Next section describes how the model generates dispatch strategies, creates fitness functions, and controls generation alteration. It covers the meanings and functions of these parameters.

Table 44: An Example of Genetic Algorithm Parameters in Optimization Module

\begin{tabular}{|l|c|l|}
\hline Variables & & Units \\
\hline Number of Individuals & 500 & Dispatches \\
\hline Number of Generations & 200 & Generations \\
\hline Crossover Rate & $50 \%$ & None \\
\hline Mutation Rate & $0.05 \%$ & None \\
\hline Number of Buses Replaced & 0 & Buses \\
\hline Convergent Ratio & 1.0 & \\
\hline
\end{tabular}

\subsubsection{Individual (a Dispatch Strategy) Creation}

A dispatch strategy (individual) is a chain of buses in the order as shown in Figure 31. Each route has its specific buses assigned into it. Fleet initial dispatch strategy was defined by the user in the Input Module. The initial dispatch strategy is special to the FMT. The initial dispatch strategy defines Total Bus Length for every route in the FMT. The tool uses the Total Bus Length to mimic passenger capacity for each route. For example, if a route has two 30 -ft buses 
and two $40-\mathrm{ft}$ buses, the total bus length of the route is $140 \mathrm{ft}$ (a result of $2 \times 30+2 \times 40$ ). The length determines bus assignment when any new dispatch strategy is created.

Certainly, the number of buses per route can change in a new dispatch strategy, because the vacancy of a large bus may require more than one smaller bus. It may cause concerns to fleet management for scheduling, passenger demand, headway regularity. In this dissertation and tool, no methodology and effort was developed to quantify and determine dispatching strategies according to those factors. To avoid the issues, the user has to require the model not to exchange buses with different sizes if the concerns exist. The simple way is to use the model to evaluate the same bus lengths only. The user has to split the original fleet into a few subfleets according to bus sizes. The FMT is used to evaluate and optimize the sub-fleets separately.

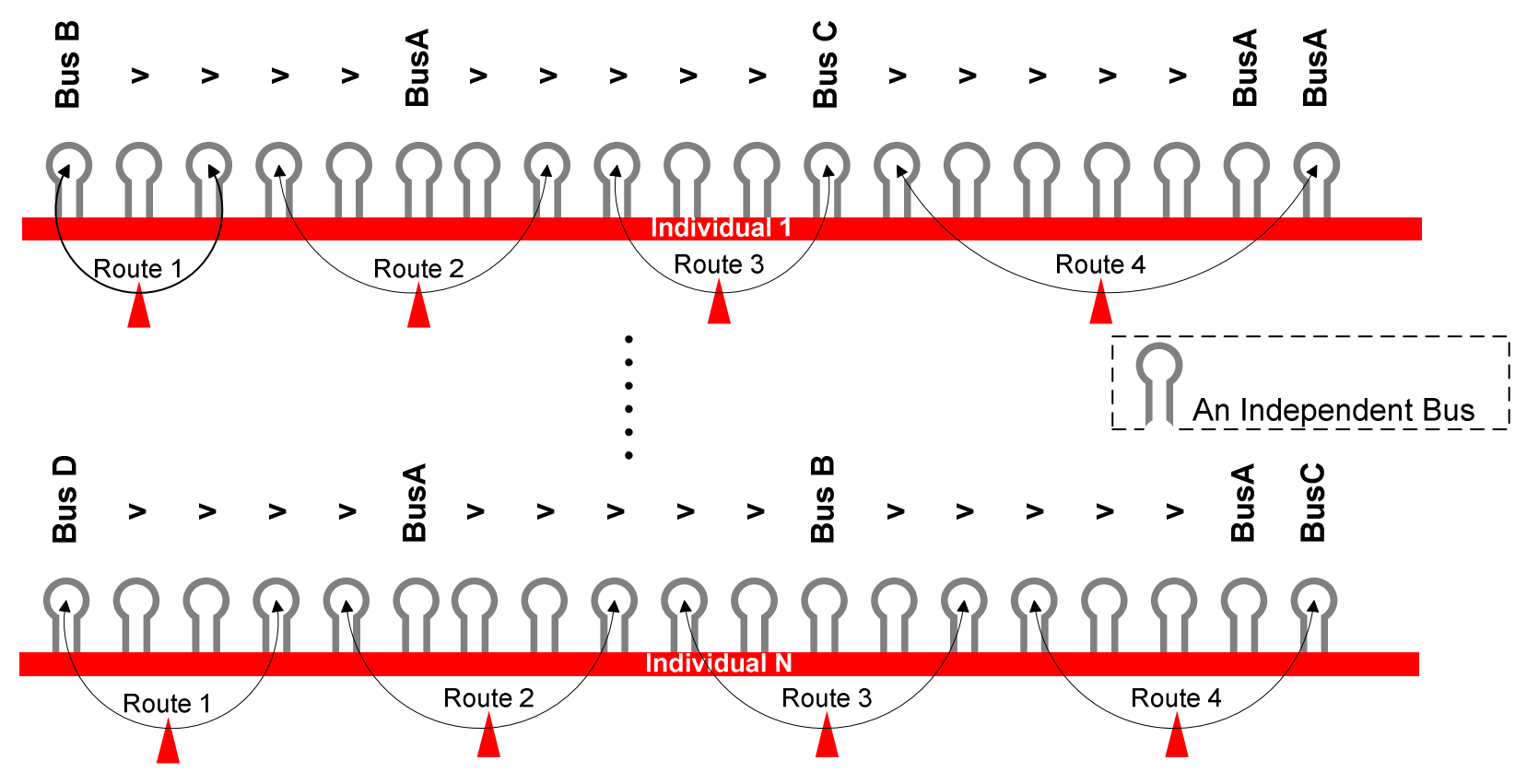

Figure 31: Examples of Bus Dispatch Strategies Represented as Gene Compositions

Here is addressed how the Total Bus Length is used to assign buses to each route, when a new dispatch strategy is created. The key rule of route assignment was to maintain Total Bus Length of each route and to remain as close to the original passenger capacity as possible. If 
the number of buses per route has to be a fix number to meet passenger demand and scheduling, the user should evaluate the mix-sized buses separately.

The initial dispatch strategy was entered by users. It assumed that the users have determined Total Bus Length for each route. As shown in the top illustration in Figure 32, Route 1 has total 140 feet in Total Bus Length and Route 2 has total 200 feet for the original route. A new bus chain was created and is shown at the bottom in Figure 32 . For Route 1 , the first three buses have a total of 110 feet. Adding the fourth bus to Route 1 would increase the Total Bus Length into 150 feet. The criteria to include the fourth bus to Route 1 are similar to the theory of numerical rounding. Inspired by "rounding to the nearest", a middle value was calculated. Between Total Bus Length of the first three buses and the first five buses, the middle value is 160 feet [(110 feet $+210 \mathrm{feet}) / 2]$. 160 feet is larger than the Total Bus Length for the first four buses (150 feet). The fourth bus was included in Route 1 as indicated in Figure 32. However, Route 2 showed the opposite case. Adding the fourth bus into Route 2 made the Total Bus Length (220 feet) larger than the middle number (205 feet). The bus was assigned into Route 3. Route 2 had five standard and small size buses. The new dispatch strategy for Route 2 replaced them with three larger and standard size buses. It would cause problems that three buses can not make up the schedule of Route 2. As described in the first paragraph of this section, user may want to only consider the exchanges between the same size buses. 


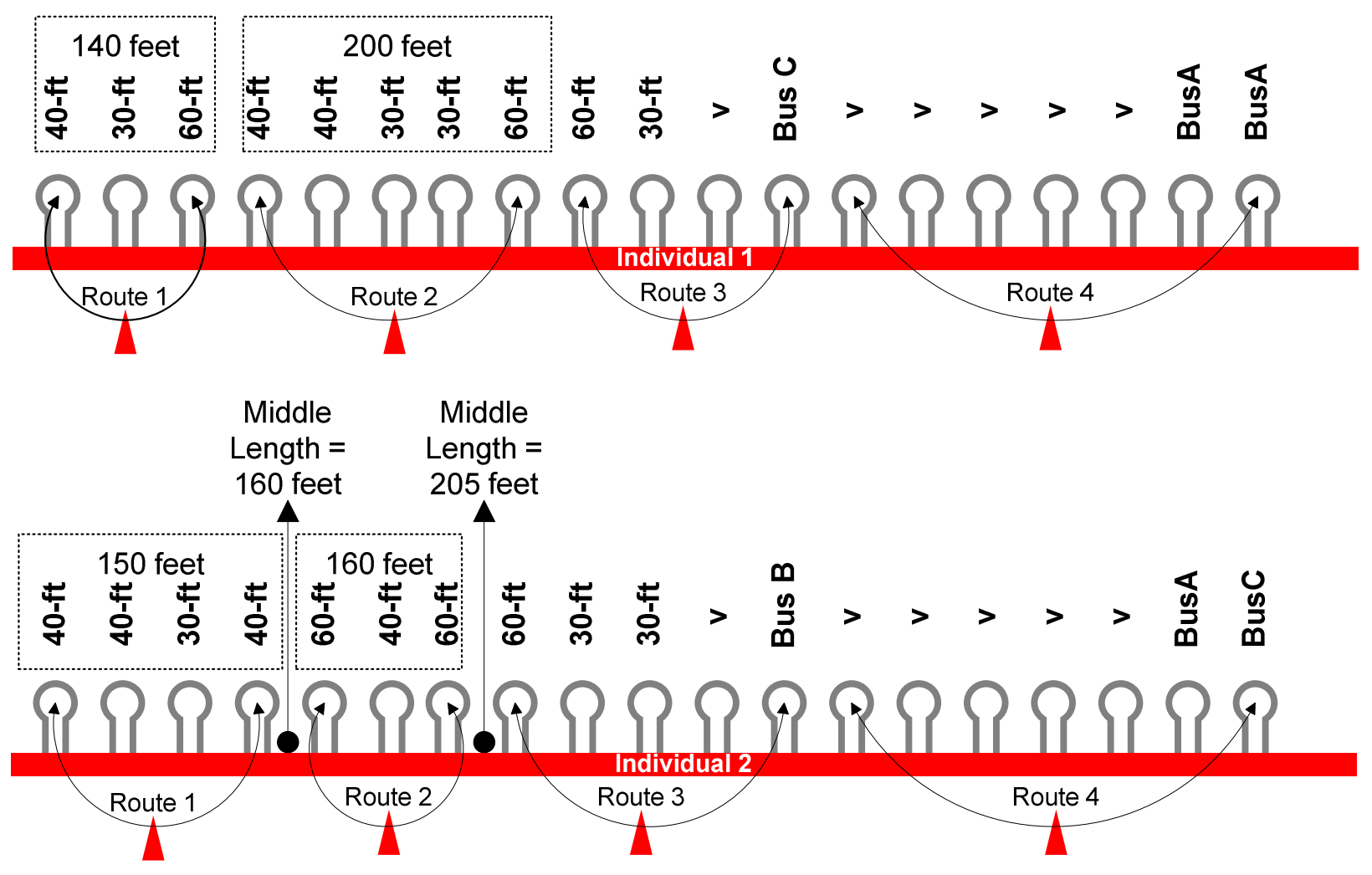

Figure 32: Illustration New Dispatch Bus-Route Assignment

\subsubsection{Fitness Functions}

The fitness functions determined how well a dispatch strategy performs against the goals. As soon as a dispatch strategy was defined, the Calculation Module computed individual's every cost and emissions elements. Costs, emissions and other performance results might not have the same units and not in the same scales. A methodology was needed to evaluate individual performance against the requirements.

A ranking matrix was introduced to transfer multi-dimensional requirements to rank and select dispatch strategies. Ranking was a critical measure in GA. Higher rank increased the probability for the dispatch strategy to be selected in the next round and to be used to create new dispatch strategy through genetic alternation in GA. 
In the ranking matrix, a rank was a compound effect of importance index and influence levels of dispatch strategy. The importance index was defined in Input Module. Number 10 indicated the most important concern to user, and number 0 indicated no concern. Influence levels to cost or emissions requirements were determined by dispatch strategy performance from the cost and emissions model. A few other requirements such as public image might be perception of a technology or public options formed by media.

The results calculated from the cost and emissions model are mostly like in different scales and units. Bus purchase could easily be worth millions of dollars, but training cost could be as little as thousands of dollars. GHG emissions were in $\mathrm{CO}_{2}$ equivalent tons per year, not directly measured by dollar value. Normalization was used so that the cost and GHG emissions factors could be compared in the same scale as shown in the following example.

In this example, the fleet was required to reduce TTW GHG emissions under the constraint of using the existing fleet. The fleet has five bus types (Type A to Type E). The buses served eight routes namely Route 1 to Route 8 . There were 40 possible combinations/pairs of bus and route.

The GHG emissions model could calculate the TTW GHG emissions from each combination or pair. Among the 40 pairs, it was easy to find the maximum and minimum TTW GHG emissions. Two values were labeled and recorded as TTW GHG Emissions max $_{\text {ax }}$ and TW GHG

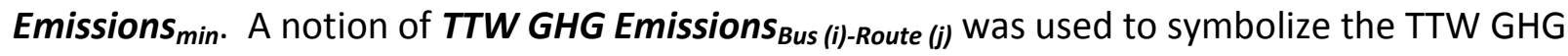
emissions if Bus i was operated on the Route $j$. $i$ was between $A$ to $D$ and $j$ was between 1 to 8 .

The rule of normalization in this study was to make good pair have larger value. In this case, the pair with least TTW GHG emissions would be 1 as a normalization output. 0 mean the bus-route pair produces highest TTW GHG emissions. Other bus-route pairs have their normalized TTW GHG emissions calculated in the following equation.

$$
\overbrace{\text { TTW GHG Emissions }}^{i, j}=\frac{T T W G H G \text { Emissions }_{\max }-\text { TTW GHG Emissions }_{\text {Bus }(i)-\text { Route }(j)}}{\text { TTW GHG Emissions } \text { Emax }_{\max }-\text { TTW GHG Emissions }}
$$


The bus dispatch strategy is a series of bus-route pairs. So TTW GHG Emissions of the dispatch strategy was a summarization of each bus-route pair. The following equation shows the normalized TTW GHG emissions for a dispatch strategy. The fleet has $n$ number of busroute pairs. The normalized emissions value ranges between 0 and $n$.

Dispatch TTW GHG Emissions

$$
\begin{aligned}
& =i \times \overbrace{\text { TTW GHG Emissions }}^{A, 1}+j \times \overbrace{\text { TTW GHG Emissions }}^{A, 2}+\cdots+y \\
& \times \overbrace{T_{T W G H G ~ \text { Emissions }_{D, 7}}}+z \times \overbrace{\text { TTW GHG Emissions }}^{D, 8}
\end{aligned}
$$

where,

$\mathrm{i}, \mathrm{j}, \ldots, \mathrm{z}$ are numbers of repeated bus-route pairs found in the dispatch strategy.

Similar calculation was carried for every requirement. Table 45 below represents how each requirement was determined in the Important Index.

Table 45: Characteristic of Requirements in Importance Index

\begin{tabular}{|l|l|c|c|}
\hline Requirements & \multicolumn{1}{|c|}{ Calculation } & Low Output Meaning & High Output Meaning \\
\hline GHG Emissions & $\begin{array}{l}\text { = Total } \mathrm{CO}_{2} \text { Equivalent Emissions over a } \\
\text { year }\end{array}$ & High $\mathrm{CO}_{2}$ Emissions & Low $\mathrm{CO}_{2}$ Emissions \\
\hline $\begin{array}{l}\text { Vehicle Related } \\
\text { Capital Cost } \\
+ \text { Bus Price } \\
+ \text { ESS Replacement Cost } \\
+ \text { +Engine R\&R Cost at Current Year } \\
+ \text { Transmissions R\&R Cost at Current Year }\end{array}$ & High Cost & Low Cost \\
\hline $\begin{array}{l}\text { Other Capital } \\
\text { Cost }\end{array}$ & $\begin{array}{l}\text { Training Cost } \\
\text { + Infrastructure Cost per Bus } \\
+ \text { Equipment Cost per Bus }\end{array}$ & High Cost & Low Cost \\
\hline Operation Cost & $\begin{array}{l}\text { Maintenance Cost } \\
+ \text { Fuel Cost }\end{array}$ & High Cost & Low Cost \\
\hline $\begin{array}{l}\text { Infrastructure } \\
\text { Cost }\end{array}$ & $=$ Infrastructure Cost per Bus & High Cost & Low Cost \\
\hline Staff Training & $=$ Training Cost & High Cost & Low Cost \\
\hline Social Image & $=$ Function of Bus Technology & $\begin{array}{c}\text { Advanced Drivetrain } \\
\text { Technology }\end{array}$ \\
\hline
\end{tabular}

Table 46 shows a ranking matrix example used to compare dispatch strategies. The fleet goals are listed in top row, and the importance levels are listed below. The importance level ranged from 0 to 10 . Again, number 0 meant the goal had no value to users. Number 10 meant 
user the goal is critical to user. Dispatch strategies were listed on the first column. Each element at $x$ column and y row represented the level of influence from Dispatch y on requirement $\mathrm{x}$. It was a real number between 0 and total number of buses. Calculation was based on the normalization calculation described in the previous paragraph. Larger values indicated that the dispatch strategy has good impact on the goal and vice versa. For example, Table 46 shows that Dispatch N is superior in GHG emissions to Dispatch 2, when Dispatch N and Dispatch 2 score 42.7 and 20.4 on GHG Emissions requirement respectively.

Table 46: An Example of Ranking Matrix for Fitness Function

\begin{tabular}{|c|c|c|c|c|c|c|c|c|}
\hline & 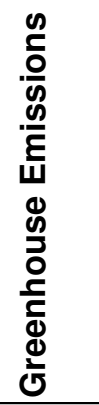 & 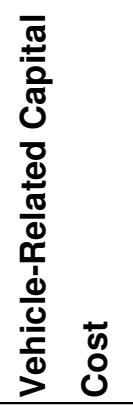 & 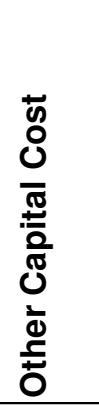 & 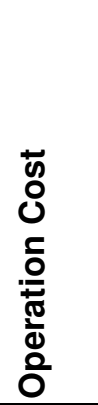 & 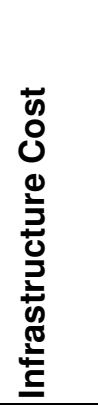 & 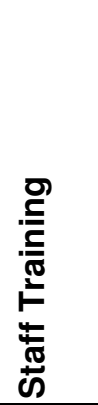 & 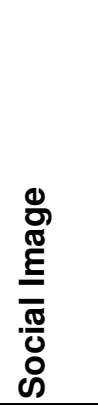 & 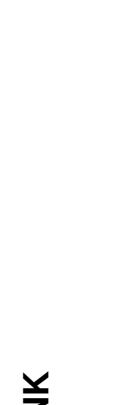 \\
\hline & 10 & 5 & 8 & 9 & 1 & 1 & 3 & $\underset{\mathbb{x}}{\mathbb{x}}$ \\
\hline Dispatch 1 & 20.4 & 47.2 & 42.7 & 15.2 & 27.6 & 23.7 & 22.4 & 1036.9 \\
\hline Dispatch 2 & 11.8 & 38.6 & 40.4 & 40.1 & 38.4 & 15.8 & 34.4 & 1152.5 \\
\hline$\ldots$ & $\ldots$ & $\ldots$ & $\ldots$ & $\ldots$ & $\ldots$ & $\ldots$ & $\ldots$ & $\ldots$ \\
\hline Dispatch N & 42.7 & 39.4 & 41.2 & 28.9 & 45.6 & 5.9 & 11.2 & 1298.8 \\
\hline
\end{tabular}

Overall performances were compared in Rank column on the far right of Table 46. Rank was calculated as shown in the following equation.

$$
\text { Rank }=\sum_{i}^{n} \text { ImptIndex }_{i} \times \text { InfluenceLevel }_{i}
$$

In that way, Dispatch N with 1298.8 was the best one to have better overall performance. The dispatch strategy would have higher chance to be selected or evaluated in next generation.

\subsubsection{Genetic Evolution}

Genetic evolution involved environment selection, genetic crossover, and genetic mutation. For fleet optimization, environment selection used fitness function to select dispatch strategies 
basing on their performance. The crossover and mutation was used to create new dispatch strategies. Crossover recombined and rearranged existing buses to all routes. Mutation introduced new buses to change bus type composition.

\subsubsection{Environment Selection}

The roulette wheel selection algorithm was used to select fit dispatch strategies in the model. The method selected dispatch strategies based on its fitness (normalized performance output). A dispatch strategy rank was evaluated against all dispatch strategies rank (total fitness) in the population. The following equation defines the probability for a dispatch strategy to be selected. Higher the dispatch strategy rank was, higher chance the dispatch strategy was selected.

$$
\text { Selection Probability } i=\frac{\text { Rank }_{\mathrm{i}}}{\sum_{\mathrm{j}=1}^{\mathrm{n}} \operatorname{Rank}_{\mathrm{j}}}
$$

where,

Rank $_{\mathrm{i}}$ is the rank of dispatch strategy i calculation,

$\mathrm{n}$ is total number of dispatch strategies in its population.

A random number between 0 and 1 was generated after each dispatch strategy's probability was defined. Selection of dispatch strategy was determined by the random number and cumulative probability value associated to dispatch strategies.

Figure 33 shows an example of selecting one dispatch strategy in a population with $\mathrm{N}$ dispatch strategies. Dispatch strategies' probabilities were calculated and are shown in Figure 33 (a). Relative cumulative probabilities were calculated and are presented in Figure 33 (b). In this example, a random number of 0.37 was used. The random number was between Dispatch 4 and Dispatch 5's cumulative probabilities. Thus, Dispatch 5 was picked in the process of the roulette wheel selection algorithm. 

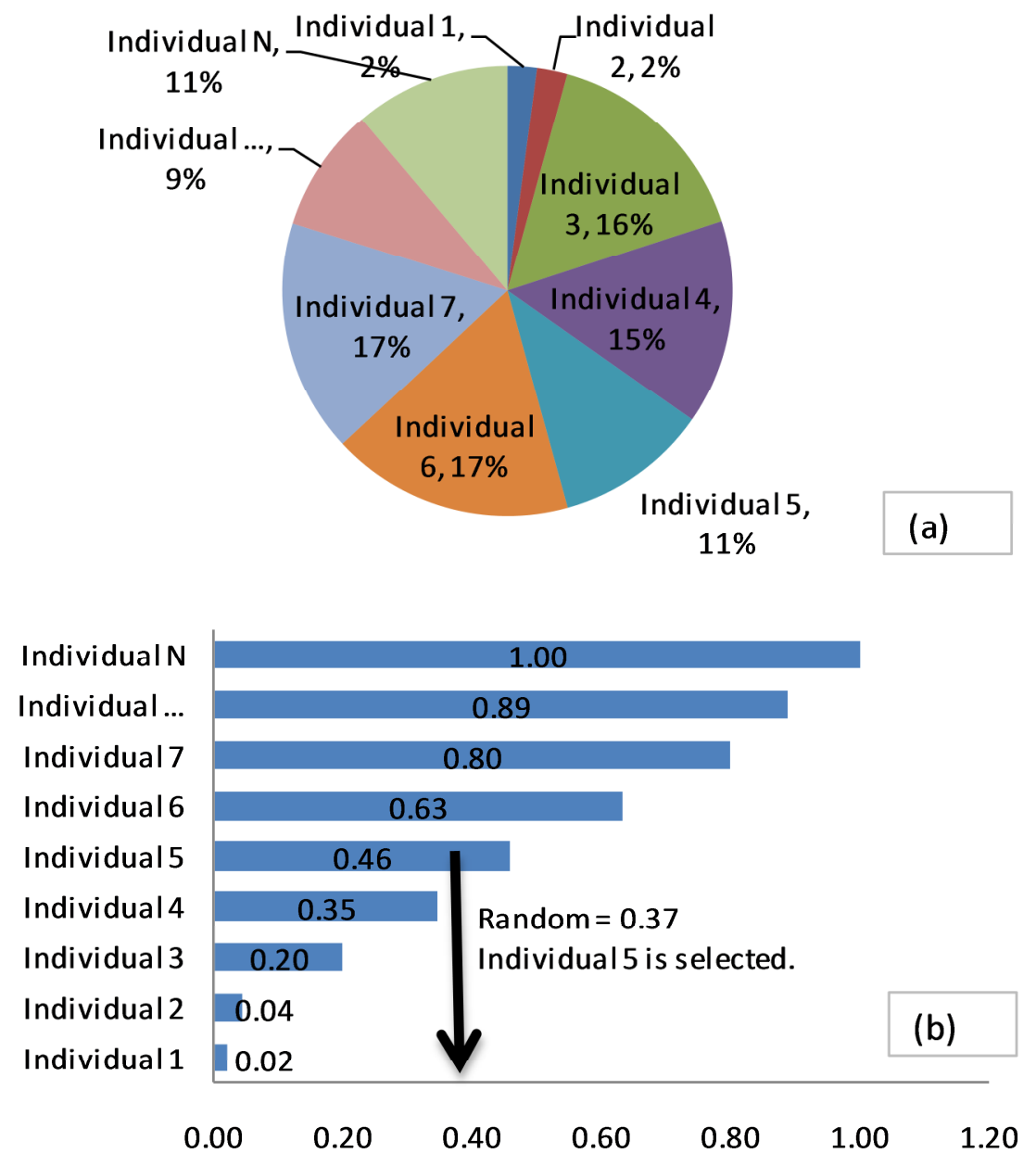

Figure 33: Roulette Wheel Dispatch Selection Algorithm

The selection algorithm was used to pick dispatch strategies in following circumstances.

1. Selecting dispatch strategies for the new generation.

2. Selecting parent dispatch strategies used for create new offspring dispatch strategies for Crossover operation addressed below.

\subsubsection{Crossover}

A process of finding two different dipatches and recombining their bus assigment to create one or more new dispatch strategies was used. Not all dispatch strategies could become parent dispatch strategies. A crossover rate was set to determine the number of parent dispatch strategies to reproduce new offspring dispatch strategies for a new generation. The rate was a percentage. For example, when the rate was set at 0.5 , it meant $50 \%$ of new dispatch 
strategies would be a result of crossover process. The remaining $50 \%$ of dispatch strategies were from the previous generation.

A pair of parent dispatch strategies created a pair of new offspring dispatch strategies during crossover. The roulette wheel selection method was used to select one parent dispatch strategy, the father dispatch strategy. The selection method ensured that the father dispatch strategy generally contained more good bus-route pairs. The other dispatch strategy (mother dispatch strategy) selection however was a random pick among all available dispatch strategies in the generation. It helped to exploit the whole generation. It assumed that even a low rank dispatch strategy might contain some new and unknown good bus-route pairs.

An uniform algorithm was adopted to create offspring dispatch strategies. The offsrping dispatch strategies randomly picked bus-route combinations from the parent dispatch pair. In other words, father and mother dispatch strategies had the equal chance to continue their genetic information (bus-route combinations) during the creation of offspring dispatch strategies. The following charts (Figure 34 and Figure 35 ) below use an example to illustrate the process. The example is for a fleet of nine buses. The arabic number indicates the bus number for each buses.

Step 1: Select Parents

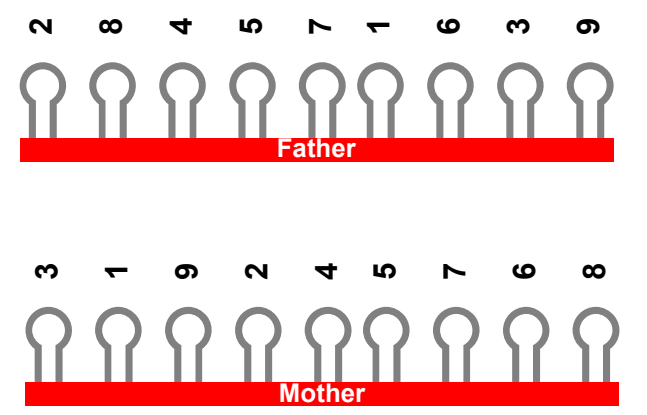

Step 2: Create Two Siblings (Sibling 1 identical to Father, Sibling 2 identical to Mother)

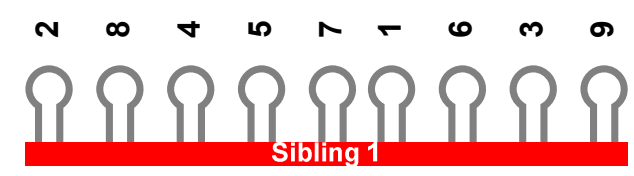

Figure 34: Crossover Process Illustration (Step 1 and 2 of the three steps)

Step 1 in Figure 34 shows a pair of parent dispatch strategies. They were selected per the selection alogrithm described in the beginning of the section. Buses were in different 
sequences (there was a chance that the parent dispatch strategies were the same). So crossover could be implemented.

Step 2, two offspring dispatch strategies were temperately created. Offspring 1 was identical to the father dispatch strategy, and Offspring 2 was the same as the mother dispatch strategy.

Step 3 (Figure 35), a 9-number chain was created randomly. It was made of digits 0 and 1. 0 and 1 occurrence probabilties are 50-50. Crossover started from the right side to the left side.

The rule of using bus-route pair from parent dispatch strategies was:

- For offspring dispatch strategy 1 , digit 1 in the random number chain meant to keep the bus number from the father dispatch strategy.

- For offspring dispatch strategy 1 , digit 0 meant to take what the mother dispatch strategy was.

- For offspring dispatch strategy 2, digit 1 in the random number chain meant to keep the bus number from the mother dispatch strategy.

- For offspring dispatch strategy 2, digit 0 meant to take what the father dispatch strategy was.

- Digit 0 required a change of bus number. Bus number was unique in a transit fleet. Each number indicated a specific bus. A rule had to be established to avoid assigning one bus number to multiple locations. Figure 35 shows the process. 
(1)

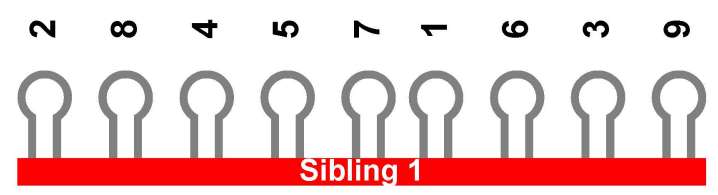

(2)

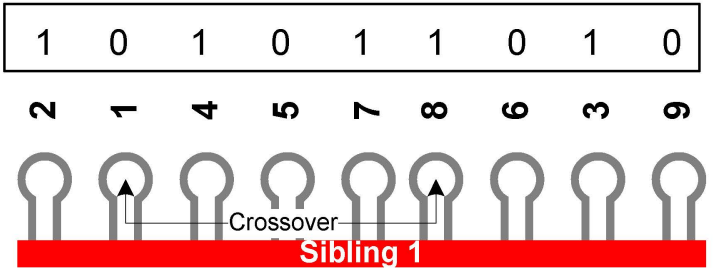

$\underset{\text { Dad }}{\mathbf{4}} \underset{\text { Dom }}{\mathbf{\Lambda}}$

$\begin{array}{lll}\text { I } & \text { I }\end{array}$

$\infty \quad+N \wedge \infty \quad 0 \quad m \quad 0$

(3)

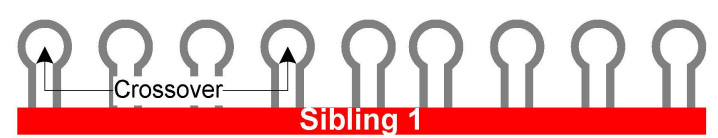

(4)

$$
\underset{\text { Mom }}{4} \underset{\text { Dad }}{4} \underset{\text { Mom }}{4}
$$

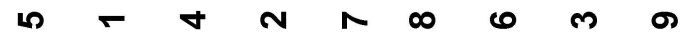

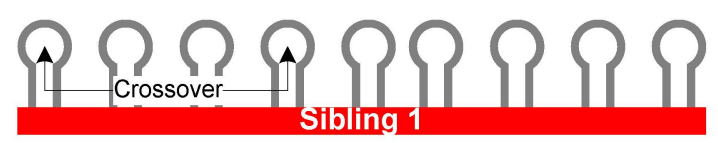

(5)

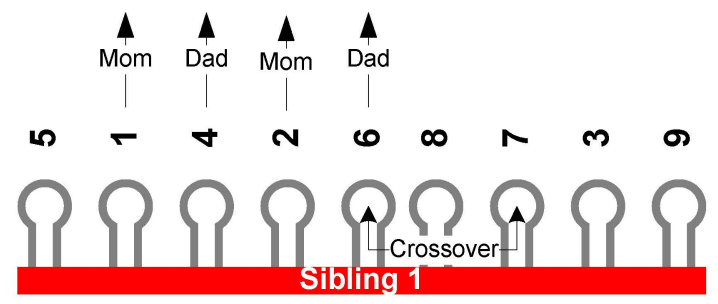

(6)

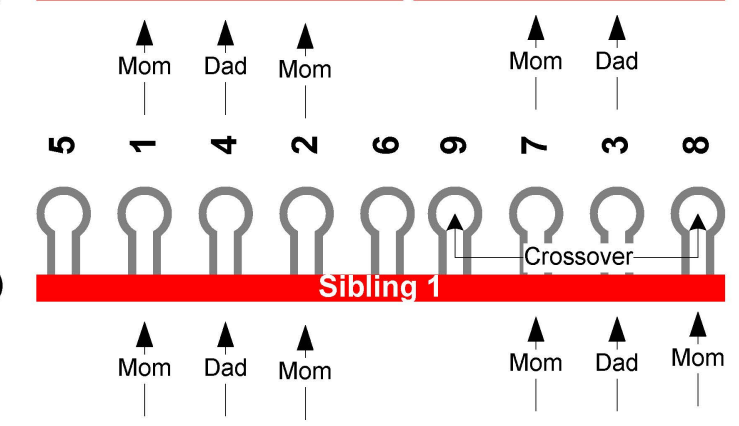

- Mom - Mother Dispatch

- Dad - Father Dispatch
(1) Offspring dispatch 1 has the same bus sequence with father dispatch. An Arabic number is associated to a bus number

(2) A chain of digits 0 or 1 was created in random order before crossover. Digits 0 and 1 had equal chance to be created. Total number of 0 and 1 equals to the number of buses.

Crossover starts from left to right. If digit 1 is found, no change to Sibling dispatch 1 . In this case, the first bus is still Bus 2 .

If digit 0 is found, its bus switched to the bus number in mother dispatch. As shown in (2), the second bus number becomes bus number 1 . Now offspring dispatch 1 had two Bus 1. So an internal crossover was made. Offspring dispatch 1's original bus number was bus number 8 . Instead of simply changing Bus 8 to Bus 1 , Bus 8 and Bus 1 swap with each other in offspring dispatch 1 . As shown in (2), the second gene swap with bus number 1 which used to at the sixth spot.

The digit 1 is found for the third bus location, no change was made.

(3) Digit 0 was found for the fourth location, the internal crossover was made between fourth and first one.

(4) The fifth and sixth location did not change because of the digit 1 .

(5) Again the Internal crossover was made between the fifth and seventh locations. No change was made to the eighth one.

(6) Internal crossover is made between sixth and ninth.

* In the end of crossover, the offspring dispatch 1 has four bus locations same to the mother dispatch and two gene order same to the father dispatch. A new dispatch was created.

Figure 35: Step 3 in Crossover Process 


\subsubsection{Mutation}

Mutation was a process of gene alteration in the gene reproduction. The process changed and created new genes rather than taking genes from parents. When implementing the mutation process to the bus fleet, it was a good way for fleet to exploit new choice on bus technologies. Mutation process replaced certain number of existing buses in a dispatch strategy with new buses. The new dispatch strategy generated by the mutation process entered into the new generation and would go through the environment selection like the other dispatch strategies. Mutation process was used in assisting decision making on choosing right bus types, when fleet needed to retire old buses.

There were two variables used in mutation process in the FMT, mutation rate and number of replacement buses. Mutation rate defined the chance for mutation to occur in a new dispatch strategy generation. The mutation rate in the model was a percentage. For example, a $5 \%$ mutation rate indicated that $5 \%$ of total dispatch strategies could be mutated to include new technologies. The number of replacement buses defined the number of buses would be replaced during the mutation process in a given dispatch strategy.

The following chart (Figure 36) shows how mutation was carried in the FMT. 


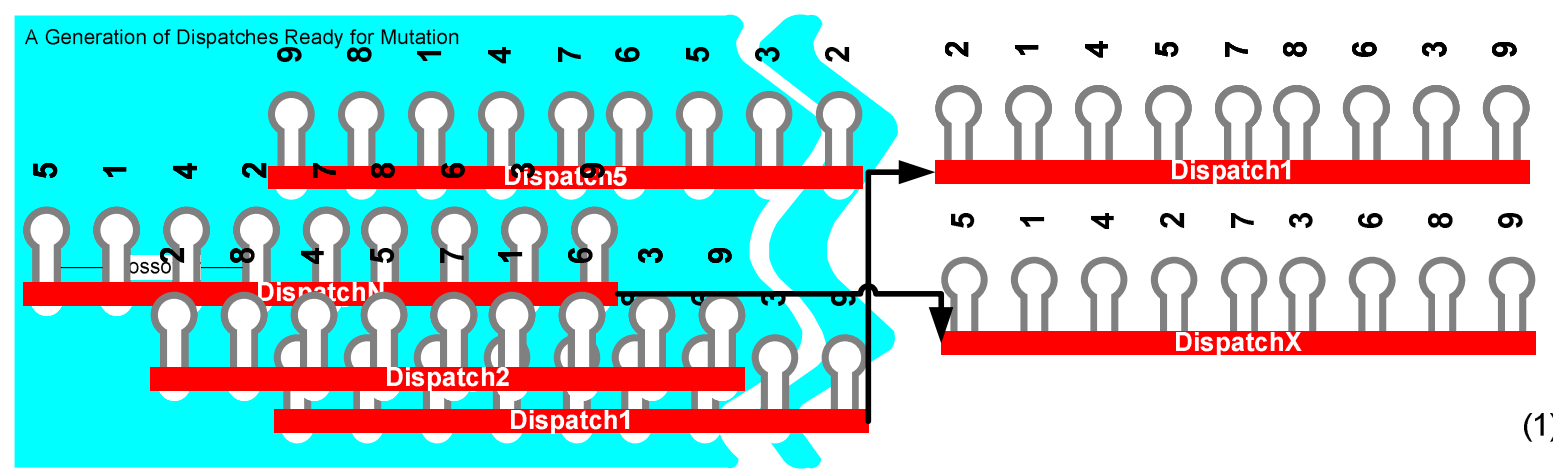

(1) Dispatches selected randomly from the whole generation of dispatches.

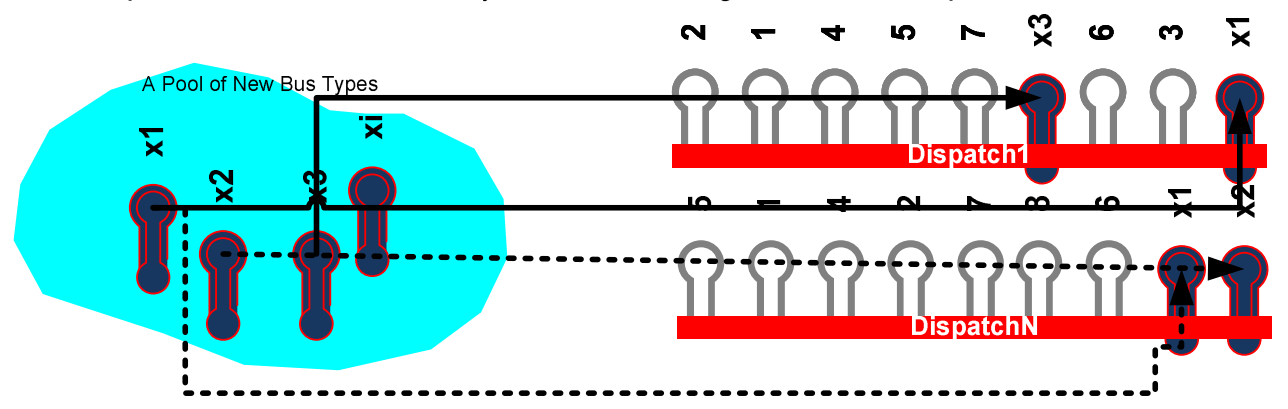

(2) Aged buses in the individuals picked in Step 1were forced to be replaced by new bus types randomly selected from a pool of new bus types.

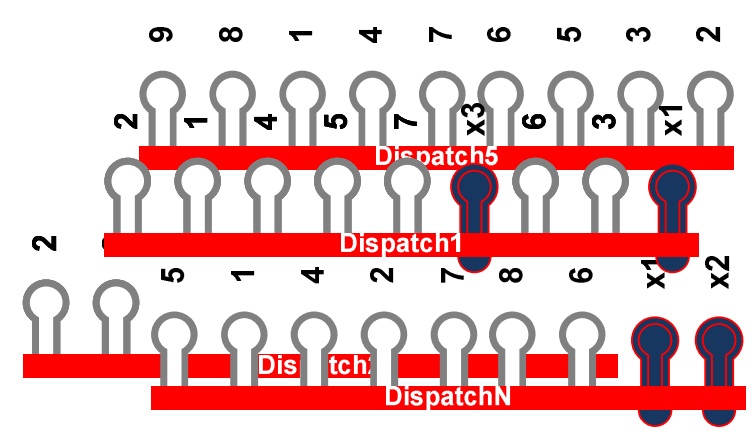

(3) The mutated dispatches were mixed into the rest unmutated dispatches together so that a new generation was created.

Figure 36: Steps of Searching New Bus Technologies in Mutation 


\section{CHAPTER 3 - TOOL DEMONSTRATION AND USERS INSTUCTION}

The first step was to test the tool on a four-bus fleet. It is easy to evaluate all possible dispatch strategies with four buses. It demonstrated the capability of the tool to search elite dispatch strategies in different optimization scenarios. Section 2 presents using the tool in two scenarios,

- The first aimed on reducing monetary spending over the fleet,

- The second aimed at reducing total WTW GHG emissions from operating the buses.

The tool was then applied to a larger fleet operating 35 buses in Section 3.2. A step-bystep illustration is presented to serve as an users instruction to the tool. The tool was not only used to search the best dispatch strategy, but also used to find new bus technologies. The tool was applied in three optimization scenarios,

- The first aimed at reducing monetary expense,

- The second aimed at reducing the total WTW GHG emissions,

- The third aimed at reconciling multiple goals of cost and emissions reductions.

\subsection{Validation Test of Using Fleet Management Tool on a Four-Bus Fleet}

\subsubsection{The Four-Bus Fleet Bus and Route Information}

The fleet had four different types of buses. Table 47 gives the detailed bus information of the four buses including one conventional diesel bus, one hydrogen fuel cell bus, one diesel hybrid-electric bus, and one CNG bus.

Table 47: Bus Information of a Four-Bus Fleet

\begin{tabular}{|c|c|c|c|c|c|}
\hline Bus Series & Bus Technologies & Model Year & Total Amt* & Bus Length & Bus Age \\
\hline BusD & Conventional CNG & Post 2010 & 1 & $40-\mathrm{ft}$ & 1 \\
\hline BusC & Fuel Cell - Hydrogen & $2007-2010$ & 1 & $40-\mathrm{ft}$ & 2 \\
\hline BusB & Diesel Hybrid-Electric & Post 2010 & 1 & $40-\mathrm{ft}$ & 1 \\
\hline BusA & Conventional Diesel & Pre-2007 & 1 & $40-\mathrm{ft}$ & 10 \\
\hline \multirow{2}{*}{ Total Amt } & \multicolumn{5}{|l}{} \\
\hline
\end{tabular}


The CNG bus and hydrogen fuel cell bus each had a fueling facility that was built with a capacity of serving five buses. Components such as engine, transmission, hybrid drive system all followed the default replacement schedules for each bus types (default schedules were described in Section 2.2.1). Similarly, default maintenance costs (Section 2.2.1) were applied for all bus technologies as well.

The four buses were operated over four routes (Table 48). Two routes were urban transit routes, where their average speeds were less than $10 \mathrm{mph}$. The third one was a suburban route ( $24 \mathrm{mph}$ in average speed). The remaining one was a high-speed route (43 $\mathrm{mph}$ in average speed). Each route required only one bus trip a day. Annual distances of four routes ranged from $1 \mathrm{k}$ to $7 \mathrm{k}$ miles. These distances were far below the national average in the U.S. The assumptions were only for the sake of calculation convenience. As the result, the cost and WTW GHG emissions would be much lower compared to the realistic output from a typical bus fleet operation.

Table 48: Route Information of the Four-Bus Fleet in Validation Test

\begin{tabular}{|c|c|c|c|c|c|c|}
\hline Route ID & Distance & Trip Time & Trips Per Day & Ave Speed & Daily Distance & Annual Distance \\
\hline Unit & Mile & Minute & Trips/Day & mph & Mile & Mile \\
\hline Route 1 & 3.5 & 40.0 & 1.0 & 5.3 & 3.5 & 1277 \\
\hline Route 2 & 9.0 & 55.0 & 1.0 & 9.9 & 9.0 & 3285 \\
\hline Route 3 & 19.0 & 47.0 & 1.0 & 24.3 & 19.0 & 6935 \\
\hline Route 4 & 12.9 & 18.0 & 1.0 & 43.0 & 12.9 & 4708 \\
\hline
\end{tabular}

\subsubsection{The Four-Bus Fleet Test Validation Result}

The four-bus fleet has 24 possible bus dispatch strategies from all possible permutations. Figure 37 lists all 24 dispatch strategies named Dispatch 1 to Dispatch 24. Figure 37 shows GHG emissions and cost for each dispatch strategy.

The best dispatch strategy was found by exploring all possible dispatch strategies. Dispatch 5 was found as the best dispatch strategy with the lowest GHG emissions (36 ton/yr). Dispatch 19 was the best dispatch strategy with the lowest operation cost $(17,540 \$ / y r)$. 


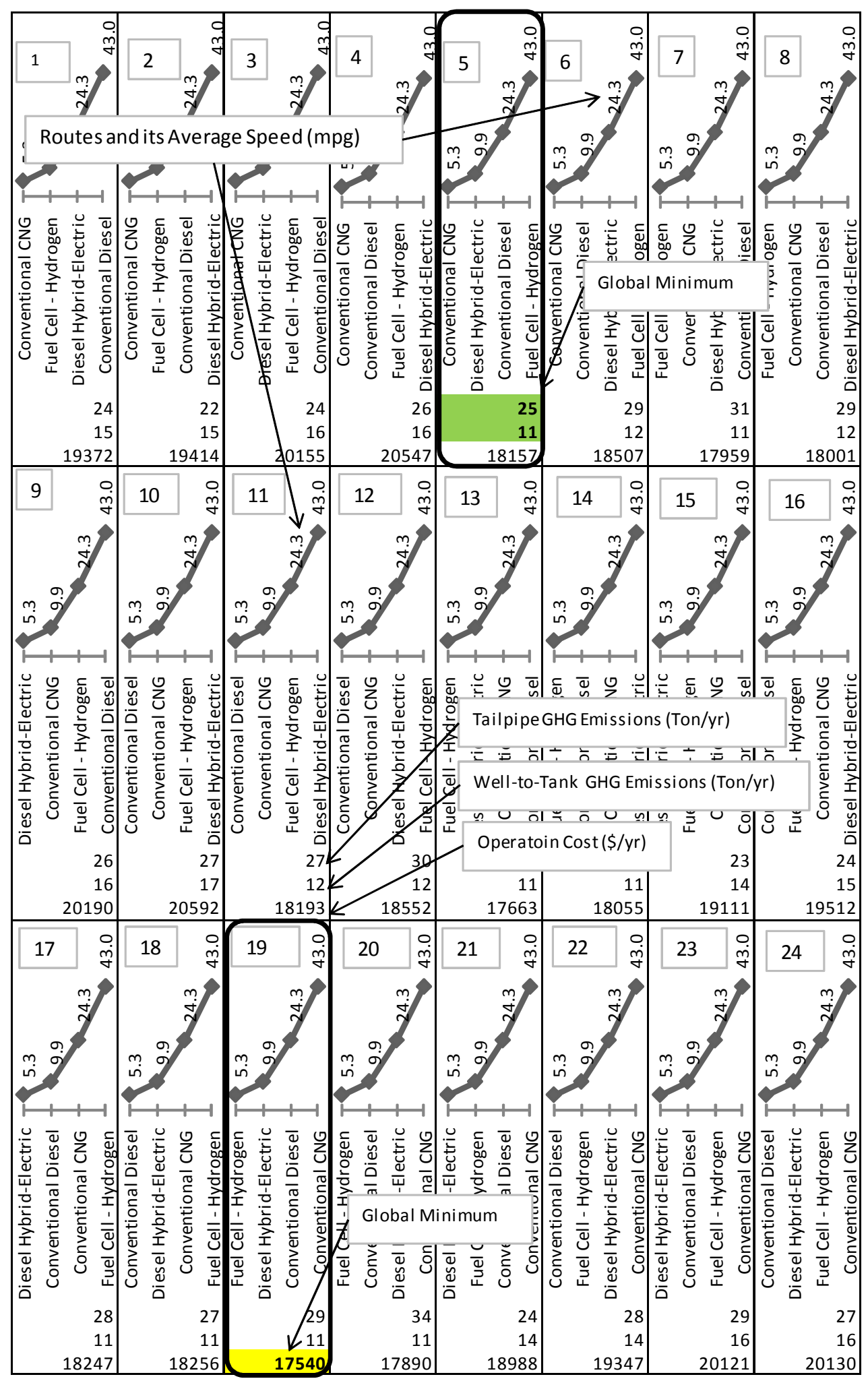

Figure 37: The Four-Bus Fleet Complete Solution Space (24 Different Dispatch Strategies and Their GHG Emissions and Costs). Dispatch 5 and 19 were found to have lowest GHG emissions and operation cost. 
The tool was set up to search for the best dispatch strategies for the two different scenarios. The GA's control parameters were set up as the following. Initial population of the GA had five dispatch strategies. The maximum number of generations was 20 in both scenarios. The crossover rate used a typical setting at 0.6 for one-point crossover method. The mutation process was not used in the two cases, because there was no desire to search new buses. Thus, mutation rate was set at zero.

Two criteria were set to terminate GA's evolution, i.e., the loop of generations. One criterion was when the GA reached its maximum number of generations. The other criterion was when the GA population converged based on the fitness statistics, i.e., elite dispatch strategies dominated the generation. In that criterion, the fitness of the best dispatch strategy was within $0.1 \%$ of the average fitness of the whole population.

In both cost and emissions scenarios, the tool converged and found the best dispatch strategies before reaching its maximum number of generations (Figure 38 and Figure 39). Figure 38 presents the lowest cost optimization scenario. It shows that the tool found the best dispatch strategy (Dispatch 19), when the GA converged at the $5^{\text {th }}$ generation. Figure 39 is for the lowest GHG emissions optimization scenario. The figure shows that the tool found the best dispatch strategy to be Dispatch 5 at the 6th generation. 


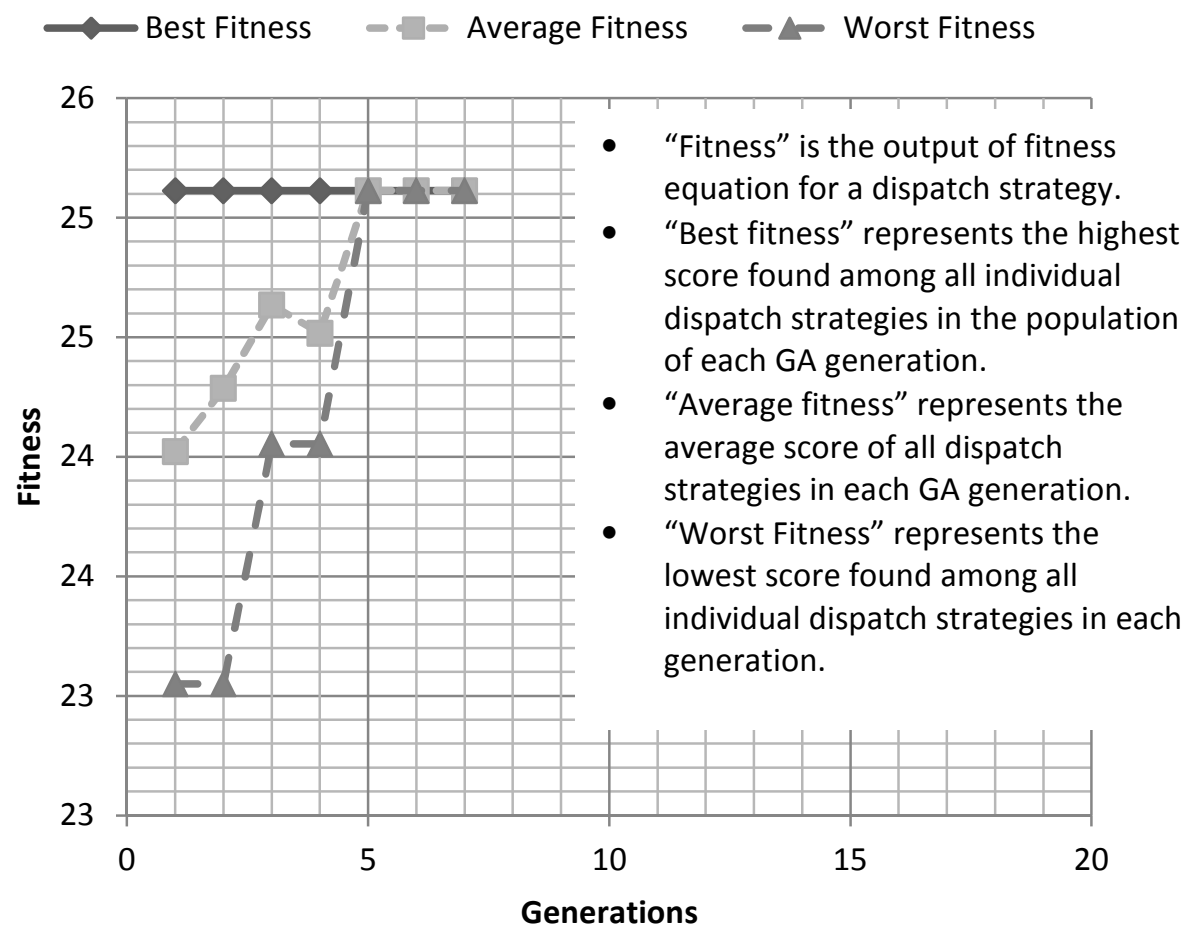

Figure 38: The Four-Bus Fleet Fitness Evolution for Low Cost Case

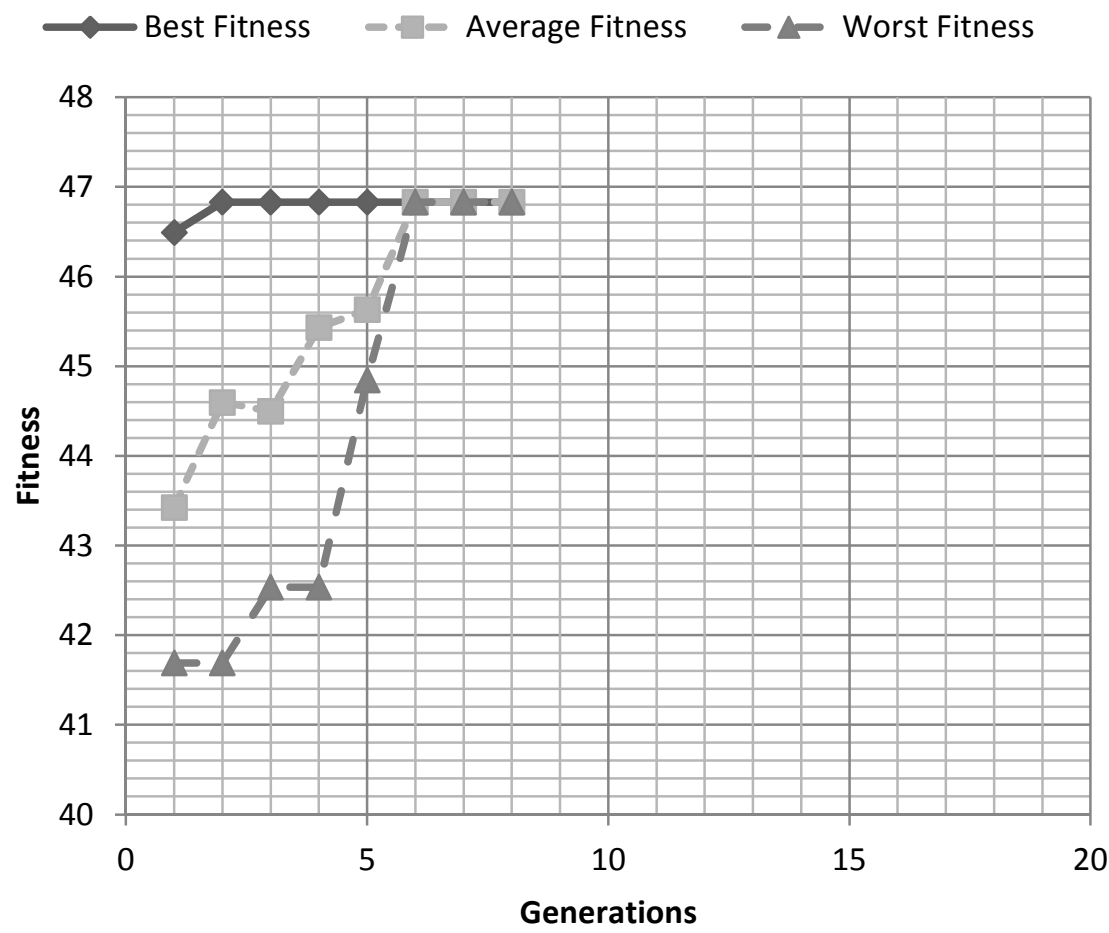

Figure 39: The Four-Bus Fleet Fitness Evolution for Low GHG Emissions Case 


\subsection{Case Studies for a 35-Bus Fleet and User Instruction}

In this section, the tool was used to evaluate and optimize a larger fleet that operated 35 buses over ten different routes. The case study was constructed to serve as a step-by-step guide to completing the fleet evaluation and optimization study.

The tool was developed with a Microsoft ${ }^{\circledR}$ Excel $^{\circledR} 2007$ spreadsheet. The analysis of the 35bus fleet was made with version 4.6 (file name FMT_4.6.xlsm), released on March 15 ${ }^{\text {th }}, 2012$. The user would need Microsoft ${ }^{\circledR}$ Excel $^{\circledR} 2007$ or 2010 to run the program. The program file was not tested with other Excel $^{\circledR}$ versions.

The first step was to setup the input sections in the tool. Double clicking the file icon (file name FMT_4.6.xlsm) started the program. Once the file was opened, input sections (Figure 40) should appear first in the "FleetInfo" tab. If the "FleetInfo" tab (Figure 40) was not shown up, clicking its sheet tab that was located at the bottom of the program interface. The user could use the "save as" option of Excel ${ }^{\circledR}$ to save a new copy of the file at this step. Saving a copy of original file was recommended. 
Section I: Basic Fleet Information

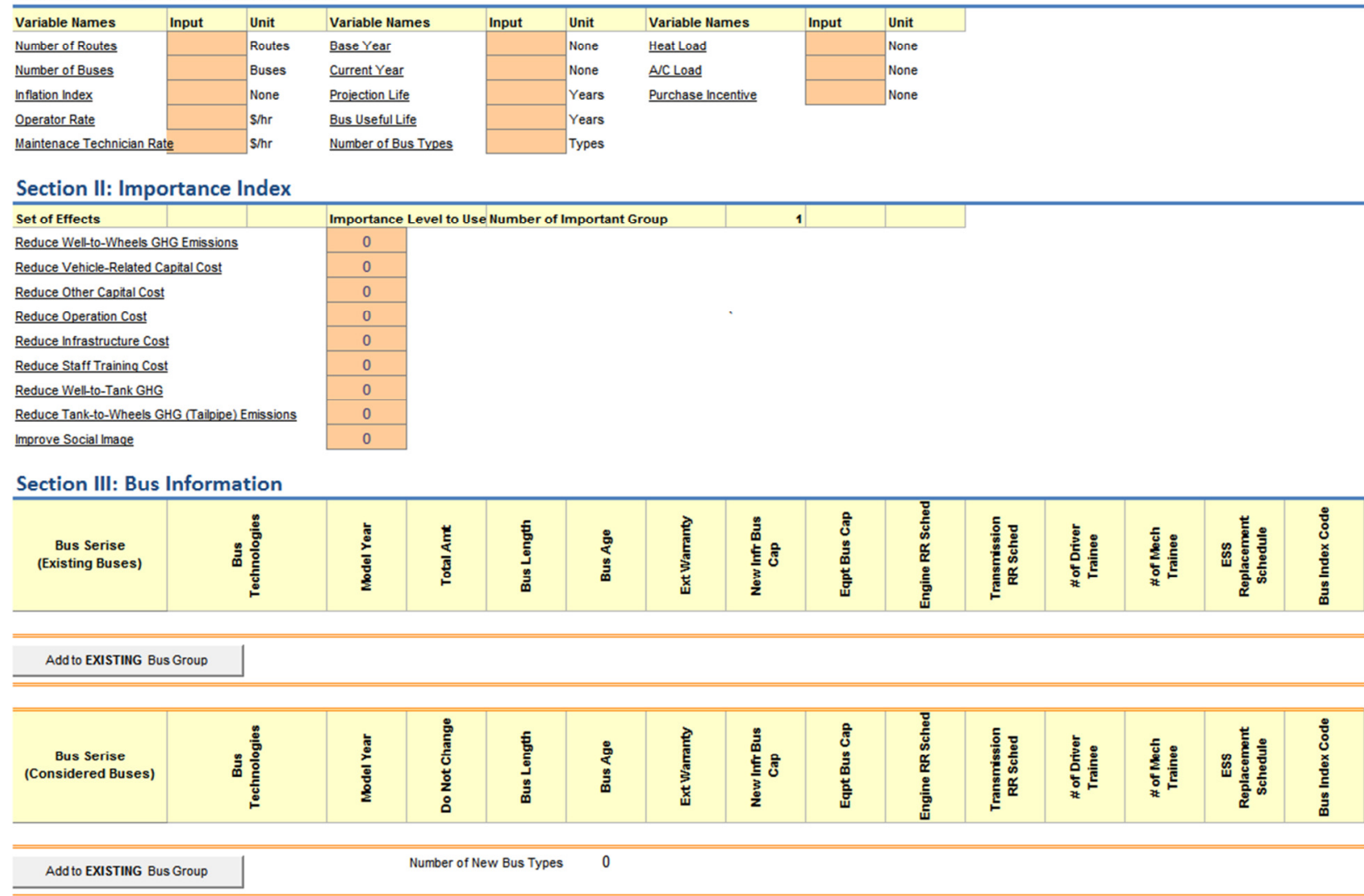

Section IV: Route Information

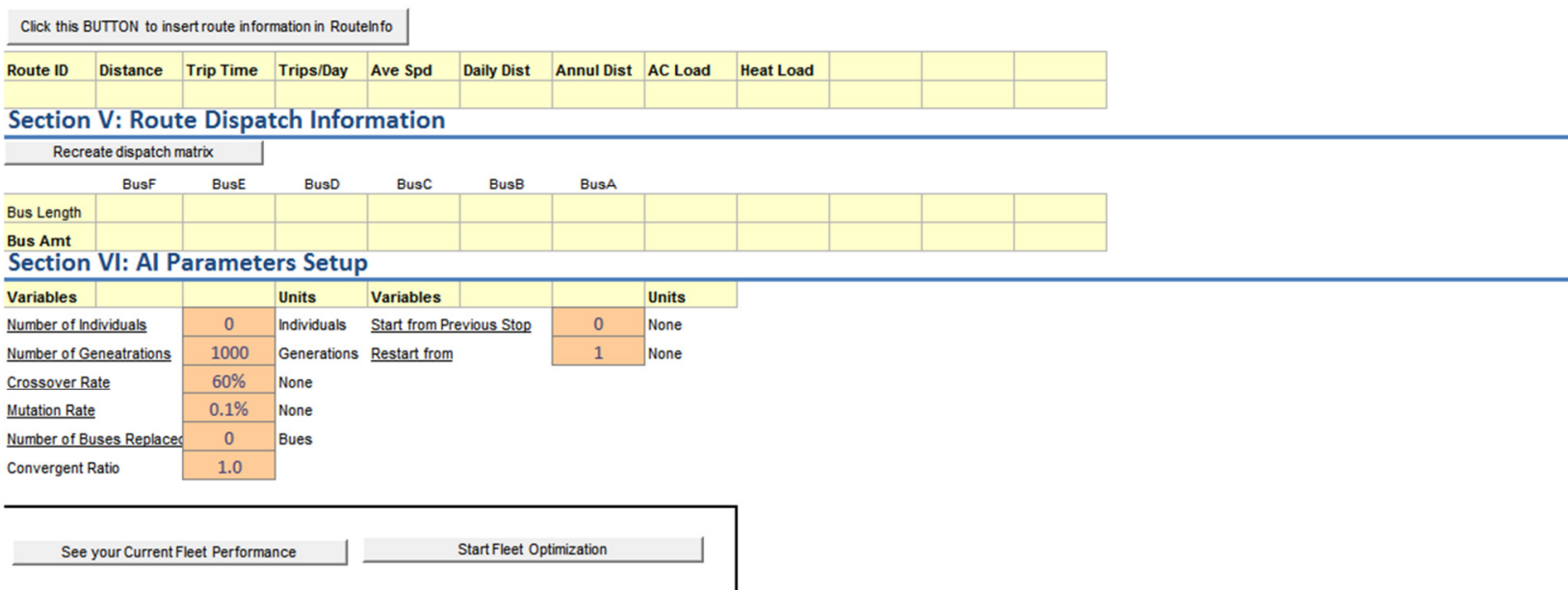

Figure 40: Screenshot of "FleetInfo" tab in the Fleet Management Tool (version 4.6)

The next steps show how to enter the following four types of information into the tool:

- Bus and Route Information (required for calculating current fleet performance) 
- Original Bus Dispatch Strategy (required for calculating current fleet performance)

- GA Parameters Setup (required for fleet optimization scenarios)

- Important Index Table (required for fleet optimization scenarios)

\subsubsection{Bus and Route Input Information}

In "FleetInfo" Tab (Figure 40), user entered bus and route information in Section I, Section III, Section IV, and Section V. Section II and Section VI are for importance index inputs and GA parameters setup. They were separately addressed in Section 3.2.6 for different optimization scenarios.

Section I requires basic fleet information as shown in Figure 41. The user clicks the orange cells to highlight the cells, before entering in the values. Use Section 2.1.1 to see the description of each cell's information. For the 35-bus fleet case, number of routes, buses, and bus types were entered as 10 routes, 35 buses, and 6 types. The rest of the parameters were set as default values. The ten routes included nine real physical routes and a virtual route for a backup fleet.

Section I: Basic Fleet Information

\begin{tabular}{|c|c|c|c|c|c|c|c|c|}
\hline Variable Names & Input & Unit & Variable Names & Input & Unit & Variable Names & Input & Unit \\
\hline Number of Routes & 10 & Routes & Base Year & 2010 & None & Heat Load & 5 & None \\
\hline Number of Buses & 35 & Buses & Current Year & 2010 & None & A/CLoad & 5 & None \\
\hline Inflation Index & $3 \%$ & None & Projection Life & 12 & Years & Purchase Incentive & $80 \%$ & None \\
\hline Operator Rate & 50 & $\mathrm{~S} / \mathrm{hr}$ & Bus Useful Life & 12 & Years & & & \\
\hline Maintenace Technician Rat & 50 & $\mathrm{~S} / \mathrm{hr}$ & Number of Bus Types & 6 & Types & & & \\
\hline
\end{tabular}

\section{Figure 41: Basic Fleet Information of the 35-Bus Case Study (Screenshot of FMT Section I)}

Section III needs detailed bus information. The bus types varied in technologies and model years. Appendix I presents the steps of inputting bus information into the tool. Use Section 2.1.3 to see the description of each cell's information.

The existing six bus types were entered with their bus series names: BusA through BusF. CNG buses (BusF series) used a CNG fueling station, which were built to have a capability to serve up to 50 CNG buses. The capacity was larger than the existing CNG buses needed. The excess fueling capacity would allow future CNG buses to be purchased without extra infrastructure expense. Engine and transmission replacement schedules for diesel and CNG 
buses set were at $(6,4,4,4 \ldots)$, whereas the hybrid bus's corresponding replacement schedules for engine and hybrid drive system were set at $(7,6,6,6 \ldots)$. Default maintenance costs were used for all technologies. Table 49 presents the key information of the six bus types. Figure 42 shows all bus information that was entered to the tool.

Table 49: Key Bus Information of the 35-bus Fleet Entered into the FMT.

\begin{tabular}{|c|c|c|c|c|c|}
\hline Bus Series & Bus Technologies & Model Year & Total Amt & Bus Length & Bus Age \\
\hline BusF & Conventional CNG & Post 2010 & 9 & $40-\mathrm{ft}$ & 1 \\
\hline BusE & Fuel Cell - Hydrogen & $2007-2010$ & 2 & $40-\mathrm{ft}$ & 2 \\
\hline BusD & Diesel Hybrid-Electric & Post 2010 & 4 & $40-\mathrm{ft}$ & 1 \\
\hline BusC & Diesel Hybrid-Electric & Pre-2007 & 5 & $40-\mathrm{ft}$ & 7 \\
\hline BusB & Conventional Diesel & Pre-2007 & 5 & $40-\mathrm{ft}$ & 5 \\
\hline BusA & Conventional Diesel & Pre-2007 & 10 & $40-\mathrm{ft}$ & 10 \\
\hline
\end{tabular}

Table 50 lists a series of new buses. They were the bus technologies considered in possible new bus purchase scenarios. The tool assumed that the fleet management had to keep their buses for a certain number of years before the buses can be retired. The tool was designed to replace the oldest buses first. New bus information was entered in the tool in a similar way as shown in Appendix I. Figure 42 shows all new bus information that was entered into the tool.

Table 50: Replacement Bus Information

\begin{tabular}{|l|l|l|c|c|c|}
\hline Bus Series & \multicolumn{1}{|c|}{ Bus Technologies } & Model Year & Total Amt $^{*}$ & Bus Length & Bus Age \\
\hline NewBusE & Conventional CNG & Post 2010 & 0 & $40-\mathrm{ft}$ & 1 \\
\hline NewBusD & Conventional Diesel & Post 2010 & 0 & $40-\mathrm{ft}$ & 1 \\
\hline NewBusC & Battery Electric & Post 2010 & 0 & $40-\mathrm{ft}$ & 1 \\
\hline NewBusB & Diesel Hybrid-Electric & Post 2010 & 0 & $40-\mathrm{ft}$ & 1 \\
\hline NewBusA & B20 Biodiesel & Post 2010 & 0 & $40-\mathrm{ft}$ & 1 \\
\hline$* 0$ is just a placeholder, not a part of calculation. & & \\
\hline
\end{tabular}


Section III: Bus Information

\begin{tabular}{|c|c|c|c|c|c|c|c|c|c|c|c|c|c|c|}
\hline $\begin{array}{c}\text { Bus Serise } \\
\text { (Existing Buses) }\end{array}$ & 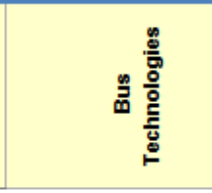 & 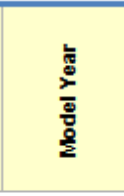 & $\begin{array}{l}\text { है } \\
\frac{5}{9} \\
\frac{0}{5}\end{array}$ & 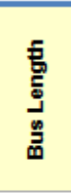 & 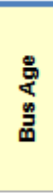 & 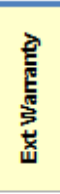 & 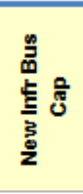 & 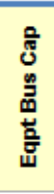 & 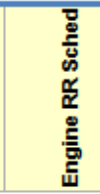 & 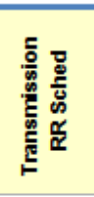 & 总 & 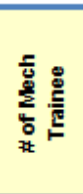 & 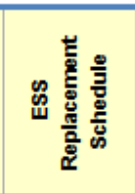 & 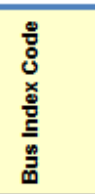 \\
\hline BusF & Conventional CNG & Post 2010 & 10 & $40-\mathrm{ft}$ & 10 & 0 & 50 & 0 & $6,4,4,4,4$ & $4,4,4,4$ & 15 & 15 & No Replacer & 2320 \\
\hline
\end{tabular}

\begin{tabular}{|c|c|c|c|c|c|c|c|c|c|c|c|c|c|}
\hline & s Group & & & & & & & & & & & & \\
\hline BusF & Conventional CNG & Post 2010 & 9 & $40-\mathrm{ft}$ & 1 & 0 & 50 & 0 & $6,4,4,4,4,4 \ldots 6,4,4,4,4,4 \ldots$ & 1 & 1 & No Replacer & 2320 \\
\hline BusE & Fuel Cell - Hydrogen & $2007-2010$ & 2 & $40-\mathrm{ft}$ & 2 & 3 & 10 & 1 & $7,6,6,6,6,6 \ldots 7,6,6,6,6,6 \ldots$ & 1 & 1 & 6 Year Life & 5220 \\
\hline BusD & Diesel Hybrid-Electric & Post 2010 & 4 & $40-\mathrm{ft}$ & 1 & 3 & 0 & 5 & $7,6,6,6,6,6 \ldots 7,6,6,6,6,6 \ldots$ & 1 & 1 & 6 Year Life & 6320 \\
\hline BusC & Diesel Hybrid-Electric & Pre-2007 & 5 & $40-\mathrm{ft}$ & 7 & 0 & 0 & 0 & $7,6,6,6,6,6 \ldots 7,6,6,6,6,6 \ldots$ & 0 & 0 & 4 Year Life & 6120 \\
\hline BusB & Conventional Diesel & $2007-2010$ & 5 & $40-\mathrm{ft}$ & 5 & 0 & 0 & 0 & $6,4,4,4,4,4 \ldots 6,4,4,4,4,4 \ldots$ & 0 & 0 & No Replacer & 1220 \\
\hline BusA & Conventional Diesel & Pre-2007 & 10 & $40-\mathrm{ft}$ & 10 & 0 & 0 & 0 & $6,4,4,4,4,4 \ldots 6,4,4,4,4,4 \ldots$ & 0 & 0 & No Replacer & 1120 \\
\hline
\end{tabular}

\begin{tabular}{|c|c|c|c|c|c|c|c|c|c|c|c|c|c|c|}
\hline $\begin{array}{c}\text { Bus Serise } \\
\text { (Considered Buses) }\end{array}$ & 离 & 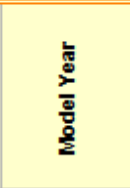 & 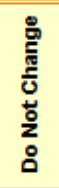 & 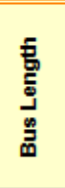 & 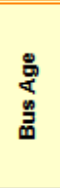 & 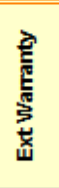 & 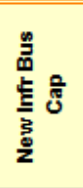 & 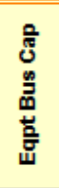 & 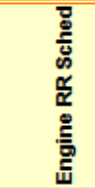 & 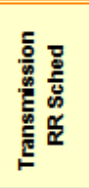 & 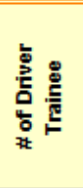 & 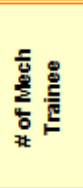 & 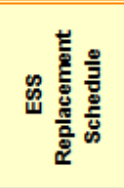 & 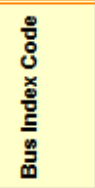 \\
\hline NewBusI & Fuel Cell - Hydrogen & Post 2010 & 0 & $40-\mathrm{ft}$ & 1 & 3 & 0 & 0 & $6,4,4,4,4$ & $4,4,4,4,4$ & 0 & 0 & 4 Year Life & 5320 \\
\hline
\end{tabular}

Add to EXISTING Bus Group

Number of New Bus Types

\begin{tabular}{|c|c|c|c|c|c|c|c|c|c|c|c|c|c|}
\hline \multirow{2}{*}{$\begin{array}{l}\text { NewBusG } \\
\text { NewBusF }\end{array}$} & \multicolumn{2}{|c|}{ Gasoline Hybrid-Electric Post 2010} & \multirow{2}{*}{0} & \multirow{2}{*}{$40-\mathrm{ft}$} & \multirow{2}{*}{1} & \multirow{2}{*}{3} & \multirow{2}{*}{0} & \multirow{2}{*}{0} & \multirow{2}{*}{$\begin{array}{l}6,4,4,4,4,4 \ldots 6,4,4,4,4,4 \ldots \\
6,4,4,4,4,4 \ldots 6,4,4,4,4,4 \ldots\end{array}$} & \multirow{2}{*}{20} & \multirow{2}{*}{20} & \multirow{2}{*}{ 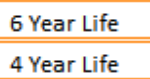 } & \multirow{2}{*}{$\begin{array}{l}7320 \\
5320\end{array}$} \\
\hline & Fuel Cell - Hydrogen & Post 2010 & & & & & & & & & & & \\
\hline NewBusE & Conventional CNG & Post 2010 & 0 & $40-\mathrm{ft}$ & 1 & 3 & 0 & 0 & $6,4,4,4,4,4 \ldots 6,4,4,4,4,4 \ldots$ & 20 & 20 & No Replacer & 2320 \\
\hline NewBusD & Conventional Diesel & Post 2010 & 0 & $40-\mathrm{ft}$ & 1 & 3 & 0 & 0 & $6,4,4,4,4,4 \ldots 6,4,4,4,4,4 \ldots$ & 0 & 0 & No Replacer & 1320 \\
\hline NewBusC & Battery Electric & Post 2010 & 0 & $40-\mathrm{ft}$ & 1 & 3 & 20 & 20 & $7,6,6,6,6,6 \ldots 7,6,6,6,6,6 \ldots$ & 20 & 20 & 4 Year Life & 4320 \\
\hline NewBusB & Diesel Hybrid-Electric & Post 2010 & 0 & $40-\mathrm{ft}$ & 1 & 3 & 0 & 0 & $7,6,6,6,6,6 \ldots 7,6,6,6,6,6 \ldots$ & 0 & 0 & 6 Year Life & 6320 \\
\hline NewBusA & B20 Biodiesel & Post 2010 & 0 & $40-\mathrm{ft}$ & 1 & 3 & 0 & 10 & $6,4,4,4,4,4 \ldots 6,4,4,4,4,4 \ldots$ & 0 & 20 & No Replacer & 3320 \\
\hline
\end{tabular}

Figure 42: Existing and Replacement Bus Technology Information in the 35-bus Fleet (Screenshot of FMT Section III) 
The ten routes included nine real routes and a virtual route called a backup route. The backup route was an imaginary or nonphysical route for backup buses. A simple assumption was that the backup route was a zero speed zero distance route. About the backup fleet (i.e. spare buses), there was no much public cost and emissions data. The cost and emissions models of the tool were applied to the buses in the backup fleet. These buses would end up with zero GHG emissions and zero operation cost because of a zero distance.

The other nine routes were derived from nine routes operated by Mountain Line Transit, Morgantown, West Virginia. For each route, Google ${ }^{\circledR}$ Maps was used to obtain the distances between stops. The January 2012 bus schedule per route was used to calculate time durance between stops. The schedule also defined number of bus trips on each route. Appendix II presents the steps to enter the distances, time and number of trips to create route models in the tool. Use Section 2.1.4 to see the description of route information, definitions, and parameters as shown in Figure 43.

\section{Section IV: Route Information}

\begin{tabular}{|c|c|c|c|c|c|c|c|c|}
\hline \multicolumn{9}{|c|}{ Click this BUTTON to insert route information in Routeln fo } \\
\hline Route ID & Distance & Trip Time & Trips/Day & Ave Spd & Daily Dist & Annul Dist & AC Load & Heat Load \\
\hline Backup & 0.0 & 0.0 & 0.0 & 0.0 & 0.0 & 0.0 & 5.0 & 5. \\
\hline District & 4.6 & 29.0 & 40.0 & 9.6 & 184.0 & 67160.0 & 5.0 & 5.0 \\
\hline CampusPM & 6.0 & 30.0 & 20.0 & 12.0 & 120.0 & 43800.0 & 5.0 & 5. \\
\hline Southside & 11.5 & 45.0 & 11.0 & 15.4 & 126.5 & 46172.5 & 5.0 & 5.0 \\
\hline Blue \& Gold & 3.0 & 10.0 & 65.0 & 18.0 & 195.0 & 71175.0 & 5.0 & 5.0 \\
\hline Cassville & 18.9 & 55.0 & 21.0 & 20.7 & 396.9 & 144868.5 & 5.0 & 5.0 \\
\hline Blue Line & 21.6 & 55.0 & 10.0 & 23.6 & 216.0 & 78840.0 & 5.0 & 5.0 \\
\hline Tyrone Roar & 38.2 & 85.0 & 16.0 & 27.0 & 611.2 & 223088.0 & 5.0 & 5.0 \\
\hline Mt Height & 25.4 & 55.0 & 5.0 & 27.8 & 127.0 & 46355.0 & 5.0 & 5. \\
\hline Gray Line & 330.3 & 505.0 & 2.0 & 39.3 & 660.6 & 241119.0 & 5.0 & 5.0 \\
\hline
\end{tabular}

Figure 43: Route Information of the 35-bus Fleet (Screenshot of FMT Section IV)

Figure 44 shows the distance-speed profiles of the nine routes. The four short distance routes (District, Campus PM, Southside, and Blue \& Gold) were 4.6 to 12.6 miles per trip. The four routes were within Morgantown and supported connections between campuses of West Virginia University. The average speeds of the short routes were between $9.6 \mathrm{mph}$ to $18 \mathrm{mph}$. 
Routes (Cassville, Blue Line, Tyrone Road, and Mt Height) were near 20 to 40 miles per trip. They connected the nearby villages or small towns to Morgantown. The four routes had average speed between 20 to $28 \mathrm{mph}$. The single long distance route (Gray Line) was 330.3 mile per trip. It operated at an average speed of $39.3 \mathrm{mph}$. It provided the inter-urban bus service between Morgantown and Pittsburgh, PA.
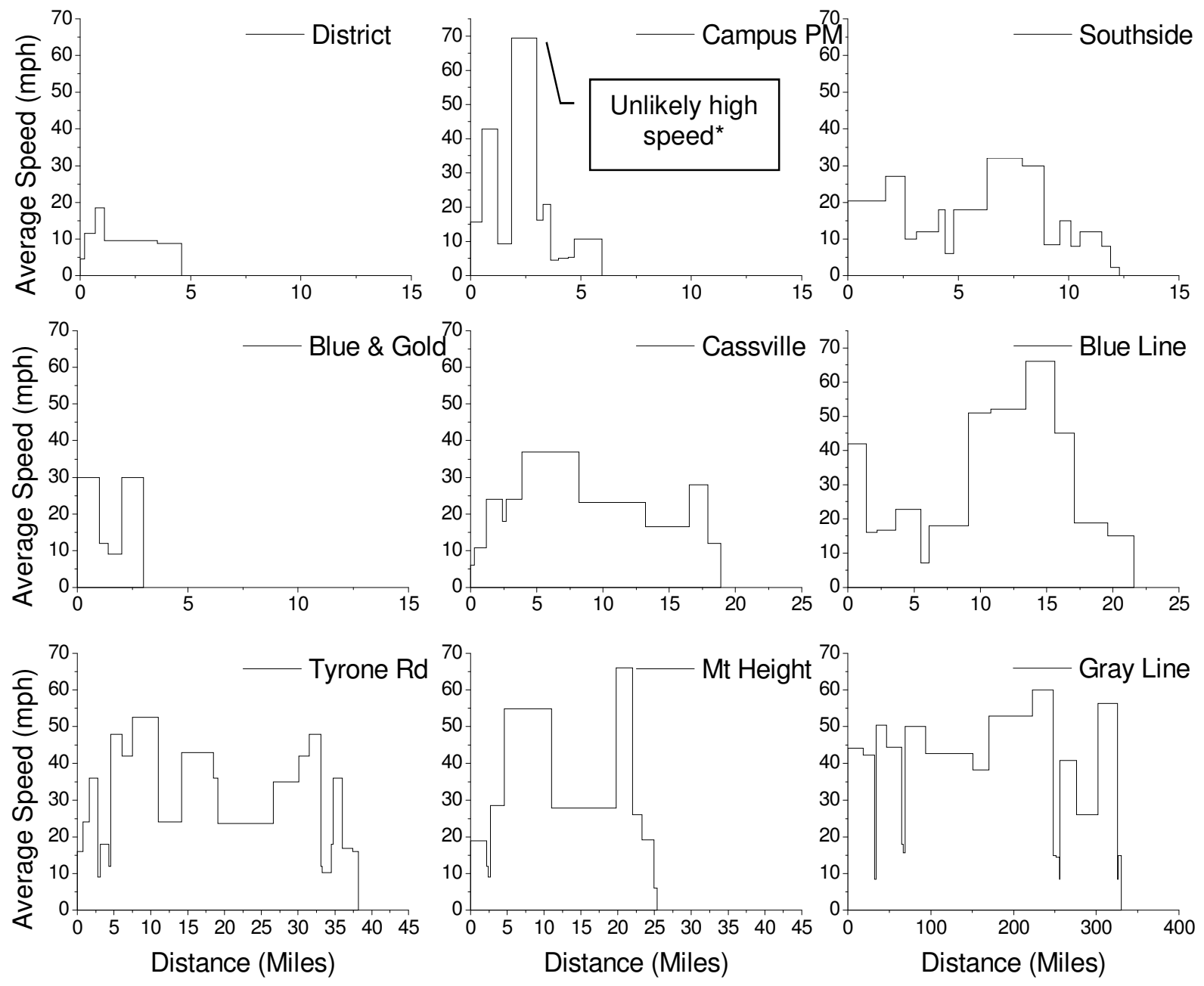

Figure 44: Route Distance-Speed Profile of the 35-Bus Fleet Based on Nine Actual Routes Operated by Mountain Line Transit at Morgantown, West Virginia. Speed calculation was based on bus schedule from the transit agency and distance obtained from Google online map application. The bus schedule might not be completely accurate in time, so a small section of speed profile (70 $\mathrm{mph})$ could be unrealistic. For example, Route Campus PM has nearly 70 mph operating speed between the fifth and sixth stops, because the schedule shows it takes 1 minute to cover 1.2 mile distance. 


\subsubsection{Bus Route Dispatch Strategy Information}

The original dispatch strategy (i.e. current dispatch strategy) was critical to the optimization process. The original dispatch determined the number of buses on each route and initial distribution of bus types. Since each route had a fixed daily distance, the number of buses per route determined the travel distance per each bus on the specific route. Travel distance is one of factors that affect buses' operation cost and GHG emissions performance significantly. Appendix III describes the steps of entering the original dispatch strategy into the tool.

Figure 45 shows the table of the original bus dispatch strategy. As seen in the table, ten pre-2007(the oldest) conventional diesel buses (BusA) were assigned in the backup fleet, represented by the Backup route in the dispatch strategy. Other than that, there were no preferences of assigning specific bus types to certain routes. To meet the bus departure schedule, most routes managed two or three buses. The tool could generate a chart (Figure 46) graphically showing the original dispatch strategy over the ten routes. Section 3.2.6 included the steps to generate Figure 46 and the steps to create fleet cost and emissions summary (Figure 52) for the current dispatch strategy. 


\section{Section V: Route Dispatch Information}

\begin{tabular}{|c|c|c|c|c|c|c|}
\hline \multicolumn{3}{|c|}{ Recreate dispatch matrix } & \multirow[b]{2}{*}{ BusD } & \multirow[b]{2}{*}{ BusC } & \multirow[b]{2}{*}{ BusB } & \multirow[b]{2}{*}{ BusA } \\
\hline & BusF & BusE & & & & \\
\hline Bus Length & $40-\mathrm{ft}$ & $40-\mathrm{ft}$ & $40-\mathrm{ft}$ & $40-\mathrm{ft}$ & $40-\mathrm{ft}$ & $40-\mathrm{ft}$ \\
\hline Bus Amt & 9 & 2 & 4 & 5 & 5 & 10.0 \\
\hline Backup & 1 & 0 & 0 & 1 & 1 & 10 \\
\hline District & 0 & 1 & 1 & 1 & 0 & 0 \\
\hline CampusPM & 1 & 0 & 1 & 0 & 1 & 0 \\
\hline Southside & 1 & 0 & 0 & 1 & 1 & 0 \\
\hline Blue \& Gold & 1 & 1 & 0 & 1 & 0 & 0 \\
\hline Cassville & 1 & 0 & 1 & 0 & 1 & 0 \\
\hline Blue Line & 1 & 0 & 0 & 0 & 1 & 0 \\
\hline Tyrone Roac & 1 & 0 & 0 & 1 & 0 & 0 \\
\hline Mt Height & 1 & 0 & 0 & 0 & 0 & 0 \\
\hline Gray Line & 1 & 0 & 1 & 0 & 0 & 0 \\
\hline
\end{tabular}

Figure 45: Original Dispatch Strategy Information of the 35-bus Fleet (Screenshot of FMT Section V) 


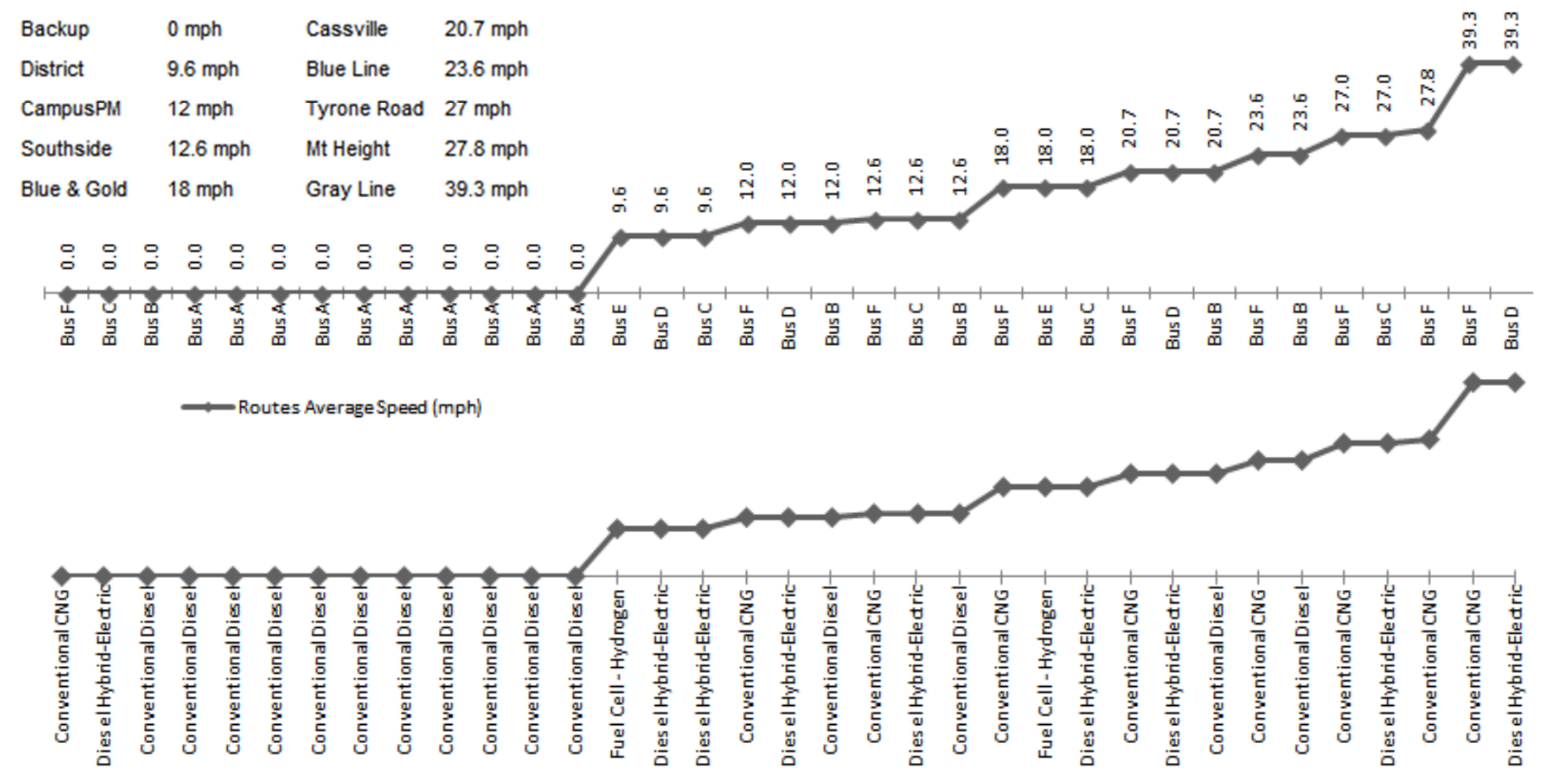

Figure 46: Bus ID and Bus Technology Distribution of Original Fleet Dispatch Strategy of the 35-Bus Fleet. Buses with the same speed data labels are operated in the same route. The top chart shows bus series names, and the bottom chart shows the bus propulsion technologies. 


\subsubsection{Genetic Algorithm Parameters Setup}

GA parameters were setup in Section VI of "FleetInfo" tab as shown in Figure 47. The tool provided a default setting in the orange cells. Experienced users can optimize and override the values in the cells. Use Section 2.3.1 to see the description of GA parameter information.

\section{Section VI: Al Parameters Setup}

\begin{tabular}{|c|c|c|c|c|c|}
\hline Variables & & Units & Variables & & Units \\
\hline$\underline{\text { Number of Individuals }}$ & 260 & Individuals & Start from Previous Stop & 0 & None \\
\hline Number of Generations & 1000 & Generations & Restart from & 1 & None \\
\hline$\underline{\text { Crossover Rate }}$ & $60 \%$ & None & & & \\
\hline Mutation Rate & $0.1 \%$ & None & & & \\
\hline Number of Buses Replaced & 0 & Buses & & & \\
\hline
\end{tabular}

Figure 47: Original GA Settings Information of the 35-Bus Fleet. (Screenshot of FMT Section VI)

The first parameter, Number of Individuals (i.e. population size), was twice the number of all possible building blocks as the default setting [125-127]. Any combination of a single route and bus type is a "building block" to the GA, i.e. an independent variable in fitness function (Section 2.3.3). In this case, the population size was set at 260, twice the product of number of bus types and number of routes. Crossover and mutation rates used the Dejong setting [128], that Scholand recommended from several promising GA parameter settings [128-131]. Figure 47 shows the Number of Generation sets that GA computation can only reach maximum 1000 generations. Crossover and mutation rates are at $60 \%$ and $0.1 \%$ respectively. Number of Bus Replaced is zero in this example. If new bus purchase is considered, Number of Bus Replaced defines how many new buses will be purchased to replace the oldest buses.

The variables on the right are "Start from Previous Stop" and "Restart from." The optimization process can be interrupted by pressing CTRL key in conjunction with BREAK key. The tool will present the latest optimization results, once the break is implemented. The variable "Restart from" will be updated with the last generation number of the break point. Changing the variable "Start from Previous Stop" to " 1 " in the orange cell allows the tool to resume from the break point. If the variable is set to " 0 ," the tool will restart the optimization process from the beginning. 


\subsubsection{Scenarios of Optimizing Current Fleet}

This section presents how to set up the tool for different optimization scenarios. The optimization process begins with updating Important Index Table, i.e. Section II in "FleetInfo" tab as shown in Figure 48. Appendix IV illustrates the steps of entering weights in the table.

The first optimization scenario targeted minimizing operation cost of the whole fleet. As seen in Figure 48, it was very simple to set zero weights to all options but the "Reduce Operation Cost" item. The item (the fourth row in Figure 48) was set with a weight at "10." Zero weights made those options have no impact on fitness functions (Section 2.3.3). The dispatch strategies of low operation cost would distinguish themselves in the population during the GA optimization process.

\section{Section II: Importance Index}

\begin{tabular}{|c|c|c|}
\hline Set of Effects & to User & \\
\hline Reduce Well-to-Wheels GHG Emissions & 0 & \multirow{9}{*}{ 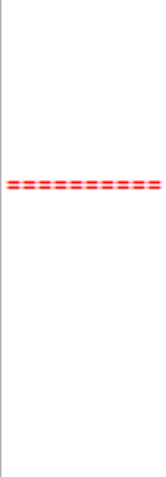 } \\
\hline Reduce Vehicle-Related Capital Cost & 0 & \\
\hline Reduce Other Capital Cost & 0 & \\
\hline Reduce Operation Cost & 10 & \\
\hline Reduce Infrastructure Cost & 0 & \\
\hline Reduce Staff Training Cost & 0 & \\
\hline Reduce Well-to-Tank GHG & 0 & \\
\hline Reduce Tank-to-Wheels GHG (Tailpipe) Emissions & 0 & \\
\hline Improve Social Image & 0 & \\
\hline
\end{tabular}

Figure 48: Example of an Important Index Targeting Reducing Operation Cost. (Screenshot of FMT Section II)

Similarly, Table 51 shows the Importance Index Tables setting for the other two scenarios. One of the scenarios aimed for a dispatch strategy with the lowest WTW GHG emissions (Case 2 in Table 51). There is only one weight assigned to the option of "Reducing Well-to-Wheels GHG Emissions." The other scenario tried to reconcile between costs and emissions (Case 3 in Table 51). The weight distribution shows that reducing operation cost was a primary goal to the user given a weight of "9." The user also considered TTW GHG emissions an important factor given a weight of "6." Infrastructure cost was important to the user as well having a weight of "6." The user had minor or minimal concerns with the remaining factors. 
Table 51: Important Index Table for Three Cases in Existing Fleet Optimization

\begin{tabular}{|l|c|c|c|}
\hline \multicolumn{1}{|c|}{ Set of Effects } & $\begin{array}{c}\text { Importance Level } \\
\text { (Cost Driven Case) }\end{array}$ & $\begin{array}{c}\text { Importance Level } \\
\text { (GHG Emissions } \\
\text { Driven Case) }\end{array}$ & $\begin{array}{c}\text { Importance Level } \\
\text { (Compromise } \\
\text { Driven Case) }\end{array}$ \\
\hline Case 2 & 10 & 0 \\
\hline Reduce Well-to-Wheels GHG Emissions & Case 1 & 0 & 3 \\
\hline Reduce Vehicle-Related Capital Cost & 0 & 0 & 6 \\
\hline Reduce Other Capital Cost & 0 & 0 & 10 \\
\hline Reduce Operation Cost & 0 & 0 & 6 \\
\hline Reduce Infrastructure Cost & 0 & 0 & 1 \\
\hline Reduce Staff Training Cost & 0 & 0 & 1 \\
\hline Reduce Well-to-Tank GHG & 0 & 0 & 6 \\
\hline Reduce Tank-to-Wheels GHG (Tailpipe) Emissions & 0 & 0 & 1 \\
\hline Improve Social Image & 0 & 0 & \\
\hline
\end{tabular}

The user has defined all required input sections for optimization. At the bottom of the "FleetInfo" tab are two buttons as shown in Figure 49. Clicking "See Your Current Fleet Performance" button starts evaluating the current or original dispatch strategy. The process updates a cost and emissions summary for current dispatch strategy. The results are displayed in three sections in the "FleetPerformance" tab. The three sections are described in the next paragraph. The user needed not define the GA setting and Importance Index Table for the evaluation process. Clicking "Start Fleet Optimization" button starts the GA searching process. Once the search process completes and stops, it proposes new dispatch strategies and updates output tables and charts in the "FleetPerformance" tab.

Figure 49: Start Buttons in "FleetInfo" Tab of Fleet Management Tool. The first button is for generating performance report of original dispatch strategy. The section button is for starting searching algorithm of new dispatch strategies.

In the "FleetPerformance" tab, the first section is Section VII of the tool, which is a straightforward input summary table of the current fleet as shown in Figure 50 . The summary table breaks down the input factors for every route and bus combination. The next section is 
Section VIII (Figure 51), which presents the corresponding capital and operation cost of every bus and route combination in table format. Section IX of the tool is the last section in the "FleetPerformance" tab, which combines cost and emissions and provides an overall fleet performance.

Section VII: Current Fleet Inputs Summary

\begin{tabular}{|c|c|c|c|c|c|c|c|}
\hline & Backup & Backup & Backup & Backup & District & District & District \\
\hline Bus Series & BusF & BusC & BusB & BusA & BusE & BusD & BusC \\
\hline \# of Buses on Route & 1 & 1 & 1 & 10 & 1 & 1 & 1 \\
\hline Annual Mileage per Bus & 0 & 0 & 0 & 0 & 22387 & 22387 & 22387 \\
\hline Bus Technologies & Cenventional CNG & Dir.erl Habrid-Ele..lrie & Conventional Diorel & Conventional Dierel & Fuelcell-Hydreqen & Dir.el Habrid-El..elri. & Dir.erl Habrid-Ele..lei. \\
\hline Model Year & Post 2010 & Pre-2007 & $2007-2010$ & Pre-2007 & $2007-2010$ & Post 2010 & Pre-2007 \\
\hline Total Amt & 9 & 5 & 5 & 10 & 2 & 4 & 5 \\
\hline Bus Length & $40-\mathrm{ft}$ & $40-\mathrm{ft}$ & $40-\mathrm{ft}$ & $40-\mathrm{ft}$ & $40-\mathrm{ft}$ & $40-\mathrm{ft}$ & $40-\mathrm{ft}$ \\
\hline Bus Age & 1 & 7 & 5 & 10 & 2 & 1 & 7 \\
\hline Ext Warranty & 0 & 0 & 0 & 0 & 3 & 3 & 0 \\
\hline New Infr Bus Cap & 50 & 0 & 0 & 0 & 10 & 0 & 0 \\
\hline Eqpt Bus Cap & 0 & 0 & 0 & 0 & 1 & 5 & 0 \\
\hline Engine RR Sched & $6,4,4,4,4,4 \ldots \ldots \ldots$ & $7,6,6,6,6,6 \ldots \ldots \ldots$ & $6,4,4,4,4,4 \ldots \ldots \ldots$ & $6,4,4,4,4,4 \ldots \ldots \ldots .$. & $7,6,6,6,6,6 \ldots \ldots \ldots$ & $7,6,6,6,6,6 \ldots \ldots \ldots$ & $7,6,6,6,6,6 \ldots \ldots \ldots$ \\
\hline Transmission RR Sched & $6,4,4,4,4,4 \ldots \ldots \ldots$ & $7,6,6,6,6,6 \ldots \ldots \ldots$ & $6,4,4,4,4,4 \ldots \ldots \ldots \ldots$ & $6,4,4,4,4,4 \ldots \ldots \ldots \ldots$ & $7,6,6,6,6,6 \ldots \ldots \ldots$ & $7,6,6,6,6,6 \ldots \ldots \ldots$ & $7,6,6,6,6,6 \ldots \ldots \ldots$ \\
\hline \# of Driver Trainee & 1 & 0 & 0 & 0 & 1 & 1 & 0 \\
\hline \# of Mech Trainee & 1 & 0 & 0 & 0 & 1 & 1 & 0 \\
\hline ESS Replacement Schedule & No Replsecment & 4 Year Life & No Replsecment & No Replseement & 6 Year Life & 6 Year Life & 4 Year Life \\
\hline Fuel Economy & 0.00 & 0.00 & 0.00 & 0.00 & 5.64 & 3.87 & 3.87 \\
\hline Route Ave Speed & 0 & 0 & 0 & 0 & 9.6 & 9.6 & 9.6 \\
\hline
\end{tabular}

Figure 50: Input Summary Table of Breaking down Each Route and Bus Combination. (Screenshot of a Partial FMT Section VII). The complete table is too large to display in one page. 
Section VIII: Current Year Fleet Cost and Emissions Performance

\begin{tabular}{|c|c|c|c|c|c|c|c|c|c|c|c|c|c|c|c|}
\hline & & \multicolumn{2}{|c|}{ Backup } & \multicolumn{2}{|c|}{ Backup } & \multicolumn{2}{|c|}{ Backup } & \multicolumn{2}{|c|}{ Backup } & \multicolumn{2}{|c|}{ District } & \multicolumn{2}{|c|}{ District } & \multicolumn{2}{|c|}{ District } \\
\hline Bus Series & & \multicolumn{2}{|c|}{ BusF } & \multicolumn{2}{|c|}{ BusC } & \multicolumn{2}{|c|}{ BusB } & \multicolumn{2}{|c|}{ BusA } & \multicolumn{2}{|c|}{ BusE } & \multicolumn{2}{|c|}{ BusD } & \multicolumn{2}{|c|}{ BusC } \\
\hline \multicolumn{16}{|l|}{ Capital Cost } \\
\hline Bus Purchase & S/bus-yr & s & 6,192 & $s$ & 9,652 & s & 5,646 & $s$ & 54,636 & s & 43,709 & $s$ & 7,895 & s & 9,652 \\
\hline Bus Warranty & S/bus-yr & s & - & $s$ & - & s & - & $\$$ & - & $\$$ & 4,553 & $s$ & 1,821 & 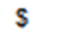 & - \\
\hline Infrastructure (Fractional) & S/bus-yr & s & 3,187 & s & - & s & - & s & - & 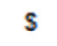 & 10,912 & $s$ & - & s & - \\
\hline \multirow[t]{2}{*}{ Equipment (Fractional) } & S/bus-yr & $s$ & - & $s$ & - & s & - & s & - & s & 546 & $s$ & 55 & $s$ & - \\
\hline & & & 0 & & 0 & & 0 & & 0 & & 57068 & & 35661 & & 31900 \\
\hline Engine R \& R & S/yr & $\$$ & 4,845 & $s$ & 2,582 & $s$ & 5,277 & s & 53,691 & $s$ & 12,856 & $s$ & 2,646 & $s$ & 2,582 \\
\hline Transmission R \& R & S/yr & s & 2,846 & $s$ & 6,172 & $s$ & 3,100 & $s$ & 31,544 & $s$ & 6,529 & $s$ & 6,325 & $\mathrm{~s}$ & 6,172 \\
\hline Training (Fractional) & $\$ / y r$ & s & 601 & $s$ & - & $s$ & - & $s$ & - & $s$ & 1,639 & $s$ & 1,038 & $s$ & - \\
\hline Scheduled PMS & S/bus-yr & & 0 & & 0 & & 0 & & 0 & & 10147 & & 6895 & & 4388 \\
\hline Unscheduled PMS & S/bus-yr & & 0 & & 0 & & 0 & & 0 & & 16235 & & 13477 & & 12224 \\
\hline ESS Replacement & S/bus-yr & & 0 & & 3101 & & 0 & & 0 & & 4852 & & 4852 & & 3101 \\
\hline Fuel & S/bus-yr & & 0 & & 0 & & 0 & & 0 & & 30685 & & 15288 & & 15288 \\
\hline
\end{tabular}

Figure 51: Cost and GHG Emissions Summary Table of Breaking down Each Route and Bus Combination. (Screenshot of a Partial FMT Section VIII). The complete table is too large to display in one page.

Section IX includes a performance summary table (Figure 52), a dispatch strategy chart (Figure 53), and an evolution progress chart (Figure 54).

The summary table (Figure 52) consists of six dispatch strategies and their performance summaries. The far left column showed the performance of the original dispatch strategy. The next five columns displayed five dispatch strategies, which were found during GA optimization process. It provided the progress trend of the optimization process. For example, Figure 53 shows that the GA optimization process completed at the $384^{\text {th }}$ generation. The user can define a new stop by changing the cell "Click Button to Generation". In this case, "200" was entered. By clicking the "go to gen" button, the summary table (Figure 52) updates the five columns framed around in Figure 52.

The dispatch strategy chart (Figure 53) illustrates the bus distribution over the routes. The default chart shows the very last generation, where the GA process stops. When user appoints a generation number in the section (Figure 53), the chart updates with best dispatch strategy in that generation (shown as $200^{\text {th }}$ generation in Figure 53). The user can display the original dispatch strategy by changing the generation number to one. 
As long as the GA process progresses, the fitness evolution chart (Figure 54) updates the fitness performance of the best, average, and the worst dispatch strategies of all processed generations. The user can find details of the fitness function and its performance in Section 2.3.3 and Figure 38 .

Section IX: Optimized Current Year Fleet Cost and Emissions Performance

\begin{tabular}{|c|c|c|c|c|c|c|c|c|c|}
\hline Generation & & Current Fleet & 0 & 1 & 120 & 160 & 200 & Change & Change $\%$ \\
\hline Well-to-Wheels GHG & $\mathrm{CO} 2-\operatorname{Ton} / \mathrm{Yr}$ & 2074 & 2074 & 1906 & 1772 & 1770 & 1772 & -301 & $-14.5 \%$ \\
\hline Well-to-Tank GHG & $\mathrm{CO} 2-\mathrm{Ton} / \mathrm{Mr}$ & 479 & 479 & 426 & 401 & 402 & 401 & -78 & $-16.2 \%$ \\
\hline Tank-to-Wheels GHG & $\mathrm{CO} 2-\mathrm{Ton} / \mathrm{Yr}$ & 1595 & 1595 & 1480 & 1371 & 1369 & 1371 & -224 & $-14.0 \%$ \\
\hline Vehicle-Related Capital Cost & $\$ / / \mathrm{r}$ & 414995 & 414995 & 414995 & 414995 & 414995 & 414995 & 0 & $0.0 \%$ \\
\hline Other Capital Cost & $\$ / M r$ & 628254 & 628254 & 628254 & 628254 & 628254 & 628254 & 0 & $0.0 \%$ \\
\hline Operation Cost & $\$ / \mathrm{Mr}$ & 1034927 & 034927 & 982111 & 973258 & 973807 & 968501 & -66427 & $-6.4 \%$ \\
\hline Infrastructure Cost & $\$ / / r$ & 606099 & 606099 & 606099 & 606099 & 606099 & 606099 & 0 & $0.0 \%$ \\
\hline Staff Training & $\$ / / r$ & 6420 & 6420 & 6420 & 6420 & 6420 & 6420 & 0 & $0.0 \%$ \\
\hline Social Image & None & 141 & 141 & 141 & 141 & 141 & 141 & 0 & $0.0 \%$ \\
\hline
\end{tabular}

Figure 52: An Example of Fleet Overall GHG Emissions and Cost Summary Table of Current (in blue box) and Proposed Dispatch Strategies (in red box). The table lists five proposed dispatch strategies during the optimization process. The five strategies are evenly distributed in the optimization process. (Screenshot of a Partial FMT Section IX) 


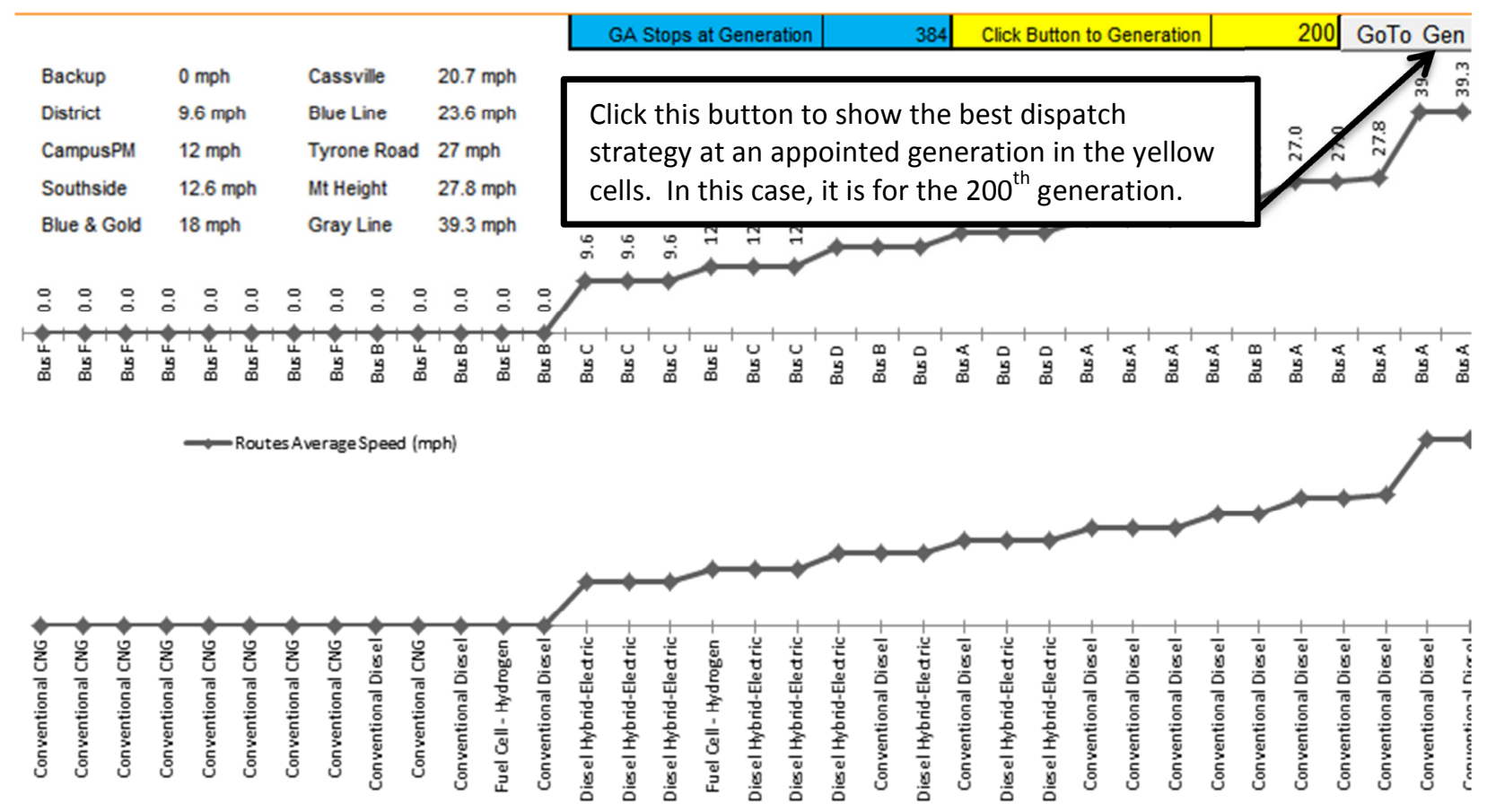

Figure 53: An Example of Dispatch Strategy Chart. (Screenshot of a Partial FMT Section IX)
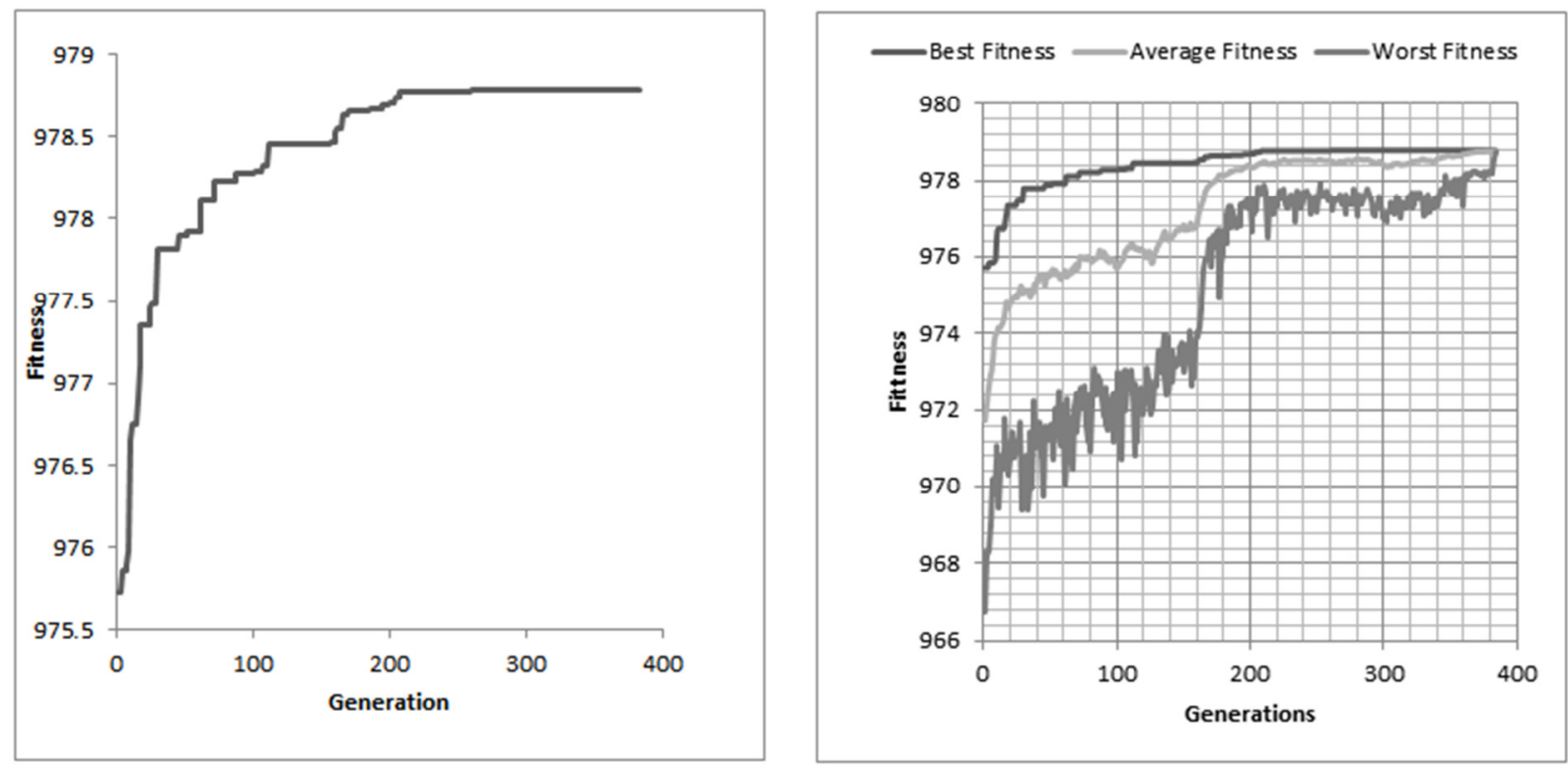

Figure 54: An Example of Fleet Fitness Evolution Progress Chart over GA Optimization Process. The left chart is for the best fitness progress. The right chart includes the best, average, the worst fitness. Detail definitions are described in Figure 38. (Screenshot of a Partial FMT Section IX) 


\subsubsection{Optimization Results for Minimal Operation Cost}

This optimization scenario was based on case 1 of the Important Index Table (Table 51). After clicking "Start Fleet Optimization" button, GA process converged at the 282th generation before reaching the maximum number of generations as shown in Figure 55. Section IX (Figure 56) in the "FleetPerformance" tab summarizes the cost and emissions results.
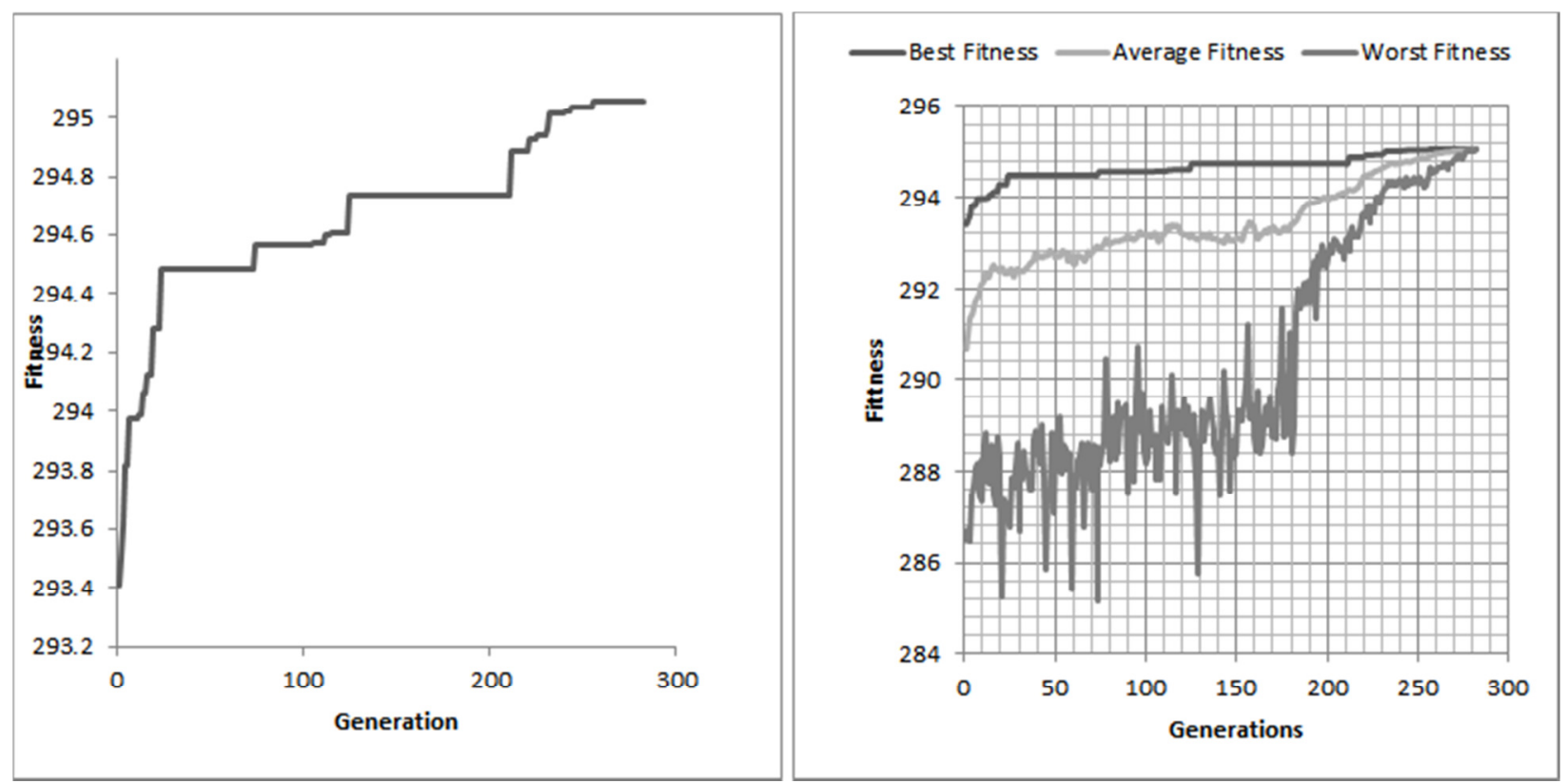

Figure 55: Fitness Evolution Progress Chart over GA Optimization Process for Minimal Operation Cost Scenario. The process converged at the 282th generation. 


\section{Section XI: Optimized Current Year Fleet Cost and Emissions Performance}

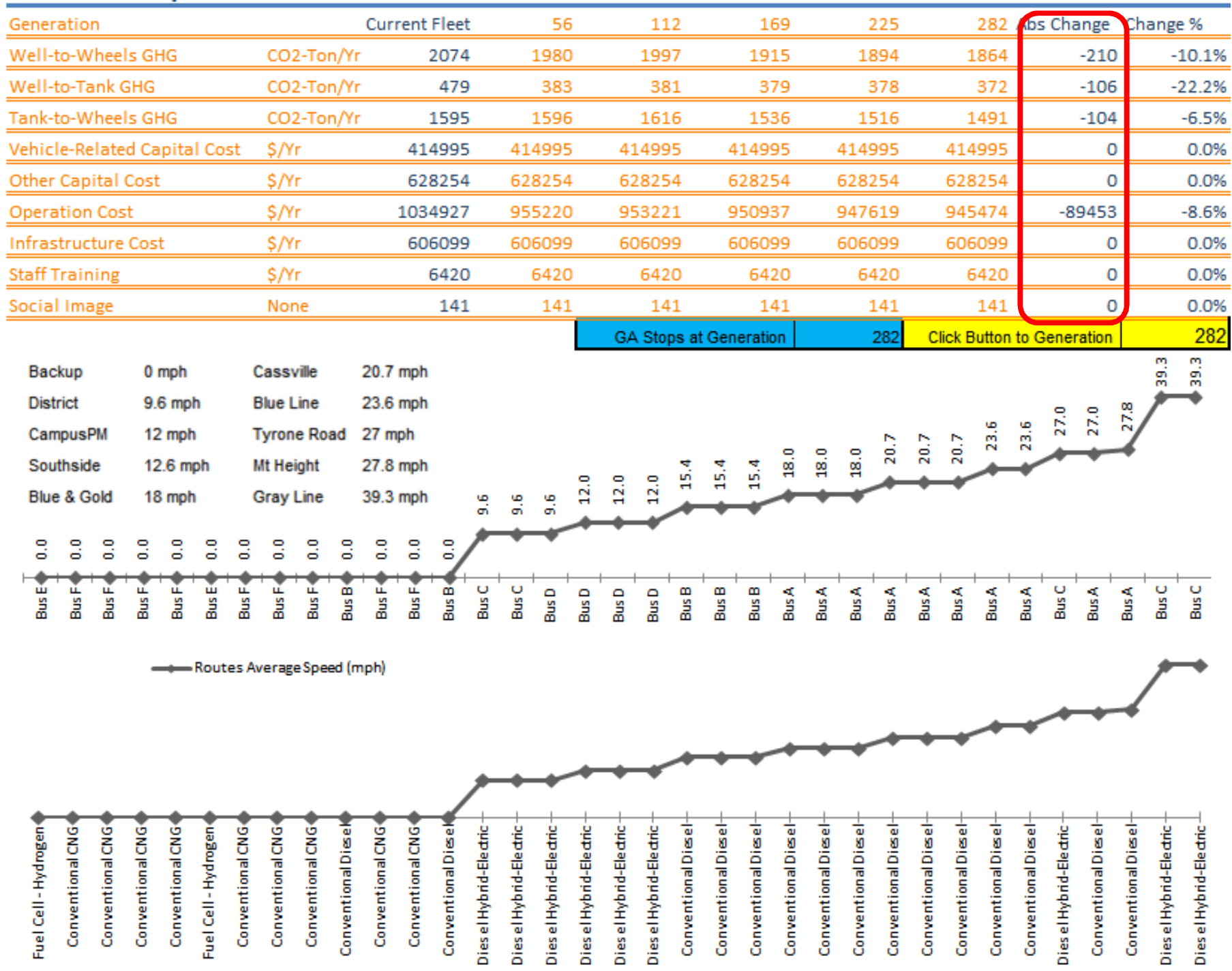

Figure 56: Performance Summary Table and Optimized Fleet Dispatch Strategy for the 35-bus Fleet. The dispatch strategy was for minimizing operation cost. 
With the current dispatch strategy, the fleet spent $\$ 1,034,927$ in annual operation cost. The proposed dispatch strategy reduced operation cost by $9 \%$, representing savings of about $\$ 90 \mathrm{~K}$ per year. The dispatch strategy was also associated with $210 \mathrm{CO}_{2}$ equivalent tons less WTW GHG emissions per year from the fleet. This reduction was roughly $10 \%$ of total WTW GHG emissions with the current dispatch strategy. There were no changes in capital cost, because there was no new bus purchase.

Figure 56 shows that the diesel buses and diesel hybrid-electric buses performed the best in the low cost optimization scenario for the defined fuel costs. The proposed dispatch strategy assigned diesel hybrid-electric buses to the two slowest routes (District Line and CampusPM Line). The strategy also assigned diesel HEBs to two fast routes (Tyrone Road Line and Gray Line). The two routes are among the fastest routes ( $27 \mathrm{mph}$ and $39.3 \mathrm{mph}$ in average speed). High-speed operation reduced the fuel economy advantage of diesel HEBs to conventional diesel buses. However, buses that operated on the two routes travelled more than 300 miles a day as shown in Figure 57. The long distance helped diesels HEBs overcome the diminished fuel economy advantage by saving more on fuel cost.

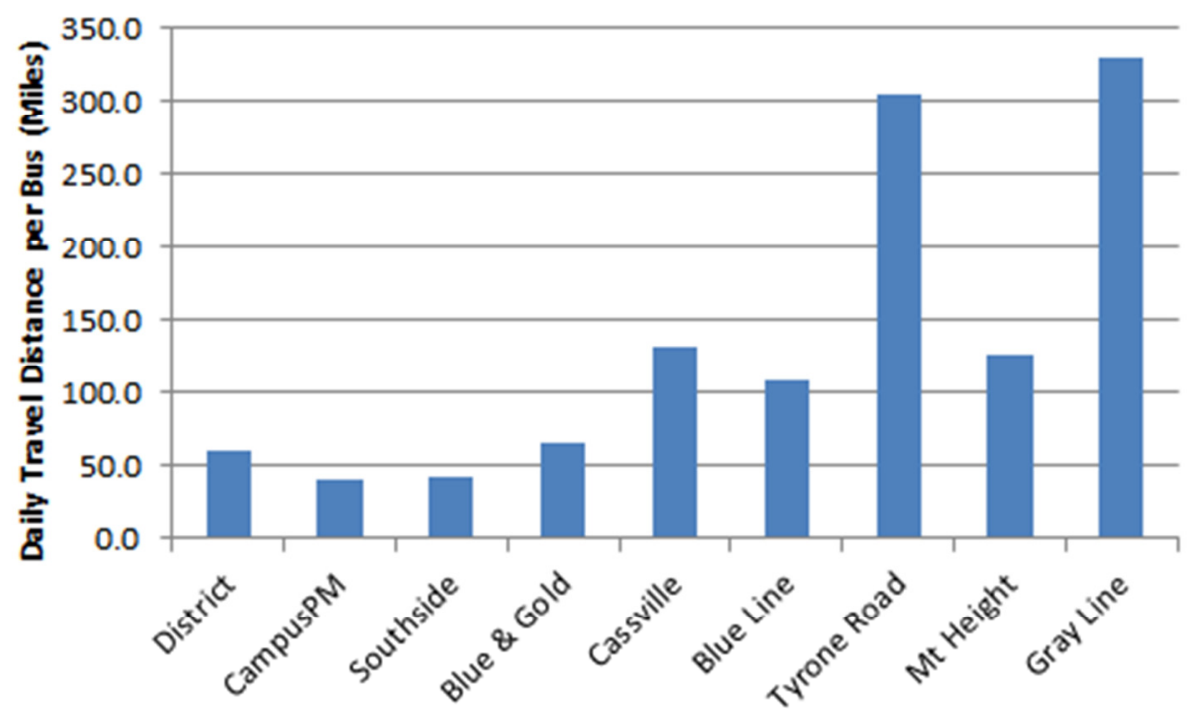

Figure 57: Bus Daily Travel Distance per Routes in the 35-Bus Fleet

The proposed strategy did not favor CNG and fuel cell HEBs in this scenario. They were assigned into the back up fleet in order to save operation cost. Average diesel prices were set 
at $\$ 3.09$ per gallon (2012 dollar) in the model. Average CNG prices were close to $\$ 1.82$ per DEG. The tool was rerun after raising diesel price to $\$ 4.00$ per gallon. CNG buses became competitive and replaced conventional diesel buses in the new proposed dispatch strategy (Figure 58).

The tool was modified to search for the worst dispatch strategy that the fleet could face. The "worst" dispatch strategy would cost the fleet \$130K more in operation cost per year, a $12.6 \%$ rise from the original dispatch strategy (Figure 59). For the 35-fleet bus, operation cost can vary $\$ 220 \mathrm{~K}$ a year with different dispatch strategies. 


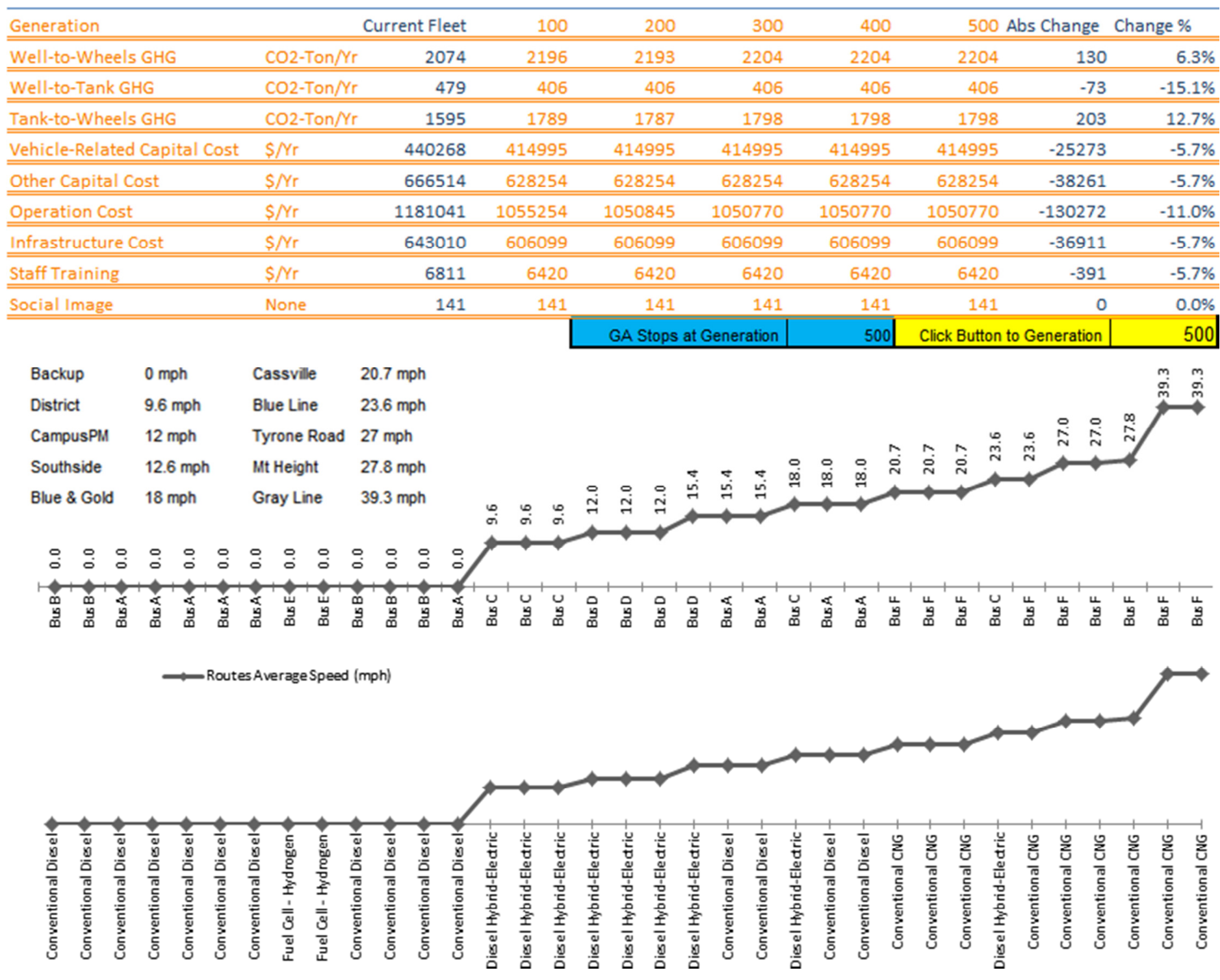

Figure 58: Performance Summary Table and Optimized Fleet Dispatch Strategy for the 35-bus Fleet. The dispatch strategy was for minimizing operation cost, when diesel price were changed from default \$3.09/gal to \$4/gal. 


\section{Section XI: Optimized Current Year Fleet Cost and Emissions Performance}

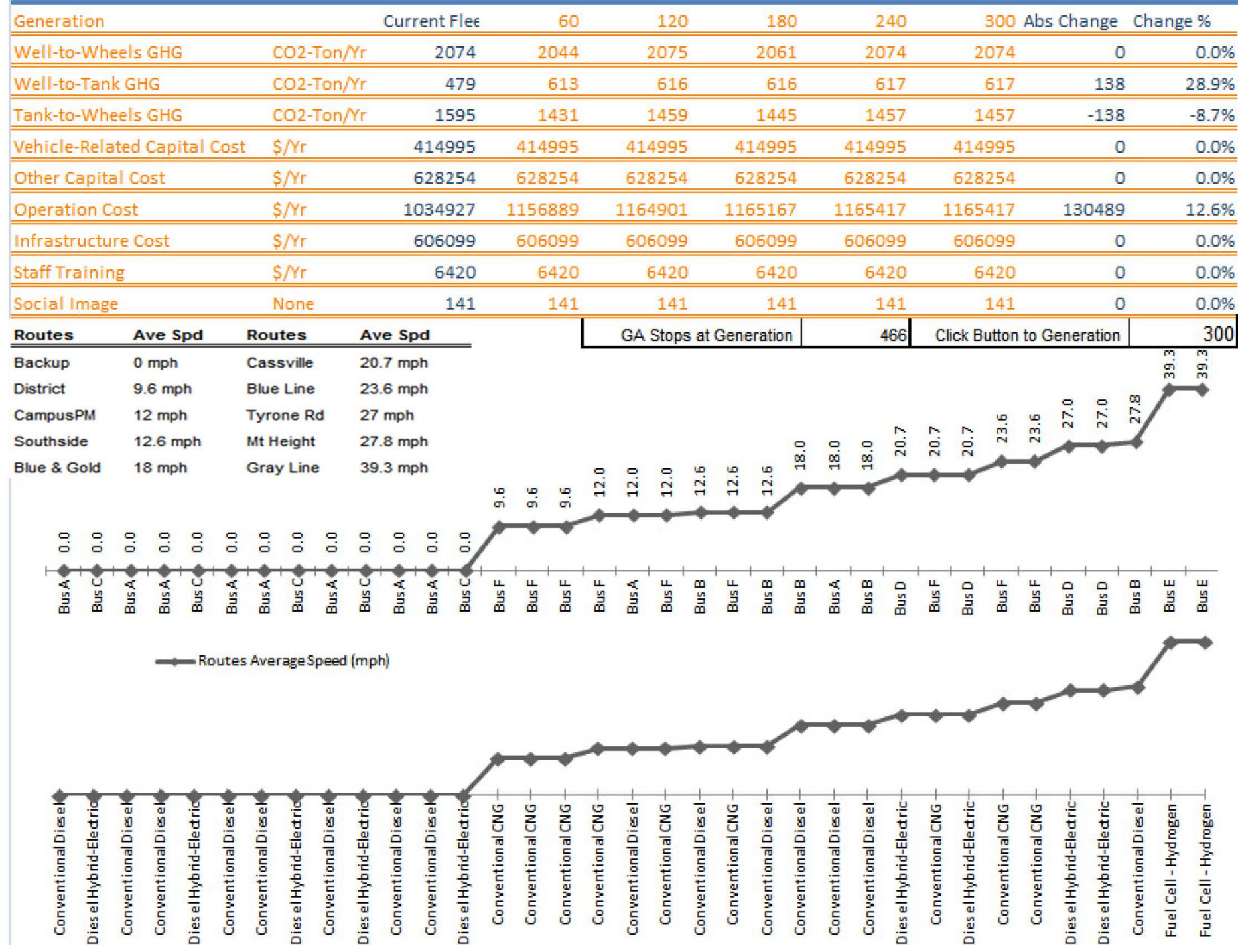

Figure 59: Performance Summary Table and Optimized Fleet Dispatch Strategy for the 35-bus Fleet. (Screenshot of FMT Section XI) The dispatch strategy was for maximizing operation cost. It is a worst case scenario used to compare to the low operation cost scenario. 


\subsubsection{Optimization Results for Minimal WTW GHG Emissions}

This scenario was to reduce WTW GHG emissions as much as possible from the fleet (case 2 in Table 51). Figure 60 shows the proposed dispatch strategy, which reduced $364 \mathrm{CO}_{2}$ equivalent tons of WTW GHG emissions per year, $17.6 \%$ less than the current 2,074 $\mathrm{CO}_{2}$ equivalent tons annual WTW GHG emissions. The reduced emissions were a combination of 98 $\mathrm{CO}_{2}$ equivalent tons of increased WTT GHG emissions and 462 tons trimmed TTW GHG emissions. The side effect was a $\$ 75 \mathrm{~K}$ increment in operation cost per year to the fleet.

Fuel cell buses cost more on maintenance and operation in comparison to other three technologies. Cost driven cases left them to the backup fleet (Section 3.2.6.1). However, the proposed strategy in this scenario used fuel cell buses to operate on Gray Line, where zero TTW GHG emissions would maximally offset the WTT GHG emissions for hydrogen fuel production and transportation.

Diesel HEBs filled the three slow-speed routes. Conventional diesel buses were selected for the remaining routes. High $\mathrm{CO}_{2}$ equivalent $\mathrm{GHG}$ emissions are inherent in $\mathrm{CNG}$ technology. No CNG buses were selected in this optimization scenario.

Separate efforts were made to search for two other dispatch strategies that emit the lowest TTW (Figure 61) and the lowest WTT GHG emissions (Figure 62). Table 52 presents the comparison of the performance of the three optimization scenarios.

Table 52: Comparison of Three Cases Targeting WTW, WTT, and TTW GHG Emission Reduction

\begin{tabular}{|c|c|c|c|c|}
\hline \multirow[t]{2}{*}{ Focus in Important Index } & $\begin{array}{l}\text { Current Fleet } \\
\text { GHG } \\
\text { Emissions }\end{array}$ & $\begin{array}{l}\text { WTW GHG } \\
\text { Emissions } \\
\text { Reduction }\end{array}$ & $\begin{array}{l}\text { WTT GHG } \\
\text { Emissions } \\
\text { Reduction }\end{array}$ & $\begin{array}{l}\text { TTW GHG } \\
\text { Emissions } \\
\text { Reduction }\end{array}$ \\
\hline & & Case 1 & Case 2 & Case 3 \\
\hline WTW GHG Emissions in $\mathrm{CO}_{2}$ ton/year & 2074 & -364 & -182 & -364 \\
\hline WTT GHG Emissions in $\mathrm{CO}_{2}$ ton/year & 479 & +98 & -110 & +98 \\
\hline TTW GHG Emissions in $\mathrm{CO}_{2}$ ton/year & 1595 & -462 & -72 & -462 \\
\hline Operation Cost in \$/year & $1,035 \mathrm{~K}$ & $+75 \mathrm{~K}$ & $-73 K$ & $+69 K^{*}$ \\
\hline \multicolumn{2}{|l|}{ Result Figures (Summary Table Included) } & Figure 60 & Figure 61 & Figure 62 \\
\hline \multicolumn{5}{|c|}{$\begin{array}{l}\text { * Operation cost difference were from maintenance cost associated with different MY buses dispatches. } \\
\text { However, two dispatch strategies were same on bus technologies distribution. } \\
\text { * Operation cost had zero weighing factors in the three cases. }\end{array}$} \\
\hline
\end{tabular}




\section{Section XI: Optimized Current Year Fleet Cost and Emissions Performance}

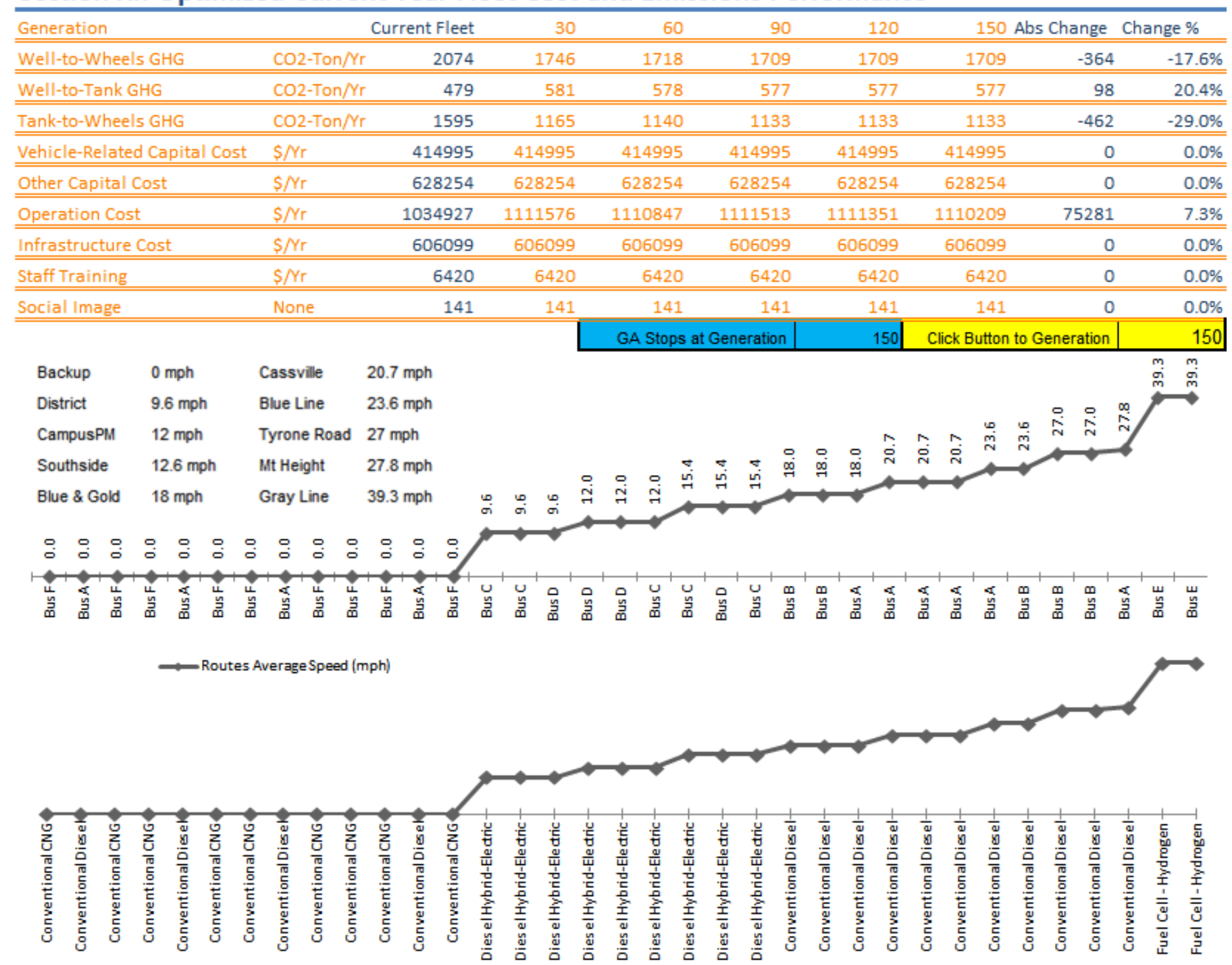

Figure 60: Performance Summary Table and Optimized Fleet Dispatch Strategy for the 35-bus Fleet. The dispatch strategy was for minimizing well-towheels greenhouse gas emissions. 


\section{Section XI: Optimized Current Year Fleet Cost and Emissions Performance}

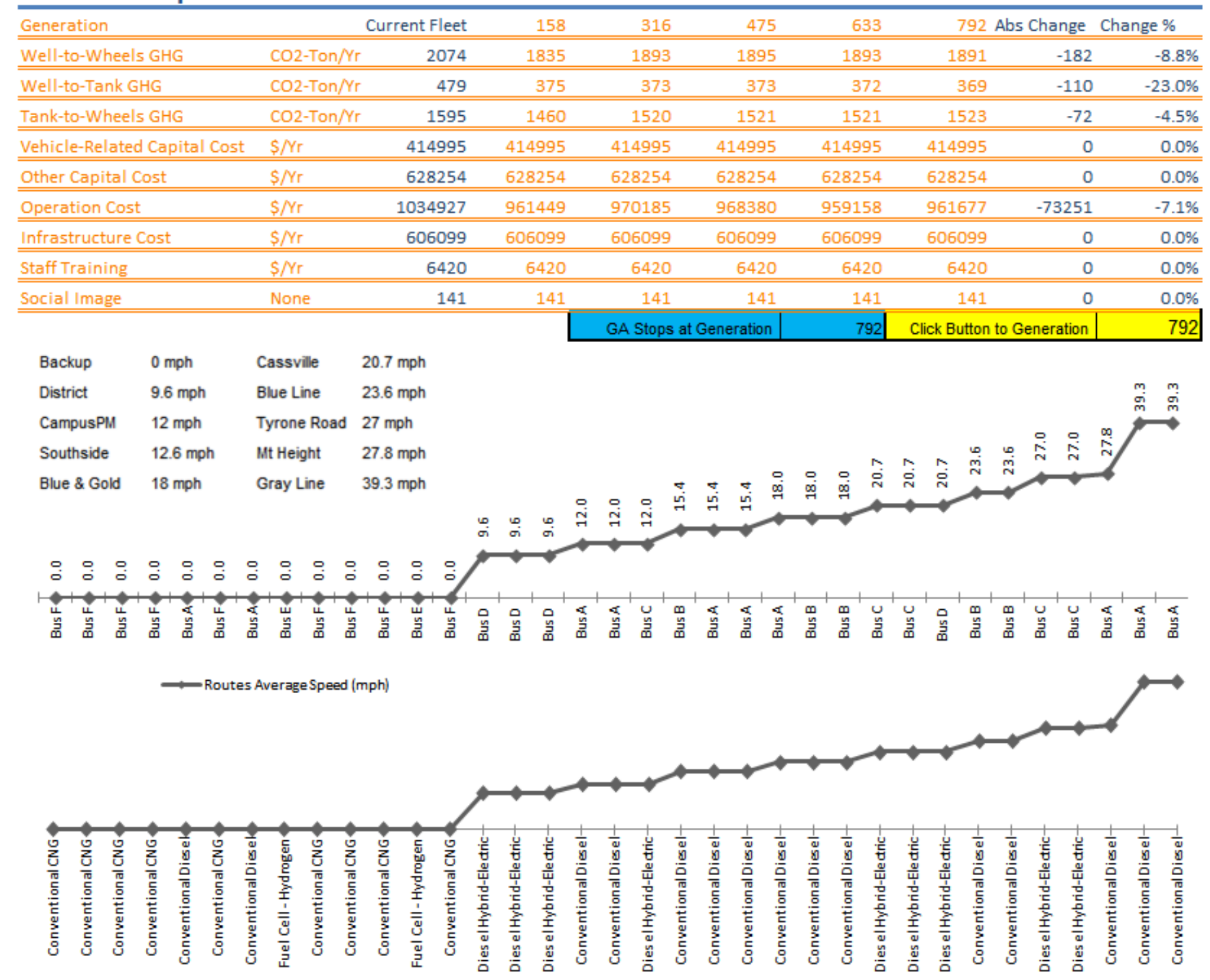

Figure 61: Performance Summary Table and Optimized Fleet Dispatch Strategy for the 35-bus Fleet. The dispatch strategy was for minimizing well-totank greenhouse gas emissions. 


\section{Section XI: Optimized Current Year Fleet Cost and Emissions Performance}

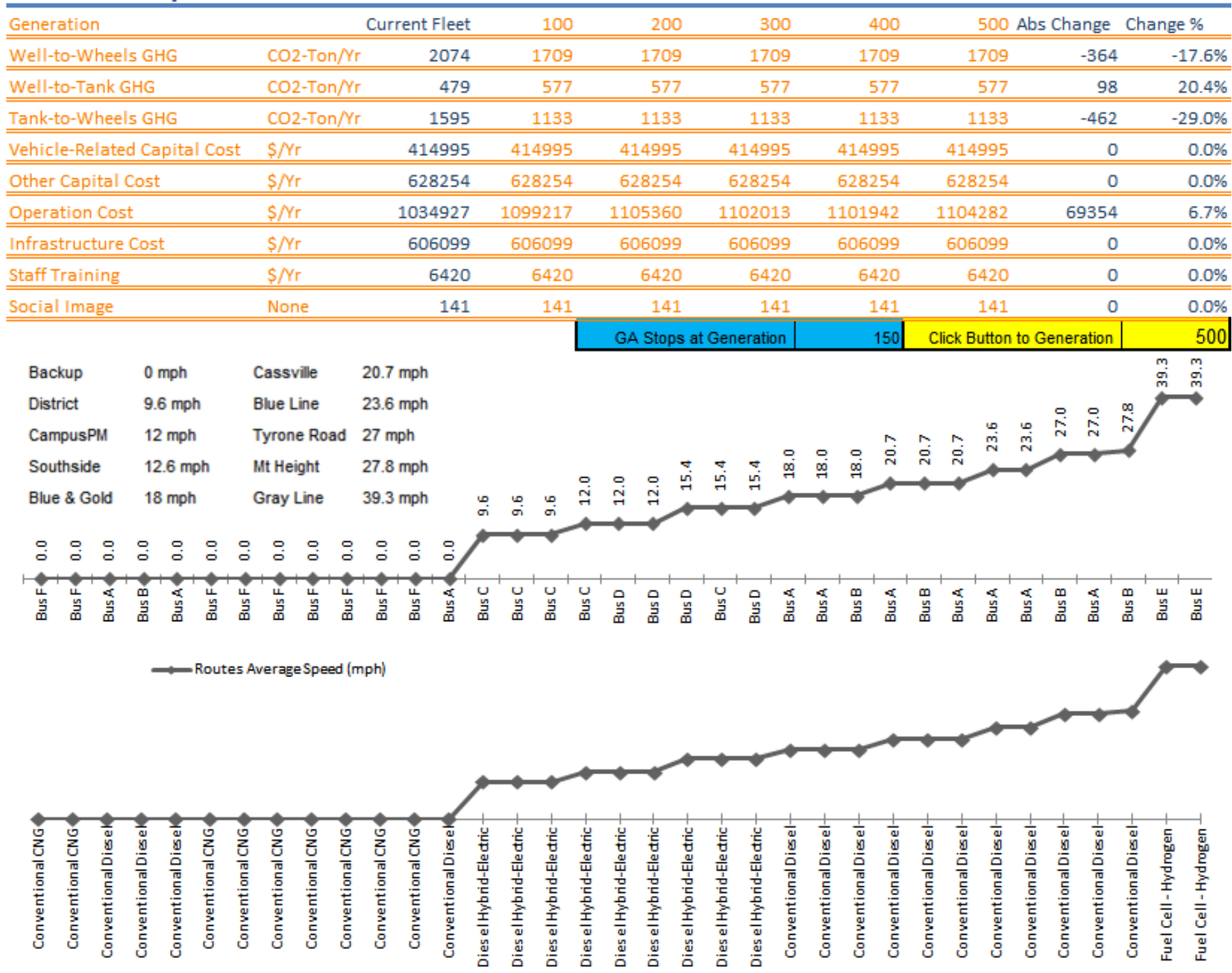

Figure 62: Performance Summary Table and Optimized Fleet Dispatch Strategy for the 35-bus Fleet. The dispatch strategy was for minimizing tank-towheels greenhouse gas emissions. 


\subsubsection{Optimization Results for Reconciling Multiple Goals}

In this scenario, the tool was to search for a dispatch strategy per multiple aspects (case 3 Table 51). The primary or critical goal was to reduce operation cost (weight "9"). The major goal was to reduce TTW GHG emissions (weight " 6 "). The least important goal was to reduce WTT GHG emissions (weight " 3 ").

Figure 63 presents the proposed dispatch strategy, which was close to the proposed dispatch strategy in case of reducing operation cost. It favored diesel HEB and diesel buses. However, HEB were assigned into different routes. In the low cost scenario (Section 3.2.6.1), Gray Line (39.3 mph and 330 miles per day) had two diesel HEB and Tyrone Road Line ( $27 \mathrm{mph}$ and 300 miles per day) had one diesel HEB. In this scenario, two diesel HEB were assigned to Blue \& Gold Line ( $18 \mathrm{mph}$ and 60 miles per day) and one was assigned to Southside Line (15.4 $\mathrm{mph}$ and 40 miles per day).

As a result, the proposed dispatch strategy compromised between the low cost and low TTW GHG emissions scenarios. It could reduce $80 \mathrm{~K}$ (7.7\% reduction) in operation cost, which was less than the cost of $\$ 90 \mathrm{~K}$ (9\% reduction) achieved in low cost scenario. GHG emissions reductions were $105 \mathrm{CO}_{2}$ equivalent tons/year in WTT GHG emissions and $181 \mathrm{CO}_{2}$ equivalent tons/year in TTW GHG emissions. TTW GHG emissions performance was better than it was in the low cost scenario (181 CO $\mathrm{CO}_{2}$ equivalent tons/year vs. $104 \mathrm{CO}_{2}$ equivalent tons/year). However, TTW GHG emissions reduction in this scenario was not comparable to what was in the TTW GHG emissions reduction scenario (Figure 62). The latter could reduce $462 \mathrm{CO}_{2}$ equivalent tons/year TTW GHG emissions. 


\section{Section XI: Optimized Current Year Fleet Cost and Emissions Performance}

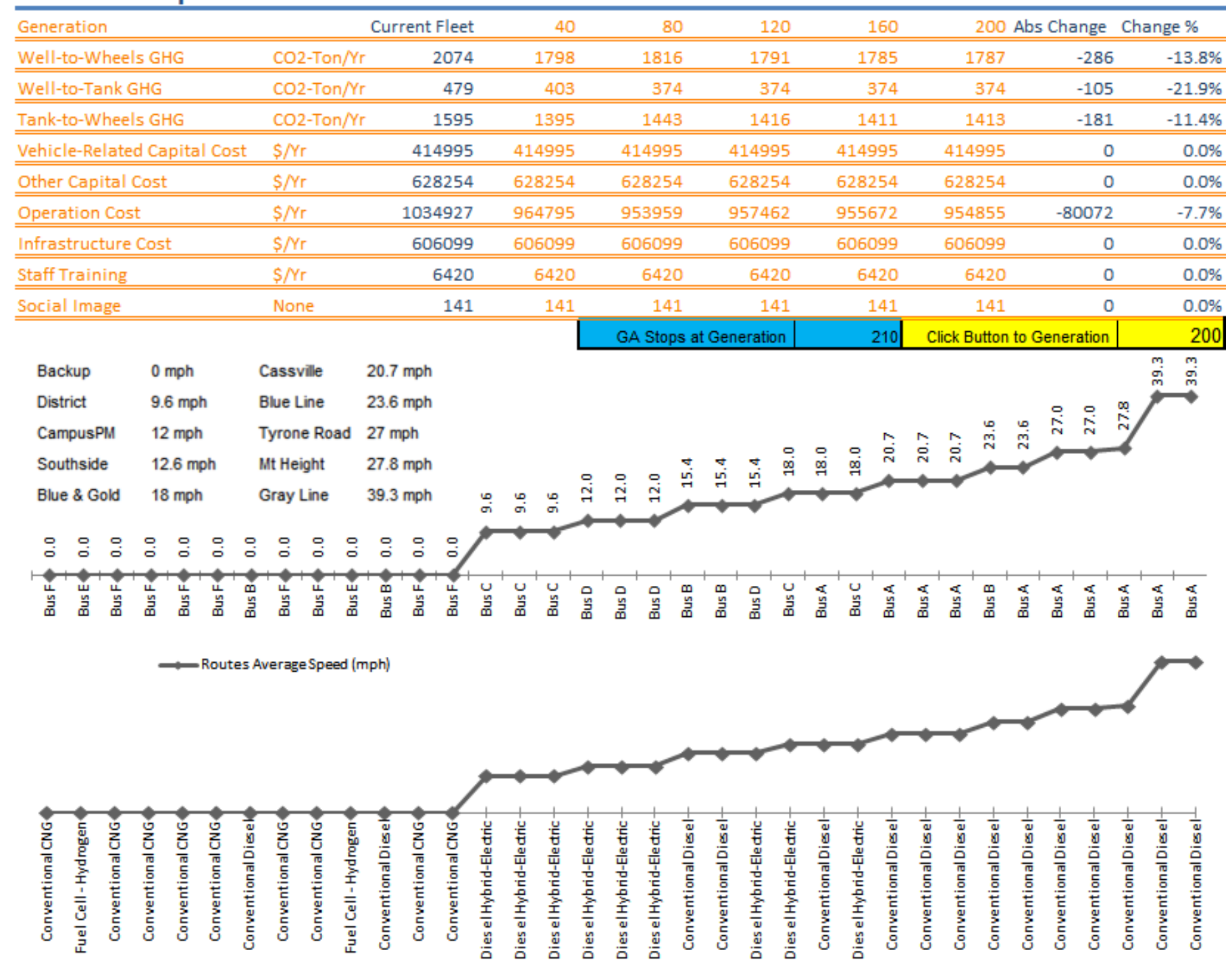

Figure 63: Performance Summary Table and Optimized Fleet Dispatch Strategy for the 35-bus Fleet. The dispatch strategy was for multiple goals. Operation cost was set with weight " 9 ", TTW GHG emissions were set with weight " 6 ", and WTT-GHG emissions gas emissions were set with weight " 3 ". 


\subsubsection{Selection of New Bus Technologies for Multiple Goals}

This section presents how the tool can help management to pick new bus technologies to replace aged buses. The 35-bus fleet continued serving as the case study site. The management decided to purchase five new buses. They considered seven different propulsion technologies. Figure 42 list the technical information of the seven new bus technologies.

The management identified the weighting of each selection criteria (Table 53). The most concern to the management was the operation cost control (a weighing factor of " 9 "). The management gave moderate concerns (a weight factor of "6") to non-vehicle related capital cost, infrastructure cost, and TTW GHG emissions. The management had least or no concerns to WTW GHG emissions, vehicle-related capital cost, staff training cost, WTT GHG emissions and social image. Those criteria were given weight factors less than 3.

Table 53: Importance Index Table for Bus Technology Selection Case

\begin{tabular}{|l|c|}
\hline \multicolumn{1}{|c|}{ Set of Effects } & Importance Level \\
\hline Reduce Well-to-Wheels GHG Emissions & 0 \\
\hline Reduce Vehicle-Related Capital Cost & 3 \\
\hline Reduce Other Capital Cost & 6 \\
\hline Reduce Operation Cost & 9 \\
\hline Reduce Infrastructure Cost & 6 \\
\hline Reduce Staff Training Cost & 1 \\
\hline Reduce Well-to-Tank GHG & 1 \\
\hline Reduce Tank-to-Wheels GHG (Tailpipe) Emissions & 6 \\
\hline Improve Social Image & 1 \\
\hline
\end{tabular}

For comparison purposes, the tool was first used to optimize the original dispatch strategy without considering new bus purchases. The tool was then used to search for new bus technologies and also optimize the dispatch strategy. The dispatch strategy from the first optimization was named case 1 strategy in this section, and the latter one was named case 2 strategy. 
Case 1 strategy reduced operation cost by 5.5\% and TTW GHG emissions by 16\% (Table 54) by only implementing a new dispatch strategy. Case 2 strategy purchased three new batteryelectric buses and two new diesel HEBs to replace five diesel buses (the oldest five, see explanation in Section 3.2.3). Case 2 strategy reduced operation cost by $17 \%$ from the current dispatch strategy. TTW GHG emissions were 39\% less (Table 54).

"Other capital cost" and "infrastructure cost" were also important (weight "6") factors (Table 53). Case 1 strategy did not change the two costs, because there was no bus composition change in the fleet. However, the new bus procurement in case 2 strategy raised the "other capital cost" by $3.8 \%$ and infrastructure cost by $3.5 \%$.

Table 54: Effects of Two Proposed Dispatch Strategies on the Performance of Cost, Emissions, etc. Both strategies had the same weighing on selection criteria. Dispatch strategy one was based on improving existing bus fleet. Dispatch strategy two was based on improving new future bus fleet that includes five new buses.

\begin{tabular}{|c|c|c|c|c|c|c|}
\hline \multirow{2}{*}{$\begin{array}{l}\text { Set of Effects } \\
\text { Well-to-Wheels GHG }\end{array}$} & \multirow{2}{*}{$\begin{array}{c}\text { Unit } \\
\text { CO2-Ton/Yr }\end{array}$} & \multirow{2}{*}{$\begin{array}{c}\begin{array}{c}\text { Current } \\
\text { Dispatch } \\
\text { Strategy }\end{array} \\
2074\end{array}$} & \multicolumn{2}{|c|}{$\begin{array}{l}\text { Proposed Dispatch } \\
\text { Strategy One } \\
\text { (with Exist Buses) }^{1}\end{array}$} & \multicolumn{2}{|c|}{$\begin{array}{c}\text { Proposed Dispatch } \\
\text { Strategy Two } \\
\text { (with New Five Buses) }\end{array}$} \\
\hline & & & 1759 & $-15 \%$ & 1529 & $-26 \%$ \\
\hline Well-to-Tank GHG & CO2-Ton/Yr & 479 & 426 & $-11 \%$ & 551 & $15 \%$ \\
\hline Tank-to-Wheels GHG & CO2-Ton/Yr & 1595 & 1333 & $-16 \%$ & 978 & $-39 \%$ \\
\hline Vehicle-Related Capital Cost & $\$ / Y r$ & $415 \mathrm{~K}$ & $415 \mathrm{~K}$ & $0.0 \%$ & $486 \mathrm{~K}$ & $17 \%$ \\
\hline Other Capital Cost & $\$ / Y r$ & $628 \mathrm{~K}$ & $628 \mathrm{~K}$ & $0.0 \%$ & $652 \mathrm{~K}$ & $3.8 \%$ \\
\hline Operation Cost & $\$ / Y r$ & $1035 \mathrm{~K}$ & $978 \mathrm{~K}$ & $-5.5 \%$ & $862 K$ & $-17 \%$ \\
\hline Infrastructure Cost & $\$ / Y r$ & $606 K$ & $606 \mathrm{~K}$ & $0.0 \%$ & $627 \mathrm{~K}$ & $3.5 \%$ \\
\hline Staff Training & $\$ / Y r$ & $6.42 \mathrm{~K}$ & $6.42 \mathrm{~K}$ & $0.0 \%$ & $8.88 \mathrm{~K}$ & $38 \%$ \\
\hline Social Image & None & 141 & 141 & $0.0 \%$ & 181 & $28 \%$ \\
\hline $\begin{array}{l}\text { 1. Existing fleet optimi } \\
\text { 2. New fleet optimizat } \\
\text { replace five oldest }\end{array}$ & $\begin{array}{l}\text { ion only. Th } \\
\text { The tool st } \\
\text { el buses. }\end{array}$ & sted usir & diese & $\begin{array}{l}\text { רge. } \\
\text { id th }\end{array}$ & ry e & es to \\
\hline
\end{tabular}

Case 1 strategy (Figure 61) assigned all diesel HEBs and two fuel cell HEBs to the four slowest routes, and assigned all conventional diesel buses to the remaining routes. CNG buses were assigned into the backup fleet. Case 2 strategy (Figure 62) moved one of the two fuel cell HEBs to the backup fleet. The two new HEBs and other HEBs were assigned to the four slowest routes. Three battery electric buses replaced three conventional diesel buses in the two fastest and longest routes (Gray Line and Mt Height). 
Among the seven new technologies (Figure 42 ), battery-electric bus technology produced zero TTW GHG emissions and was superior in the fuel economy model. The merits were big plus for case 2 strategy, although the technology required extra infrastructure and special equipment to service. Case 2 strategy also selected diesel HEBs to the purchase profile. Diesel HEBs produced low TTW GHG and had great fuel saving compared to conventional diesel, biodiesel and CNG buses. HEB technology did not require new infrastructure. The equipment cost for HEB battery handling was so trivial in front of other capital cost. The management did not have much concerns with WTT GHG emissions, vehicle related capital cost, staff training, and social image. Case 2 strategy ended up with 15\%, 17\%, 38\% increases in WTT GHG emissions, vehicle-related capital cost, and staff training. 


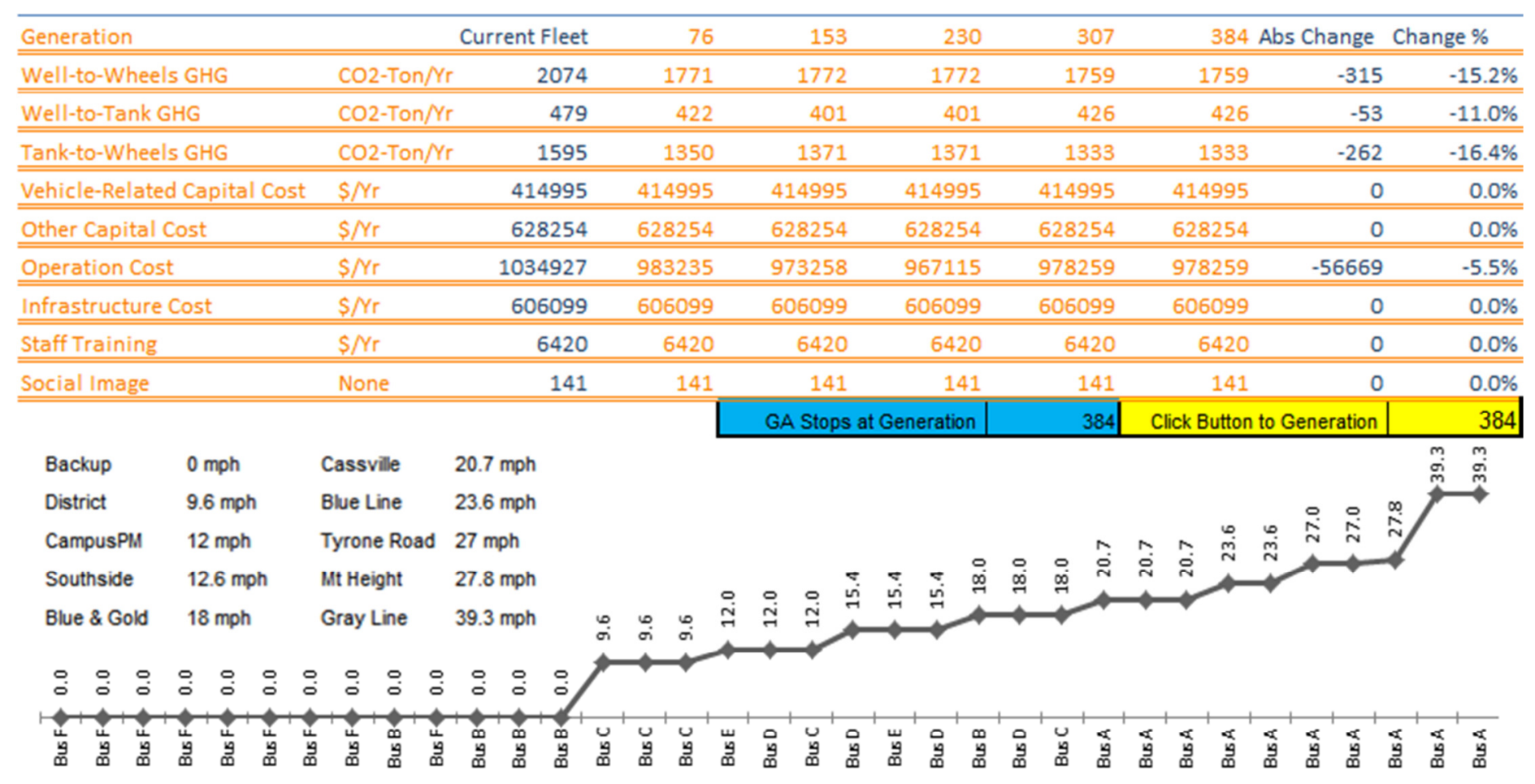

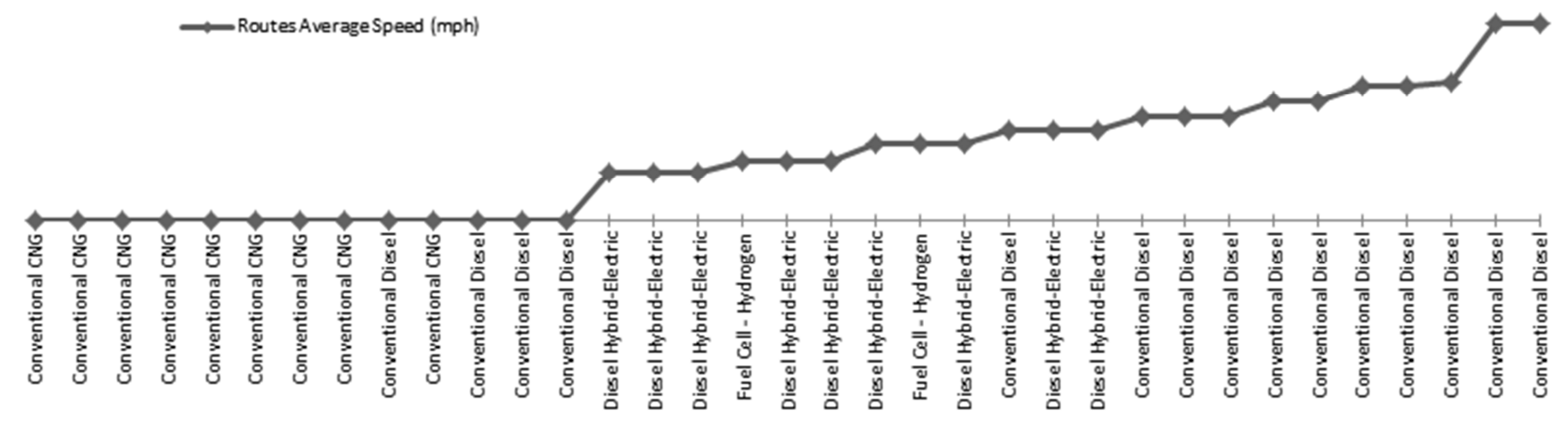

Figure 64: Performance Summary Table and Optimized Fleet Dispatch Strategy for the 35-bus Fleet. The dispatch strategy was an optimization for multiple criteria in Section 3.2.7. The dispatch strategy (case 1 strategy in the section) was for the existing fleet. 


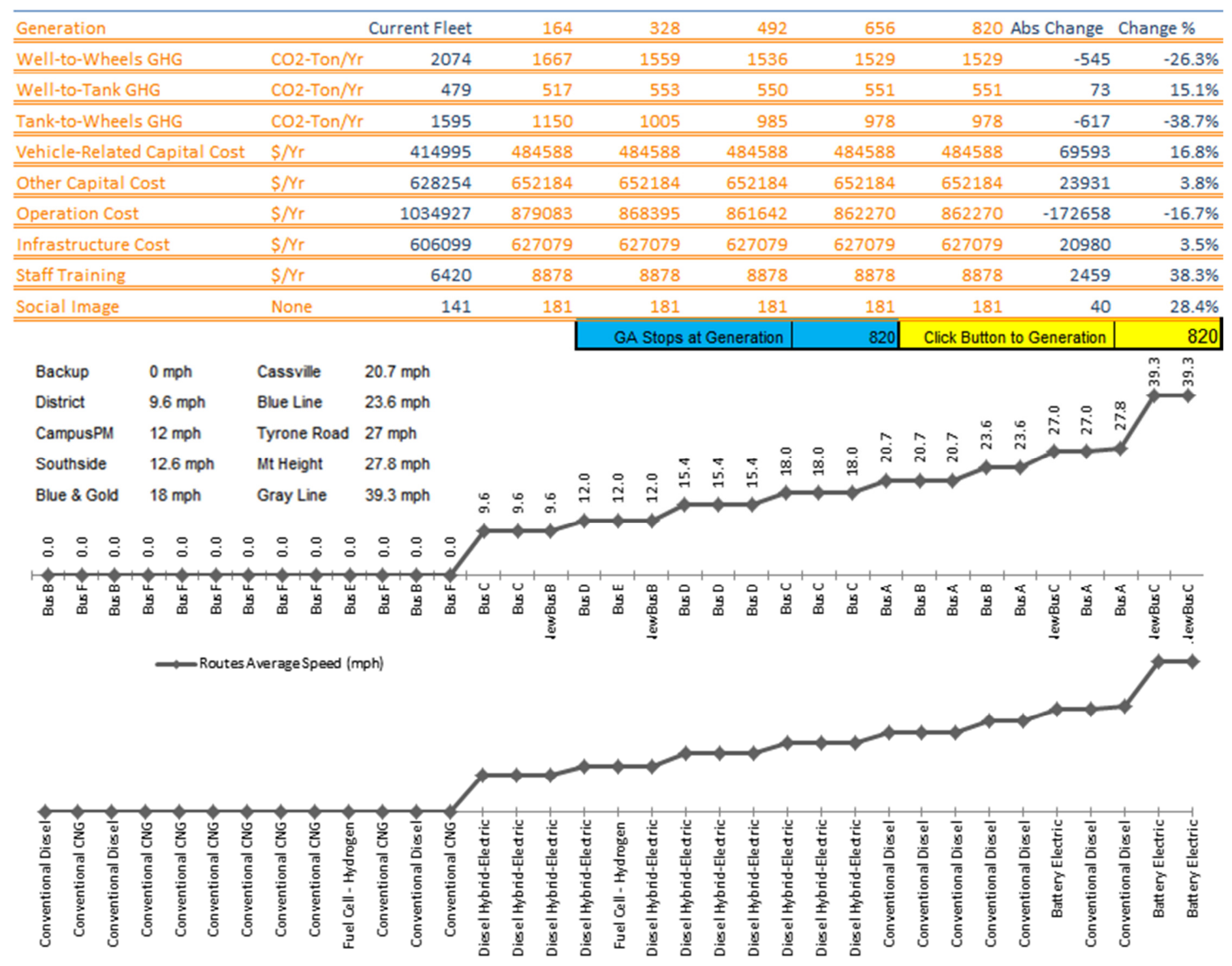

Figure 65: Performance Summary Table and Optimized Fleet Dispatch Strategy for the 35-bus Fleet. The dispatch strategy was an optimization for multiple criteria in Section 3.2.7. The dispatch strategy (case 2 strategy in the section) was for the new fleet that included five new buses. 


\section{CONCLUSIONS}

How to achieve cost efficiency or green operation without compromising targeted service level remains a critical question for transit fleet management. Over the last two decades, dozens of new advanced propulsion technologies have emerged in the transit bus business. Those new propulsion technologies could differ in fuels, engines, drivetrains, and aftertreatment devices. The environmental and economic impacts of those new bus technologies have been significantly different, especially when they were operated on various types of routes. A transit fleet could operate a mix of multiple bus technologies over multiple routes, but each technology may be more suited to some routes than others. A system level tool would be useful for the management to make best use of their existing buses and/or make best choice of new bus technologies per the specific operation.

The TCRP C-15 program research team (which included the author as a key team member) created a transit bus LCC model to systematically evaluate major costs and benefits of four major bus technologies. The model has demonstrated that different operation situations affect bus cost performance dramatically [2]. Bus capital and operation cost data were acquired from four transit fleets (NYCT, KC Metro, LBT, and WMATA) with additional information gathered from literature reviews. Data from NYCT and KC Metro were obtained from three DOE/NREL studies [6 - 8]. Additional cost data were collected through a survey of bus and hybrid drive OEMs, and from the fuel industry. The study team gathered future fuel pricing data from various agencies and government sources. Based on this data and the projections from the research team, the LCC model was built in spreadsheet format to calculate costs including vehicle purchase, insurance, warranty, personnel training, infrastructure, facility maintenance, fuel, major component replacement, and vehicle maintenance. A detailed model for FE was constructed, using field and chassis dynamometer data, for inclusion in the LCC. This FE model was essential, because route speed impacts the FE of all bus types substantially. The LCC also considered the FE impact of climate control, including air conditioning and fuel burner heating. These auxiliary loads can account for FE changes of fuel consumption at $4 \%$ to $9 \%$ from season to season. 
In this dissertation, author expanded the C-15 LCC model to cover more technologies options from biodiesel and hydrogen fuel cell HEBs to electric buses. Only a few transit fleet sites operated those bus types, and their number was limited. Literature reviews and good engineering judgment were used to estimate and define their capital and operation cost data. The Author built a GHG emissions model including WTT and TTW GHG emissions models. The WTT model derived fuel energy specific GHG emissions data from the GREET model developed by Argonne National Laboratory [13]. The TTW GHG emissions model was based on chassis dynamometer $\mathrm{CO}_{2}$ and THC data. The cost and emissions models were capable of calculating the performance of a given bus type on a defined route.

Other than the cost and emissions models, the tool included an optimization module. The optimization module was to probe the best dispatch strategy to improve fleet performance to meet different objectives. A weighted decision matrix helped to evaluate different dispatch strategies per the defined objective. The objective in this tool requested the user to weight nine criteria including five cost areas, three GHG emissions areas and one intangible area (such as improved social image of the transit fleet). The optimization module used the calculation module and the weighted decision matrix to rank bus dispatch strategies. The tool has demonstrated that different operation objections could suggest varying bus dispatch strategies.

GA was used as the search algorithm in the optimization to find the best bus dispatch strategy. GA would be redundant for fleets that might operate few types of buses or have limited number of buses and routes. GA became helpful, when search space grew exponentially upon increasing numbers of bus types and routes.

The fleet management tool was demonstrated on a 35-bus fleet that operated conventional diesel, CNG, fuel cell HEB, and diesel HEBs on nine real-world routes. The nine routes had a distance range between 4.6 to 330 miles per trip and average speed range between 9.6 and $39.3 \mathrm{mph}$. The baseline fleet employed a random bus dispatch strategy, which cost 1.03 million dollars in annual operation cost and emitted 2,074 CO2-equivalent WTW GHG emissions in tons per year. 
For the case of reducing the operation cost, the proposed dispatch strategy reduced the operation cost to $\$ 945 \mathrm{~K}$, an $\$ 85 \mathrm{~K}$ reduction in operation cost. The worst dispatch strategy would cost $\$ 1,165 \mathrm{~K}$ per year. The operation cost difference between the best and worst dispatch strategy was $\$ 220 \mathrm{~K}$ a year, roughly $\$ 6200$ per bus per year in this case. The best dispatch strategy favored operating conventional diesel and diesel HEBs when targeting low operation cost operation in general. Fuel cell HEB and CNG buses were assigned into backup route, which indicated the inactive fleet. When the diesel fuel price in model increased from the default \$3.1\$/gal to $\$ 4.0 /$ gal, CNG buses became more attractive than conventional diesel buses and were put to service if the CNG price stayed at the default $\$ 2.05 / D E G$ price.

Diesel HEBs were generally operated in the slowest routes due to their superior fuel economy advantage to conventional diesel buses. However, diesel HEBs also appeared on the high speed and long distant routes, where high fuel consumption could sufficiently compensated the weakened fuel economy advantage to conventional diesel buses.

For the case of reducing GHG emissions, the proposed dispatch strategies targeting on reducing WTT or TTW GHG emissions produced quite different results. The strategy for reducing WTT GHG emissions ended up reducing $110 \mathrm{CO}_{2}$ equivalent tons WTT GHG emissions. The same strategy could also cut $72 \mathrm{CO}_{2}$ equivalent tons TTW GHG emissions annually. The strategy intending for reducing TTW GHG emissions instead increased $98 \mathrm{CO}_{2}$ equivalent tons WTT GHG emissions. However, it could successfully eliminate $462 \mathrm{CO}_{2}$ equivalent tons TTW GHG emissions annually.

Diesel HEBs were scattered over the nine routes in the WTT GHG emissions reduction case, where reducing fuel consumption was the key to WTT GHG emissions reduction. Fuel cell HEB were assigned in the backup fleet due to its high WTT GHG emissions, which were associated with the huge energy consumption of hydrogen fuel generation, storage, and transportation. Conventional diesel buses were favored over CNG buses. However, in the case of reducing TTW GHG emissions, fuel cell HEB was a promising WTT GHG emissions reducer due to its zero TTW GHG emissions. The two fuel cell HEBs were assigned to the high speed and long distant route. CNG buses were not favored in the GHG emissions cases due to its inherent high GHG emissions. 
For the case of weighted multi-goal optimizations, the tool examined the interplay between changing criteria and dispatch strategies. In the primary (weight "9" out of a 0-10 scale) operation cost case, the management requested medium effort (weight " 6 ") to reduce TTW GHG emissions and low effort (weight "1") to reduce WTT GHG emissions. The proposed dispatch strategy relocated diesel HEBs from high-speed and long-distance routes. The compromised dispatch strategy cost $\$ 10 \mathrm{~K}$ more that the dispatch strategy found in the case of reducing operation cost did. The proposed dispatch strategy could reduce TTW GHG emissions by $105 \mathrm{CO}_{2}$ equivalent tons. The TTW GHG emissions reduction was also associated with 181 $\mathrm{CO}_{2}$ equivalent tons less WTT GHG emissions.

For the case of using the tool to assist in new bus technologies purchase, the tool was used to purchase five buses by selecting from a list of available new propulsion technologies. The focus was on operation cost (weight "9"), infrastructure cost (weight "6"), non-vehicle-related capital cost (weight "6") and TTW GHG emissions (weight "6"). The proposed dispatch strategy suggested two new diesel HEBs and three new battery electric buses into the fleet. The dispatch strategy assigned all diesel HEBs into the slow routes, and battery electric buses were into the two long and fast routes. One fuel cell HEB was put into the service to utilize its key contribution of zero TTW GHG emissions. The proposed dispatch strategy ended up reducing $\$ 862 \mathrm{~K}$ in operation cost (17\% drop), increasing $\$ 21 \mathrm{~K}$ in infrastructure cost (3.5\% rise), increasing $\$ 24 \mathrm{~K}$ in non-vehicle-related capital cost (3.8\% rise), and reducing $617 \mathrm{CO}_{2}$ equivalent tons TTW GHG emissions (39\% drop). 


\section{SUGGESTED FUTURE RESEARCH AND MODEL DEVELOPMENT}

The tool is expandable to include more evaluation criteria, as long as the user is capable of discerning the nature of the criteria and to quantify them mathematically. The tool (version 4.6) was programmed by Microsoft ${ }^{\circledR}$ VBA and designed for a single transit fleet management. The concept can be applied to an even larger scale, such state transit fleet management, incentive match study or regional GHG emissions inventory development. In those cases, the processing time may increase and become too large to be handled with the VBA program and personal computers. In that case, the VBA program should be reprogramed with other advanced languages such as MATLAB, $\mathrm{C}++$, FORTRAN, etc. Additional improvement of the GA algorithm can be made to converge fast to global extreme with less computation processing time. The tool can also be expanded to a route design tool by using GA to search the best routes instead of best dispatch strategies.

When the tool is used to optimize a fleet with multiple bus sizes, the tool managed to keep the total bus length consistent on each route in any new generated dispatch strategy. For example, two $60-\mathrm{ft}$ long buses can possibly be replaced with three $40-\mathrm{ft}$ long buses if customers will tolerate headway differences. The potential number changes of buses affects the headway on the route. It can cause ridership and passenger demand issues. To avoid these issues, it was recommended to group the buses according to bus length. By analyzing buses with same length together, it preserved the number of buses and the size of buses per route the same. It is desired to develop the sophisticated functions into the tool to handle the ridership demanding or policy issues.

Long-term real-world data collection for the new advance propulsion technologies such as fuel cell HEBs and electric buses are desired. Extended data collection is suggested to study in more detail the impact of after-warranty bus operation, and to understand the reliability and longevity of advanced engines and propulsion systems. 


\section{REFERENCES}

1. Green Car Congress, "Report: Fuel Economy Benefit of Hybrid Buses in Toronto Overstated," http://www.greencarcongress.com/2008/05/report-fuel-eco.html, Accessed on August 8, 2008.

2. West Virginia University, Transit Resource Center, and Battelle Memorial Institute, "TCRP Report 132 - Assessment of Hybrid-Electric Transit Bus Technology," TRB, National Research Council, Washington, D.C., 2009.

3. Farrington R., and Rugh J., "Impact of Vehicle Air-Conditioning on Fuel Economy, Tailpipe Emissions, and Electric Vehicle Range," National Renewable Energy Laboratory, Technical Report NREL/CP-540-28960, 2000.

4. The Northeast Advanced Vehicle Consortium (NAVC), "Analysis of Electric Drive Technologies for Transit Applications: Battery-Electric, Hybrid-Electric, and Fuel Cells," Federal Transit Administration, US Department of Transportation, Publication FTA-MA26-7100-05.1, 2005.

5. Henke, C., "The Case for Hybrid in Transit Buses: A Meta-Analysis and Literature Review," Federal Transit Administration, US Department of Transportation, Publication FTA-CA26-7068-2004.2, 2005.

6. Chandler, K., and Walkowicz, K., "King County Metro Transit Hybrid Articulated Buses: Interim Evaluation Results," National Renewable Energy Laboratory, Technical Report NREL/TP-540-39742, 2006.

7. Chandler, K., and Walkowicz, K., "Emissions, Fuel Economy, and In-use Performance Evaluation of King County Metro Transit's Hybrid Buses," Presented at 2006 APTA Bus \& Paratransit Conference, Orange County, CA, 2006.

8. Chandler, K., Eberts, E., Eudy, L., “New York City Transit Hybrid and CNG Transit Buses: Interim Evaluation Results," National Renewable Energy Laboratory, Technical Report NREL/TP-540-38843, 2006.

9. Knoxville Area Transit, "Advanced Technology Vehicles in Service," National Renewable Energy Laboratory, Golden, CO, 2005. 
10. Clark, N.N., Zhen, F., Wayne, W.S., and Lyons, D.W., "Transit Bus Life Cycle Cost and Year 2007 Emissions Estimation," Federal Transit Administration, US Department of Transportation, Publication FTA-WV-26-7004.2007.1, 2007.

11. Lowell D., Chernicoff, W.P., and Lian, F.S., "Fuel Cell Bus Life Cycle Cost Model: Base Case \& Future Scenario Analysis," Federal Transit Administration, US Department of Transportation, Publication DOT-T-07-01, 2007.

12. Hellgren J., "Life Cycle Cost Analysis of a Car, a City Bus and an Intercity Bus Powertrain for Year 2005 and 2020," Energy Policy, Vol. 35, pp. 39-49, 2007.

13. Wang, M., "Development and Use of GREET 1.6 Fuel-Cycle Model for Transportation Fuels and Vehicle Technologies," Energy System Division, Argonne National Laboratory, Technical Report ANL/ESD/TM-163, 2001.

14. Beer, T., Grant, T., Brown, R., Edwards, J., Nelson, P., Watson, H., and Williams, D., "Lifecycle Emissions Analysis of Alternative Fuels for Heavy Vehicles," CSIRO Atmospheric Research Report C/0411/1.1/F2, 2000.

15. Hackney, J., and Neufville, R.D., "Life Cycle Model of Alternative Fuel Vehicles: Emissions, Energy, and Cost Trade-offs," Transportation Research Part A: Policy and Practice, Volume 35, Issue 3, pp. 243-266, 2001.

16. Holland, J.H., "Adaptation in Natural and Artificial Systems", the MIT Press, 1975.

17. American Public Transportation Association, "2008 Public Transportation Fact Book," 59th Edition, 2008.

18. American Public Transportation Association, "2010 Public Transportation Fact Book," 61th Edition, 2010.

19. IBISWorld Industry Report, "Truck \& Bus Manufacturing in the US: 33612," 2008.

20. American Public Transportation Association, "2008 APTA Transit Vehicle Database," CDROM, 2008.

21. Burnham, A., Wang, M. and Wu, Y., "Development and Applications of GREET 2.7 - the Transportation Vehicle-Cycle Model," Energy System Division, Argonne National Laboratory, Technical Report ANL/ESD/06-5, 2006. 
22. Wang, M., "Development and Use of GREET 1.6 Fuel-Cycle Model for Transportation Fuels and Vehicle Technologies," Energy System Division, Argonne National Laboratory, Technical Report ANL/ESD/TM-163, 2001.

23. Delucchi, M., "A Lifecycle Emissions Model (LEM): Lifecycle Emissions from Transportation Fuels, Motor Vehicles, Transportation Modes, Electricity Use, Heating and Cooling Fuels, and Materials - Documentation of Methods and Data," Main Report UCD-ITS-RR-03-17, 2003.

24. Nylund, N., Erkkila, K., and Hartikka, T., "Fuel Consumption and Exhaust Emissions of Urban Buses - Performance of the New Diesel Technology," VTT Tiedotteita - Research Notes 2373, page 48, 2007.

25. Johnson, T., "Diesel Engine Emissions and their Control," Platinum Metals Review, Volume 52, Number 1, pp. 23-37, 2008.

26. US Department of Energy, "Technology Roadmap for the 21st Century Truck Program," Report 21CT-001, 2000.

27. US Environmental Protection Agency, "EPA Heavy--Duty Hybrid Test Protocol Update," 2006 Hybrid Truck Users Forum Conference, San Diego, CA, 2006.

28. Chandler, K.L., Clark, N.N., Zhen, F., Wayne, W.S., Schiavone, J.J., Chambers, C., “HybridElectric Transit Bus Performance in North America," presented at Transportation Research Board, 88th Annual Meeting, Washington, D.C., 2007.

29. Chandler, K., Walkowicz, K., and Eudy, L., “New York City Transit Diesel Hybrid-Electric Buses: Final Results - DOE/NREL Alternative Fuel Transit Bus Evaluation Project," National Renewable Energy Laboratory, Golden, CO, 2000.

30. Chandler, K., and Walkowicz, K., "Emissions, Fuel Economy, and In-use Performance Evaluation of King County Metro Transit's Hybrid Buses," Presented at 2006 APTA Bus \& Paratransit Conference, Orange County, CA, 2006.

31. Pramanik, K., "Properties and Use of Jatropha Curcas Oil and Diesel Fuel Blends in Compression Ignition Engine," Renewable Energy, Volume 28, Issue 2, pp. 239-248, 2003. 
32. Ozsezen, A., Canakci, M., Turkcan, A., and Sayin, C., "Performance and Combustion Characteristics of a DI Diesel Engine Fueled with Waste Palm Oil and Canola Oil Methyl Esters," Volume 88, Issue 4, pp. 629-636, 2009.

33. http://www.ups.com/pressroom/us/press_releases/press_release/0,0,5052,00.html, Accessed on November 2008.

34. Chandler, K. and Eudy, L., "Alameda-Contra Costa Transit District (AC Transit) Fuel Cell Transit Buses: Third Evaluation Report," NREL/TP-560-43545-1, 2008

35. Chandler, K. and Eudy, L., "SunLine Transit Agency Hydrogen-Powered Transit Buses: Third Evaluation Report," National Renewable Energy Laboratory, Technical Report NREL/TP-560-43741-1, 2008

36. http://www.advancedenergy.org/corporate/news/2007/hesb_webinar.html, Accessed on July 4, 2008.

37. http://www.advancedenergy.org/corporate/initiatives/heb/plugin_hybrid_bus_testing. php, Accessed on July 4, 2008.

38. http://articles.directorym.net/Electric_Rail_or_Electric_Bus-a909497.html, Accessed on November 11, 2008.

39. http://www.newflyer.com/index/trolley, Accessed on November 11, 2008.

40. http://www.sfmta.com/cms/mfleet/trolley.htm, Accessed on November 11, 2008.

41. Environmental Protection Agency (EPA), "National Ambient Air Quality Standards," http://www.epa.gov/air/criteria.html, Accessed on Aug 8, 2005.

42. Northeast Advanced Vehicle Consortium, M. J. Bradley \& Associates, Inc., West Virginia University, “Hybrid-Electric Drive Heavy-duty Vehicle Testing Project Final Emissions Report," Defense Advanced Research Projects Agency, Arlington, VA, 2000.

43. NOx Emissions, "Low NOx," http://www.raypak.com/lownoxtech.htm, Accessed on Aug 8, 2005.

44. US Environmental Protection Agency, “Code of Federal Regulations, Part 86, Subpart N, Title 40," US Government Printing Office, 2004. 
45. Clark, N.N., Azu, A., Jarrett, R., Balon, T., Moynihan, P., Lynch, S. and Webb, T., “Operating Envelopes of HEB Engines," SAE Transactions 2001, Journal of Engines Vol. 110, pp. 2214-2225, 2001.

46. Bata, R., Clark, N.N., Lyons, D.W., Palmer, G.M., Long, T.R., Howell, A., Loth, J., Rapp, B.L. and Wang, W., "The First Transportable Heavy-Duty Vehicle Emissions Testing Laboratory," 1991 SAE Transactions: Journal of Commercial Vehicles, Vol. 100, pp. 433440, 1991.

47. Chaterjee, S., McDonald, C., Conway, R., Windawi, H., Vertin, K., Letavec, C.A., Clark, N.N., and Gautam, M., "Emissions Reductions and Operational Experiences with HeavyDuty Diesel Fleet Vehicles Retrofitted with Catalytically Regenerated Particulate Filters in Southern California," 2001 SAE Congress, Detroit, MI, SAE Paper 2001-01-0512, 2001.

48. Chandler, K., Malcosky, N., Motta, R., Norton, P., Kelly, K., Schumacher, L., and Lyons, D., “Alternative Fuel Transit Bus Evaluation Program Results," SAE Paper 961082, 1996.

49. Gautam, M., Thompson, G.J., Clark, N.N., Carder, D.K., Craven, R. and Lyons, D.W., "Mobile Emissions Measurement Systems: State of the Art," 10th CRC On-Road Vehicle Emissions Workshop, San Diego, CA, 2000.

50. Gautam, M., Thompson, G.J., Carder, D.K., Clark, N.N., Shade, B.C., Riddle, W.C. and Lyons, D.W., “Measurement of In-Use, On-Board Emissions from Heavy-Duty Diesel Vehicles: Mobile Emissions Measurement System," SAE Fall Fuels \& Lubricants Meeting, SAE Paper 2001-01-3643, 2001.

51. Toth-Nagy, C., Jarrett, R., Thompson, G., and Clark, N.N. “On the Road Exhaust Emissions Predictions for a Class 8 Tractor using an Artificial Neural Network," 'What will move you' Student Conference, University of California Davis, Davis, CA, 2003.

52. Shade, B.C., "A Performance Evaluation of the MEMS - an On-Road Emissions Measurement System Study," Thesis, College of Engineering and Mineral Resources, West Virginia University, Morgantown, WV, 2000.

53. Norbeck, J.M., Miller, J.W., Welch, W.A., Smith, M., Johnson, K., and Pankraz, D., "Develop On-Road System for Emissions Measurement from Heavy-Duty Trucks," South Coast Air Quality Management District Technology Advancement Office, Diamond Bar, 
CA, http://www.cert.ucr.edu/research/pubs/trailer_build_fr_20906b.pdf, Accessed on March $5^{\text {th }}, 2005$.

54. Clark, N., Gadapati, C., Kelly, K., White C., Lyons, D.W., Wang, W., Gautam, M., and Bata, R., "Comparative Emissions from Natural Gas and Diesel Buses," SAE Paper 952746, 1995.

55. Meyer, N. and Rideout, G., "Allison Ep System Electric Hybrid Test Program Regulated Emissions and Fuel Economy Results," Environmental Technology Center, Emissions Research and Measurement Division, Environment Canada, ERMD Report 02-25-1, 2002.

56. Chandler, K., Walkowicz, K., and Eudy, L., "New York City Transit Diesel Hybrid-Electric Buses: Final Results - DOE/NREL Alternative Fuel Transit Bus Evaluation Project," National Renewable Energy Laboratory, Technical Report NREL/BR-540-32427, 2002.

57. Meyer, N. and Rideout G., "Orion VII Transit Bus Equipped with BAE SYSTEMS HybrDrive $^{\text {TM }}$ Propulsion System (MY2004): Emissions and Fuel Economy Test Report," Environmental Technology Center, Emissions Research and Measurement Division, Environment Canada, ERMD Report 04-18, 2004.

58. Singh, M., Vyas, A., and Steiner, E., "VISION Model: Description of Model Used to Estimate the Impact of Highway Vehicle Technologies and Fuels on Energy Use and Carbon Emissions to 2050," Argonne National Laboratory, Technical Report ANL/ESD/04-1, 2003.

59. "Integration and Validation," Office of Energy Efficiency and Renewable Energy, FreedomCAR and Vehicle Technology, US Department of Energy, http://www1.eere.energy.gov/vehiclesandfuels/technologies/systems/integration.html, Accessed on Dec 12, 2011.

60. Rousseau, A., "What can Automotive do for you," Energy Efficiency and Renewable Energy, US Department of Energy, Washington, D.C., 2010.

61. "SAE Standard J2711 Recommended Practice for Measuring Fuel Economy and Emissions of Hybrid-Electric and Conventional Heavy-Duty Vehicle," SAE Document No. J2711, 2002. 
62. “Diesel Fuel and Exhaust Emissions (EHC 171, 1996)," United Nations Environment Program, http://www.inchem.org/documents/ehc/ehc/ehc171.htm, Accessed on Aug 8, 2005.

63. New S15 (Ultra Low Sulfur Diesel -ULSD Regulations, Chevron Corporation, http://www.chevron.com/products/prodserv/fuels/diesel/ulsd.shtml\#A2, Accessed on Feb 4, 2006.

64. Yeh, L.I., Rickeard, D.J., Duff, J.L.C., Bateman, J.R., Schlosberg R.H. and Caers, R.F., “Oxygenates: an Evaluation of their Effects on Diesel Emissions," SAE Paper 2001-012019, 2001.

65. Clark, N.N., Atkinson, C.M., Thompson, G.J., and Nine, R.D., "Transient Emissions Comparisons of Alternative Compression Ignition Fuels," SAE Paper 1999-01-1117, 1999.

66. Clark, N.N., Boyce, J.E., Xie, W., Gautam, M., Lyons, D.W., Vertin, K., LeTavec, C.A., and Coburn, T.C., "Class 8 Trucks Operating On Ultra-Low Sulfur Diesel with Particulate Filter Systems: Regulated Emissions," SAE Paper 2000-01-2815, 2000.

67. Kouremenos, D.A., Hountalas, D.T. and Kouremenos, A.D., "Experimental Investigation of the Effect of Fuel Composition on the Formation of Pollutants in Direct Injection Diesel Engines," SAE Paper 1999-01-0189, 1999.

68. Mann, N., Kvinge, F., and Wilson, G., “Diesel Fuel Effects on Emissions: Towards a Better Understanding," SAE Paper 982486, 1998.

69. Clark, N., Gautam, M., Lyons, D., Atkinson, C., Xie, W., Norton, P., Vertin, K., Goguen, S., and Eberhardt, J., "On-Road Use of Fischer-Tropsch Diesel Blends," SAE Paper 1999-012251, 1999.

70. Alleman, T.L., Eudy, L., Miyasato, M., Oshinuga, A., Allison, S., Corcoran, T., Chatterjee, S., Jacobs, T., Cherrillo, R.A., Clark, R., Virrels, I., Nine, R., Wayne, S., and Lansing, R., “Fuel Property, Emission Test, and Operability Results from a Fleet of Class 6 Vehicles Operating on Gas-to-Liquid Fuel and Catalyzed Diesel Particle Filters, " SAE Paper 200401-2959, 2004. 
71. Schaberg, P.W., Myburgh, I.S., Botha, J.J., Roets, P.N., Viljoen, C.L., Dnacuart, L.P., and Starr, M.E., "Diesel Exhaust Emissions Using Sasol Slurry Phase Distillate Process Fuels," SAE Paper 972898, 1997.

72. Grimaldi, C.N., Mariani, F., and Postrioti, L., "Performance and Emissions of a Common Rail DI Diesel Engine Using Fossil and Different Bio-Derived Fuels," SAE Paper 2001-012017, 2001.

73. Clark, N.N., and Lyons, D.W., "Class 8 Truck Emissions Testing: Effects of Test Cycles and Data on BioDiesel Operation," American Society of Agricultural Engineering, Vol. 42, No. 5, pp. 1211-1219, 1999.

74. Gateau, P. and Staat, F., "The Effects of Rapessed oil Methyl-Ester on Diesel Engine Performances, Exhaust Emissions and Long-Term Behavior," SAE Paper 950053, 1995.

75. Schumacher, L.G., Hires, W.G., and Borgelt, S.C., "Fueling a Diesel Engine with MethylEster Soybean Oil," http://www.biodiesel.org/resources/reportsdatabase/reports/tra/ 19950101_tra-051.pdf, Accessed on Aug 10, 2005.

76. Last, R.J., Krueger, M., and Duernholz, M., "Emissions and Performance Characteristics of a 4-stroke, Direct Injected Diesel Engine Fueled with Blends of Biodiesel and Low Sulfur Diesel Fuel," SAE Paper 950054, 1995.

77. Nine, R.D., Clark, N.N., Mace, B.E., Morrison, R.W., Remcho, V.T., Lowe, P.C., and McLaughlin, L.W., "Use of Soy-Derived Fuel for Environmental Impact Reduction in Marine Engine Applications," American Society of Agricultural Engineering Meeting Presentation Paper 986083, 1998.

78. “Auto/Oil Air Quality Improvement Research Program," SAE SP-920, (Collection of 16 SAE Papers), 1992.

79. Koehi, W.J., Grose, R.A., Benson, J.D., Hochhauster, A.M., Burns, V., and Reuter, R.M., "Effects of Gasoline Composition and Properties on Vehicle Emissions: A Review of Prior Studies," Auto/Oil Air Quality Improvement Research Program, SAE Paper 912321, 1992.

80. den Otter, G.J., Malpas, R.E., and Morgan, T.D.B., "Effect of Gasoline Reformulation on Exhaust Emissions in Current European Vehicles," SAE Paper 930372, 1993. 
81. Clark, N.N., Kern, J.M., Christopher, K., and Nine, R.D., "Factors Affecting Heavy-Duty Diesel Vehicle Emissions," ISSN 1047-3289, Journal of the Air \& Waste Management Association, Vol. 52, pp. 84-94, 2002.

82. Clark, N., Khan, A., Wayne, S., Gautam, M., Thompson, G., McKain, D., and Lyons, D., "Weight Effect on Emissions and Fuel Consumption from Diesel and Lean-Burn Natural Gas Transit Buses," SAE Paper 2007-01-3626, 2007.

83. Gajendran, P. and Clark, N.N., "Effect of Truck Operating Weight on Heavy-Duty Diesel Emissions," Environmental Science \& Technology, Vol. 37, Issue 18, pp. 4309-4317, 2003.

84. Hucho, W., "Aerodynamics of Road Vehicles," $4^{\text {th }}$ Edition, SAE International, 1998.

85. Graboski, M.S., McCormick, R.L., Yanowitz, J., and Ryan, L., "Heavy-Duty Diesel Vehicle Testing for the Northern Front Range Air Quality Study," Colorado School of Mines, Golden, CO, 1998.

86. Fuel Economy Measurement Test (Engineering Type) for Trucks and Buses (Cancelled Dec 1997), Society of Automotive Engineering Standards J1376, 1984.

87. McKain, D.L., Clark, N.N., Balon, T.H., Moynihan, P.J., Lynch, S.A. and Webb, T.C., "Characterization of Emissions from Hybrid and Conventional Transit Buses," SAE Fuels \& Lubricants Meeting, Paris, France, June 2000, SAE Paper 2000-01-2011, 2000.

88. Clark N.N., Tehranian, A., Jarrett, R.P., and Nine, R.D., "Translation of Distance-Specific Emissions Rates Between Different Heavy-Duty Vehicle Chassis Test Schedules," SAE Paper 2002-01-1754, 2002.

89. Wayne, S., Clark, N., Nine, R., and Rosepiler, S., "Washington Metropolitan Area Transit Authority Diesel Emissions Control Retrofit Project," Final Report, West Virginia University, Morgantown WV, 2002.

90. Nine, R.D., Clark, N.N., Daley, J.J., and Atkinson, C.M., "Development of a Heavy-Duty Chassis Dynamometer Driving Route," Proceedings of the Institute of Mechanical Engineers, Part D., Journal of Automobile Engineers, Vol. 213, pp. 561-574, 1999.

91. European Transient Cycle (ETC), http://www.dieselnet.com/standards/cycles /etc.html, Accessed on Aug 10, 2005. 
92. Braunschweig City Driving Cycle, http://www.dieselnet.com/standards/cycles/ braunschweig.html, Accessed on Aug 10, 2005.

93. Pelkmans, L., "Influence of Vehicle Test Cycle Characteristics on Fuel Consumption and Emissions of City Buses," SAE 2001-01-2002, 2001.

94. Ikonen, M., Westerholm, M., and Nylund, N., "Emission and Fuel Consumption Measurements for Transit Buses Running on Gaseous Fuels Using a Mobile Measurement System," SAE Paper 2001-01-3638, 2001.

95. The Center for Alternative Fuels, Engines, and Emissions, of the Department of Mechanical and Aerospace Engineering, West Virginia University (WVU), "Chassis Dynamometer Emissions Characterization of Buses in Mexico City, Mexico," Final Report to the Mexico City Secretariat of Environment, West Virginia University, Morgantown, WV, 2005.

96. Clark, N., Wayne, S., Khan, A., Lyons, D., Gautam, M., McKain, D., Thompson, G., and Barnet., R., “Effects of Average Driving Cycle Speed on Lean-Burn Natural Gas Bus Emissions and Fuel Economy," SAE Technical Paper 2007-01-0054, 2007.

97. Bass, E. and Alfermann, T., "The Influence of Idle, Drive Cycle and Accessories on the Fuel Economy of Urban Hybrid-electric Buses Chassis Dynamometer Tests," SAE Paper 2003-01-3438, 2003.

98. Ciccarelli, T., Tossi, R., and Goodarzi, A., "Assessment of Hybrid Configuration and Control Strategies in Planning Future Metropolitan/Urban Transit Systems," SAE Paper 2001-01-2502, 2001.

99. Wayne, W.S., Clark, N.N., Gautam, M., and Lyons, D., "Transit Bus Emissions Survey Task 2 Interim Report," Presented to US Department of Transportation, Federal Transit Administration, West Virginia University, Morgantown, WV, 2005.

100. Lev-on, M., Letavec, C., Uihlein, J., Kimura, K., Alleman, T., Lawson, D., Vertin, K., Thompson, G., Clark, N.N., Gautam, M., Wayne, W.S., Okamoto, R., Rieger, P., Yee, G., Zielinska, B., Sagebeil, J., Chatterjee, S., and Hallstorm, K., "Speciation of Organic Compounds from the Exhaust of Trucks and Buses: Effect of Fuel and After-treatment on 
Vehicle Profiles," 2002 SAE Transactions, Journal of Fuels \& Lubricants, Vol. 111, pp. 1948-1973, 2002.

101. Chaterjee, S., McDonald, C., Conway, R., Windawi, H., Vertin, K., Letavec, C.A., Clark, N.N., and Gautam, M., "Emissions Reductions and Operational Experiences with HeavyDuty Diesel Fleet Vehicles Retrofitted with Catalytically Regenerated Particulate Filters in Southern California," 2001 Society of Automotive Engineers Congress, Detroit, MI, SAE Paper 2001-01-0512, 2001.

102. “Diesel Emission Control - Sulfur Effects (DECSE) Program, Phase 1 Interim Report No. 4: Diesel Particulate Filter - Final Report," Web Publication, http://www.nrel.gov/ vehiclesandfuels/apbf/pdfs/interim4.pdf, Accessed on Aug 8, 2005.

103. Yanowitz, J., McCormick, R.L., and Graboski, M.S., "In-Use Emissions from Heavy-Duty Diesel Vehicles," Environmental Science \& Technology, Vol. 34, No. 5, pp. 729-740, 2000.

104. Graham, L.A., "Evolution of Urban Bus Emissions 1984-2004," Personal Communication with Emission Research and Measurement Division, Environment Canada, 2007.

105. Dawood, V. and Emadi, A., "Performance and Fuel Economy Comparative Analysis of Conventional, Hybrid, and Fuel Cell Heavy-Duty Transit Buses," IEEE 58th Vehicular Technology Conference, Vol. 5, pp. 3310-3315, 2003.

106. Markel, T., Brooker, A., Hendricks, T., Johnson, V., Kelly, K., Kramer, B., O’Keefe, M., Sprik, S., and Wipke, K., "ADVISOR: a Systems Analysis Tool for Advanced Vehicle Modeling," Journal of Power Sources, Vol. 110, Issue 2, pp. 255-256, 2002.

107. Wipke, K., Cuddy, M., and Burch, S., “ADVISOR 2.1: A User-Friendly Advanced Powertrain Simulation Using a Combined Backward/Forward Approach," IEEE Transactions on Vehicular Technology, Vol. 48, No. 6, pp. 1751-1761, 1999.

108. Ciccarelli, T., Tossi, R., and Goodarzi, A., "Assessment of Hybrid Configurations and Control Strategies in Planning Future Metropolitan/Urban Transit Systems," SAE Paper 2001-01-2502, 2001.

109. Bass, E. and Alfermann, T., "The Influence of Idle, Drive Cycle and Accessories on the Fuel Economy of Urban Hybrid-electric Buses Chassis Dynamometer Tests," SAE Paper 2003-01-3438, 2003. 
110. Lowell, D., "NYCT Operating Experience with Hybrid Transit Buses," HEB Workshop, Community College of Baltimore, Baltimore, MD, 2003.

111. Barnitt, R., "BAE/Orion Hybrid Electric Buses at New York City Transit," National Renewable Energy Laboratory, Technical Report NREL/TP-540-42217, 2008.

112. “Annual Energy Outlook 2007," DOE/EIA-0383(2007), Energy Information Administration, US Department of Energy, Washington, D.C., 2007.

113. "World Energy, Technology, and Climate Policy Outlook WETO 2030," European Commission, Technical Report WETO EUR 20366, 2003.

114. "Crude Oil and Natural Gas Price Escalation Forecast 2006 Tax Year," Texas Comptroller of Public Accounts, January 2006, Web Publication, http://www.cpa.state.tx.us/taxinfo /proptax/cong06/, Accessed on December 19, 2006.

115. Smedley, M., "Revised German Energy Forecast Raises Oil Price Assumptions," Energy Intelligence Group, Inc., International Oil Daily, 2006.

116. Gately, D., "Important Issues in Modeling the Oil Transition: What Can We Expect from OPEC?" ORNL Conference on Modeling the Oil Transition, Oak Ridge, TN, 2006.

117. Nelson, Y., Gemis, G., and Nix H.D., "Results of the Delphi IX Survey of Oil Price Forecasts," California Energy Commission, Sacramento, CA, 1997.

118. Henning, B.B., "The Gas Price Roller Coaster: the Ride Continues," A.G.A. Energy Industry Outlook Meeting, Winter Fuels Outlook Conference, Washington, DC, 2003.

119. Bolinger, M., and Wiser, R., "Comparison of AEO 2007 Natural Gas Price Forecast to NYMEX Futures Prices," Lawrence Berkley National Laboratory Memorandum, Berkley, CA, 2006.

120. "Natural Gas Price Forecast," Bonneville Power Administration WP-07 Power Rate Case Workshop, Portland, OR, 2005.

121. Wayne, W.S., Clark, N.N., Khan, A.S., Gautam, M., Thompson, G.J., and Lyons, D.W., "Emissions and Fuel Economy from Conventional Diesel, Hybrid-Electric Diesel, and Natural Gas Transit Buses," Journal of Transportation Research Forum, Vol. 47, No. 3, pp. 105-125, 2008. 
122. Clark, N., Khan, A., Wayne, S., Gautam, M., Thompson, G., McKain, D., and Lyons, D., "Weight Effect on Emissions and Fuel Consumption from Diesel and Lean-Burn Natural Gas Transit Buses," SAE Technical Paper 2007-01-3626, 2007.

123. Clark, N.N., Kern, J.M., Atkinson, C.A., and Nine, R.D., "Factors Affecting Heavy-Duty Diesel Vehicle Emissions," Journal of the Air \& Waste Management Association, Vol. 52, pp. 84-94, 2002.

124. He, H., Sun, F., and Yu, X., "An Analysis of Energy Consumption of BJD6100-EV Bus in Urban Driving," Transactions of Beijing Institute of Technology, Vol. 24, No. 3, pp. 222225, 2004.

125. Diaz-Gomez, P.A., and Hougen, D.F., "Initial Population for Genetic Algorithms: a Metric Approach," Proceedings of the 2007 International Conference on Genetic and Evolutionary Methods, pp. 43-49, 2007.

126. Goldberg, D.E., Deb, K., and Clark, J.H., "Genetic Algorithms, Noise and the Sizing of Populations," Complex Systems, Vol. 6, pp. 333-362, 1992.

127. Harik, G.R., and Lobo, F.G., "A Parameter-less Genetic Algorithm," Proceedings of the Genetic and Evolutionary Computation Conference, pp. 258-265, 1999.

128. DeJong, K.A. and Spears, W.M., "An Analysis of the Interacting Roles of Population Size and Crossover in Genetic Algorithms," Proceeding of the First Workshop Parallel Problem Solving from Nature, pp. 38-47, 1990.

129. Scholand, A.J., "Genetic Algorithm (GA) Parameter Settings," Web Publication, http://eislab.gatech.edu/people/scholand/gapara.htm, Accessed on January $6^{\text {th }}, 2012$.

130. Grefenstette, J.J., "Optimization of Control Parameters for Genetic Algorithms," IEEE Trans. Systems, Man, and Cybernetics, Vol. SMC-16, No. 1, pp. 122-128, 1986.

131. Krishnakumar, K., "Micro-Genetic Algorithms for Stationary and Non-Stationary Function Optimization," SPIE: Intelligent Control and Adaptive Systems, Vol. 1196, pp. 289-296, 1989. 


\section{Inserting Bus Information to Section III of the FMT}

Is to enter data in the arrow-pointed input cells. Simple click the cells to highlight them. Then enter the data is Series" on the far left can use either a number or a word. The other input cells need integral. ation

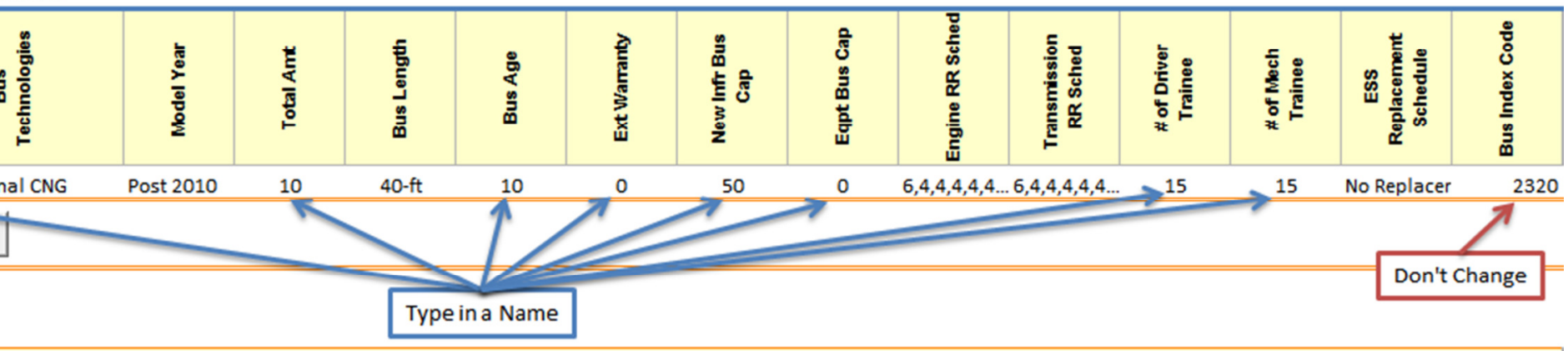

Is select one option from each pull-down menu in the arrow-pointed input cells. Simply click the cell first and wnward triangle on the right side of the cell. Then click the triangle to show all opinions before moving mouse ion. tion

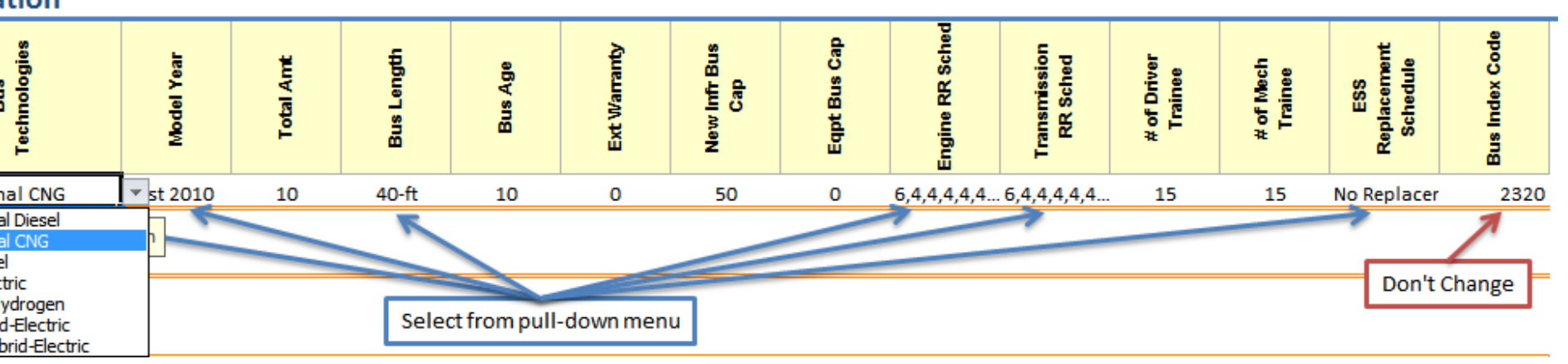




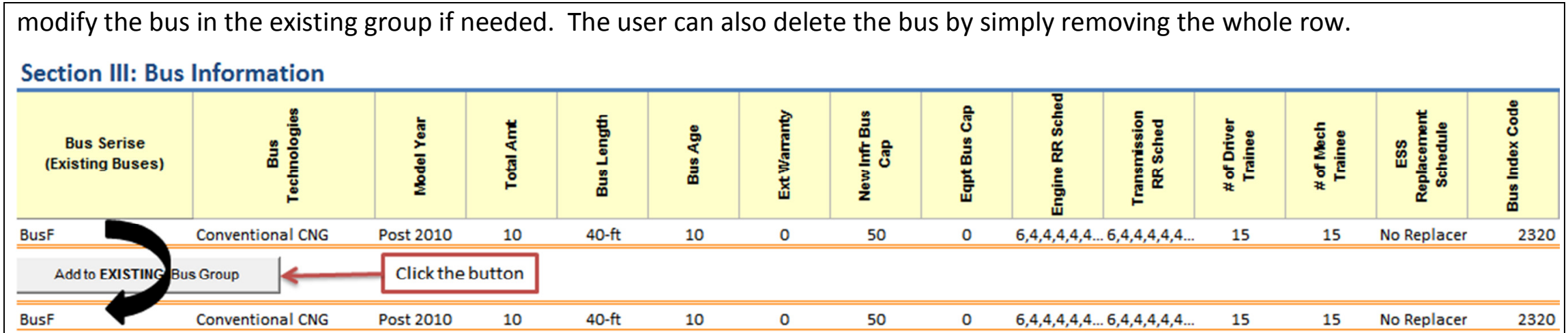

STEP 4 - By taking the same step 1-3, user can add new bus series into the considered bus group.

\begin{tabular}{|c|c|c|c|c|c|c|c|c|c|c|c|c|c|c|}
\hline $\begin{array}{c}\text { Bus Serise } \\
\text { (Considered Buses) }\end{array}$ & 岗 & $\begin{array}{l}\frac{2}{5} \\
\frac{2}{\Phi} \\
\frac{0}{2} \\
\frac{8}{2}\end{array}$ & 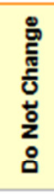 & 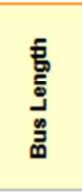 & 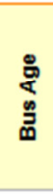 & 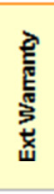 & 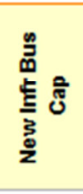 & 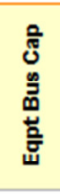 & 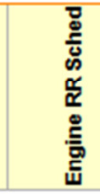 & 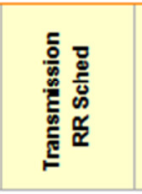 & 总 & 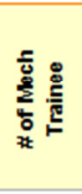 & 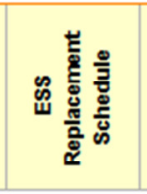 & 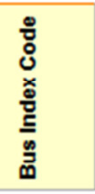 \\
\hline NewBusF & Fuel Cell - Hydrogen & +2010 & 0 & $40-\mathrm{ft}$ & 1 & 3 & 0 & 0 & \multicolumn{2}{|c|}{$6,4,4,4,4,4 \ldots 6,4,4,4,4,4 \ldots$} & 0 & 0 & 4 Year Life & 5320 \\
\hline \multicolumn{2}{|c|}{ Add to Considered Bus Group } & \multicolumn{3}{|c|}{ Number of New Bus Types } & 6 & & & & & & & & & \\
\hline NewBusF & Fuel Cell - Hydrogen & 2010 & 0 & $40-\mathrm{ft}$ & 1 & 3 & 0 & 0 & $6,4,4,4,4$ & $6,4,4,4,4,4 \ldots$ & 20 & 20 & 4 Year Life & 5320 \\
\hline NewBusE & Conventional CNG & Post 2010 & 0 & $40-\mathrm{ft}$ & 1 & 3 & 0 & 0 & $6,4,4,4,4$ & $6,4,4,4,4,4 \ldots$ & 20 & 20 & No Replacer & 2320 \\
\hline NewBusD & Conventional Diesel & Post 2010 & 0 & $40-\mathrm{ft}$ & 1 & 3 & 0 & 0 & $6,4,4,4,4$ & $6,4,4,4,4,4 \ldots$ & 0 & 0 & No Replacer & 1320 \\
\hline NewBusC & Battery Electric & Post 2010 & 0 & $40-\mathrm{ft}$ & 1 & 3 & 20 & 20 & $7,6,6,6,6$ & $7,6,6,6,6,6 \ldots$ & 20 & 20 & 4 Year Life & 4320 \\
\hline NewBusB & Diesel Hybrid-Electric & Post 2010 & 0 & $40-\mathrm{ft}$ & 1 & 3 & 0 & 0 & $7,6,6,6,6$ & $7,6,6,6,6,6 \ldots$ & 0 & 0 & 6 Year Life & 6320 \\
\hline NewBusA & B20 Biodiesel & Post 2010 & 0 & $40-\mathrm{ft}$ & 1 & 3 & 0 & 10 & $6,4,4,4,4$ & $6,4,4,4,4,4 \ldots$ & 0 & 20 & No Replacer & 3320 \\
\hline
\end{tabular}

\section{Appendix II - Steps of Inserting Route Information to Section IV of the FMT}

STEP 1 - The user clicks the arrow-pointed button in Section IV of the FMT to switch to "Routelnfo" tab as shown in the next row. 


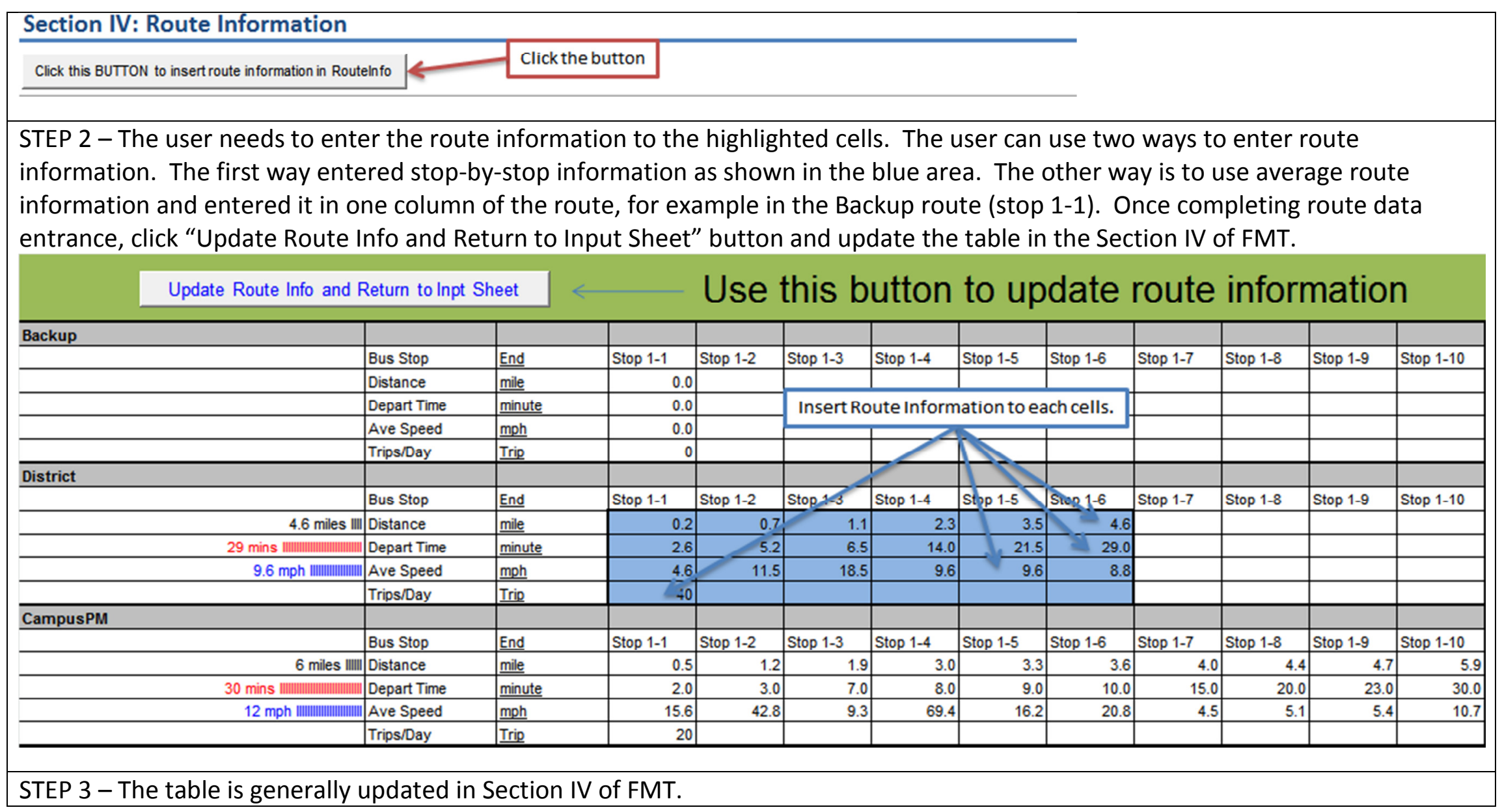




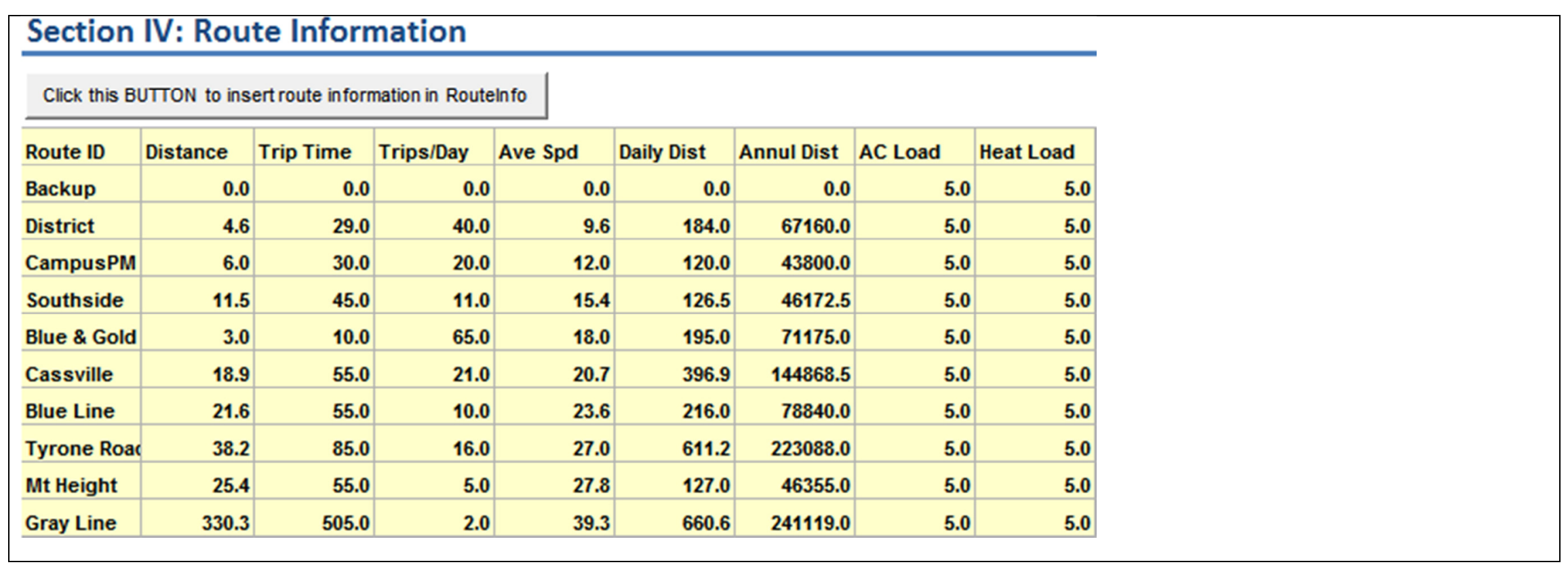

\section{Appendix III - Steps of Inserting Route Dispatch Information to Section V of the FMT}

STEP 1 - The user needs to complete Section III and Section IV input before starting this section. Once Section III and Section IV are done, click the button. The tool will import bus and route information to generate a dispatch matrix as shown in the next step.

\section{Section V: Route Dispatch Information}

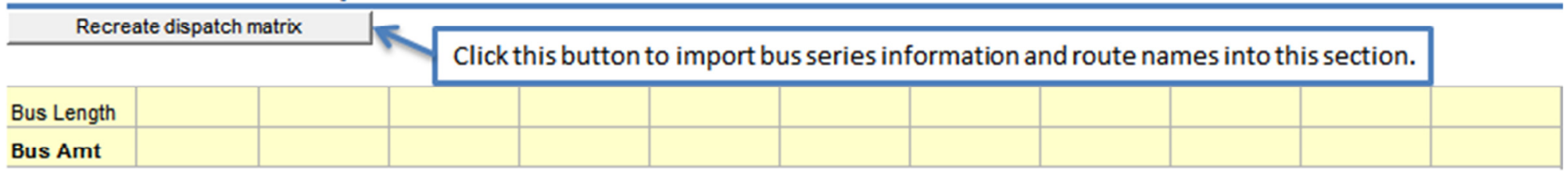




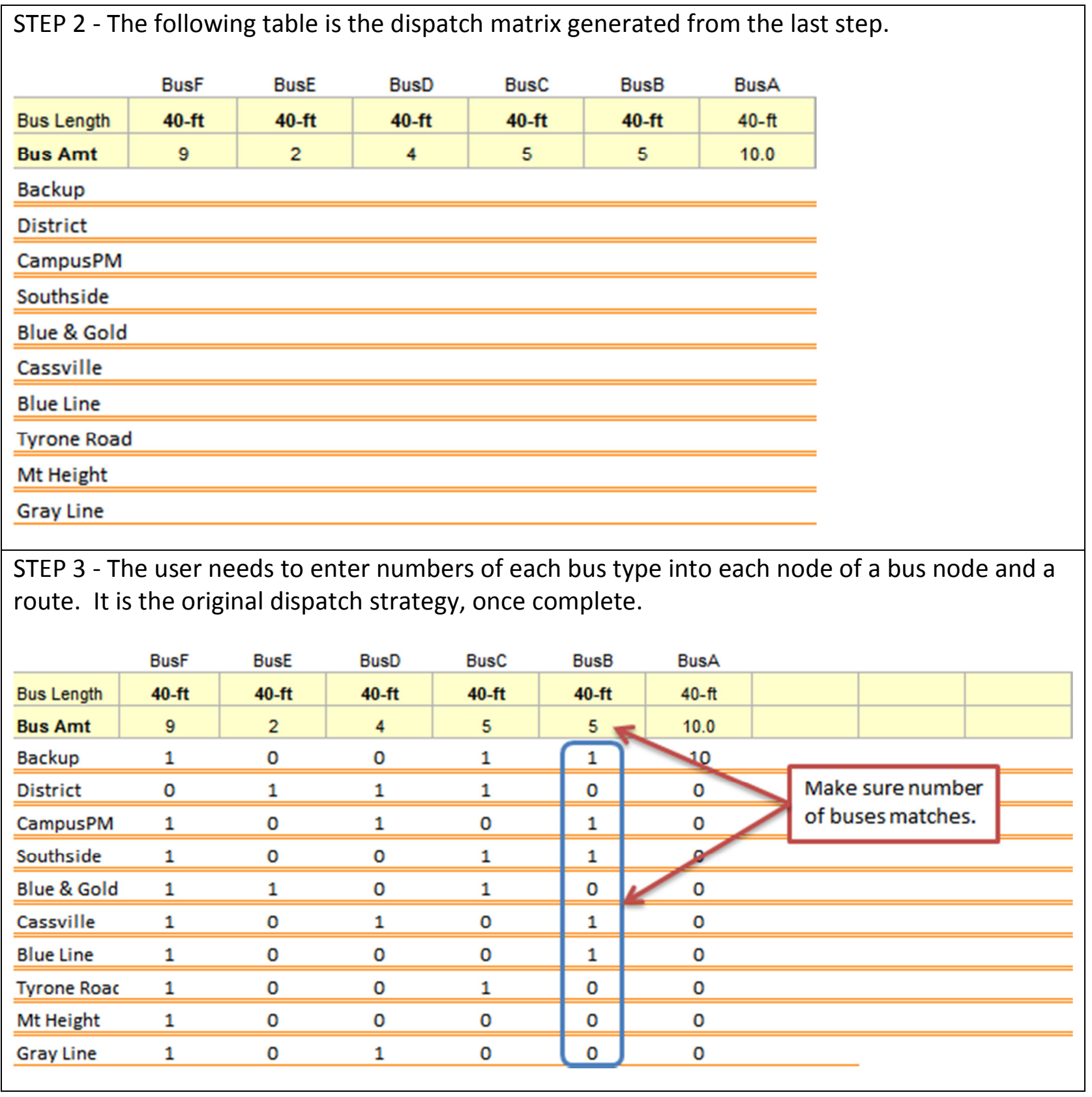


Appendix IV - Steps of Inserting Importance Index table to Section II of the FMT

STEP 1 - Click an orange cell in the section. The highlighted cell will show a selection triangle on the right. Click the triangle, and a pull-down menu will show up.

\section{Section II: Importance Index}

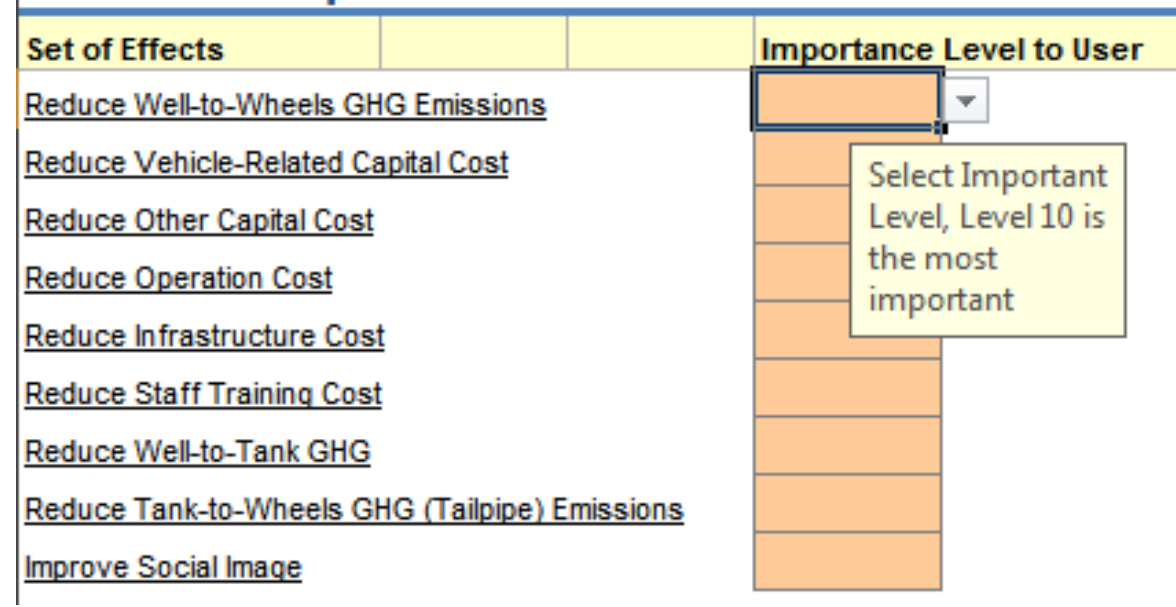

STEP 2 - The user selects a weight depending upon how important the criterion is to user. Weight " 10 " represents the most critical one. Weight " 0 " means no concern.

Set of Effects
Reduce Well-to-Wheels GHG Emissions
Reduce Vehicle-Related Capital Cost
Reduce Other Capital Cost
Reduce Operation Cost
Reduce Infrastructure Cost
Reduce Staff Training Cost
Reduce Well-to-Tank GHG

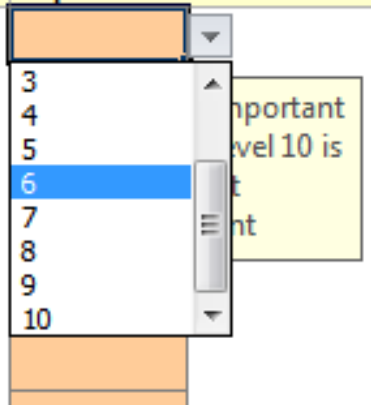

